\title{
Relative performance evaluation
}

Citation for published version (APA):

Timmermans, O. R. (2021). Relative performance evaluation: implications for policy, practice and research. [Doctoral Thesis, Maastricht University]. ProefschriftMaken. https://doi.org/10.26481/dis.20210917ot

Document status and date:

Published: 01/01/2021

DOI:

10.26481/dis.20210917ot

Document Version:

Publisher's PDF, also known as Version of record

\section{Please check the document version of this publication:}

- A submitted manuscript is the version of the article upon submission and before peer-review. There can be important differences between the submitted version and the official published version of record.

People interested in the research are advised to contact the author for the final version of the publication, or visit the DOI to the publisher's website.

- The final author version and the galley proof are versions of the publication after peer review.

- The final published version features the final layout of the paper including the volume, issue and page numbers.

Link to publication

\footnotetext{
General rights rights.

- You may freely distribute the URL identifying the publication in the public portal. please follow below link for the End User Agreement:

www.umlib.nl/taverne-license

Take down policy

If you believe that this document breaches copyright please contact us at:

repository@maastrichtuniversity.nl

providing details and we will investigate your claim.
}

Copyright and moral rights for the publications made accessible in the public portal are retained by the authors and/or other copyright owners and it is a condition of accessing publications that users recognise and abide by the legal requirements associated with these

- Users may download and print one copy of any publication from the public portal for the purpose of private study or research.

- You may not further distribute the material or use it for any profit-making activity or commercial gain

If the publication is distributed under the terms of Article $25 \mathrm{fa}$ of the Dutch Copyright Act, indicated by the "Taverne" license above, 
Relative Performance Evaluation 
Copyright (C) Oscar Timmermans 2021

Printed by ProefschriftMaken

Cover design by Stefanie van den Herik

ISBN 9789464233827

All rights reserved. No part of this publication may be reproduced, stored in a retrieval system, or transmitted in any form or by any means, electronic, mechanical, photocopying, recording or otherwise, without prior permission of the copyright owner. 


\title{
Relative Performance Evaluation
}

Implications for Policy, Practice and Research

\author{
Dissertation
}

to obtain the degree of Doctor at Maastricht University, on the authority of the Rector Magnificus prof. dr. Rianne M. Letschert, in accordance with the decision of the Board of Deans, to be defended in public on Friday, 17 September, 2021 at 14:00 hours.

by

Oscar R. Timmermans 


\section{Supervisor}

Prof. dr. Frank Moers

Co-supervisors

Prof. dr. Isabella Grabner

Dr. Christoph Feichter

Assessment committee

Prof. dr. Ann Vanstraelen (Chair)

Prof. dr. Rob Bauer

Prof. dr. Mary Ellen Carter (Boston College)

Prof. dr. Christopher Ittner (The Wharton School) 


\title{
Contents
}

\author{
Acknowledgments i
}

(1) Introduction 1

(2) STUDY 1 / Risk-Taking Properties 11

(3) STUDY 2 / Competitive Aggressiveness 67

4 STUDY 3 / Information Disclosure 109

5 Discussion and Summary 152

6 Discussion and Summary in Dutch 156

$(7$ Impact 162

8 References 168

(9) Vitae 184 


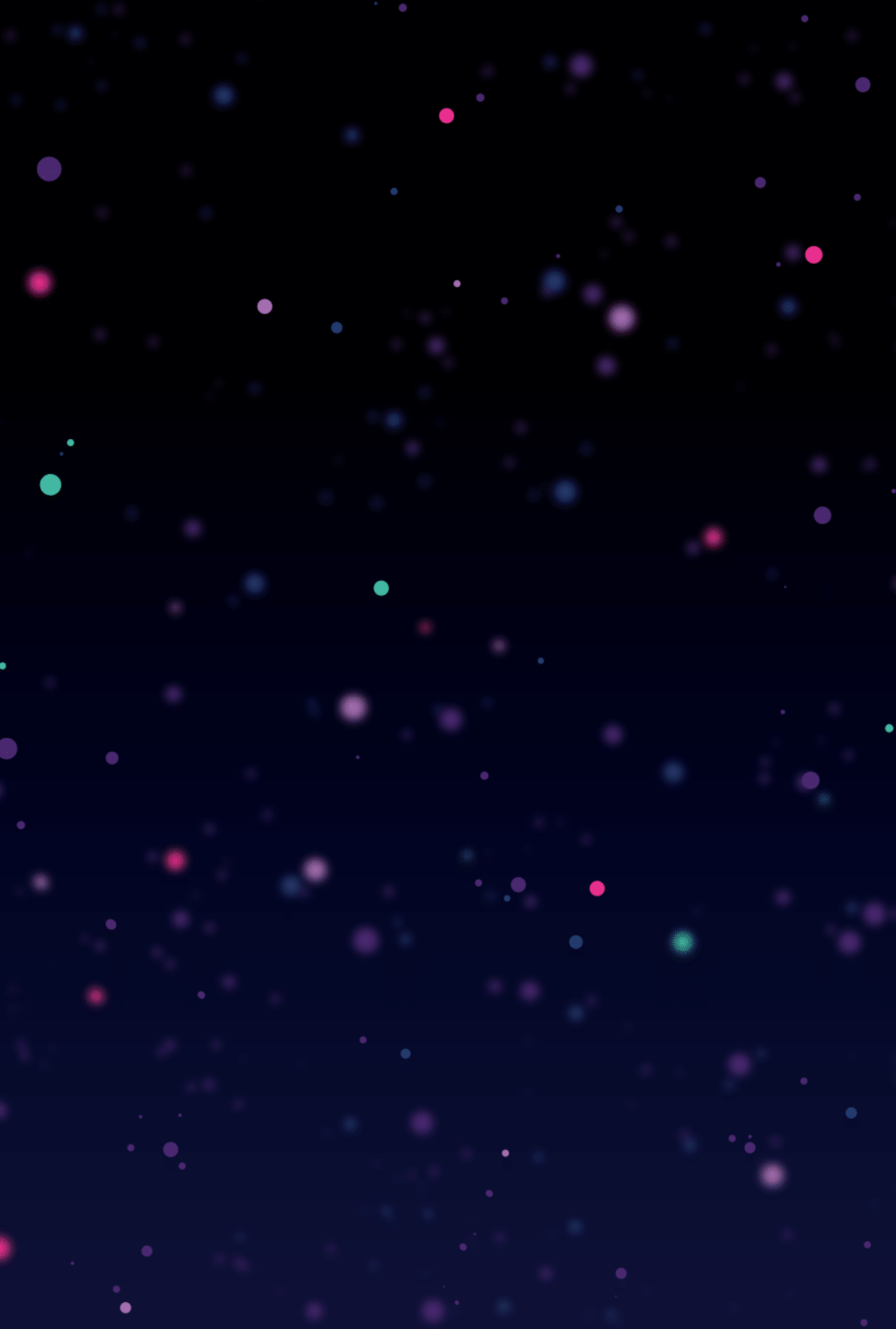




\section{Acknowledgments}

First, I want to thank my supervisors. Frank, my promotor, you guided me through — and got me in-this whole thing of a "Ph.D." It started when you were assigned to supervise my Master thesis. At the time-coming from a Bachelor of Applied Sciences-I had little (admittedly, zero) understanding of research. I even remember asking what it meant to "control for something in a regression model." Nevertheless, through your guidance during these six months I developed a deeper understanding of what research is about. You then encouraged me to pursue a Ph.D. in the area of incentive-compensation contracting under your supervision, which has been an awesome experience. Thank you for taking me from student to researcher and showing me what it takes to do rigorous accounting research. Your analytical reasoning, critical thinking, ability to communicate research easily and effectively, and, of course, your econometric skills have inspired me-and, to this day, I bow down to those skills. You also opened the door to the Wharton School for me, for which I am forever grateful.

Isabella and Christoph, my co-supervisors, I am also grateful for your guidance. Isabella, I still remember one of our first conversations. You asked me whether I had an interest in "experimental" research methods or "empirical" research methods. When I answered I did not see the point of using students as experimental subjects to draw conclusions about managerial behavior, you knew enough and were happy to cosupervise my Ph.D. We then quickly started working on a research project for which we requested access to a company's proprietary data. Unfortunately, we received a "no go" and our efforts did not result in a research paper together. Despite this bummer, I still learned a lot from it - and from your guidance throughout my Ph.D. And although you moved from Maastricht to Vienna shortly after I started my Ph.D., you still always made time for me to talk about all kinds of issues. Thank you for always being there for me. Also thank you for pushing me-numerous times - to get out of my comfort zone. I would not be where I am today without your support.

Christoph, when you joined the supervision team, you just finished your own Ph.D. This was very convenient for me because I could—and did—persistently bombard you with everyday questions. To facilitate these Q\&A sessions and make sure I received help on whatever it was I needed in a timely manner, you placed me under a strict monitoring regime: every day you came in, at least twice, to check how-and I guess, to be more precise, what-I was doing. I would often point you to the academic paper on "the learning effects of monitoring," but you persisted with your tight monitoring regime. All 
jokes aside, I learned a lot from you. To name but a few: as an experimentalist, you taught me to think in $2 \times 2$ matrices; you helped me feel comfortable and introduce me to people at large conferences, which can be quite overwhelming as a young Ph.D. student; and you taught me there are different taste functions in writing a paper (and, oftentimes, our taste functions happen to be different). And although you also moved from Maastricht to Vienna during my Ph.D., you also still always made time for me. I am thankful for all your help and support.

Frank, Isabella, and Christoph, I was very lucky to have the three of you supervising me. I cannot thank you enough for your wisdom, support, and incredible mentoring, and look forward to continuing working together!

Melissa, I also want to thank you for your continuous support. We met when you gave a seminar at Maastricht University during the first year of my Ph.D., after which we quickly became co-authors and friends. I enjoy working together with you on our projects and I hope we will continue working together.

In refining the content of this dissertation, I also want to thank-in addition to everyone already mentioned-the members of my assessment committee, Ann Vanstraelen, Rob Bauer, Mary Ellen Carter and Chris Ittner for their thoughtful and candid comments, questions, and suggestions on an earlier version of my dissertation. I must also thank many conference participants, seminar participants, coordinators of and participants in external Ph.D. courses, and countless others whose knowledge, feedback, and questions honed the end product of my dissertation.

I also want to thank several colleagues that I closely worked with during my visit at the Wharton School-who, without a doubt, also had a positive impact on the content of this dissertation. Chris Ittner, I owe a great debt of gratitude to you. It goes without saying that I am very thankful for the opportunity to visit the Wharton School. You quickly made me feel welcome and your door was literally always open for me, which made the visit not only a pleasant experience but also a productive and enriching period. I consider you as one of my mentors and want to thank you for, among other things, teaching me how to phrase a research question, how to write crisply the first, but crucial, paragraphs of an academic paper, and how to strip away unnecessary blocks of text. Also thanks for the considerable time you spent giving feedback on my job market paper (and other papers). Your feedback took my job market paper to the next level and certainly made my life on the job market less stressful. I am still not sure how I can return the favor. Wayne, I obviously also want to thank you for welcoming me to the Ph.D. program and inviting me to all associated events. You taught me that an academic paper should be written as simple as possible and should have tables that are easy to understand-and, oftentimes, simple tables can be further simplified. I look forward to continuing working together on incentive-compensation issues. Matt, the same goes for you. I enjoy working together and look forward to continuing doing so. I also want to thank Chris Armstrong for making my visit at the Wharton School very productive. Although you were on a sabbatical during my visit, you made much time to not only give feedback on my job market paper but also to help develop and work together on new research ideas. Also thanks for always helping me with a plan to address editors' and reviewers' comments. Dan, I want to thank you for your amazing Empirical Design in Accounting Research course, which taught me that you always need theory (!!!). Also thanks to Cathy, Chris, Jennifer, Paul, Rick, and Wayne for your insightful courses 
during this period. I also want to thank all the other great people I met during my visit in Philadelphia. A special thank you to Amadeus, Brad, and Nate for making my visit an awesome and memorable experience.

I also want to thank Benjamin and Patrick for agreeing to being my paranymphs. Benjamin, you only recently joined the Department of Accounting and Information Management at Maastricht University, but we got along very well and very quickly. I wish you all the best for your Ph.D., and am sure you will do well. Patrick, you are one of a kind. When you are present at lunch-nearly every day-we have extremely highlevel conversations about absolute nonsense. At the same time, you are always happy to read my work- "that is," critique my writing. Thanks for that. Also thanks for all the fun (and beers) we had together in Maastricht, at conferences, in Philadelphia, and, hopefully, in London, too. Britt, Judith, and Katlijn, thank you for always bringing happiness to the department; I cannot remember a day where you were not happy. Also thank you for all the coffee breaks we had at the university as well as all the drinks and fun we had outside the university. Alex and Annelies, thanks for all the help in setting up my first course as a course coordinator at Maastricht University and being a great course coordinator at the first course I taught at Maastricht University, respectively. I wish both of you all the best running the department in the upcoming years. My (former) colleague Ph.D. students, Daria, Florian, Harry, Iver, Lena, Lu, Nadine, Olga, Paul, Raginee, Simon, Sophie, and Ulrike, thanks for the amazing time and all Ph.D. dinners. I wish you all the best in finishing your own Ph.D. Anant and Mathijs, thank you for all the positivity. Matthias and Ruud, we took our first Ph.D. courses together and spent endless days learning the basics of matrix algebra, econometrics, and coding in $\mathrm{R}$-in retrospect, a great time. Máté, Razvan, and Sebastian, we had a great job market experience together-thanks for that. Rick, thank you for helping me with everything relating to teaching. Tanja, thank you for taking care of many administrative things. I also want to thank all other members of the Department of Accounting and Information Management at Maastricht University for the great time in Maastricht, including all memorable department trips.

Daarnaast wil ik ook mijn vrienden bedanken voor alle tijd buiten de universiteit. Erik en Ivo, jullie bedankt voor alle feestjes, festivals, powerlifting events en whiskyavonden die we samen gehad hebben. Ook bedankt voor alle-vaak nuttelozeYouTube filmpjes die we tot diep in de nacht gekeken hebben, waarin we niet altijd wisten of het wel "real” was. Gilbert, Jean, Joey, Kay, Kevin, Lars, Luc, Oscar, Raoul, Roman, Teun en Tom, jullie ook bedankt voor alle plezier, shotjeeeees limoncello, en natuurlijk de katers. Bastiaan, Bart, Daniël, Luuk en Steef, bedankt voor het up-to-date houden van mijn voetbalkennis door middel van quizzen en weddenschappen, alle goudgele rakkers die we samen gedronken hebben en het lachen tijdens onze wereldtrips naar Gulpen, Susteren en Zaandam. Joris, Ruben, Thomas en Tom, ook jullie bedankt voor het lachen en de tijd bij Albert Heijn, waarin we altijd met trots de kar trokken zodat we niet de bietenbrug opgingen.

Tot slot wil ik mijn familie bedanken. Pap en mam, ik wil jullie bedanken omdat jullie mij altijd hebben gemotiveerd en ondersteund. Ook respecteerden jullie altijd mijn keuzes; daarvoor ben ik jullie erg dankbaar. Anouk, jij ook bedankt dat je er altijd voor mij bent. Als laatste wil ik Britt bedanken voor haar liefde. Jij stond—en staat-altijd voor mij klaar en steunt mij in alle (moeilijke) beslissingen die ik maak. Voor dit, en nog 
veel meer anderen dingen, ben ik je dankbaar. Onze tijd samen betekent ontzettend veel voor mij!

\section{Oscar Timmermans}

Maastricht, the Netherlands

August 13, 2021 



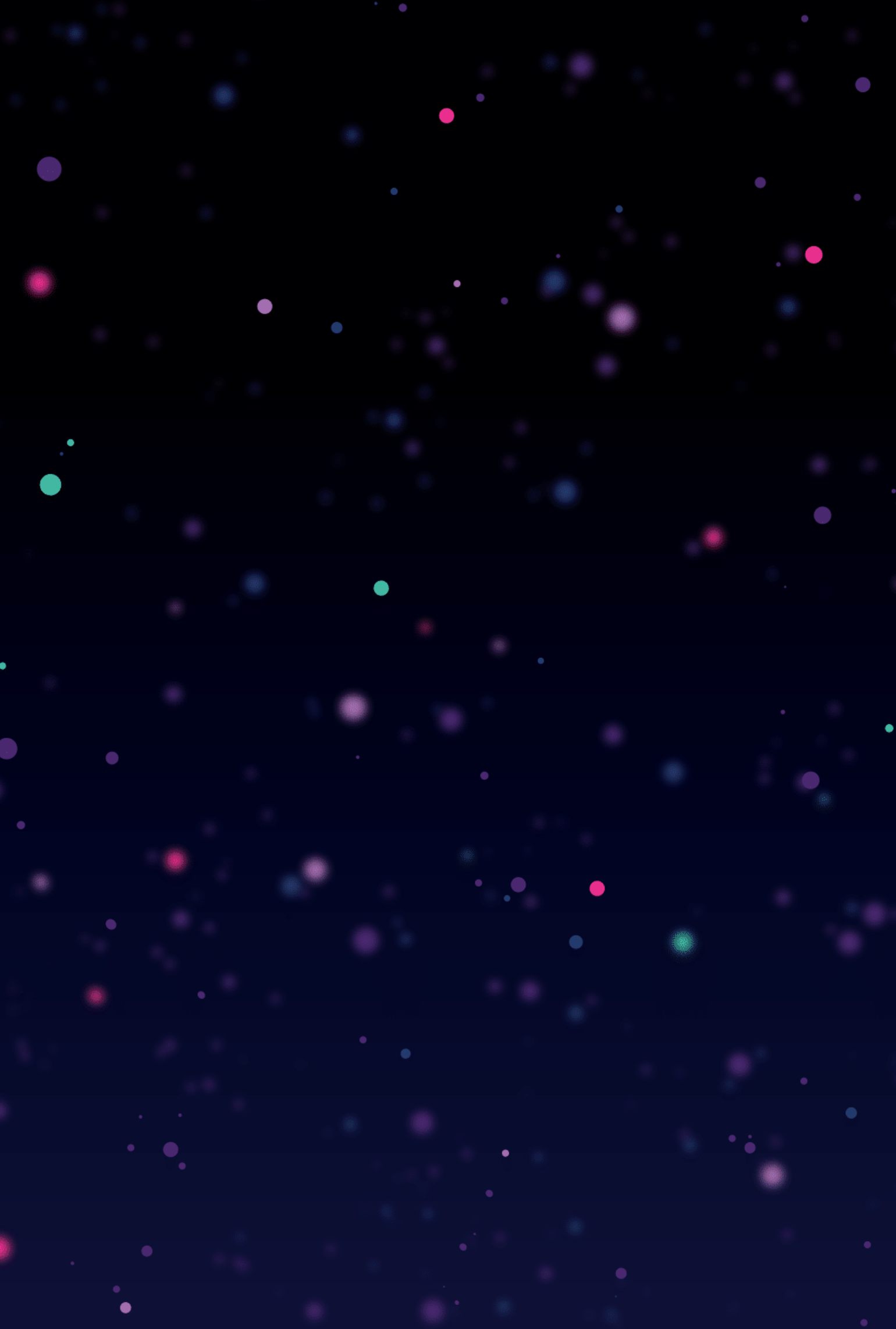




\section{(1)}

\section{Introduction}

In this dissertation, I examine how the use of relative performance evaluation in compensation contracts of managers of large firms affects decisions of those managers. The primary feature of these relative performance plans is that managers' pay is determined based on their performance compared to performance of managers at other firms. ${ }^{1}$ The benefit of this practice is that it shields managers' pay from random-both negative and positive-factors: performance trends that are common between firms are stripped away-similar to how the effects of weather on sport performance are "ignored" when athletes compete in the same race. ${ }^{2}$ However, basing pay on relative performance at the same time puts managers in direct competition to peer managers. My goal is to shed light on the implications of these strategic interactions.

To an outsider, this examination may seem futile. However, there are compelling reasons why this is important. I outline several of these reasons below.

First, many investors, regulators and practitioners argue that poorly calibrated pay packages encouraged inefficient decision-making leading up to the financial crisis of 2007-2008. For example, both The Wall Street Journal and The New York Times promoted views that skewed financial incentives led to too many big bets. But also, chairmen of oversight bodies such as the Federal Reserve System and the U.S. Securities and Exchange Commission expressed concerns about the structure of managers' pay packages. The severeness of these concerns motivated President Barack Obama to introduce major changes to the financial regulatory system so as to provide adequate oversight and prevent crises in the future. In this regard, President Barack Obama (2009) stressed that the "sweeping overhaul of the financial regulatory system [is] a transformation on a scale not seen since the reforms that followed the Great Depression." Central to the reforms with respect to executive compensation is the revived role-and power-of shareholders through shareholder voting. Firms must also be much more transparent toward shareholders about their managers' pay packages. Moreover, firms must disclose whether-and, if so, how and why-managers' pay

1. Although it is common that lower-level employees are rewarded not simply for their own performance but rather for their performance measured relative to performance of co-workers (e.g., promotions, forceddistribution performance appraisals, and fixed bonus pools), this is less straightforward for top-level managers for the simple reason that co-top-level managers work at other firms.

2. A good example of such a random factor is Coronavirus disease 2019, which has a significant negative impact on performance of most firms, but also a significant positive impact on performance of other firms. 
packages expose firms to material risks. Collectively, these amendments made firms much more cognizant of the role managerial incentives play in shaping firm decisions. Most importantly, due to this radical reform, the interest in understanding the link between pay packages and decisions is at an all-time high.

Second, since the reforms, there has been a massive shift in the structure of managers' pay packages. At the most fundamental level, there are two major changes that took place in the last decade. The first relates to the type of pay components in managers' pay packages. Whereas before the financial crisis “stock options" emerged as the single largest vehicle to incentivize managers, after the financial crisis firms shifted back toward "stock-based compensation." 3 The second relates to the conditions upon which stock and stock options vest. Whereas before the financial crisis most provisions were "timebased" vesting, after the financial crisis firms rely much more on "performance-vesting" provisions. ${ }^{4}$ In light of earlier concerns, it is of paramount interest to understand how these current incentive-compensation practices affect managerial decision-making. At the time of writing this dissertation, there is little empirical evidence on this.

Third, for an increasing number of these "performance-vesting" provisions performance is defined relative to performance of other firms. Figure 1 depicts the trend in the use of relative performance evaluation in large U.S. firms. This figure shows that in 2006, when this information became first public, approximately 20 percent of firms provide managers with an explicit incentive to outperform peer firms. Nowadays, this statistic exceeds 50 percent. Given the ubiquity of relative performance plans, it is of great importance to investors, regulators, and practitioners to clearly understand how this type of performance-vesting scheme affects managerial decision-making. However, there is no such thing as a uniform relative performance plan. There are many features to this type of scheme, all of which differ considerably across firms. For example, one crucial characteristic is the amount of compensation that vests upon reaching performance targets-that is, upon beating peers. Whereas some firms give their managers hefty schemes that may result in payments of tens of millions, many other managers receive more moderate incentives to beat peers. Another fundamental aspect is how performance is defined. Most firms give their managers an incentive to increase the

3. A stock option gives the manager the right to buy a share of stock at a prespecified exercise price for a pre-specified term. For example, a manager gets the right to buy a share of his/her firm at $\$ 75$ in three years. If the current share price is $\$ 50$, then the manager has a strong incentive to take risks to lift the share price to, at least, $\$ 75$-below $\$ 75$, these stock options are worthless, but all above $\$ 75$ generates hefty gains. (These "allor-nothing" incentives are indeed the skewed financial incentives that are claimed to incentivize excessive risktaking.) Stock-based compensation directly grants a manager with shares of stock. In contrast to options, the manager thus receives something of value irrespective of the share price-if the share price drops to $\$ 35$, his/her shares are still worth $\$ 35$ each. This removes the strong incentive to "gamble-up" the stock price to the exercise price of an option.

4. Time-based vesting implies that managers earn stock and stock options over time-irrespective of performance. The idea behind this vesting scheme is that managers must stay with the firm to earn their incentive-compensation. To the extent that the value of stock and stock options is increasing in the firm's performance, managers have an indirect incentive to increase performance. In contrast, performance-vesting implies that managers earn stock and stock options upon reaching a minimum performance level. This vesting scheme gives managers a direct incentive to increase performance. Moreover, because performance-vesting schemes need not be bounded by time, these provisions may accelerate stock and stock options grants to managers. 
Figure 1. Use of relative performance evaluation in large U.S. firms

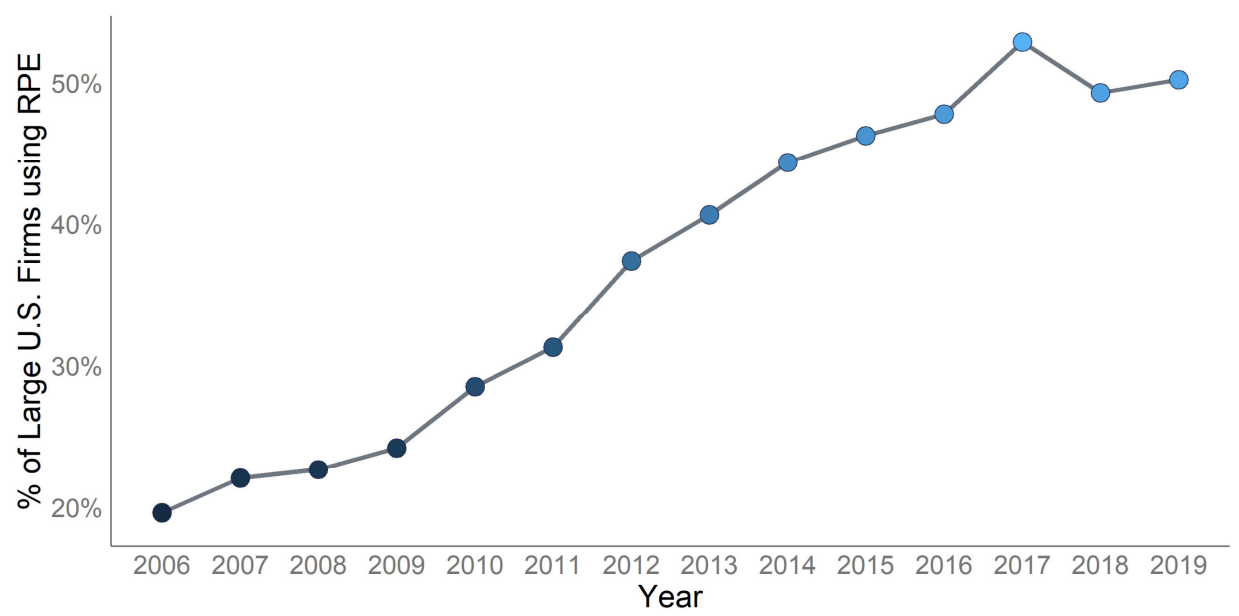

This figure illustrates the use of relative performance evaluation in large U.S. firms over time.

firm's stock price, but there are also managers that must beat peer firms based on accounting numbers, such as profit. Intuitively, another feature that matters is how difficult it is to beat those peers. This may refer to the ability differences between managers of different firms, but also to the likelihood that peer firms will retaliate upon jeopardizing their position in the product market. This abundance of features implies there is no "one effect" on managerial decision-making. As such, it is vital to carefully examine how each feature-individually as well as synergistically with other featuresaffects managerial decision-making. The goal of this dissertation is to fill this important void.

With regard to managerial decision-making, I consider three broad categories of decisions: (1) risk-taking; (2) competitive aggressiveness; and (3) information disclosure. I discuss each category in turn below.

The first category is decisions relating to managers' risk-taking. In the academic context-and the remainder of this dissertation-risk refers to the uncertainty or volatility associated with the return of a decision. Risk-related decisions lie at the heart of many firm decisions. For example, long-term decisions that involve innovation manifest in uncertainty and volatility, but also more day-to-day decisions such as advertisement or pricing decisions entail risk. In most cases, shareholders want managers to take more risks-they want their managers to create the next great innovation. More formally, shareholders prefer more risk, because risk is a fundamental determinant of returns. That is to say that, in a mean-variance space of investment projects, there exists a positive relation between the risk and the return of a set of available investment projects. To the extent that shareholders can diversify away unwanted risks (more on 
this below), shareholders always prefer investment projects with the greatest returnthose with the greatest risks. ${ }^{5}$

The second category is decisions relating to managers' competitive aggressiveness. Competitive aggressiveness refers to the tendency to challenge rival firms intensely and directly. Such aggressiveness can take many forms. For example, managers can engage in aggressive pricing strategies, the introduction of a new promotional campaign, the acquisition of another firm to gain synergistic benefits, invest in marginal cost reductions, develop integrated marketing strategies, etc. In this regard, aggressiveness refers to both the number of competitive actions as well as the variation in the repertoire of competitive actions. Whether shareholders want managers to act aggressively toward rivals depends on a variety of factors. A first consideration is the type of competitive environment. If peer firms mutually reinforce the focal firm (in academic language: these firms are "strategic complements"), it makes less sense to act aggressively toward peer firms. It is only when peer firms mutually offset the focal firm (in academic language: these firms are "strategic substitutes") that it is lucrative to act aggressively so to improve the firm's position in the product market. However, even in this case, an aggressive strategy may not always be the optimal strategy. A second consideration is the anticipated retaliation of peer firms. If peer firms have little incentive to retaliate (because they, for example, are much smaller or have other incentives), the optimal strategy is to be aggressive. However, if peer firms have strong incentives to retaliate, the decision to act aggressively becomes much more complex.

The third category is decisions relating to managers' information disclosure. Information disclosure refers to amount_and quality —of information that managers mandatory and voluntary disclose to the market (the "market" refers to all securities market participants, including institutional investors, retail investors, credit rating agencies, exchanges, etc.). For firms examined in this dissertation, mandatory disclosures include, for example, the annual report (Form 10-K), the quarterly report (Form 10-Q) and reports to be filed after significant events during the year (Form 8-K). These filings typically contain boilerplate information about the current financial situation of the firm. The main reason to voluntarily disclose more information to the market is to ensure that investors have adequate information to correctly price the firm and its associated cost of capital. Voluntary disclosures, therefore, typically refer to the firm's own prediction of its own near-future profit/loss, sales, etc. (in academic language: "guidance"). However, by voluntarily disclosing this information to investors, at the same time managers reveal private-and often proprietary-information to peer firms. Whether managers voluntarily disclose more information to investors, thus, depends on the proprietary cost associated with the disclosure of private information. With regard to mandatory disclosures, note that if the proprietary costs associated with the disclosure of mandatory

5. Let me emphasize that this does not imply that shareholders want managers to take inappropriate or excessive risks. In a mean-variance space of investment projects, shareholders want managers to pick only projects that lie on the "efficient frontier." The efficient frontier reflects those projects that offer the highest expected return for a defined level of risk-or, equivalently, it characterizes the maximum amount of risk a project may entail given its expected return. Projects that do not lie on the efficient frontier are suboptimaland should not be chosen. These projects either do not provide enough return for their level of risk or entail too much risk for their return. Thus, even though shareholders do not necessarily care about risk, managers certainly face a tradeoff between risk and return in choosing their investment projects. 
information are sufficiently high, managers may also redact sections of their mandatory disclosures upon approval by the U.S. Security and Exchange Commission. In this case, managers typically voluntary complement their concealments with additional nonproprietary information so as not to harm price formation in the market.

In this dissertation, I devote one study to each category of decisions, each of which attempts to examine some small piece of the overall relative performance evaluation and managerial decision-making puzzle. That is, the first study concerns the risk-taking properties of relative performance evaluation, the second examines the relation between relative performance evaluation and competitive aggressiveness, and the third investigates how information disclosure is affected by relative performance evaluation. The way in which an incentive plan based on relative performance affects each decision depends crucially on the characteristics of the incentive plan. The key characteristics that matter for decisions related to managers' risk-taking are the strength of the payperformance relation and the difficulty of beating the peer group. Intuitively, playing against difficult-to-beat peers for big prizes gives the greatest incentive to take risks. The key characteristic that matters for decisions related to managers' competitive aggressiveness is whether peer firms have an incentive to retaliate-that is, whether peer firms also have an incentive plan based on relative performance in which the focal firm is selected as a peer. Intuitively, if both managers have an incentive to outperform each other, their firms' levels of competitive aggressiveness are greatest. The key characteristic that matters for decisions related to managers' information disclosure is the performance dimension in the plan. Intuitively, if managers are evaluated on price, they have a greater incentive to ensure investors have adequate pricing information than if managers are evaluated on accounting numbers.

This sequencing of topics serves a further purpose. The purpose is to gradually introduce more parties to the story. The first study considers managers' decisions in a vacuum, and examines how characteristics of one manager's individual incentivecompensation contract influences his/her own decisions. The second study introduces peer effects, and examines how characteristics of peer managers' influence managers' decisions. The third study layers on top of peer effects stock market effects, and examines how characteristics and preferences of investors influence managers' decisions. While the intuition from later studies continues from-and builds on-the intuition from earlier studies, suffice it to say that each of the three studies is a self-contained discussion and there is no harm in reading the studies out of the suggested order.

Collectively, these studies draw from, at least, four literatures to which relative performance evaluation connects: accounting, finance, economics and strategic management. To paint a clear picture of the relation between relative performance evaluation and managerial decision-making, it is important to bridge these literatures. As an introduction for later chapters, below I lay out what I regard as the connection between these distinct-yet related-literatures. This discussion supplements-and harmonizes - the succinct theoretical discussions presented in each respective study.

With regard to finance and economics, I draw from theories of asset pricing, and the principal-agent theory and discounted expected utility theory, respectively. These literatures are largely distinct yet complement nicely. They differ because they tend to rely on different theoretical frameworks that invoke what are, in many cases, inherently incompatible assumptions. To illustrate, consider one of the central research questions 
in the first study, which asks how managers evaluate risks in choosing their investment projects. In this regard, standard asset pricing theory assumes that one can perfectly hedge any unwanted exposure to risk in a portfolio of assets. That is to say that if one buys an asset (for example, a stock, a house, or any other investment), he/she can buy another asset (for example, an option, a short position, or another investment) that perfectly offsets all potential losses that may be incurred by the former asset. In academic language, one's ability to hedge risks implies that one is "diversified" and has "neutral" preferences toward risk-i.e., he/she exclusively invests in the combination of assets that yields the highest expected return, ignoring their risk features. However, missing from this theoretical framework is the notion of agency problems.

Agency problems are conflicts of interest inherent in relationships where one party (the "agent") is expected to act in another party's (the "principal”) best interests. These problems are ubiquitous in any employer-employee relationship, in which the employee is expected to act in the employer's best interests. ${ }^{6}$ The severeness of agency problems amplifies when the employee has more information than the employer, or when the employer cannot-or it is very costly to-observe the actions of his/her employees. Intuitively, in these cases employees can exploit this leeway for their own benefit.

Much of this dissertation focuses on the principal-agent relationship between managers (i.e., the agents) and shareholders (i.e., the principals) of large U.S. firms. To the extent that these managers are expected to act in the best interests of their firms' shareholders, while at the same time have much more information about the firm and it is impossible to observe their actions as an outside shareholder, agency problems build the foundation for much of the discussions in this dissertation. To combat agency problems in practice, shareholders appoint a set of directors (the board of directors or the board, henceforth) who are responsible for, among other things, setting incentivecompensation contracts and policies (such as relative performance evaluation) for management. In this regard, the most fundamental idea in this dissertation is that the sole purpose of these incentive-compensation contracts is to increase the likelihood that managers act in shareholders' best interests-to reduce "agency costs" associated with agency problems.

The omission of agency problems from standard asset pricing theories is non-trivial. For example, the key assumption that one can perfectly hedge any unwanted exposure to risk in his/her portfolio of assets is not plausible for managers of large firms. The reason is that a common incentive-compensation policy set by boards-which is de facto mandatory at virtually all large firms - is that managers must hold large quantities of equity (i.e., stocks and stock options) in their firms. ${ }^{7}$ The intuition behind tying managers' wealth to the value of the firm is that managers become shareholders of their own firm. This naturally aligns managers' interests with those of shareholders. However,

6. A good and simple illustration of an agency problem is in the restaurant context. Employees are expected to provide good diner service. However, if employees merely receive an hourly salary, it is not in their best interest to always deliver good diner service, as this requires significant effort. To combat employees' effort reduction, an employer would also pay his/her employees with tips. This provides employees with an incentive to deliver without exception good diner service-the better the diner's experience, the greater employees' own wealth.

7. Academic research documents that the average U.S. CEO holds about $\$ 39$ million in equity (e.g., Armstrong, Core, and Guay, 2018). 
at the same time, this implies that managers are "undiversified" - that is to say that managers are required to put most of their eggs (money) in one basket (asset). And when one is undiversified, he/she evaluates risk and return tradeoffs differently. Moreover, because managers cannot buy instruments that offset potential losses that may be incurred by the firm, managers must bear the risks that are inherent to the firm (whereas investors could diversify away such risks). ${ }^{8}$ And to the extent that managers hold large quantities of equity, their exposure to these firm-specific risks is significant. In many cases, managers thus prefer to abstain from further lifting their exposure to this firmspecific risk component. This implies that managers have non-neutral preferences toward some risks. In other words, managers are "risk-averse" because they are undiversified. Consequently, undiversified, risk-averse managers price assets differently than do diversified, risk-neutral investors.

Another idea that extends the traditional principal-agent theory-and is central in this dissertation-lies at the intersection of economics and strategic management: strategic interactions-a subset of game theory. The strategic management literature is primarily concerned with questions that involve the formulation and execution of firms' strategies. One key factor that requires firms to constantly assess and update their strategies for success is their business environment. Changes in business environments are largely impacted by other firms' decisions. This implies that when a manager stipulates his/her firm's strategy and associated decisions, he/she must not only consider the "direct" impact of decisions on the firm, but also consider the "indirect" impact of peer retaliations upon jeopardizing peer firms' position in the product market, as well as higher order dynamics of this type. The traditional principal-agent theory fails to recognize strategic dynamics between managers of multiple firms. The strategic interaction framework recognizes this and formalizes the notion that the interaction between managers and shareholders occurs in an environment of strategic interactions between firms in competitive markets. This extension is non-trivial, because the type of strategic interaction has significant implications for the optimal incentive-compensation policy set by boards. For example, if firms are strategic substitutes, it makes much sense to give managers a great incentive to minimize the value of peer firms-and, thus, implement a strong relative performance plan. However, if firms are strategic complements, it makes no sense to offer such an incentive plan. In this case, a plan that incentivizes cooperation would make more sense.

The accounting literature has much resemblance to the other three literatures. However, its strength is measurement. Whereas other fields are more concerned with high-level problems, accounting research generally sifts through more of the nitty-gritty of the problem. This can take many forms, including, but not limited to, improving measurement of empirical variables (for example, the strength of incentives), sifting through the details of the concept of interest (for example, the details of incentivecompensation contracts), outlining and exploiting organizational details, and extensively examining whether some effects differ in subsamples of the full sample. This accounting

8. Managers cannot buy such instruments, because virtually all firms prohibit their managers from trading in options, puts, calls, or other derivative instruments related to the firm's stock or debt. In this regard, the U.S. Securities and Exchange Commission (2018) adopted final rules that require companies to disclose in their proxy statements their policies on hedging employer securities. Meridian Compensation Partners LLC. (2019, p. 25 ) reports that $97 \%$ of firms have such anti-hedging policies in place. 
perspective lies at the heart of all studies presented in this dissertation. For example, the first study develops new methods to measure the strength of managerial incentives, which is crucial to answering the research question of that study. The second study takes a deeper dive into the details of managers' incentive-compensation contracts by exploiting the similarity with incentive-compensation contracts of managers at other firms. This study also brings measurement techniques from strategic management to the accounting literature so to clearly answer the research question of that study. The third study further decomposes managers' incentive-compensation contracts and examines in detail how differences in these contracts give managers differential incentives to disclose information to and withhold information from the market.

The aim of the above discussion is to present a synopsis of all literatures in this dissertation. Even though this discussion highlights the discrepancies between literatures and theories, collectively they have important implications for answering the research questions in this dissertation. These theories, for example, guide me in developing my predictions about the phenomena of interest, but also help me in carefully designing my research tests.

With regard to this last point, a brief discussion about the research methodology used in this dissertation is appropriate. Ideally, the goal of this dissertation is to present "causal evidence" on the relation between relative performance evaluation and managerial decision-making-that is that relative performance evaluation causes managers to take certain decisions. However, the difficulty in statistically identifying such relations is that no statistical test signifies a direct causal relation between two concepts-it merely indicates that there exists an association. In this regard, a positive association between relative performance evaluation and managers' decisions, such as their risk-taking, could imply one of two things. It could imply that relative performance evaluation indeed causes managers to increase firm risk. However, if firm risk is influenced by relative performance evaluation, then it could also simply be that the use of relative performance evaluation is a function of firm risk-in which case causality goes the other way.

I attempt to overcome this causality hurdle in two ways. The first way is theoretically. In all studies, I ensure that my predictions and tests are closely tied to first principles from numerous theories. The idea is that if these theories underpin the economic intuition for my predictions, it becomes difficult to propose a plausible and convincing alternative story that is consistent with the empirical evidence presented. The second way is empirically. In all studies, I rely on an array of econometrics tools and tactics, each of which attempts to eliminate a small piece of endogeneity. Moreover, I extensively examine subsamples of the full sample where theory predicts the effects will be stronger. The idea is that the combined set of analyses provides a convincing story that mitigates concerns that an alternative story is behind my findings. Collectively, the conjunction of theory and econometrics should strengthen the inferences presented in this dissertation.

A brief summary of this dissertation is as follows. My studies on risk-taking properties, competitive aggressiveness and information disclosure are offered in Chapters 2, 3, and 4, respectively. In Chapters 5 and 6, I present a synopsis of and discuss from my own point of view the key findings and contributions of the studies described in Chapters 2 through 4 in English and Dutch, respectively. In the final chapter of the 
dissertation, Chapter 7, I reflect on the scientific impact of the studies described in Chapters 2 through 4. 
"[... J since misaligned or poorly-calibrated incentive compensation programs were widely believed to have promoted inappropriate risk-taking that contributed to the financial crisis, we added a requirement that companies assess whether their compensation programs expose them to material risks.

[...] I think it is vital that boards understand how compensation practices affect risk-taking, and this new requirement brought that issue front and center for boards."

-Mary L. Schapiro, Chair of the U.S. Securities and Exchange Commission (speech to the National Association of Corporate Directors, October 19, 2010) 


\section{What are the Risk-Taking Properties of Long-Term Incentive Plans Based on Relative Performance? ${ }^{\text {is }}$}

This paper analyzes the risk-taking properties of long-term incentive plans based on relative performance. In stark contrast to traditional time-vested stock options, these incentive plans give undiversified, risk-averse managers an incentive to pursue projects characterized by idiosyncratic rather than systematic risk. I find evidence consistent with my central prediction that this differential incentive manifests synergistically through two plan characteristics: payout convexity and peer group difficulty. Moreover, I find that this incentive is moderated by the "pureness" of the relative performance plan and contextual factors. Finally, I show that boards' contract-design choices for payout convexity and peer group difficulty are consistent with moral hazard considerations for project selection. Collectively, my study highlights several new dimensions to consider in assessing whether and how incentivecompensation contracts alter firms' risk profiles.

\section{Introduction}

Many investors, regulators and practitioners argue that misaligned incentivecompensation contracts induced managers to take inappropriate risks leading up to the

is I gratefully acknowledge the guidance from my dissertation committee: Frank Moers (chair), Christoph Feichter, and Isabella Grabner. Special thanks are due to my dissertation committee, Chris Armstrong, Chris Ittner, and two anonymous referees. I also thank Jeffrey Wooldridge for his guidance regarding the estimation techniques used. The paper has benefited from discussions with Philip Berger, Henry Eyring, Wayne Guay, Michelle Hanlon, Iny Hwang (discussant), Matthias Mahlendorf, Melissa Martin, F. Asís Martínez-Jerez (discussant), Mathijs van Peteghem, Nina Schwaiger (discussant), Patrick Vorst, and Frank Zhou. I further thank seminar participants at Amsterdam Business School, Bocconi University, Copenhagen Business School, Frankfurt School of Finance \& Management, KU Leuven, London School of Economics and Political Science, Maastricht University, The Wharton School and University of Rochester, and conference participants at the 16th Annual Conference for Management Accounting Research, the 42nd Annual Congress of the European Accounting Association and the 2020 Management Accounting Section Midyear Meeting for their valuable comments. Lastly, I am grateful to The Wharton School for access to ISS Incentive Lab. 
2008 financial crisis. It is therefore of paramount interest to understand how current incentive-compensation practices affect managerial risk-taking. The past decade has witnessed a boom in the use of incentive plans based on relative performance-nowadays two-thirds of S\&P 500 firms provide considerable and explicit incentives to managers to outperform peers, whereas only a quarter used relative incentives in 2006. To illustrate such an arrangement, consider Chevron Corporation (2019). If Chevron beats all of its peers, the CEO receives $\$ 15$ million, but if all peers beat Chevron, the CEO receives $\$ 0$.

The goal of this paper is to identify whether, how and why relative performance plans impact firm risk. Conceptually, risk-taking incentives stemming from relative performance plans differ from risk-taking incentives induced by traditional time-vested stock options. In particular, relative performance plans give managers more of an incentive to pursue projects characterized by idiosyncratic risk, whereas time-vested stock options incentivize systematic risk-taking. The intuition behind this differential risk-taking incentive is as follows. By evaluating managers on relative performance, performance trends that are common between the focal firm and peer firms are stripped away-similar to how the effects of weather on sport performance are "ignored" when athletes compete in the same race. The reduction in the sensitivity of managers' pay to systematic performance in turn reduces managers' incentive to increase risk through the systematic component of risk. The incentive that remains is to pursue projects characterized by idiosyncratic risk. This differential risk-taking incentive is important, because it shows that relative performance plans can help boards to reduce agency problems relating to differential risk preferences of shareholders and managers.

Identifying a relation between firm risk and managerial incentives, such as relative performance incentives, is complicated. Intuitively, if firm risk is influenced by relative performance evaluation, then the use and design of incentive plans based on relative performance is a function of firm risk. To formalize the intuition for how and why relative performance plans give undiversified, risk-averse managers more of an incentive to pursue projects characterized by idiosyncratic risk, I examine this incentive equilibrium in two stages in the standard backward fashion. In the first stage, I consider the best response of the manager to an-from his/her perspective-exogenous relative performance plan. In the second stage, I examine in more detail which firms wouldfrom the board's perspective-endogenously choose which weight on the characteristics within these relative performance plans, given managers' anticipated responses to thefrom the managers' perspective-exogenous incentive plan.

To ease the discussion of the first stage, I develop a succinct numerical model of risktaking incentives, and use this model to form predictions about the channels through which this differential risk-taking incentive arises. The model's central prediction is that this incentive manifests synergistically through two characteristics of relative performance plans. The first characteristic stems from the prizes the manager can win upon beating the peer group-i.e., the convexity of the incentive plan. The second characteristic stems from the ability differences between the manager and the peer group-i.e., the difficulty of beating the peer group used as the benchmark for measuring relative firm performance. Intuitively, the incentive effects of these two characteristics interact: playing against superior peers for big prizes gives a greater incentive to take risks than does playing for smaller prizes. And so does playing for big prizes against superior 
peers compared to inferior peers. In Section II, I provide an extensive discussion of the economic intuition underpinning these predictions.

In the second stage, I examine in more detail which firms would-from the board's perspective-endogenously place a greater weight on these plan characteristics, given managers' anticipated responses to the-from the managers' perspective-exogenous incentive plan. In this regard, I predict that firms that want to give their managers relatively strong relative performance incentives are those firms that have access to a sufficiently large array of investment projects. The intuition behind this prediction is that if the number of available projects is sufficiently large, then managers can actively shift the firm's strategy into the direction that yields the highest absolute returns (and, by definition, the highest relative return)—consistent with shareholders' preferences. With limited project choice, relative performance incentives motivate managers to choose only those projects where they can marginally outperform peers, rather than to choose those projects that offer the highest absolute return to shareholders-inconsistent with shareholders' preferences.

I empirically test my predictions using a large sample of U.S. firms over the period 2006 through 2017. In my first set of tests, I empirically show that payout convexity and peer group difficulty synergistically give managers an incentive to alter their firms' idiosyncratic risk profiles. In this regard, I show that playing against superior peers for big prizes gives managers the greatest incentive to pursue idiosyncratic risk. This effect manifests because managers must take great risks to beat superior peers and the large sums of incentive-compensation at stake justify doing so. In contrast, if managers play against inferior peers for big prizes, relative performance plans need not give managers an incentive to pursue idiosyncratic risk. The reason why managers abstain from lifting their firms' risk profiles under these circumstances is that they dislike uncertainty about incentive-compensation stemming from "unnecessary" risks-unnecessary in the sense that managers anticipate beating inferior peers and take home those big prizes without taking risks. Thus, my collective findings indicate that relative performance plans canbut need not unambiguously-induce managers to pursue projects characterized by idiosyncratic risk: a blend of payout convexity and peer group difficulty is required to motivate idiosyncratic risk-taking.

In my second set of tests, I show that the choices for payout convexity and peer group difficulty are consistent with moral hazard considerations for project selection. Specifically, I show that the probability of imposing steep relative performance incentives on managers is increasing in the firm's access to idiosyncratic investment projects. This finding completes the puzzle and strengthens the economic intuition for why we observe the characteristics within-and, thus, the effects of-relative performance plans in executive pay packages.

Collectively, the evidence is consistent with my incentive equilibrium predictions and suggests that relative performance plans affect firms' idiosyncratic risk profiles. To bolster this evidence, I additionally explore settings where theory predicts that this relation will be particularly strong. Specifically, theory predicts that the relation between payout convexity, peer group difficulty and firm risk is stronger among: (1) managers evaluated on incentive plans that provide "purer" RPE incentives, vis-à-vis noisier variants of RPE incentives; and (2) managers with contextual factors that provide a stronger incentive to pursue risky projects. Consistent with these predictions, I find that 
the relation is stronger among managers evaluated on "dollar-based" plans vis-à-vis "share-based" plans (which do not fully shield managers from systematic performance because the firm's stock price is still a function of systematic performance) and among managers who have investment opportunities that have a relatively high rate of return per unit of risk. By further linking the relation between relative performance evaluation and firm risk to managerial characteristics, these findings strengthen my inference that the relation is attributable to the decisions of managers.

While I cannot completely rule out the possibility that an omitted correlated variable is behind my results, I assess this likelihood as negligible for several reasons. First, the model developed in this study is closely tied to first principles from theories of discounted utility and asset pricing and underpins the economic intuition for the synergistic risk-taking properties of payout convexity and peer group difficulty. Second, my inferences are not unique to one specific specification but are robust to a battery of alternative specifications (see Section IV for details). Third, my differential theoretical predictions and empirical evidence on the relation between risk and payout convexity conditional on peer group difficulty (and vice versa) reduce concerns about correlated omitted variables that are inherent in typical research designs. That is to say that if a correlated omitted variable were to explain my results, it would need to: (1) be correlated with idiosyncratic risk, but not be correlated with systematic risk; (2) differentially affect firms using relative performance plans with different payout convexity, but with similar peer group difficulty; and (3) differentially affect firms using relative performance plans with different peer group difficulty, but with similar payout convexity. Furthermore, that omitted variable should: (4) vary systematically with: (i) the "pureness" of the relative performance plan; and (ii) contextual factors that alter managers' incentive to pursue risky projects; and (5) be immune to invariant: (i) heterogeneity within industries; and (ii) heterogeneity across time. Although this variable may exist, these requirements preclude many typical candidates such as the firm's growth opportunities or product market competition.

My study should be of interest to both practitioners and academics. With respect to practitioners, my work adds to the public debate on the structure of incentivecompensation contracts. I show that increasingly common convex relative incentives differ from traditional convex incentives induced by time-vested stock options. Whereas time-vested stock options give managers an incentive to increase systematic risk, relative performance plans encourage managers to pursue idiosyncratic risk. This finding has an important societal implication, since it highlights the role boards play in controlling/shifting firms' risk profiles and, thus, in controlling systematic risk in equity markets-of which an excess led to the 2008 financial crisis.

In light of the Securities and Exchange Commission Chairman Mary L. Schapiro's (2010) speech to the National Association of Corporate Directors (see opening quote), my study also offers insights into which plan characteristics affect firms' risk profiles. Although my study highlights the importance of the interaction between payout convexity and peer group difficulty in shaping firm risk, I show that other plan characteristics matter too. For example, my study suggests that "dollar-based" plans provide significantly stronger incentives than do "share-based" plans. Interestingly, the use of these dollar-based plans has decreased dramatically over the past years-whereas roughly $40 \%$ of the RPE plans is dollar-based in 2006, only about 15\% is in 2017 (e.g., 
Bizjak, Kalpathy, Li, and Young, 2021)—which suggests that boards recognize the differential incentives of differing payout schemes. All in all, my findings provide investors, regulators and practitioners with additional dimensions to consider in assessing whether and how incentive-compensation contracts expose firms to risks. In this regard, it may be important to note that peer group difficulty-on which all relations hinge-is not directly observable from information in one firm's proxy statement. As such, one key practical takeaway from my study is that proxy statements yield an incomplete picture of managers" "true" risk-taking incentives.

My study also contributes in multiple ways to academia. First, I develop a framework of risk-taking properties of relative performance plans. In doing so, I advance the traditional certainty equivalent framework (e.g., Hall and Murphy, 2002, Lambert, Larcker, and Verrecchia, 1991, Tian, 2004). In this regard, I move beyond prior studies' focus on stock options, and apply the framework to long-term incentive plans. Since many large U.S. firms are shifting back toward long-term incentives (e.g., Equilar, 2020), this adjustment to the traditional framework provides fruitful opportunities for future research. Moreover, I integrate into the traditional framework several unique elements of relative performance plans to closely model the setting in this study. This departure from the traditional framework moves the needle on studying effects of incentivecompensation contracts on managerial decision-making and allows me to extend prior studies' findings. For example, although Wruck and Wu (2021) and Tice (2020) show that the use of relative performance evaluation is positively associated with firms' idiosyncratic risk profiles, these studies provide little insight into which underlying plan characteristics give managers this incentive to pursue idiosyncratic risk. My study complements these studies by providing such insights. This extension is relevant because it sheds light on how relative performance plans can be structured to address omnipresent risk-related agency problems.

Other academic contributions of my study are several advancements in the empirical realm. For example, I develop measurement approaches to calculate payout convexity and peer group difficulty in relative performance plans. These approaches are easily applied to a large sample of firms, and the intuition can be applied to other (i.e., nonrelative) incentives of executives as well as lower-level employees. Furthermore, my study provides evidence that different relative performance plans with different plan characteristics give managers differential incentives to alter their firms' risk profiles. This finding has an important academic implication, since it indicates that lumping complex types of incentive-compensation contracts into one construct may limit inferences one can draw.

The paper proceeds as follows. Section II discusses related literature and develops the model and hypotheses. Section III discusses variable measurement and sample selection. Section IV develops the empirical model, discusses my identification strategy, and presents my primary results. Section $\mathrm{V}$ discusses my additional cross-sectional tests. Section VI concludes. 


\section{Related Literature and Hypothesis Development}

\section{II.A. Related Literature}

Holmström (1982) shows that when performance outcomes of homogenous agents are affected by common exogenous shocks (e.g., market-wide movements), peer performance serves as an instrument to filter these shocks from performance. Under these circumstances, incentive plans based on relative performance are preferable to individual incentive plans (e.g., Lazear and Rosen, 1981, Nalebuff and Stiglitz, 1983). Although the theoretical benefits associated with evaluating agents on relative performance are not new (e.g., Diamond and Verrecchia, 1982, Gibbons and Murphy, 1990, Janakiraman, Lambert, and Larcker, 1992), the ubiquity of relative performance evaluation in incentive-compensation contracts is in recent years (e.g., Equilar, 2020, Meridian Compensation Partners LLC., 2019). This boom set off empirical studies that examine how firms design their grants (e.g., Carter, Ittner, and Zechman, 2009, De Angelis and Grinstein, 2019) and determine their peers (e.g., Bakke, Mahmudi, and Newton, 2020, Bizjak et al., 2021, Bloomfield, Guay, and Timmermans, 2021, Drake and Martin, 2020, Ma, Shin, and Wang, 2021).

Besides stripping away systematic performance shocks, relative performance plans also play a central role in the strategic choice of incentives, which commits firms to more competitive actions toward peers (e.g., Aggarwal and Samwick, 1999, Sklivas, 1987, Vickers, 1985). Although the economics of relative performance plans are well theorized in this regard, there are only a handful of empirical studies that link the use of relative performance plans to strategic firm outcomes. In one such study, Feichter, Moers, and Timmermans (2021) (i.e., study 2 or Chapter 3 in this dissertation) show that firms using relative performance plans have greater levels of competitive aggressiveness than firms not using relative performance plans. In the same vein, Gong, $\mathrm{Li}$, and Yin (2019) show that relative performance plans trigger strategic disclosure decisions. Bloomfield, Marvão, and Spagnolo (2020) argue that competitive actions induced by relative performance plans are potentially value-destroying. They posit and find that firms that are restricted to engage in such actions (e.g., through explicit collusion via cartel memberships) are more likely to use a relative performance plan, since those firms suffer less from value-destroying competitive actions, but still benefit from systematic risk reduction. Collectively, the evidence in these studies is consistent with the notion that relative performance plans commit managers to more competitive actions toward peers.

Relative performance plans can therefore also help to reduce agency problems related to differential risk preferences of shareholders and managers, since one way to challenge peers is to pursue risky projects (e.g., Campbell, Lettau, Malkiel, and Xu, 2001, Fu, 2009, Merton, 1987). ${ }^{9}$ The central tension in this regard relates to differential preferences for the type of risk. Shareholders want managers to pursue projects characterized by idiosyncratic risk, because they cannot get exposure to idiosyncratic risk themselvesonly through the firm (whereas they can expose themselves to systematic risk by holding

9. First principles from theories of asset pricing say that risk is a fundamental determinant of returns. That is to say that, in a mean-variance space of investment projects, there exists a positive relation between the risk and the return of a set of available investment projects (e.g., Markowitz, 1952, Merton, 1973a, Sharpe, 1964). This ubiquitous risk-return assumption has been confirmed by numerous empirical studies (e.g., Fama and MacBeth, 1973, French, Schwert, and Stambaugh, 1987, Lundblad, 2007, Tsui, 2018). 
the market portfolio). ${ }^{10}$ However, managers may pass up such projects when alternative projects with systematic risk are available (e.g., Acharya and Bisin, 2009, Garvey and Milbourn, 2003, Jin, 2002). Managers generally like idiosyncratic risk less than shareholders, because most of managers' wealth is already tied/exposed to the idiosyncratic value of their firm due to binding ownership guidelines put in place to reduce other agency problems related to the separation of ownership and control (e.g., Jensen and Meckling, 1976). In contrast, managers can unwind any undesired exposure to systematic risk by going "less long" in the market in their own investment portfolio. ${ }^{11}$ Thus, when projects with systematic risk are available, managers favor those projects. This "risk substitution" creates a gap in the risk preferences of shareholders and managers.

To resolve this agency problem, boards require a mechanism that reduces the gap in idiosyncratic risk preferences of shareholders and managers-a mechanism that motivates managers to pursue projects characterized by idiosyncratic risk. Relative performance evaluation perfectly suffices this mechanism: by explicitly evaluating managers on performance relative to peers, a portion of the sensitivity of managers' pay to the systematic component of performance is stripped away. Thus, a blend of performance-based incentives and relative performance evaluation unambiguously induces managers to take risk by increasing the idiosyncratic component of risk. This idea that relative performance evaluation motivates managers to increase the idiosyncratic component of risk is consistent with existing empirical evidence. ${ }^{12}$ For example, Wruck and Wu (2021) and Tice (2020) show that firms using relative performance plans have greater idiosyncratic risk than firms not using relative performance plans, especially when the plan strips away a substantial amount of systematic risk. In addition, Park and Vrettos (2015) show that when stock options are coupled with relative performance evaluation, the incentive-compensation contract gives managers an incentive to increase the idiosyncratic component of risk.

The above discussion suggests that boards can steer managers' risk preferences toward those of shareholders by evaluating managers on relative performance. Now, the more pressing question is how such a relative performance plan should be structured. Addressing this question is the goal of my study.

10. Modern portfolio theory suggests that all investors hold the market portfolio (in equilibrium). In reality, however, investors do not hold perfectly diversified portfolios (e.g., Goetzmann and Kumar, 2005, Kumar, 2009, Mitton and Vorkink, 2007). Instead, investors prefer to invest in those firms that through their innovative projects - which are primarily characterized by idiosyncratic risk (e.g., Pástor and Veronesi, 2009)— yield abnormal returns over the systematic return of the market portfolio (e.g., Fu, 2009, Goyal and SantaClara, 2003, Merton, 1987). Intuitively, one can only earn abnormal returns through exposure to firms' idiosyncratic risk, because abnormal event-related returns are strictly determined by the volatility of individual stock returns relative to the market or industry (e.g., Campbell et al., 2001).

11. In theory, managers could also unwind undesired exposure to idiosyncratic risk by either taking a short position in their own firm's stock or taking a long position in peer firms' stocks. However, this is not plausible since managers are not allowed to buy such instruments with respect to their own firm. That is, virtually all firms prohibit their managers from trading in options, puts, calls, or other derivative instruments related to the firm's stock or debt (e.g., Meridian Compensation Partners LLC., 2019, p. 25).

12. In contrast, empirical evidence suggests that incentive-compensation arrangements solely based on own firm performance-such as traditional time-vested stock options—give managers an incentive to increase the systematic component of risk, since managers can trade in their own investment portfolios (e.g., Armstrong and Vashishtha, 2012, Panousi and Papanikolaou, 2012, Tian, 2004). 


\section{II.B. Hypothesis Development}

In this section, I examine the issue of differential risk preferences of shareholders and managers in more detail. In a real-world setting, boards would make a decision about which characteristics to include in their managers' relative performance plans as well as how much weight to put on these characteristics, so that those managers act in the firm's shareholders' interests. In this regard, economic theory predicts that two fundamental determinants of the level of risk an agent takes when evaluated on relative performance are: (1) the prizes the agent can win; and (2) the ability differences between the agent and his/her competitors (e.g., Hvide, 2002, Lazear and Rosen, 1981, Nalebuff and Stiglitz, 1983). ${ }^{13}$ Certainly, big prizes give agents a greater incentive to alter risk to outperform peers than do small prizes. In the same vein, if an agent plays against superior agents, he/she is likely willing to-and must—-take more risks to beat peers than if he/she plays against inferior peers.

Boards are free to choose the level of these "prizes" and "ability differences." As such, there exists much cross-sectional variation in the design of relative performance plans of large firms (e.g., Carter et al., 2009, Gong, Li, and Shin, 2011). To illustrate some of this variation, consider the relative performance plans of The Coca-Cola Company (2019) and Chevron Corporation (2019) displayed in Figure 1.1. Two noteworthy differences in these plans emerge from this figure. First, the relative performance plan of The Coca-Cola Company (2019) has fewer performance hurdles and less incentives attached to each hurdle than does Chevron Corporation's (2019) plan. Second, both firms compete against completely different peers.

In designing these relative performance plans, boards decide on the characteristics in two stages. In the first stage, boards consider what the best response of the manager isi.e., how the manager will respond once he/she has observed the characteristics in his/her relative performance plan. In the second stage, boards choose the weight on the characteristics so that the relative performance plan maximizes the firm's objective, anticipating the predicted response of the manager. In a subsequent period, the manager observes this relative performance plan and, in equilibrium, responds as predicted.

Below I examine this incentive equilibrium in two stages in the standard backward fashion (e.g., Gibbons, 1992). That is, in the first stage I develop a succinct principalagent model that examines how distinct prizes and ability differences impact a manager's incentives to alter his/her firm's risk profile. Then, in the second stage I examine which firms would choose which combination of prizes and ability differences, given managers' anticipated responses. In relative performance plans of U.S. firms, prizes and ability differences manifest through the curvature, or convexity of the incentive plan and the difficulty of beating the peer group used as the benchmark for measuring relative firm performance, respectively.

13. More formally, prizes matter because this affects the convexity of the incentive plan, which is crucial in motivating managers to undertake risky projects (e.g., Guay, 1999). Ability differences matter because this turns global convexity into "local convexity"-i.e., it highlights the fraction of the award structure where the manager is likely going to end up and, thus, focuses on. For example, if a manager anticipates beating all his/her peers, then the manager only cares about the largest prizes. In this case, even if an award structure has a high global convexity, it need not imply that the award structure is locally convex for such a manager. 
Figure 1.1. Illustration of relative performance plans

Panel A. Payout structures

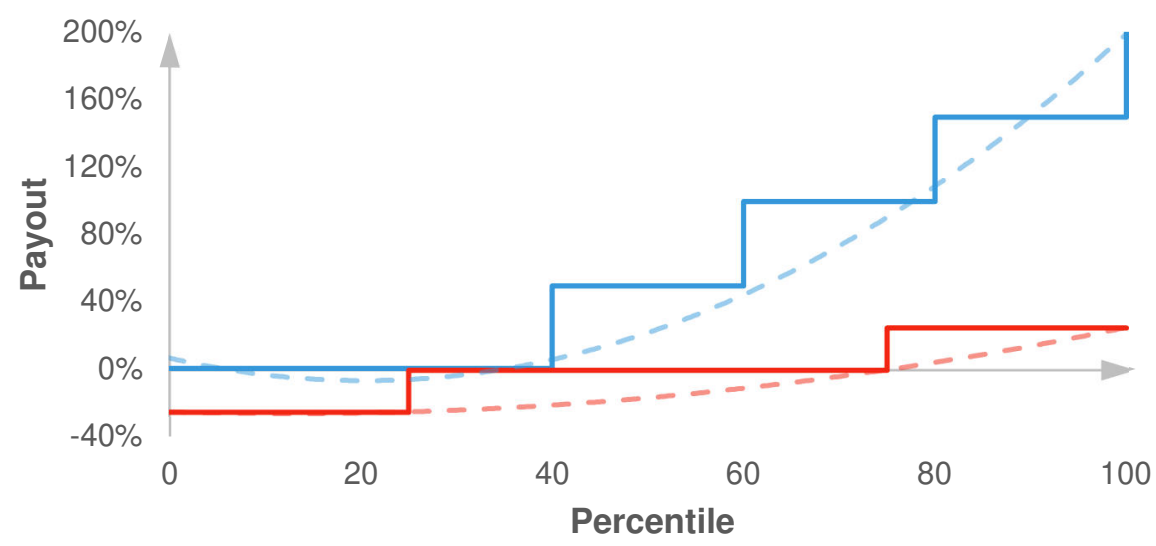

Panel B. Peer groups

Coca-Cola Company: AT\&T Inc., Colgate-Palmolive Company, Danone S.A., General Mills, Inc., International Business Machines Corporation, Johnson \& Johnson, KimberlyClark Corporation, McDonald's Corporation, Mondelēz International, Inc., Nestlé S.A., NIKE, Inc., PepsiCo, Inc., Philip Morris International Inc., Pfizer, Inc., The Procter \& Gamble Company, Unilever plc, and Wal-Mart Stores, Inc.

Chevron Corporation: BP plc, ExxonMobil Corporation, Royal Dutch Shell plc, Total S.A., and S\&P 500 Total Return Index.

This figure illustrates the relative performance plans of The Coca-Cola Company (2019) and Chevron Corporation (2019). Panel A illustrates the payout structures. The bolded red line illustrates the payout structure of The Coca-Cola Company's (2019) plan. The bolded blue line illustrates the payout structure of Chevron Corporation's (2019) plan. The dashed lines represent the plans' convexity. In this panel, the $x$-axis represents the performance hurdles that result in the payouts displayed on the $y$-axis. Panel B illustrates the peer groups for both plans.

First Stage. In this section, I examine how a manager will respond once he/she has observed the characteristics in his/her relative performance plan. The way in which managers respond to such incentives depends on the value they attach to those incentives. As is standard in the literature (e.g., Hall and Murphy, 2000, 2002, Lambert et al., 1991), I adopt the certainty equivalent framework to estimate the value an undiversified, risk-averse agent attaches to incentive plans that strip away a portion of systematic performance. ${ }^{14}$ This framework stipulates that the value of uncertain incentive-compensation is equal to an immediate cash payment that provides the same expected utility as the uncertain incentive-compensation does. In other words, the agent's subjective value (or "certainty equivalent") of the incentive plan can be thought

14. A variant of this framework is also used by, among others, Armstrong and Vashishtha (2012), Conyon, Core, and Guay (2011), Gormley, Matsa, and Milbourn (2013), Huddart (1994) and Tian (2004). 
of as the guaranteed sum of pay the agent would accept now, rather than taking a chance on greater, but uncertain, pay. Intuitively, the agent prefers the incentive plan with the greatest subjective value.

Appendix I provides details that underlie the analytical model. Since closed-form solution is not available for certainty equivalent value, it is necessary to solve it numerically. This can be done by solving the maximization problem (1.A.6) in Appendix I. Specifically, to examine the agent's risk-taking incentives, I compare the agent's certainty equivalent before and after lifting the firm's idiosyncratic risk profile. This comparison allows me to assess how much incentive the agent has to increase his/her firm's idiosyncratic risk profile. Thus, idiosyncratic risk-taking incentives are measured as the percentage change in the certainty equivalent of the agent's incentive plan from moving from the safe to the risky state of the world-the greater the percentage change, the greater an agent's incentive to pursue idiosyncratic risk.

To examine the effects of differing payout convexity and peer group difficulty, I construct a series of incentive plans by-independently as well as simultaneously-(1) altering the curvature of the incentive plan to vary payout convexity; and (2) adjusting the performance thresholds that determine the relative performance payouts to vary peer group difficulty. I then compare the agent's risk-taking incentives across this series of incentive plans. These comparisons allow me to assess how-and how much — the agent's incentive to increase his/her firm's idiosyncratic risk profile changes with respect to changes in payout convexity and peer group difficulty.

There are other plan characteristics that may moderate the relation between payout convexity, peer group difficulty and firm risk, based on the idea that these other characteristics define whether a relative performance plan provides "pure" RPE incentives, vis-à-vis noisier variants of RPE incentives. For now, to keep the model and discussion tractable, I hold other plan characteristics constant. In Section V, I explore cross-sectional variation in the relative incentives-risk relation, allow other plan characteristics to vary, and provide some intuition for their moderating effects by amending the analytical model.

I present a synopsis of all main numerical estimations for the idiosyncratic component of risk in Figure 1.2. This figure illustrates the effects of increasing payout convexity and peer group difficulty on an agent's incentives to alter his/her firm's idiosyncratic risk profile by providing plots of the percentage change in the certainty equivalent of his/her incentive plan. Panel A of Figure 1.2 shows that the percentage increase in an agent's certainty equivalent caused by payout convexity is nonlinear with diminishing marginal returns. This effect manifests because a risk-averse agent's subjective value-risk trade-off decreases: the disutility from incentive-compensation uncertainty starts to outweigh the utility from the chance of greater compensation (e.g., Carpenter, 2000, Gormley et al., 2013, Ross, 2004). ${ }^{15}$ This observation leads to my first hypothesis (stated in alternative form), which predicts a nonlinear relationship between payout convexity and idiosyncratic risk.

15. This effect is consistent with the "magnification effect" of equity pay described by Ross (2004). The magnification effect relates to how different levels of exposure to the firm's share price affect managers' risk aversion. If managers are overexposed, they become risk-averse because they bear too much risk. 
Figure 1.2. Idiosyncratic risk properties of relative performance plans

Panel A. Convexity

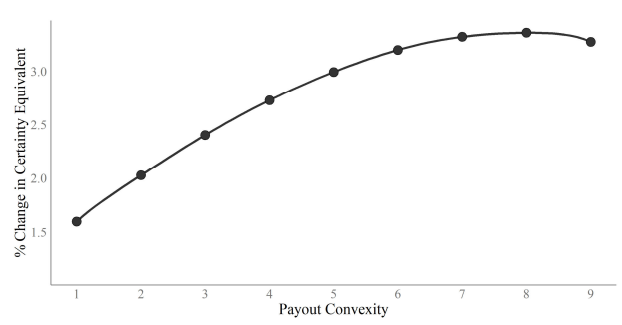

Panel C. Interactions
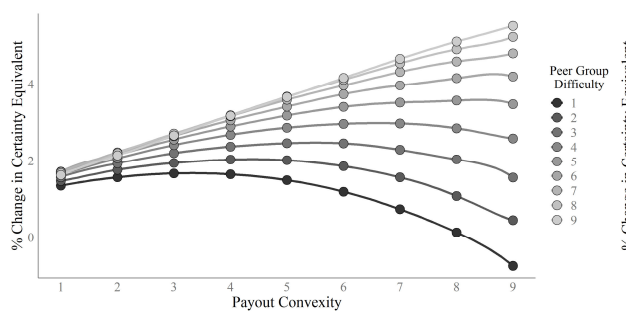

Panel B. Peer group difficulty

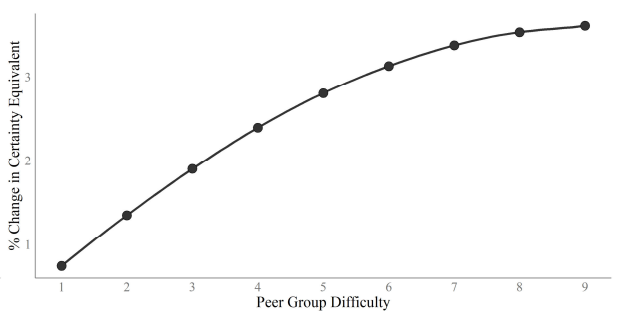

Panel D. Interactions

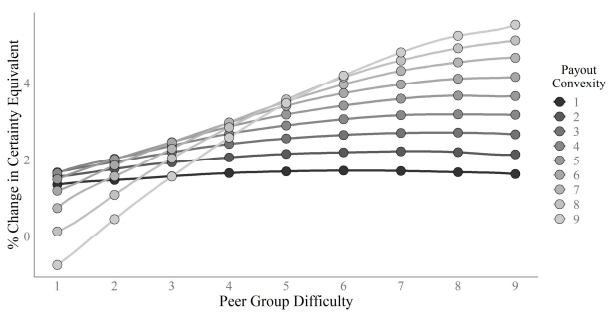

This figure illustrates a risk-averse agent's incentives to increase idiosyncratic risk in response to changes in payout convexity and peer group difficulty in a long-term incentive plan based on relative performance that strips away a portion of the systematic component of performance. Risk-taking incentives are measured as the percentage change in the subjective value (i.e., certainty equivalent) of the agent's incentive plan for a 0.1 change in the idiosyncratic volatility of the firm's stock returns for different levels of payout convexity and peer group difficulty, computed by simulating the model described in Appendix I for one holding period. Panels A and $\mathrm{B}$ alter payout convexity and peer group difficulty, respectively, while holding both the other constant (at its mean level) and the market value of the agent's total wealth constant at $\$ 15$ million. Panels C and D alter payout convexity and peer group difficulty, respectively, while also varying the other characteristic but holding the market value of the agent's total wealth constant at $\$ 15$ million. Thus, for a given level of payout convexity and peer group difficulty, the agent's outside wealth is determined such that his/her total wealth is equal to $\$ 15$ million. The agent is assumed to have power utility with a coefficient of relative risk aversion of three, and to optimally allocate his/her outside wealth (both long and short) between the risk-free asset and the market portfolio to maximize his/her expected utility. Different levels of payout convexity are simulated by increasing the number of shares the agent receives after each performance threshold, holding constant the agent's total wealth. Different levels of peer group difficulty are simulated by increasing performance levels that are required for each performance threshold, holding constant the agent's own performance-generating process. For both payout convexity and peer group difficulty, I simulate nine increasing levels to analyze their impact on risk-averse agent's incentives to increase idiosyncratic risk in response to the relative performance plan. The relative nature of the incentive plan decreases the sensitivity of the agent's utility to systematic performance by $40 \%$. The annualized parameters for the stockprice process and the market-value process are as follows: stock price is $\$ 30$, idiosyncraticreturn volatility is $20 \%$, systematic-return volatility is $20 \%$, market-return volatility is $20 \%$, market-risk premium is $7 \%$, and risk-free rate is $2 \%$. 
Hypothesis 1. Idiosyncratic risk is concave in payout convexity.

Panel B of Figure 1.2 shows that increasing peer group difficulty unambiguously increases an agent's certainty equivalent. This effect manifests because an agent expecting to win does not want to imperil his/her favorable position and prefers low risk, whereas an agent expecting to lose can only gain by increasing risk (e.g., Knoeber and Thurman, 1994, Kräkel and Sliwka, 2004). ${ }^{16}$ This observation leads to my second hypothesis (stated in alternative form), which predicts a positive relationship between peer group difficulty and idiosyncratic risk.

Hypothesis 2. Idiosyncratic risk is increasing in peer group difficulty.

Furthermore, Panel C of Figure 1.2 shows that for a given level of payout convexity, a greater level of peer group difficulty results in a greater increase in an agent's certainty equivalent than does a smaller level of peer group difficulty. And Panel D of Figure 1.2 shows that for a given level of peer group difficulty, greater levels of payout convexity likewise alter an agent's certainty equivalent. The economic intuition behind these interaction effects is as follows. If an agent plays against inferior agents (and anticipates to win), then imposing strong incentives on an agent merely decreases his/her utility from taking risks (e.g., Lambert, Larcker, and Weigelt, 1993, Rosen, 1986) - the agent does not want to gamble his/her large price for nothing. In contrast, if an agent plays against superior agents (and anticipates to lose), then imposing strong incentives on an agent increases his/her utility from taking risks - the agent has nothing to lose, can gain much, but can only beat peers by taking risks. Thus, the incentive effects of payout convexity are affected by the incentives of peer group difficulty, and vice versa. Note that these synergistic incentive effects are analogous to how out-the-money and in-themoney stock options give managers differential incentives to alter (i.e., increase and decrease, respectively) their firms' risk profiles (e.g., Lewellen, 2006). This observation leads to my third hypothesis (stated in alternative form), which predicts that payout convexity and peer group difficulty synergistically impact idiosyncratic risk.

\section{Hypothesis 3. The effect on idiosyncratic risk caused by payout convexity is affected by} peer group difficulty, and vice versa.

An assumption underlying these hypotheses is that these relations do not hold-or, at least, are much weaker-for the systematic component of risk. I examine this assumption in more detail in Appendix II, in which I repeat all numerical estimations for the systematic component of risk. In this appendix I show that payout convexity and peer group difficulty indeed give an agent barely an incentive to increase the systematic

16. Brown, Harlow, and Starks (1996) and Chevalier and Ellison (1997) provide empirical evidence that expected losers prefer high risks while expected winners prefer low risks. 
component of risk. ${ }^{17}$ To empirically test this prediction, I examine both the total and idiosyncratic risk-taking properties of relative performance plans.

Second Stage. In this section, I examine which firms would choose which combination of payout convexity and peer group difficulty—given managers' anticipated responses. Panels C and D of Figure 1.2 provide some intuition for which combination of payout convexity and peer group difficulty would lead, in equilibrium, to the most extreme levels of idiosyncratic risk. That is, these figures suggest that "high convexitylow difficulty" leads to the lowest levels of-and suggestively decreases in-idiosyncratic risk, whereas "high convexity-high difficulty" leads to the greatest levels of idiosyncratic risk. The remaining question in this incentive equilibrium is for which type of firms these choices (i.e., managers' anticipated risk responses) are desired. Phrased differently: conditional on evaluating managers on their relative performance, which type of firms would give their managers relatively strong idiosyncratic risk-taking incentives, and which type of firms would give their managers relatively weak idiosyncratic risk-taking incentives?

Economic theory predicts that firms that want to give their managers relatively strong relative performance incentives are those firms that have access to a sufficiently large array of investment projects. The reason for this is that the gains achievable from relative performance evaluation vary with the number of projects to which the manager has access (e.g., Dye, 1992). Intuitively, if managers are evaluated on relative performance, they prefer those projects where their relative performance is greatest. However, shareholders obviously prefer those projects where their firm's absolute value is greatest (which would have been chosen in the absence of RPE). These projects need not coincide when there is limited discretion in project choice. That is, if there are only a few projects available, relative performance incentives will strictly motivate managers to self-select/invest only in those projects where they can marginally outperform peers, rather than to invest in projects that offer the highest return on an absolute basis (e.g., Lambert, 2001). In contrast, if the number of available projects is sufficiently large, then managers can pick those idiosyncratic projects that offer both the highest relative and absolute returns-consistent with shareholders' preferences. This implies that if there is limited discretion in project choice, steep relative incentives may induce inappropriate project selection and lead to little improvement on contracting (e.g., Dye, 1992).

Figure 1.3 provides some formal intuition for the notion that firms whose managers have different levels of strategic flexibility yield different levels of idiosyncratic returns. In this figure, I simulate a firm's idiosyncratic returns by measuring the difference in returns of a firm whose agent is strategic flexible and can choose from $N \in\{2, \ldots, 9\}$ investment projects vis-à-vis a firm whose agent is not strategic flexible and can choose from only one investment project. This figure confirms the idea that a firm's idiosyncratic returns are increasing in the number of investment projects to which the

17. Simulations in Appendix II indicate this incentive is not zero. If payout convexity is sufficiently large, then relative performance plans do give agents a small incentive to increase the systematic component of riskalbeit much smaller than the incentive to increase idiosyncratic risk. This finding makes intuitive sense, because, although a fraction of systematic risk is stripped away under relative performance evaluation (e.g., the mean/median), ultimately an agent can still outperform his/her peers by increasing systematic risk relatively more than his/her peers (e.g., more than the mean/median). 
Figure 1.3. Idiosyncratic risk and strategic flexibility

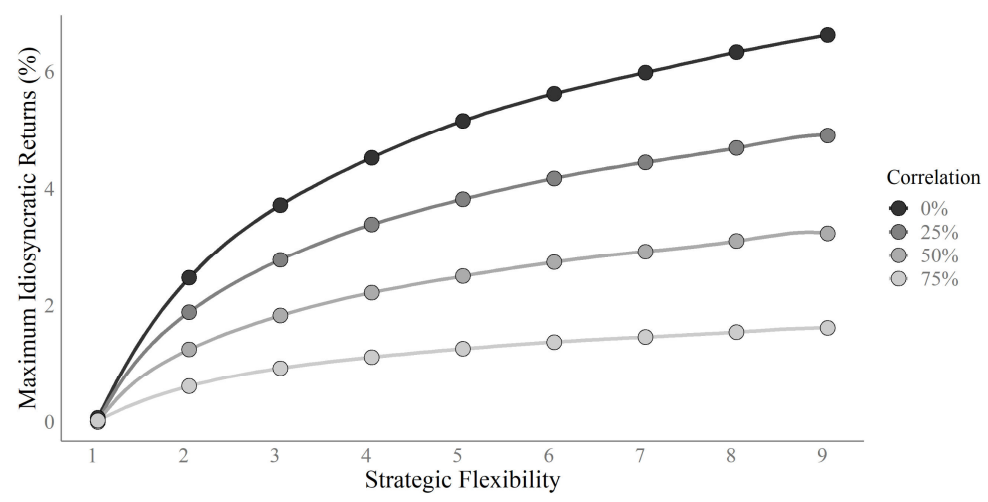

This figure illustrates the maximum idiosyncratic returns of firms whose agents have different levels of strategic flexibility. Maximum idiosyncratic returns are measured as the difference in returns of a firm whose agent is strategic flexible and can choose from $N$ investment projects vis-à-vis a firm whose agent is not strategic flexible and can choose from only one investment project. I simulate nine increasing levels of strategic flexibility by increasing the number of segments the firm of the agent operates in, whereby each segment gives an agent access to one additional investment project. Irrespective of the level of strategic flexibility, the agent can only invest in one project. The agent chooses the project that gives the maximum returns. The returns of one investment project follow a joint geometric Brownian motion with the returns of all other investment projects, and are equal to $R_{n}=\exp \left(\mu_{n}-\frac{1}{2} \sigma_{n}^{2}+\sigma_{n} \varepsilon_{n}\right)$, where $\mu_{n}=10 \%$ and $\sigma_{n}=20 \%$ are the expected return and expected return volatility of the investment project, and $\varepsilon_{n}$ is a joint normal shock with correlation $\eta$ between investment projects. I simulate four increasing levels of this correlated joint normal shock-i.e., $\eta=\{0,0.25,0.50,0.75\}$ - and simulate, for each $\eta, 25,000$ iterations of the return process. The $y$-axis represents the median of the 25,000 maximum idiosyncratic returns for each level of strategic flexibility displayed on the $x$-axis.

manager has access. This effect manifests because if the number of projects to which one manager has access (and to which other managers do not have access-i.e., idiosyncratic projects) is sufficiently large, then that manager is more likely to find those investment opportunities that yield superior returns (e.g., Dye, 1992). Figure 1.3 also shows that this edge remains even if the investment opportunities of all agents become more similari.e., if the idiosyncratic (systematic) nature of all investment projects decreases (increases). Hence, this figure corroborates the notion that it seems reasonable to impose relatively steeper relative incentives on those managers that have access to a sufficiently large array of investment projects.

There is a further benefit to imposing relatively steeper relative incentives on those managers that have access to a sufficiently large array of investment projects. If managers have access to many projects, then their peers likely also have access to many projects. This is important, because firms may want to send a signal to curtail competitive actions of peers on certain idiosyncratic projects. Firms can do this by explicitly disclosing that managers are evaluated on their performance relative to peers-as well as naming these 
peers (e.g., Bloomfield, 2021, Fershtman and Judd, 1987, Katz, 1991).${ }^{18}$ However, this signal-and thus firms' curtailment of competitive actions - is only credible if peers have access to alternative projects. If peers have no access to other investments projects, and the focal firm and its peers are competing for a handful of similar investment projects, then imposing relatively steeper relative incentives on managers can lead to costly competitive sabotage (e.g., Aggarwal and Samwick, 1999).

The above discussion leads to my fourth hypothesis (stated in alternative form), which predicts a positive relationship between the strength of idiosyncratic risk-taking incentives and the access to investment projects.

\section{Hypothesis 4. The probability of imposing steep relative performance incentives on} managers is increasing in the firm's access to investment projects.

\section{Variable Measurement, Sample Selection and Descriptive Statistics}

In this section, I define my variable construction processes, data sources and sample selection procedures.

\section{III.A. Risk}

I measure risk using the Armstrong and Vashishtha (2012) measure for risk. ${ }^{19}$ This measure captures risk in terms of the firm's ex ante asset diversification across industries. To calculate risk in this manner, I consider each firm to be a portfolio of assets in separate industry segments. I determine each industry segment's riskiness based on valueweighted returns of firms operating solely in that industry segment for that year. ${ }^{20} \mathrm{I}$ then define the firm's total risk profile, Total Risk, as weighted sum of the riskiness of all industry-segments the firm operates in for that year, and the firm's idiosyncratic risk profile, Idiosyncratic Risk, as the portion of total risk unexplained by the Fama and French (1993) factors.

\section{III.B. Relative Performance Plans}

I restrict my sample to firms using relative performance plans. I code the presence of a relative performance plan for a firm-year observation if the Compensation Discussion and Analysis section of the firm's proxy statement states that executive

18. To make the intuition for this point clearer, consider two pharmaceutical firms, A and B. Suppose that firm A recently developed a drug that dominates in market share. Then, if manager B knows that manager A has explicit incentives to outperform him/her, it is in firm B's best interest not to directly compete with firm A in the market it currently dominates, but instead to challenge firm A by developing a different "idiosyncratic" drug.

19. The Armstrong and Vashishtha (2012) measure for risk has several benefits over other measures for risk. First, this measure captures the aggregate risk profile of the firm. In contrast, measures such as research and development expenditures and capital expenditures focus on a specific aspect of firm risk. Second, this measure captures the actual risk decision, whereas measures based on realized accounting performance volatility or realized stock return volatility primarily capture the outcome of the risk decision. Nevertheless, in Section IV.A, I present robustness checks whereby I measure firm risk using these alternative measures and find, by and large, similar inferences using these measures.

20. For the mean and median observation in my sample, imputed variance is computed based on 225 and 148 “single industry firms," respectively. 
incentive-compensation is determined based on the firm's performance relative to performance of a self-selected peer group.

Appendix III exemplifies two relative performance plans. Panel A presents AT\&T Inc.'s (2019) relative performance plan and Panel B presents United Parcel Service Inc.'s (2019) relative performance plan. A similarity between both plans is that incentivecompensation is a function of relative three-year total shareholder return. An important difference between both plans, however, is that AT\&T Inc.'s (2019) plan is a "sharebased" relative performance plan (i.e., the payouts are in cash but based on the share price), whereas United Parcel Service Inc.'s (2019) plan is a “dollar-based” relative performance plan. In Section V, I exploit this cross-sectional variation in payout schemes in my empirical analysis.

\section{III.C. Payout Convexity}

I infer each plan's payout convexity from the following incentive plan-year specific regression of payouts on percentiles and their square:

$$
\text { Payout }_{i j t}=\alpha_{0 i j t}+\beta_{1 i t} \text { Percentile }_{i j t}+\beta_{2 i t} \text { Percentile }_{i j t}^{2}+\varepsilon_{i j t}
$$

where $\hat{\beta}_{2 i t}$ measures firm $i$ 's payout convexity, Convexity, in year $t$.

Given that firms are free to choose the number of hurdles as well as whether to specify the hurdles as percentiles (i.e., 100, $\ldots, 1$ ) or ranks (i.e., $1, \ldots, N$ ), there exists much cross-sectional variation in payout structures. This complicates the comparability of a measure for payout convexity across firms when estimating that measure through Equation (1.3.1). I circumvent such issues by expressing incentive plans in "percentages." ${ }^{21}$ Intuitively, if a firm reaches percentile 100 or rank 1, the firm beats 100 percent of peers, and if a firm reaches percentile 1 or $\operatorname{rank} N$, the firm beats 0 percent of peers. This implies that-irrespective of the payout structure-any percentile/rank lies on the continuum between 0 percent and 100 percent.

A further "issue" that arises when estimating Equation (1.3.1) is that regression techniques estimate the least squares line passing through the combination of data points. This implies that I must explicitly specify payouts for "imaginary" percentiles. To see why, consider the following incentive plan:

\begin{tabular}{l|rrrr} 
Percentile & $<40$ & 40 & 60 & $\geq 80$ \\
\hline Payout & $0 \%$ & $50 \%$ & $100 \%$ & $150 \%$
\end{tabular}

21. Expressing incentives in this "percent-percent" format is consistent with the notation in the proxy statements of the vast majority of large U.S. firms (see, e.g., Figure 1). Incentives expressed in percent-percent (in lieu of "dollar-dollar" or "dollar-percent") have two convenient empirical properties (e.g., Edmans, Gabaix, and Landier, 2008), since percent-percent incentives are independent of both firm size and the level of compensation (which itself is a function of the firm's stock price). This implies that a measure for convexity based on percent-percent incentives is comparable across a large cross-section of size-varying firms and prevents many issues of endogeneity by blocking the "backdoor path" via the firm's stock price. In untabulated analyses, I find that a measure for convexity based on dollar-percent incentives exhibits a correlation of 0.780 with the percent-percent measure. 
Figure 1.4. Empirical properties of Convexity

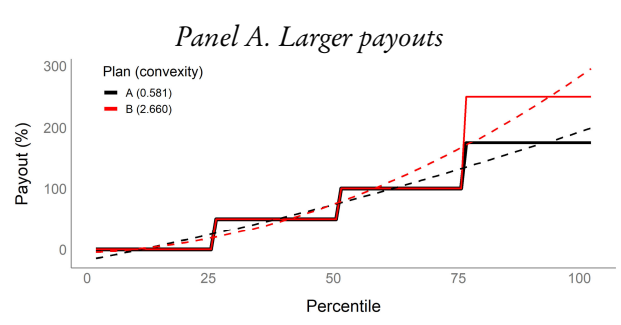

Panel C. More hurdles, same payouts

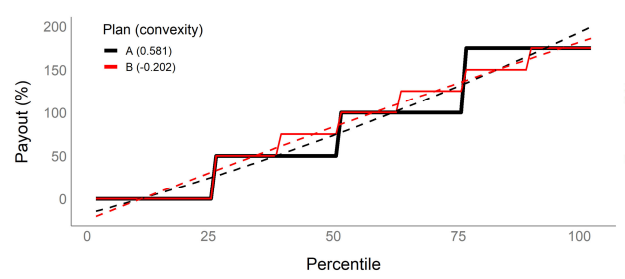

Panel B. Lower hurdles

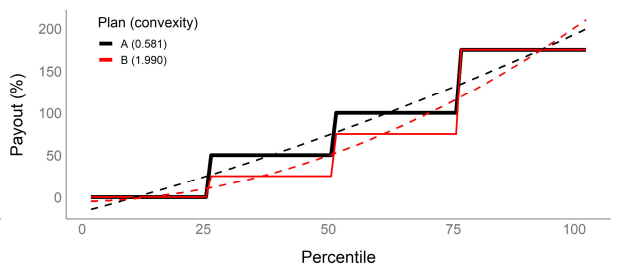

Panel D. Interpolation

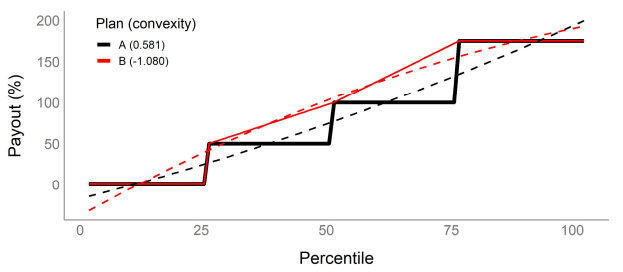

This figure illustrates the ceteris paribus effect of design choices in payout structures on my measure of payout convexity, Convexity. Panel A modifies payout levels. Panel B modifies hurdle levels. Panel C modifies the number of hurdles. Panel D modifies interpolation rules. In each panel, the bolded black line represents a basic relative performance plan with payouts $50 \%$ $100 \%-175 \%$ for the percentile hurdles 25 th-50th-75th, respectively, without interpolation between percentiles; its convexity is illustrated by the dashed black line. The red line represents a relative performance plan for which one feature is modified relative to the baseline plan; its convexity is illustrated by the dashed red line. In each panel, the $x$-axis represents the performance hurdles that result in the payouts displayed on the $y$-axis.

In this case, I must explicitly specify that the payouts for, for example, percentiles 41 through 59 are 50 percent (cf. percentile 40), because otherwise ordinary least squares interpolates the payouts between percentiles-which renders the incentive plan linear. ${ }^{22}$

The above two steps transform each incentive plan in a 2-by-100 matrix measuring payouts and percentiles. These incentive plan-year specific matrices are then the inputs for Equation (1.3.1).

To get a sense of how Convexity changes with respect to changes in the underlying convexity of payout structures, I run several simulations estimating its sensitivity to four crucial features of incentive plans: (1) payout levels; (2) hurdle levels; (3) number of hurdles; and (4) interpolation rules between hurdles. Figure 1.4 illustrates these results and shows that—consistent with the notion of convexity-my measure for payout convexity increases when the payout structure has: (1) larger payouts for extraordinary performance (Panel A); (2) lower hurdles for ordinary performance (Panel B); (3) less hurdles for the same payouts (Panel C); and (4) no interpolation between hurdles (Panel D). ${ }^{23}$

22. There do exist incentive plans that allow interpolation between percentiles. I carefully determine the payouts for imaginary percentiles using the actual interpolation rules of each firm-year's incentive plan.

23. For ease of interpretation, I transform all convexity estimates in my empirical analyses in non-negative values by adding a trivial constant. 


\section{III.D. Peer Group Difficulty}

A measure for peer group difficulty is absent from the literature. Therefore, I construct my own measure, which has two key features. The first feature relates to the idea that, in a perfect RPE setting, the peer group exhibits on average the same expected systematic volatility as the focal firm (e.g., Ma et al., 2021). Hence, to outperform the listed set of peers over the event performance period, a focal firm must pursue projects characterized by idiosyncratic risk. This implies that variation in peer group difficulty must come from ex ante differences in expected idiosyncratic performance. The second key feature relates to the idea that this measure should capture how difficult it is to beat peers in future periods, which requires some sort of out-of-sample simulation of stock prices.

With regard to the first feature, I capture expected idiosyncratic performance through analyst forecasts of the firm's target price. These analyst forecasts are relevant, because the reflect the idiosyncratic component of returns-and not necessarily the systematic component of returns (e.g., Lys and Sohn, 1990). In addition, there is evidence that these forecasts are informative about the future idiosyncratic (i.e., abnormal) component of firm returns (e.g., Abdel-Khalik and Ajinkya, 1982, Givoly and Lakonishok, 1979, Imhoff and Lobo, 1984, Stickel, 1991). With regard to the second feature, I follow the logic of the certainty equivalent framework developed in the theoretical section of this paper and assume that the distribution of stock prices is lognormal. This assumption implies that returns are normally distributed with mean $\mu$ and variance $\sigma^{2}$.

I compute $\mu$ and $\sigma^{2}$ based on the firm-year distribution of analyst forecasts about the firm's returns. After computing expected returns for all firms and their peers, I construct a measure of peer group difficulty called Peer Difficulty. This variable is defined as the median of expected excess returns each of peer has over the focal firm at the beginning of the fiscal year. To illustrate, consider a firm that has three peers. The focal firm's expected returns are $10 \%$, and its peers' expected returns are $13 \%, 15 \%$ and $17 \%$. In this case, Peer Difficulty is $5 \%$ : the median of $\{13 \%-10 \%, 15 \%-10 \%, 17 \%-10 \%\} .^{24}$

\section{III.E. Access to Idiosyncratic Investment Projects}

To evaluate the role of access to idiosyncratic investment projects in boards' contract-design choices with respect to combinations of payout convexity and peer group difficulty, I construct three variables to capture the firm's access to idiosyncratic investment projects. The first variable is the number of segments the firm is operating in. Intuitively, if the firm operates in many segments, the firm has access to a larger number of investment projects. To ensure that I not only consider the number of segments, but also the firm's share among segments, I construct a measure using the

24. This "median-approach" creates a variable that more accurately captures peer group difficulty compared to, for example, firms' expected percentile, because there exists considerable cross-sectional variation in: (1) the size of peer groups; and (2) the dispersion of peer performance. To illustrate, consider three firms. All firms' percentile rank is 0.50 . However, the first firm only has 4 peers, whereas the second and third firm both have 15 peers. But, for the second firm, peer performance is narrowly distributed around the firm's performance, whereas, for the third firm, peer performance is dispersed. The expected percentile-approach would label all peer groups as equally difficult to beat, which is not the case in reality. In contrast, the medianapproach considers how difficult it is to actually beat the median peer. 
intuition from the Herfindahl-Hirschman Index. I call this variable Segments $H H I$, which captures the firm's Herfindahl-Hirschman Index with respect to its own sales across all segments. For this variable, larger values correspond to fewer available investment projects.

The intuition behind the other two variables is as follows. If a firm has access to a sufficiently large array of idiosyncratic investment projects, this implies the firm's rivals are not "too similar." Intuitively, if those rivals were similar (in the extreme: exactly similar and, thus, the same firm), they would already have picked up those idiosyncratic projects. Thus, rival similarity should also proxy for firms' access to idiosyncratic investment projects. In this regard, I use two proxies for rival similarity. The first variable is the firm's mean similarity to its Hoberg and Phillips' (2010, 2016) product market peers, Rival Similarity. This variable captures the firm's similarity to its product market peers, with larger values corresponding to fewer available investment projects. The second variable is the mean idiosyncratic risk profile of the firm's relative performance peers, Peer Idiosyncratic Risk. This variable captures the firm's dissimilarity to its relative performance peers, as well as those peers' dissimilarity to the overall market, with larger values corresponding to more available investment projects. Collectively, these measures capture variation in firms' access to idiosyncratic investment projects both across product markets and within peer groups.

\section{III.F. Controls}

In all of my specifications, I include the following variables as controls. First, I control for alternative incentives to make sure that the observed relation between relative performance plans and firm risk is not simply an artifact of complementary incentives. Under the assumption that managers select into incentive-compensation contracts according to, inter alia, their risk preferences, controlling for alternative incentives also partially controls for unobserved variation in managers' degree of risk aversion. Following an extensive prior literature, I measure incentives using portfolio delta, portfolio vega and total cash compensation. My measures for portfolio delta and vega, Delta and Vega, are the sensitivity of the risk-neutral value of the CEO's portfolio of stock and stock options to a 1 percent change in the price of the underlying stock and a 0.01 change in the volatility of the underlying stock, respectively (e.g., Core and Guay, 2002, Guay, 1999). I estimate the risk-neutral value of the CEO's option portfolio using the Black and Scholes (1973) model, as modified by Merton (1973b) to account for dividend payouts. Cash Compensation is the sum of the CEO's salary, bonus and nonequity incentives.

In addition to these contractual incentives, I also control for the CEO's tenure, because tenure impacts the shape of long-term incentive plans through two forces. First, greater tenure implies less uncertainty about ability, which allows firms to impose steeper incentives on managers (e.g., Core and Guay, 1999, Gibbons and Murphy, 1992). Second, firms increase incentives for managers with greater tenure to reduce horizon issues (e.g., Dechow and Sloan, 1991). Tenure is the number of years the CEO has held his/her office.

Next, I control for the firm's competitive environment for two reasons. First, competition affects the use/design of relative performance plans. For example, the weight on relative performance-and, as such, the firm's propensity to use relative performance evaluation-is increasing in the degree of product market competition (e.g., 
Aggarwal and Samwick, 1999, Vrettos, 2013). Second, there is ample theory and empirical evidence on the relation between competition and risk (e.g., Boyd and De Nicoló, 2005, Chevalier and Ellison, 1997). Thus, to make sure I do not observe a spurious relation between relative performance plans and firm risk created by competition, I include two proxies for competition. My measures for competition, Number of Rivals and Rival Similarity, are the firm's number of product market peers and the firm's mean similarity to its product market peers, respectively. Product market peers and similarity scores are as defined by Hoberg and Phillips $(2010,2016)$. (It may be important to note that these product market peers differ from the peers in relative performance plans.)

I also include several firm characteristics to replicate a representative set of control variables used in prior literature examining the relation between incentives and firm risk. These firm characteristics affect either firm risk, the use/design of incentives, or both. First, I include the firm's size, because larger firms take smaller risks (e.g., Coles, Daniel, and Naveen, 2006, Guay, 1999), and firm size plays an important role in peer selection (e.g., Albuquerque, 2009, Gong et al., 2011). I use the firm's annual revenue, Sales, to proxy for firm size. ${ }^{25}$ Second, I include the firm's leverage to control for the relation between the debt structure of the firm and firm risk. ${ }^{26} \mathrm{I}$ measure the firm's leverage, Leverage, as the book value of total long-term debt, scaled by total assets. Third, I include a set of variables for the firm's investment and growth opportunities, because firms with greater investment and growth opportunities invest in riskier projects than do firms with smaller opportunities (e.g., Armstrong and Vashishtha, 2012, Guay, 1999). In addition, firm investment and growth opportunities negatively impact the firm's propensity to use incentive plans based on relative performance (e.g., Albuquerque, 2014, Gong et al., 2011). I use the firm's book-to-market ratio, Book-to-Market, prior period's sales growth, Sales Growth, and net investment in property, plant and equipment scaled by total assets, $P P E E$, to proxy for investment/growth opportunities.

\section{III.G. Sample Selection and Descriptive Statistics}

I construct my sample using six data sources. First, I obtain data on relative performance plans for CEOs of the largest 750 firms by market capitalization from ISS Incentive Lab. Second, I obtain data on incentive-compensation and equity portfolio holdings from Standard and Poors' ExecuComp. Third, I rely on Compustat Segments Data to determine in which segments each firm operates. Fourth, I obtain data on firm returns and Treasury bond yields from Center for Research in Security Price. Fifth, I rely on the Hoberg-Phillips Data Library to determine the degree of competition in the product market. Finally, I obtain firm fundamentals from Compustat. The sample begins in 2006, when information on relative performance plans becomes available, and ends in 2017 , because I require one leading year of data on firm risk. The final sample contains 1,606 observations for all firms in ISS Incentive Lab from 2006 to 2017 using relative

25. It is common in the empirical risk literature to use the firm's annual revenue as a proxy for firm size (e.g., Armstrong and Vashishtha, 2012, Coles et al., 2006, Coles, Li, and Wang, 2018). The idea is that the firm's revenue reflects the operating size of the firm, which plays an important role in firm risk decisions. Inferences are unaffected if I use the firm's market value of equity or total assets as a proxy for firm size.

26. On the one hand, leverage gives managers an incentive to transfer wealth from bondholders to shareholders through firm risk (e.g., Leland, 1998). On the other hand, bondholders have an incentive to reduce leverage in risky firms that face a high probability of financial distress (e.g., Lewellen, 2006). 
performance plans with self-selected peers and with non-missing values for all required variables.

Table 1.1 presents descriptive statistics for the primary variables in my design. Table 1.2 presents year and industry distributions of Convexity and Peer Difficulty. Table 1.1 shows that the mean (median) values for Idiosyncratic Risk and Total Risk are 0.037 (0.032) and $0.064(0.063)$, respectively. These statistics are consistent with Armstrong and Vashishtha (2012) and imply that the average firm has an annual total return volatility of roughly $6.4 \%$, of which roughly $57 \%$ comes from idiosyncratic-return volatility.

Table 1.1 also shows that my sample consists of relatively large and successful firms with mean and median sales of approximately $\$ 9$ billion and $\$ 5.5$ billion, respectively, and mean and median returns of $13.3 \%$ and $11.5 \%$, respectively. These statistics are consistent with the notion that the ISS Incentive Lab database covers the largest 750 firms by market capitalization. This table further shows that the managers in my sample hold significant equity-based incentives. For example, the mean (median) sensitivity of managers' wealth to a $1 \%$ increase in the firm's stock price is approximately $\$ 700,000$ $(\$ 300,000)$, and the mean (median) sensitivity of managers' wealth to a 0.01 increase in the standard deviation of the firm's returns is approximately $\$ 180,000(\$ 60,000)$.

\section{Empirical Analysis \\ IV.A. Relative Performance Plan Characteristics and Firm Risk}

In this section, I test my risk-profile hypotheses (i.e., Hypotheses 1 through 3 ) by estimating an empirical model of firm risk. This model is a generalization of that used throughout the empirical risk-taking literature (e.g., Armstrong and Vashishtha, 2012, Coles et al., 2006, Guay, 1999, Lewellen, 2006, Low, 2009, Rajgopal and Shevlin, 2002):

$$
\begin{aligned}
\text { Risk }_{i j t}= & \alpha+\beta_{1} \text { Convexity }_{i j t-1}+\beta_{1} \text { Convexity }_{i j t-1}^{2}+\beta_{3} \text { Peer Difficulty }_{i j t-1} \\
& +\beta_{4}\left(\text { Convexity }_{i j t-1} \times \text { Peer Difficulty } i_{i j t-1}\right) \\
& +\beta_{5}\left(\text { Convexity }_{i j t-1}^{2} \times \text { Peer Difficulty }_{i j t-1}\right)+\gamma^{\prime} X_{i j t-1}+\theta^{\prime} \mu_{j}+\phi^{\prime} v_{t}+\varepsilon_{i j t}
\end{aligned}
$$

where the indices $i, j$ and $t$ correspond to firm, industry and time, respectively. Convexity and Peer Difficulty measure relative performance payout convexity and peer group difficulty, respectively (see Sections III.C and III.D for details). $X$ is a vector of control variables (see Section III.F for details) that is measured prior to the dependent variable to capture the most recent incentives/controls contemporaneous with managers' risk decisions. I also add several fixed effects to control for residual systematic variation not captured by the other control variables, including: (1) year fixed effects, $v_{t}$, to control for systematic variation across year; and (2) industry fixed effects (based on the 48 industry groups identified by Fama and French (1997)), $\mu_{j}$, to control for between-industry heterogeneity in incentive-compensation contracts and risk profiles. Finally, to correct for any remaining cross-sectional and time-series dependence in the firm-year specific error term, $\varepsilon_{i j t}$, I base inferences on standard errors clustered by firm and year (e.g., Gow et al., 2010). 
Table 1.1. Descriptive statistics

\begin{tabular}{|c|c|c|c|c|c|}
\hline & Mean & Std. Dev. & 25 th & 50 th & 75 th \\
\hline$\overline{\text { Age }}$ & 56.905 & 5.309 & 54.000 & 57.000 & 61.000 \\
\hline Book-to-Market & 0.694 & 0.248 & 0.509 & 0.700 & 0.857 \\
\hline CAPEX Intensity & 0.068 & 0.072 & 0.024 & 0.048 & 0.081 \\
\hline Cash & 0.104 & 0.122 & 0.021 & 0.062 & 0.144 \\
\hline Cash Compensation & 967.598 & 603.954 & 568.471 & 843.927 & $1,194.795$ \\
\hline Convexity & 1.322 & 0.329 & 1.148 & 1.342 & 1.540 \\
\hline Delta & 705.005 & $1,352.030$ & 111.396 & 294.237 & 742.859 \\
\hline Effective Tax Rate & 0.285 & 0.168 & 0.211 & 0.301 & 0.358 \\
\hline Idiosyncratic Risk & 0.037 & 0.016 & 0.025 & 0.032 & 0.045 \\
\hline Industry $\theta$ & 1.155 & 11.058 & -4.003 & 0.423 & 5.480 \\
\hline Leverage & 0.268 & 0.170 & 0.158 & 0.257 & 0.341 \\
\hline Number of Rivals & 70.377 & 82.880 & 10.000 & 33.000 & 108.000 \\
\hline Peer Difficulty & -0.004 & 0.163 & -0.039 & 0.000 & 0.027 \\
\hline Peer Group Size & 15.737 & 13.181 & 9.000 & 13.000 & 18.000 \\
\hline Peer Idiosyncratic Risk & 0.032 & 0.019 & 0.023 & 0.030 & 0.042 \\
\hline Peer Synchronicity & 0.639 & 0.320 & 0.529 & 0.739 & 0.866 \\
\hline PPEE & 0.411 & 0.296 & 0.137 & 0.346 & 0.697 \\
\hline$R E D$ Intensity & 0.018 & 0.040 & 0.000 & 0.000 & 0.015 \\
\hline Return & 0.133 & 0.377 & -0.064 & 0.115 & 0.289 \\
\hline Rival Similarity & 0.026 & 0.017 & 0.014 & 0.023 & 0.031 \\
\hline$R O A$ & 0.048 & 0.078 & 0.024 & 0.046 & 0.082 \\
\hline$R P E^{\text {cash }}$ & 0.262 & 0.440 & 0.000 & 0.000 & 1.000 \\
\hline Sales & $9,130.506$ & $8,849.746$ & $2,613.488$ & $5,584.500$ & $12,763.000$ \\
\hline Sales Growth & 0.040 & 0.206 & -0.039 & 0.033 & 0.115 \\
\hline Segments HHI & 0.219 & 0.117 & 0.128 & 0.183 & 0.331 \\
\hline Tax Loss & 0.518 & 0.500 & 0.000 & 1.000 & 1.000 \\
\hline Tenure & 6.956 & 5.133 & 3.000 & 6.000 & 9.000 \\
\hline Total Risk & 0.064 & 0.021 & 0.047 & 0.063 & 0.080 \\
\hline Vega & 182.135 & 307.512 & 0.011 & 62.833 & 213.734 \\
\hline$\sigma$ Return & 0.337 & 0.254 & 0.171 & 0.271 & 0.430 \\
\hline$\sigma R O A$ & 0.040 & 0.047 & 0.011 & 0.024 & 0.051 \\
\hline
\end{tabular}

This table presents descriptive statistics for the full sample. The sample contains 1,606 observations for all firms in ISS Incentive Lab from 2006 to 2017 using RPE with self-selected peers and with non-missing values for all required variables. Age is the age of the CEO in years. Book-to-Market is the ratio of book value of total assets to the firm's market value. CAPEX Intensity is the firm's capital expenditures, scaled by the firm's total assets. Cash is the cash and cash equivalents balance, scaled by total assets. Cash Compensation is the total value of cash the CEO received. Convexity is the non-linearity slope of the payout structure of relative performance plans. Delta is the sensitivity of the risk-neutral value of the CEO's portfolio of stock options to a $1 \%$ change in the price of the underlying stock. Effective Tax Rate is the firm's GAAP effective tax rate over the past three years. Idiosyncratic Risk is the portion of imputed stock return volatility unexplained by the Fama and French (1993) three factors. Imputed stock returns are based on the industry segments in which the firm operates. Industry $\theta$ is the industry-year specific slope coefficient from a regression of buy-andhold return over the year on the natural log of 1 plus the variance of monthly returns over the year. Leverage is the book value of total long-term debt, scaled by total assets. Number of Rivals is the firm's number of product market peers. Peer Difficulty is the median of expected excess returns each of peer has over the focal firm at the beginning of the fiscal year. Peer Group Size is the firm's RPE peer group size. Peer Idiosyncratic Risk is the mean idiosyncratic risk profile of the firm's relative performance peers. Peer Synchronicity is the firm's three-year monthly stock return synchronicity with its actual peers. PPEE is the net investment in property, plant and equipment, scaled by total assets. RED Intensity is the firm's research and development expenditures, scaled by the firm's total assets. Return is the cumulative stock return. Rival Similarity is the firm's mean similarity to its 
Table 1.1. Descriptive statistics (continued)

product market peers. $R O A$ is net income, scaled by total assets. $R P E^{c a s h}$ is an indicator variable equal to one if: (1) the firm's proxy statement explicitly states that executive compensation is determined based on the firm's performance relative to performance of a self-selected peer group; and (2) the relative performance payout is not determined based on the firm's stock price, zero otherwise. Sales is the firm's annual revenue. Sales Growth is the growth in annual revenue over the prior year. Segments HHI is the firm's Herfindahl-Hirschman Index with respect to its sales across all segments. Tax Loss is an indicator variable equal to one if the firm had a tax loss carryforward in any of the past three years, zero otherwise. Tenure is the number of years the CEO has held his/her office. Total Risk is the firm's imputed stock return volatility. Vega is the sensitivity of the riskneutral value of the CEO's portfolio of stock options to a 0.01 change in the volatility of the underlying stock. $\sigma$ Return is the volatility in stock returns. $\sigma R O A$ is the volatility in net income, scaled by total assets.

Table 1.2. Year and industry distributions of Convexity and Peer Difficulty

Panel A. Convexity

\begin{tabular}{lcccccccccccc}
\hline & 2006 & 2007 & 2008 & 2009 & 2010 & 2011 & 2012 & 2013 & 2014 & 2015 & 2016 & 2017 \\
\hline$(1)$ & 1.460 & 1.320 & 1.220 & 1.160 & 1.310 & 1.600 & 1.120 & 1.300 & 1.350 & 1.210 & 1.440 & 1.400 \\
$(2)$ & 1.400 & 1.170 & 1.290 & 1.560 & 1.390 & 1.360 & 1.100 & 1.180 & 1.340 & 1.430 & 1.320 & 1.420 \\
$(3)$ & 1.350 & 1.320 & 1.420 & 1.330 & 1.310 & 1.320 & 1.230 & 1.320 & 1.210 & 1.180 & 1.400 & 1.400 \\
$(4)$ & 1.400 & 1.390 & 1.470 & 1.510 & 1.310 & 1.330 & 1.390 & 1.270 & 1.320 & 1.210 & 1.400 & 1.380 \\
$(5)$ & 1.510 & 1.450 & 1.330 & 1.460 & 1.350 & 1.450 & 1.420 & 1.380 & 1.400 & 1.360 & 1.390 & 1.630 \\
$(6)$ & 1.320 & 1.330 & 1.270 & 1.160 & 1.330 & 1.410 & 1.330 & 1.120 & 1.310 & 1.300 & 1.270 & 1.490 \\
$(7)$ & 1.280 & 1.260 & 1.140 & 1.410 & 1.160 & 1.170 & 1.250 & 1.200 & 1.260 & 1.250 & 1.560 & 1.430 \\
$(8)$ & 1.200 & 1.220 & 1.230 & 1.280 & 1.280 & 1.310 & 1.300 & 1.320 & 1.330 & 1.340 & 1.470 & 1.560 \\
$(9)$ & 1.650 & 1.500 & 1.600 & 1.400 & 1.260 & 1.370 & 1.300 & 1.320 & 1.200 & 0.945 & 1.330 & 1.320 \\
$(10)$ & 1.560 & 1.470 & 1.430 & 1.380 & 1.210 & 1.440 & 1.310 & 1.480 & 1.280 & 1.360 & 1.450 & 1.400 \\
$(11)$ & 1.720 & 1.340 & 1.240 & 1.390 & 1.370 & 1.220 & 1.200 & 1.460 & 1.300 & 1.240 & 1.460 & 1.410 \\
$(12)$ & 1.640 & 1.400 & 1.430 & 1.390 & 1.310 & 1.250 & 1.180 & 1.170 & 1.190 & 1.180 & 1.310 & 1.390 \\
\hline
\end{tabular}

Panel B. Peer Difficulty

\begin{tabular}{lrrrrrrrrrrrr}
\hline & \multicolumn{1}{c}{2006} & \multicolumn{1}{c}{2007} & \multicolumn{1}{c}{2008} & \multicolumn{1}{c}{2009} & \multicolumn{1}{c}{2010} & \multicolumn{1}{c}{2011} & \multicolumn{1}{c}{2012} & 2013 & 2014 & 2015 & \multicolumn{1}{c}{2016} & \multicolumn{1}{c}{2017} \\
\hline$(1)$ & 0.009 & -0.062 & -0.149 & -0.017 & 0.005 & 0.030 & 0.048 & 0.065 & 0.018 & 0.019 & 0.015 & 0.041 \\
$(2)$ & 0.363 & 0.214 & -0.043 & 0.093 & -0.085 & 0.085 & 0.006 & 0.032 & 0.002 & -0.044 & 0.006 & -0.056 \\
$(3)$ & -0.102 & 0.005 & 0.037 & 0.070 & 0.095 & 0.001 & 0.023 & -0.008 & -0.046 & -0.027 & -0.015 & -0.002 \\
$(4)$ & -0.005 & 0.030 & -0.062 & 0.046 & 0.031 & -0.060 & -0.035 & -0.025 & 0.006 & -0.100 & -0.025 & -0.010 \\
$(5)$ & 0.284 & -0.017 & 0.022 & -0.059 & -0.089 & 0.119 & 0.111 & 0.048 & 0.087 & 0.034 & 0.022 & -0.036 \\
$(6)$ & 0.042 & 0.021 & -0.016 & -0.039 & -0.039 & 0.014 & -0.024 & 0.012 & -0.032 & -0.023 & -0.001 & -0.015 \\
$(7)$ & -0.077 & -0.065 & -0.047 & 0.046 & -0.028 & 0.044 & 0.008 & -0.022 & -0.013 & -0.012 & -0.043 & 0.016 \\
$(8)$ & 0.058 & 0.032 & 0.014 & -0.003 & 0.029 & 0.023 & -0.006 & -0.002 & -0.020 & -0.005 & -0.001 & 0.010 \\
$(9)$ & 0.047 & 0.014 & -0.011 & -0.015 & -0.039 & -0.002 & 0.005 & 0.001 & -0.021 & -0.009 & -0.073 & -0.120 \\
$(10)$ & -0.017 & -0.029 & -0.043 & -0.067 & -0.097 & -0.065 & -0.005 & 0.002 & 0.033 & -0.096 & -0.002 & -0.003 \\
$(11)$ & 0.046 & -0.052 & -0.069 & -0.002 & 0.081 & 0.004 & 0.038 & 0.029 & 0.063 & 0.009 & -0.008 & 0.026 \\
$(12)$ & 0.132 & 0.077 & 0.019 & -0.118 & -0.074 & -0.167 & -0.037 & -0.011 & -0.053 & -0.046 & 0.013 & -0.030 \\
\hline
\end{tabular}

This table presents descriptive statistics about relative performance plan characteristics across time and industries. Panel A presents descriptive statistics on Convexity. Panel B presents descriptive statistics on Peer Difficulty. The industry indicators follow the 12 industry groups identified by Fama and French (1997): (1) Consumer Non-Durables; (2) Consumer Durables; (3) Manufacturing; (4) Oil, Gas, and Coal Extraction; (5) Chemicals and Allied Products; (6) Business Equipment; (7) Telephone and Television Transmission; (8) Utilities; (9) Wholesale and Retail; (10) Healthcare and Medical Equipment; (11) Finance; and (12) Other. All variables are defined in the caption of Table 1.1. 
Model Identification. The empirical goal in testing my risk-profile hypotheses is to test whether the risk-taking properties of payout convexity and peer group difficulty are consistent with the numerical estimations discussed in Section II. In Equation (1.4.1), the risk-taking properties of payout convexity and peer group difficulty are expressed as a function of Convexity and Peer Difficulty; that is:

$$
\begin{aligned}
& \frac{\partial \text { Risk }}{\partial \text { Convexity }}=\beta_{1}+2 \beta_{2} \text { Convexity }+\beta_{4} \text { Peer Difficulty } \\
& +2 \beta_{5}(\text { Convexity } \times \text { Peer Difficulty) } \\
& \frac{\partial \text { Risk }}{\text { DPeer Difficulty }}=\beta_{3}+\beta_{4} \text { Convexity }+\beta_{5} \text { Convexity }^{2}
\end{aligned}
$$

In light of Equations (1.4.2) and (1.4.3), $\beta_{1}$ and $\beta_{2}$ can be seen as a "pure" payout convexity effect on risk, $\beta_{3}$ can be seen as a "pure" peer group difficulty effect on risk, and $\beta_{4}$ and $\beta_{5}$ represent the synergistic risk-taking properties of payout convexity and peer group difficulty. My key prediction (i.e., Hypothesis 3) is that: (1) the nonlinear effect on risk caused by payout convexity is affected by peer group difficulty; and (2) the linear effect on risk caused by peer group difficulty is affected by payout convexity. This prediction is empirically descriptive if $\beta_{4}>0$ and $\beta_{5}<0$ or $\beta_{4}<0$ and $\beta_{5}>0 .{ }^{27}$

The difficulty that arises in statistically identifying these $\beta$ parameters is that the characteristics of relative performance plans are endogenously determined. Intuitively, if firm risk is influenced by relative performance evaluation, then the design of such incentive plans is a function of the desired level of firm risk. This simultaneity imposes an identification problem, which impedes ordinary least squares estimation in providing meaningful insights about the risk-taking properties of relative performance plans. My strategy for addressing this problem is a generalization of that used throughout the empirical risk literature: two-stage least squares estimation (e.g., Armstrong and Vashishtha, 2012, Coles et al., 2006, Rajgopal and Shevlin, 2002).

In employing two-stage least squares, I acknowledge that the identification assumptions are more stringent than under ordinary least squares (e.g., Larcker and Rusticus, 2010). That is, conventional two-stage least squares requires strong and perfectly exogenous instruments for the endogenous variables, which-admittedly_are difficult to find. To ensure that weak and invalid instruments are not behind my results, I undertake separate analyses in which I turn to "weak-instrument-robust confidence sets" (Andrews, 2018) and "modified-bias-corrected-two-stage least squares" (Anatolyev, 2013, Kolesár et al., 2015), respectively. The former method is robust to weak instruments; the latter method is robust to a violation of the exclusion restriction, under the identifying assumption that the direct effects of these "invalid" instruments are uncorrelated with the effects of the instruments on the endogenous treatment variable of interest (which I discuss below). Furthermore, I closely follow the procedure recommended by Wooldridge (2010) and Angrist and Pischke (2009a) to identify

27. If $\beta_{4}>0$ and $\beta_{5}<0$, then payout convexity has a convex relation with risk when inferior peers are selected and a concave relation with risk when superior peers are selected. If $\beta_{4}<0$ and $\beta_{5}>0$, then payout convexity has a concave relation with risk when inferior peers are selected and a convex relation with risk when superior peers are selected. 
parameters in models that are nonlinear in endogenous variables. For parsimony, Appendix IV details these methods and statistical identification tests. Below I discuss the economic intuition behind my instruments.

Identification requires instruments for all jointly determined risk-taking incentives-i.e., payout convexity, peer group difficulty, portfolio delta and portfolio vega. My instruments are based on the intuition/determinants identified by prior work (e.g., Armstrong and Vashishtha, 2012, Leary and Roberts, 2014). Specifically, I estimate payout convexity and the equity-based incentives using a set of variables based on the firm's past performance as well as the firm's marginal tax rate and cash position as instruments, and I estimate peer group difficulty using peers' peer group difficulty as an instrument.

My first set of instruments is based on the firm's past performance. If boards update the conditions of relative performance plans based on the firm's past performance (e.g., Kim and Shin, 2017, Murphy, 2000, Weitzman, 1980), then I expect past performance to be correlated with current relative performance payout convexity. ${ }^{28}$ In addition, the firm's past performance relates to current portfolio delta and portfolio vega through the valuation parameters in the Black and Scholes (1973)-Merton (1973b) option pricing model. That is, portfolio delta/vega is a function of the number of stock and stock options multiplied by the delta/vega per stock/stock option. The latter is a function of, among other things, the firm's stock price and volatility — both of which are strongly correlated with the firm's past performance. There is, however, no obvious reason for an association between past measures of a firm's performance and a firm's current risk profile, other than the relation through managerial incentives and the control variables in the structural equation (e.g., Armstrong and Vashishtha, 2012). Since most performance-vesting relative performance plans are measured over a three-year performance period (e.g., De Angelis and Grinstein, 2019, Gong et al., 2011) and it is typically assumed that options have a three-year vesting period at grant date (e.g., Core and Guay, 2002, Guay, 1999), I expect the firm's past performance over the previous three years to be positively correlated with payout convexity, portfolio delta and portfolio vega. Following Armstrong and Vashishtha (2012), I measure the firm's past performance using both stock returns and return on assets.

I include two other instruments for payout convexity, portfolio delta and portfolio vega based on Armstrong and Vashishtha (2012): (1) the firm's marginal tax rate; and (2) the firm's cash position. The firm's marginal tax rate impacts the strength of incentives through tax deductions from incentive-compensation. That is, when future tax rates are expected to be higher, the future tax deduction from deferred equity compensation can be favorable relative to the immediate tax deduction received from cash compensation (e.g., Core and Guay, 1999, Core, Guay, and Larcker, 2003). ${ }^{29}$ Therefore, I expect the

28. In essence, payout convexity is a function of a plan's: (1) payout levels; (2) hurdle levels; (3) number of hurdles; and (4) interpolation rules between hurdles (see Section III.C). These attributes are, however, endogenously determined and cannot serve as instruments for payout convexity. Therefore, I use instruments that are based on the economic notion of target ratcheting.

29. Bryan, Hwang, and Lilien (2000), Dechow, Hutton, and Sloan (1996) and Yermack (1995) provide evidence that long-term incentives are less costly for firms with lower marginal tax rates than for firm with higher marginal tax rates. The Tax Cuts and Jobs Act of 2017-which significantly decreases the tax benefits 
firm's marginal tax rate to be negatively correlated with payout convexity, portfolio delta and portfolio vega. Following Armstrong and Vashishtha (2012), Balakrishnan, Blouin, and Guay (2018), and Core and Guay (1999), I measure the firm's marginal tax rate with: (1) an indicator variable equal to one if the firm had a tax loss carryforward in any of the past three years, zero otherwise; and (2) the firm's GAAP effective tax rate in the past three years. ${ }^{30}$ With regard to the identifying assumption of modified-bias-corrected-twostage least squares estimation: the economic channel through which taxes affect incentive-compensation contracts (i.e., tax deductions from compensation) differs from any direct effect of taxes on firm risk, such as expected project payoffs (e.g., Armstrong, Glaeser, Huang, and Taylor, 2019) or managers' risky tax strategies (e.g., Rego and Wilson, 2012).

The firm's cash position impacts the shape of long-term incentive plans through two forces. On the one hand, Garvey (1997) shows that long-term incentives can reduce agency costs of excess cash (e.g., Jensen, 1986, Stulz, 1990). On the other hand, cashconstrained firms use long-term incentives as substitutes for cash compensation (e.g., Core and Guay, 1999). In any case, with regard to the identification assumption related to modified-bias-corrected-two-stage least squares estimation, the economic channel through which cash affects managerial incentives (i.e., agency costs) differs from its direct effect on firm risk through, e.g., growth opportunities (e.g., Palazzo, 2012). Following Armstrong and Vashishtha (2012), I measure the firm's cash position using the amount of cash and cash equivalents scaled by total assets, which captures the shortterm availability of cash.

My instrument for peer group difficulty is peers' peer group difficulty, which relates to a focal firm's peer group difficulty through peer effects (e.g., Angrist, 2014, Leary and Roberts, 2014, Seo, 2021). To make this point clearer, consider just three firms, A, B and C. I use average peer group difficulty of firms B and C to capture the impact of peer group difficulty on firm A, and vice versa. Intuitively, variation in one firm's peer group difficulty affects all of the other relevant firms. Consider, for example, a shock to firm's $\mathrm{B}$ profitability. This shock channels through its effect on firms $\mathrm{A}$ and $\mathrm{C}$ to that of every other firm linked to firms $\mathrm{A}$ and $\mathrm{C}$, and so on. Extending this intuition to a larger set of firms simply matches each firm to all other relevant firms. ${ }^{31}$ In this regard, Albuquerque (2009) and Gong et al. (2011) show that firms within the same two-digit SIC and size quartile are exposed to similar shocks. As such, I set the boundaries of these peer effects accordingly. ${ }^{32}$ Identification for this instrument in modified-bias-corrected-two-stage least squares estimation requires that peer effects have little impact on firm risk through channels other than those specified in the structural equation. Given the breadth of the specified channels in the structural equation (e.g., time-varying incentives, competition,

of equity incentive-compensation-does not impact the validity of this instrument in my sample period, since the regulatory change happens as of fiscal year 2018.

30. Inferences are unaffected by replacing the firm's GAAP effective tax rate with the firm's “cash effective tax rate” (e.g., Balakrishnan et al., 2018, Dyreng, Hanlon, and Maydew, 2008).

31. It also smoothens out noise and reduces the dimensionality of this issue (e.g., Leary and Roberts, 2014).

32. This instrument is not based on the firm's relative performance peers because that would simply move simultaneity one level deeper. 
firm fundamentals, industry composition and time shocks), I deem this untestable assumption plausible.

Results of Hypotheses Tests. In this section, I discuss results of my hypotheses tests. Hypotheses 1 and 2 predict a nonlinear effect of payout convexity and a linear effect of peer group difficulty on firm risk, respectively. Hypothesis 3 predicts a synergistic effect of payout convexity and peer group difficulty on firm risk. I tabulate the results of testing these hypotheses in Tables 1.3 and 1.4.

Table 1.3 presents results of estimating the relation between payout convexity and firms' risk profiles. In the specifications based on ordinary least squares estimation, I find that the coefficients on payout convexity are attenuated. In the specifications based on two-stage least squares estimation, I find that the coefficient on Convexity is positive and statistically significant and the coefficient on Convexity ${ }^{2}$ is negative and statistically significant. These coefficients are indicative of a concave relation between payout convexity and firm risk, which is consistent with Hypothesis 1. Another noteworthy finding is that the economic magnitudes for idiosyncratic risk are very close to the economic magnitudes for total risk. This finding suggests that payout convexity in relative performance plans gives managers an incentive to pursue projects characterized by idiosyncratic risk rather than systematic risk.

Table 1.4 presents results of estimating the relation between peer group difficulty and firms' risk profiles as well as the synergistic risk-taking properties of payout convexity and peer group difficulty. In the specifications based on two-stage least squares estimation, I find that the coefficient on Peer Difficulty is positive and statistically significant, the coefficient on Peer Difficulty $\times$ Convexity is negative and statistically significant and the coefficient on Peer Difficulty $\times$ Convexity $^{2}$ is positive and statistically significant. Consistent with Hypothesis 2, these coefficients demonstrate that the "pure" peer group difficulty effect on risk (controlling for payout convexity) is positive. Most importantly-and consistent with Hypothesis 3-these coefficients demonstrate that payout convexity and peer group difficulty synergistically give managers an incentive to pursue projects characterized by idiosyncratic risk rather than systematic risk (also see Panels C and D of Figure 1.2).33

To ease the economic interpretation of these interaction coefficients, I present a surface plot in Figure 1.5 that illustrates the synergistic risk-taking properties of payout convexity and peer group difficulty. The red surface shows that playing against superior peers (i.e., Peer Difficulty > 0) for big prizes (i.e., high Convexity) gives managers the greatest incentive to pursue projects characterized by idiosyncratic risk. This finding is consistent with the notion that managers must take great risks to beat superior peers and the large sums of incentive-compensation at stake justify doing so. In contrast, the dark blue surface indicates that if managers play against inferior peers (i.e., Peer Difficulty < 0) for big prizes (i.e., high Convexity), relative performance plans do not incentivize

33. In untabulated analyses, I also examine the relation between relative performance plans and firm risk in a broader sample of firms using RPE and firms not using RPE. The results of these analyses indicate that relative performance plans are on average associated with greater levels of idiosyncratic risk, which is consistent with the findings from other studies (e.g., Tice, 2020, Wruck and Wu, 2021). 
Table 1.3. Payout convexity and risk

\begin{tabular}{|c|c|c|c|c|}
\hline \multirow[b]{3}{*}{ Variable } & (1) & $(2)$ & (3) & (4) \\
\hline & \multicolumn{4}{|c|}{ Dependent variable: } \\
\hline & \multicolumn{2}{|c|}{ Idiosyncratic Risk } & \multicolumn{2}{|c|}{ Total Risk } \\
\hline \multirow[t]{2}{*}{ Convexity } & -0.005 & $0.081^{\dagger}$ & 0.001 & $0.109^{*}$ \\
\hline & $(0.004)$ & $(0.049)$ & $(0.006)$ & $(0.066)$ \\
\hline \multirow{2}{*}{ Convexity $^{2}$} & 0.002 & $-0.042^{* *}$ & -0.001 & $-0.058^{*}$ \\
\hline & $(0.002)$ & $(0.019)$ & $(0.002)$ & $(0.026)$ \\
\hline \multirow{2}{*}{$\log ($ Delta $)$} & 0.000 & 0.001 & 0.000 & 0.002 \\
\hline & $(0.000)$ & $(0.004)$ & $(0.000)$ & $(0.005)$ \\
\hline \multirow[t]{2}{*}{$\log (V e g a)$} & 0.000 & -0.002 & $0.000^{\dagger}$ & 0.002 \\
\hline & $(0.000)$ & $(0.004)$ & $(0.000)$ & $(0.004)$ \\
\hline \multirow[t]{2}{*}{$\log$ (Cash Compensation $)$} & $-0.001^{\dagger}$ & 0.000 & -0.001 & -0.001 \\
\hline & $(0.001)$ & $(0.003)$ & $(0.001)$ & $(0.003)$ \\
\hline \multirow[t]{2}{*}{$\log ($ Tenure $)$} & $0.001^{* * *}$ & 0.002 & $0.001^{*}$ & 0.000 \\
\hline & $(0.000)$ & $(0.005)$ & $(0.001)$ & $(0.005)$ \\
\hline \multirow[t]{2}{*}{$\log ($ Number of Rivals $)$} & -0.001 & 0.000 & 0.000 & 0.000 \\
\hline & $(0.000)$ & $(0.001)$ & $(0.000)$ & $(0.001)$ \\
\hline \multirow[t]{2}{*}{ Rival Similarity } & $0.095^{\ldots * *}$ & 0.075 & $0.074^{* * 3}$ & 0.099 \\
\hline & $(0.026)$ & $(0.080)$ & $(0.026)$ & $(0.084)$ \\
\hline \multirow[t]{2}{*}{$\log ($ Sales $)$} & 0.000 & -0.001 & $-0.001^{\prime \prime}$ & $-0.005^{\dagger}$ \\
\hline & $(0.000)$ & $(0.003)$ & $(0.001)$ & $(0.003)$ \\
\hline \multirow[t]{2}{*}{ Leverage } & 0.001 & 0.005 & 0.005 & $0.010^{\prime \prime}$ \\
\hline & $(0.002)$ & $(0.004)$ & $(0.003)$ & $(0.006)$ \\
\hline \multirow[t]{2}{*}{ Book-to-Market } & 0.002 & -0.002 & $0.006^{3}$ & -0.002 \\
\hline & $(0.002)$ & $(0.007)$ & $(0.002)$ & $(0.009)$ \\
\hline \multirow[t]{2}{*}{ Sales Growth } & -0.002 & -0.003 & -0.004 & $-0.005^{*}$ \\
\hline & $(0.003)$ & $(0.002)$ & $(0.005)$ & $(0.003)$ \\
\hline \multirow[t]{2}{*}{ PPEE } & 0.004 & 0.001 & -0.001 & -0.006 \\
\hline & $(0.003)$ & $(0.005)$ & $(0.003)$ & $(0.005)$ \\
\hline Year effects & yes & yes & yes & yes \\
\hline Industry effects & yes & yes & yes & yes \\
\hline Observations & 1,606 & 1,606 & 1,606 & 1,606 \\
\hline Estimator & ols & tsls & ols & tsls \\
\hline Adjusted $R^{2}$ & $76.276 \%$ & & $79.200 \%$ & \\
\hline \multirow{2}{*}{$\begin{array}{l}\text { Endogeneity test (Durbin-Wu-Hausman statistic) } \\
(p \text {-value })\end{array}$} & & $8.933^{* \ldots *}$ & & $13.908^{* * *}$ \\
\hline & & 0.000 & & 0.000 \\
\hline \multirow{2}{*}{$\begin{array}{l}\text { Overidentifying test (Sargan-Hansen } J \text {-statistic) } \\
\text { (p-value) }\end{array}$} & & 3.871 & & 7.583 \\
\hline & & 0.568 & & 0.181 \\
\hline
\end{tabular}

This table presents results of estimating the relation between relative performance plan characteristics and firms' risk profiles, using ordinary least squares estimation ("ols") and two-stage least squares estimation ("tsls"). Standard errors are in parentheses and are adjusted for within cluster correlation by firm and year. The industry indicators follow the 48 industry groups identified by Fama and French (1997). ${ }^{\dagger}, ", "$ and ${ }^{* * *}$ indicate significance at two-tailed probability levels of $15 \%, 10 \%, 5 \%$, and $1 \%$, respectively. All variables are defined in the caption of Table 1.1 .

managers to increase the idiosyncratic component of risk. This finding is consistent with the notion that managers abstain from lifting their firms' idiosyncratic risk profiles, because they dislike uncertainty about their incentive-compensation stemming from "unnecessary" risks - unnecessary in the sense that managers anticipate beating inferior peers and take home those big prizes without taking risks. 
Table 1.4. Payout convexity, peer group difficulty and risk

\begin{tabular}{|c|c|c|c|c|}
\hline \multirow[b]{3}{*}{ Variable } & (1) & $(2)$ & (3) & (4) \\
\hline & \multicolumn{4}{|c|}{ Dependent variable: } \\
\hline & \multicolumn{2}{|c|}{ Idiosyncratic Risk } & \multicolumn{2}{|c|}{ Total Risk } \\
\hline \multirow[t]{2}{*}{ Convexity } & -0.004 & 0.025 & 0.000 & 0.031 \\
\hline & $(0.005)$ & $(0.033)$ & $(0.006)$ & $(0.041)$ \\
\hline \multirow[t]{2}{*}{ Convexity $^{2}$} & 0.002 & -0.017 & 0.000 & $-0.023^{\dagger}$ \\
\hline & $(0.002)$ & $(0.013)$ & $(0.002)$ & $(0.016)$ \\
\hline \multirow[t]{2}{*}{ Peer Difficulty } & -0.008 & $0.342^{* * *}$ & $0.029^{\dagger}$ & $0.437^{\prime * 3}$ \\
\hline & $(0.012)$ & $(0.144)$ & $(0.016)$ & $(0.179)$ \\
\hline \multirow[t]{2}{*}{ Convexity $\times$ Peer Difficulty } & 0.018 & $-0.547^{* *}$ & $-0.041^{\dagger}$ & $-0.663^{3 *}$ \\
\hline & $(0.019)$ & $(0.226)$ & $(0.026)$ & $(0.281)$ \\
\hline \multirow[t]{2}{*}{ Convexity $^{2} \times$ Peer Difficulty } & -0.008 & $0.211^{* * *}$ & $0.015^{\dagger}$ & 0.246 \\
\hline & $(0.008)$ & $(0.088)$ & $(0.009)$ & $(0.110)$ \\
\hline Controls & yes & yes & yes & yes \\
\hline Year effects & yes & yes & yes & yes \\
\hline Industry effects & yes & yes & yes & yes \\
\hline Observations & 1,606 & 1,606 & 1,606 & 1,606 \\
\hline Estimator & ols & tsls & ols & tsls \\
\hline Adjusted $R^{2}$ & $76.271 \%$ & & $79.231 \%$ & \\
\hline \multirow{2}{*}{$\begin{array}{l}\text { Endogeneity test (Durbin-Wu-Hausman statistic) } \\
(p \text {-value })\end{array}$} & & $5.619^{* \ldots}$ & & $7.712^{* * m}$ \\
\hline & & 0.000 & & 0.000 \\
\hline \multirow{2}{*}{$\begin{array}{l}\text { Overidentifying test (Sargan-Hansen } J \text {-statistic) } \\
(p \text {-value) }\end{array}$} & & 9.642 & & $21.074^{*}$ \\
\hline & & 0.380 & & 0.012 \\
\hline
\end{tabular}

This table presents results of estimating the synergistic relation between payout convexity, peer group difficulty and firms' risk profiles, using ordinary least squares estimation ("ols”) and twostage least squares estimation ("tsls"). Standard errors are in parentheses and are adjusted for within cluster correlation by firm and year. The industry indicators follow the 48 industry groups identified by Fama and French (1997). ${ }^{\dagger}, ", "$ and ${ }^{* * *}$ indicate significance at two-tailed probability levels of $15 \%, 10 \%, 5 \%$, and $1 \%$, respectively. All variables are defined in the caption of Table 1.1 .

Collectively, these findings demonstrate that the incentive effects of payout convexity and peer group difficulty in relative performance plans depend on their synergy. In particular, the evidence suggests that these incentives can-but do not always - induce managers to pursue projects characterized by idiosyncratic risk. The key takeaway is that a blend of payout convexity and peer group difficulty is required to motivate idiosyncratic risk-taking.

Robustness Checks. In this section, I examine the robustness of my key finding-the interaction between payout convexity and peer group difficulty. In particular, I examine the robustness of this finding to: (1) using two alternative two-stage least squares estimation techniques designed to reduce concerns related to weak instruments and a violation of the exclusion restriction; (2) rigorously controlling for a common industry trend and a common time trend in risk and relative performance evaluation; and (3) using alternative measures for firm risk. ${ }^{34} \mathrm{I}$ tabulate the results of these robustness checks in Table 1.5.

34. In untabulated analyses, I also examine the robustness of my key finding to using an alternative measure for peer group difficulty. Specifically, I follow Francis, Hasan, Mani, and Ye (2016) and create a measure of peer group difficulty based on the "relative peer quality index." This measure ranks the focal firm relative to its peers based on the managerial ability scores put forward by Demerjian, Lev, and McVay (2012). 
Figure 1.5. Synergistic risk properties of payout convexity and peer difficulty

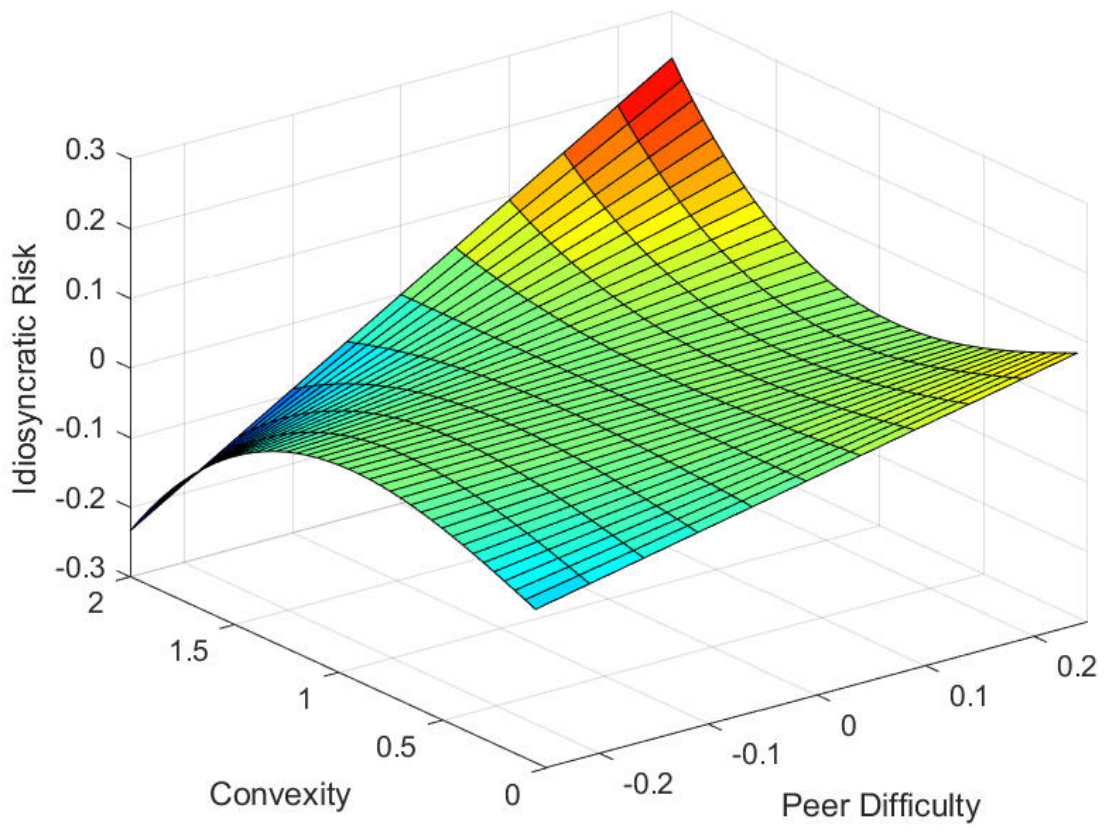

This figure visualizes the synergistic effect of payout convexity and peer group difficulty on idiosyncratic risk based on the coefficients presented in Column (2) in Table 1.4. 
Table 1.5. Payout convexity, peer group difficulty and risk—robustness checks

Panel A. Two alternative two-stage estimation techniques

\begin{tabular}{|c|c|c|c|c|}
\hline \multirow[b]{3}{*}{ Variable } & (1) & $(2)$ & (3) & $(4)$ \\
\hline & \multicolumn{4}{|c|}{ Dependent variable: } \\
\hline & \multicolumn{2}{|c|}{ Idiosyncratic Risk } & \multicolumn{2}{|c|}{ Total Risk } \\
\hline \multirow[t]{2}{*}{ Convexity } & {$[-0.026,0.076]$} & $0.097^{*}$ & {$[-0.030,0.093]$} & $0.122^{*}$ \\
\hline & & $(0.058)$ & & $(0.069)$ \\
\hline \multirow[t]{2}{*}{ Convexity $^{2}$} & {$[-0.036,0.003]$} & $-0.045^{\prime \prime}$ & {$[-0.047,0.000]$} & -0.059 \\
\hline & & $(0.023)$ & & $(0.028)$ \\
\hline \multirow{2}{*}{ Peer Difficulty } & {$[0.100,0.583]$} & 0.580 & {$[0.143,0.730]$} & $0.833^{* \ldots}$ \\
\hline & & $(0.276)$ & & $(0.365)$ \\
\hline \multirow[t]{2}{*}{ Convexity $\times$ Peer Difficulty } & {$[-0.915,-0.179]$} & $-1.010^{*}$ & {$[-1.114,-0.213]$} & $-1.380^{3 *}$ \\
\hline & & $(0.505)$ & & $(0.664)$ \\
\hline \multirow[t]{2}{*}{ Convexity $^{2} \times$ Peer Difficulty } & {$[0.071,0.352]$} & $0.400^{* *}$ & {$[0.072,0.420]$} & $0.523^{*}$ \\
\hline & & $(0.199)$ & & $(0.257)$ \\
\hline Controls & yes & yes & yes & yes \\
\hline Year effects & yes & yes & yes & yes \\
\hline Industry effects & yes & yes & yes & yes \\
\hline Observations & 1,606 & 1,606 & 1,606 & 1,606 \\
\hline Estimator & weak IV robust & mbtsls & weak IV robust & mbtsls \\
\hline
\end{tabular}

Panel A of Table 1.5 presents results of estimating the relation using Andrews' (2018) weak-instrument-robust confidence sets and Kolesár et al.'s (2015) modifiedbias-corrected-two-stage least squares estimator. The former method is robust to weak instruments and the latter method is robust to a violation of the exclusion restriction (see Appendix IV for details). Across all specifications, I find similar inferences using these techniques, which suggests that it is unlikely that my main inferences are an artifact of two-stage least squares misspecification.

Panel B of Table 1.5 presents results of estimating the relation using Fama and MacBeth (1973) regressions. This method is a more robust way to control for unobserved industry and year trends as it allows the coefficients on all variables to vary for each industry and year. If my main inferences were driven by unobserved industry or year trends, I would not expect to observe a relation within a given industry/year. I report the average of the estimated coefficients, where standard errors are based on the standard deviation of the error in the average estimated coefficients. Across all specifications whereby I exclude an anomaly, I find similar inferences using this technique, which suggests that it is unlikely that my main inferences are an artifact of unobserved year or industry trends. ${ }^{35}$

Panel $\mathrm{C}$ of Table 1.5 presents results of estimating the relation using alternative measures for firm risk. Following prior literature, I now measure risk using the firm's research and development expenditures, capital expenditures, income volatility and return volatility (e.g., Coles et al., 2006, Kini and Williams, 2012, Ljungqvist, Zhang, and Zuo, 2017). For these variables, larger values correspond to greater risk, except for capital expenditures where it is the reverse. The Sargan-Hansen $J$-statistics in the conventional two-stage least squares estimations indicate that the instruments may not be perfectly

35. With regard to the industry specifications, I find an anomaly in "industry 13: Drugs-Pharmaceutical Products." With regard to the year specifications, I find anomalies in years 2011 and 2017. If I exclude these anomalies from these alternative specifications, I find similar inferences to my main inferences. 
Table 1.5. Payout convexity, peer group difficulty and risk-robustness checks (continued)

Panel B. Fama-MacBeth regressions

\begin{tabular}{|c|c|c|c|c|}
\hline \multirow[b]{2}{*}{ Variable } & \multicolumn{4}{|c|}{$\begin{array}{l}\text { Dependent variable: } \\
\text { Idiosyncratic Risk }\end{array}$} \\
\hline & \multicolumn{2}{|c|}{ Fama-MacBeth by industry } & \multicolumn{2}{|c|}{ Fama-MacBeth by year } \\
\hline \multirow[t]{2}{*}{ Convexity } & 0.009 & 0.007 & 0.016 & 0.011 \\
\hline & $(0.017)$ & $(0.018)$ & $(0.018)$ & $(0.020)$ \\
\hline \multirow[t]{2}{*}{ Convexity $^{2}$} & -0.003 & -0.003 & -0.005 & -0.003 \\
\hline & $(0.006)$ & $(0.007)$ & $(0.007)$ & $(0.008)$ \\
\hline \multirow[t]{2}{*}{ Peer Difficulty } & 0.119 & $0.171^{*}$ & 0.075 & $0.194^{* * *}$ \\
\hline & $(0.083)$ & $(0.069)$ & $(0.108)$ & $(0.089)$ \\
\hline \multirow[t]{2}{*}{ Convexity $\times$ Peer Difficulty } & -0.135 & $-0.211^{*}$ & -0.086 & $-0.269^{*}$ \\
\hline & $(0.113)$ & $(0.089)$ & $(0.162)$ & $(0.131)$ \\
\hline \multirow{2}{*}{ Convexity $^{2} \times$ Peer Difficulty } & 0.033 & $0.060^{\prime \prime}$ & 0.023 & $0.091^{*}$ \\
\hline & $(0.040)$ & $(0.031)$ & $(0.059)$ & $(0.047)$ \\
\hline Controls & yes & yes & yes & yes \\
\hline Year effects & yes & yes & no & no \\
\hline \multirow{2}{*}{ Industry effects } & no & no & yes & yes \\
\hline & 1,350 & 1,308 & 1,606 & 1,344 \\
\hline \multirow[t]{2}{*}{ Observations } & & $(N>25$ & & $(N>25$ \\
\hline & $(N>25)$ & $\begin{array}{c}\text { except } \\
\text { Fama-French 13) }\end{array}$ & $(N>25)$ & $\begin{array}{c}\text { except } \\
2011 \text { and 2017) }\end{array}$ \\
\hline \multirow[t]{3}{*}{ Estimator } & tsls & tsls & tsls & tsls \\
\hline & (5) & (6) & $(7)$ & $(8)$ \\
\hline & & $\begin{array}{l}\text { Dependent } \\
\text { Total }\end{array}$ & $\begin{array}{l}\text { variable: } \\
\text { Risk }\end{array}$ & \\
\hline Variable & Fama-Ma & cBeth by industry & Fama-M & acBeth by year \\
\hline \multirow[t]{2}{*}{$\overline{\text { Convexity }}$} & -0.010 & -0.012 & 0.026 & 0.013 \\
\hline & $(0.011)$ & $(0.011)$ & $(0.019)$ & $(0.019)$ \\
\hline \multirow[t]{2}{*}{ Convexity $^{2}$} & 0.004 & 0.005 & -0.009 & -0.004 \\
\hline & $(0.004)$ & $(0.005)$ & $(0.008)$ & $(0.007)$ \\
\hline \multirow[t]{2}{*}{ Peer Difficulty } & $0.121^{*}$ & $0.128^{* * *}$ & 0.069 & $0.203^{* * *}$ \\
\hline & $(0.052)$ & $(0.054)$ & $(0.112)$ & $(0.072)$ \\
\hline \multirow[t]{2}{*}{ Convexity $\times$ Peer Difficulty } & $-0.164^{*}$ & $-0.173^{* * n}$ & -0.055 & $-0.276^{3 * 0}$ \\
\hline & $(0.079)$ & $(0.083)$ & $(0.180)$ & $(0.099)$ \\
\hline \multirow[t]{2}{*}{ Convexity $^{2} \times$ Peer Difficulty } & $0.053^{\prime \prime}$ & $0.055^{\prime \prime}$ & 0.005 & $0.092^{2 * 0}$ \\
\hline & $(0.030)$ & $(0.032)$ & $(0.071)$ & $(0.034)$ \\
\hline Controls & yes & yes & yes & yes \\
\hline Year effects & yes & yes & no & no \\
\hline \multirow[t]{2}{*}{ Industry effects } & no & no & yes & yes \\
\hline & 1,350 & 1,308 & 1,606 & 1,344 \\
\hline \multirow[t]{2}{*}{ Observations } & $(N>25)$ & $\begin{array}{c}(N>25 \\
\text { except }\end{array}$ & $(N>25)$ & $\begin{array}{c}(N>25 \\
\text { except }\end{array}$ \\
\hline & & Fama-French 13) & & 2011 and 2017) \\
\hline Estimator & tsls & tsls & tsls & tsls \\
\hline
\end{tabular}

exogenous with respect to these alternative measures for firm risk. Therefore, I also present specifications based on Kolesár et al.’s (2015) modified-bias-corrected-two-stage least squares estimator. Across these latter specifications, I find similar inferences with respect to the firm's research and development expenditures, capital expenditures, and income volatility. Collectively, these findings suggest that managers primarily pursue 
Table 1.5. Payout convexity, peer group difficulty and risk—robustness checks (continued)

\begin{tabular}{|c|c|c|c|c|}
\hline \multirow[b]{3}{*}{ Variable } & (1) & $(2)$ & (3) & (4) \\
\hline & \multicolumn{4}{|c|}{ Dependent variable: } \\
\hline & \multicolumn{2}{|c|}{$R E D$ Intensity } & \multicolumn{2}{|c|}{ CAPEX Intensity } \\
\hline Convexity & $\begin{array}{c}0.461^{* 3} \\
(0.232)\end{array}$ & $\begin{array}{l}0.682^{* a n} \\
(0.257)\end{array}$ & $\begin{array}{c}0.291 \\
(0.210)\end{array}$ & $\begin{array}{c}0.462 \\
(0.258)\end{array}$ \\
\hline Convexity $^{2}$ & $\begin{array}{l}-0.173 \\
(0.095)\end{array}$ & $\begin{array}{l}-0.244^{*} \\
(0.091)\end{array}$ & $\begin{array}{c}-0.102 \\
(0.079)\end{array}$ & $\begin{array}{c}-0.170 \\
(0.092)\end{array}$ \\
\hline Peer Difficulty & $\begin{array}{l}1.420 \\
(0.835)\end{array}$ & $\begin{array}{l}1.510^{*} \\
(0.720)\end{array}$ & $\begin{array}{c}-0.952 \\
(0.681)\end{array}$ & $\begin{array}{r}-1.730 \\
(0.880)\end{array}$ \\
\hline Convexity $\times$ Peer Difficulty & $\begin{array}{c}-1.921^{\dagger} \\
(1.254)\end{array}$ & $\begin{array}{l}-2.870^{\prime} \\
(1.270)\end{array}$ & $\begin{array}{c}1.638 \\
(1.191)\end{array}$ & $\begin{array}{c}2.390 \\
(1.340)\end{array}$ \\
\hline Convexity ${ }^{2} \times$ Peer Difficulty & $\begin{array}{c}0.598 \\
(0.469) \\
\end{array}$ & $\begin{array}{l}1.010^{*} \\
(0.437) \\
\end{array}$ & $\begin{array}{c}-0.680 \\
(0.502) \\
\end{array}$ & $\begin{array}{r}-0.878^{\prime \prime} \\
(0.510) \\
\end{array}$ \\
\hline $\begin{array}{l}\text { Controls } \\
\text { Year effects } \\
\text { Industry effects } \\
\text { Observations } \\
\text { Estimator } \\
\text { Endogeneity test (Durbin-Wu-Hausman statistic) } \\
\quad \text { ( } p \text {-value) } \\
\text { Overidentifying test (Sargan-Hansen } J \text {-statistic) } \\
\quad(p \text {-value) }\end{array}$ & $\begin{array}{c}\text { yes } \\
\text { yes } \\
\text { yes } \\
1,511 \\
\text { tsls } \\
18.292^{\ldots *} \\
0.000 \\
14.186^{\dagger} \\
0.116 \\
\end{array}$ & $\begin{array}{c}\text { yes } \\
\text { yes } \\
\text { yes } \\
1,511 \\
\text { mbtsls }\end{array}$ & $\begin{array}{c}\text { yes } \\
\text { yes } \\
\text { yes } \\
1,511 \\
\text { tsls } \\
2.796^{* 0.0} \\
0.007 \\
29.973^{* 0:} \\
0.000 \\
\end{array}$ & $\begin{array}{c}\text { yes } \\
\text { yes } \\
\text { yes } \\
1,511 \\
\text { mbtsls }\end{array}$ \\
\hline & (5) & $\begin{array}{c}(6) \\
\text { Depende }\end{array}$ & $\begin{array}{c}(7) \\
\text { variable: }\end{array}$ & (8) \\
\hline Variable & $\sigma R C$ & & $\sigma$ Ret & \\
\hline Convexity & $\begin{array}{c}0.423 \\
(0.313)\end{array}$ & $\begin{array}{c}0.521^{*} \\
(0.302)\end{array}$ & $\begin{array}{c}-1.715 \\
(2.114)\end{array}$ & $\begin{array}{c}-1.880 \\
(2.490)\end{array}$ \\
\hline Convexity $^{2}$ & $\begin{array}{r}-0.203^{\dagger} \\
(0.125)\end{array}$ & $\begin{array}{l}-0.211^{\prime \prime} \\
(0.121)\end{array}$ & $\begin{array}{c}0.629 \\
(0.821)\end{array}$ & $\begin{array}{c}0.386 \\
(0.982)\end{array}$ \\
\hline Peer Difficulty & $\begin{array}{c}1.934 \\
(1.308)\end{array}$ & $\begin{array}{c}2.280^{\prime \prime} \\
(1.270)\end{array}$ & $\begin{array}{l}10.226 \\
(7.550)\end{array}$ & $\begin{array}{c}3.710 \\
(4.990)\end{array}$ \\
\hline Convexity $\times$ Peer Difficulty & $\begin{array}{l}-2.510 \\
(2.004)\end{array}$ & $\begin{array}{c}-3.500^{\dagger} \\
(2.130)\end{array}$ & $\begin{array}{r}-19.721^{\dagger} \\
(12.958)\end{array}$ & $\begin{array}{l}-7.200 \\
(7.940)\end{array}$ \\
\hline Convexity ${ }^{2} \times$ Peer Difficulty & $\begin{array}{c}0.777 \\
(0.771) \\
\end{array}$ & $\begin{array}{r}1.180^{\dagger} \\
(0.796) \\
\end{array}$ & $\begin{array}{r}8.554 \\
(5.477) \\
\end{array}$ & $\begin{array}{r}3.980 \\
(3.240) \\
\end{array}$ \\
\hline Controls & yes & yes & yes & yes \\
\hline Year effects & yes & yes & yes & yes \\
\hline Industry effects & yes & yes & yes & yes \\
\hline Observations & 1,511 & 1,511 & 1,511 & 1,511 \\
\hline Estimator & tsls & mbtsls & tsls & mbtsls \\
\hline $\begin{array}{l}\text { Endogeneity test (Durbin-Wu-Hausman statistic) } \\
\quad(p \text {-value })\end{array}$ & $\begin{array}{c}14.511^{* * *} \\
0.000\end{array}$ & & $\begin{array}{l}56.997^{* 0 *} \\
0.000\end{array}$ & \\
\hline $\begin{array}{l}\text { Overidentifying test (Sargan-Hansen } J \text {-statistic) } \\
(p \text {-value })\end{array}$ & $\begin{array}{c}25.724^{* * m} \\
0.002\end{array}$ & & $\begin{array}{c}39.585^{*} \\
0.000\end{array}$ & \\
\hline
\end{tabular}

This table presents results of examining the robustness of the relation between payout convexity, peer group difficulty and firms' risk profiles. Panel A presents results of estimating the relation using Andrews' (2018) weak-instrument-robust confidence sets (“weak IV robust”) and Kolesár et al.'s (2015) modified-biascorrected-two-stage least squares estimator ("mbtsls”). Weak-instrument-robust $90 \%$ confidence sets are robust to heteroskedasticity, autocorrelation, clustering, and weak instruments. Modified-bias-correctedtwo-stage least squares estimation allows instruments to have direct effects on the outcome-i.e., a relaxation of the strict exogeneity assumption. Panel B presents results of estimating the relation using Fama and MacBeth (1973) regressions by industry and by year. Panel C presents results of estimating the relation using alternative measures for firm risk. Standard errors are in parentheses and are adjusted for within cluster correlation by firm and year (in the "tsls" specification) and are robust to the presence of direct effects of the instruments on the outcome (in the "mbtsls" specification). The industry indicators follow the 48 industry groups identified by Fama and French (1997). ${ }^{\dagger}, ", "$ and ${ }^{* * *}$ indicate significance at two-tailed probability levels of $15 \%, 10 \%, 5 \%$, and $1 \%$, respectively. All variables are defined in the caption of Table 1.1. 
idiosyncratic projects through increasing expenditures on research and development, which is consistent with the notion that the risk from research and development is, by and large, idiosyncratic (e.g., Pástor and Veronesi, 2009). Most importantly, these findings suggest that it is unlikely that my main inferences are driven by specific measurement choices related to firm risk, but rather apply to this theoretical construct more generally.

\section{IV.B. Who Chooses What?}

In this section, I test my contract-design hypothesis (i.e., Hypothesis 4) by estimating multinomial probit equations of boards' contract-design choices with respect to combinations of payout convexity and peer group difficulty. In these estimations, I analyze-jointly-four clusters of choices based on the median values of payout convexity and peer group difficulty: (1) "low convexity-low difficulty;" (2) "high convexity-low difficulty;" (3) "low convexity-high difficulty," and (4) "high convexityhigh difficulty.” Specifically, I estimate:

$$
\operatorname{Pr}\left(\text { Cluster }_{i j t}\right)=\alpha+\beta^{\prime} \text { Access }_{i j t-1}+\gamma^{\prime} X_{i j t-1}+\theta^{\prime} \mu_{j}+\phi^{\prime} v_{t}+\varepsilon_{i j t}
$$

where Cluster is a vector measuring the choices for payout convexity and peer group difficulty. For this variable, the combination of payout convexity and peer group difficulty that results in the lowest levels of idiosyncratic risk (i.e., "high convexity-low difficulty") serves as the baseline. Access is a measure for the firm's access to idiosyncratic investment projects (see Section III.V for details).

Table 1.6 presents results of estimating firms' choices for payout convexity and peer group difficulty based on the firm's access to idiosyncratic investment project, using multinomial probit estimation that jointly estimates firms' choices across all four clusters of choices. Panels A through C of Table 1.6 present results whereby Access is Segments HHI, Rival Similarity and Peer Idiosyncratic Risk, respectively. In all panels, Column (3) is of primary interest, which reports the parameter estimates for the combination of payout convexity and peer group difficulty that results in the highest levels of idiosyncratic risk (i.e., "high convexity-high difficulty") relative to the baseline that results in the lowest levels of idiosyncratic risk (i.e., "high convexity-low difficulty"). In other words, this column gives insights into the economic forces that are related to the probability of imposing steep relative performance incentives on managers (i.e., Hypothesis 4).

Across all specifications in Table 1.6, I find that the probability of imposing steep relative performance incentives on managers is increasing in the firm's access to idiosyncratic investment projects, which is consistent with Hypothesis 4. Specifically, I find that, compared to firms choosing "high convexity-low difficulty" incentives, firms imposing "high convexity-high difficulty" incentives on their managers: (1) are dispersed across segments (Panel A); (2) operate in environments where their product market peers are relatively more dissimilar (Panel B); and (3) operate in environments where their relative performance peers have relatively large idiosyncratic risk profiles (Panel C). In economic terms, these coefficients indicate that a one standard deviation increase in 
Table 1.6. Choices for payout convexity and peer group difficulty

Panel A. Segment sales Herfindabl-Hirschman Index

(2)

(3)

Dependent variable:

\begin{tabular}{|c|c|c|c|}
\hline Variable & $\operatorname{Pr}\left(\begin{array}{l}\text { low convexity } \\
\text { low difficulty }\end{array}\right)$ & $\operatorname{Pr}\left(\begin{array}{l}\text { low convexity } \\
\text { high difficulty }\end{array}\right)$ & $\operatorname{Pr}\left(\begin{array}{l}\text { high convexity } \\
\text { high difficulty }\end{array}\right)$ \\
\hline Segments HHI & $\begin{array}{l}-0.237 \\
(0.657) \\
\end{array}$ & $\begin{array}{l}-1.019 \\
(0.951) \\
\end{array}$ & $\begin{array}{l}-2.623^{3} \\
(0.914) \\
\end{array}$ \\
\hline Controls & & yes & \\
\hline Year effects & & yes & \\
\hline Industry effects & & yes & \\
\hline Observations & & 1,606 & \\
\hline Pseudo $R^{2}$ & & $10.292 \%$ & \\
\hline
\end{tabular}

Panel B. Similarity to Hoberg and Phillips' product market peers

\section{(1)}

\begin{tabular}{|c|c|c|c|}
\hline Variable & $\operatorname{Pr}\left(\begin{array}{l}\text { low convexity } \\
\text { low difficulty }\end{array}\right)$ & $\begin{array}{l}\text { Dependent variable: } \\
\operatorname{Pr}\left(\begin{array}{l}\text { low convexity } \\
\text { high difficulty }\end{array}\right)\end{array}$ & $\operatorname{Pr}\left(\begin{array}{l}\text { high convexity } \\
\text { high difficulty }\end{array}\right)$ \\
\hline HEP Peer Similarity & $\begin{array}{r}4.480 \\
(4.609) \\
\end{array}$ & $\begin{array}{l}10.199 \\
(5.971) \\
\end{array}$ & $\begin{array}{c}-22.058^{* *} \\
(6.443) \\
\end{array}$ \\
\hline Controls & & yes & \\
\hline Year effects & & yes & \\
\hline Industry effects & & yes & \\
\hline Observations & & 1,606 & \\
\hline Pseudo $R^{2}$ & & $10.609 \%$ & \\
\hline
\end{tabular}

Panel C. Peer idiosyncratic risk profiles

(1) (3)

Dependent variable:

\begin{tabular}{|c|c|c|c|}
\hline Variable & $\operatorname{Pr}\left(\begin{array}{l}\text { low convexity } \\
\text { low difficulty }\end{array}\right)$ & $\operatorname{Pr}\left(\begin{array}{l}\text { low convexity } \\
\text { high difficulty }\end{array}\right)$ & $\operatorname{Pr}\left(\begin{array}{l}\text { high convexity } \\
\text { high difficulty }\end{array}\right)$ \\
\hline Peer Idiosyncratic Risk & $\begin{array}{c}-1.944 \\
(4.385) \\
\end{array}$ & $\begin{array}{l}58.640^{*} \\
(8.430)\end{array}$ & $\begin{array}{l}67.144^{3 * 5} \\
(8.575) \\
\end{array}$ \\
\hline Controls & & yes & \\
\hline Year effects & & yes & \\
\hline Industry effects & & yes & \\
\hline Observations & & 1,606 & \\
\hline Pseudo $R^{2}$ & & $14.338 \%$ & \\
\hline
\end{tabular}

This table presents results of estimating firms' choices for payout convexity and peer group difficulty based on the firm's access to idiosyncratic investment projects, using multinomial probit estimation. Panel A presents results whereby the firm's Herfindahl-Hirschman Index with respect to its sales across all segments proxies for the firm's access to idiosyncratic investment projects. Panel B presents results whereby the firm's mean similarity to its Hoberg and Phillips' $(2010,2016)$ product market peers proxies for the firm's access to idiosyncratic investment projects. Panel $\mathrm{C}$ presents results whereby the mean idiosyncratic risk profile of the firm's relative performance peers proxies for the firm's access to idiosyncratic investment projects. In each panel, Columns (1) through (3) present results of the system estimation of the probability of using (1) "low convexity-low difficulty," (2) "low convexity-high difficulty," and (3) "high convexity-high difficulty," whereby (4) "high convexity-low difficulty" serves as the baseline (i.e., the combination that encourages the lowest levels of idiosyncratic risk). Standard errors are in parentheses and are adjusted for within cluster correlation by firm and year. The industry indicators follow the 48 industry groups identified by Fama and French (1997). $+, ", "$ and ${ }^{* * *}$ indicate significance at two-tailed probability levels of $15 \%, 10 \%, 5 \%$, and $1 \%$, respectively. All variables are defined in the caption of Table 1.1. 
the firm's access to idiosyncratic investment projects is associated with a $31 \%$ (Panel A), $39 \%$ (Panel B), and 130\% (Panel C) increase in the probability that the firm gives their managers "high convexity-high difficulty" incentives (compared to "high convexity-low difficulty" incentives).

Collectively, these findings demonstrate that boards' choices for payout convexity and peer group difficulty are consistent with moral hazard considerations for project selection. In particular, the evidence suggests that boards alter the magnitude of managers' idiosyncratic risk-taking incentives consistent with the notion that steeper idiosyncratic risk incentives make most sense for those managers that have access to a sufficiently large array of investment projects.

\section{Cross-Sectional Variation in the Relative Incentive-Risk Relation}

In this section, I additionally examine settings where theory predicts that the relation between payout convexity, peer group difficulty and firm risk will be particularly strong. In particular, I examine whether this relation varies in the cross-section of firms with differing: (1) other relative performance plan characteristics; and (2) contextual factors. If my predictions are empirically descriptive, then these settings should provide more powerful tests to examine the relation between relative performance evaluation and managerial risk-taking. ${ }^{36}$

\section{V.A. Other Relative Performance Plan Characteristics}

I examine whether the relation between payout convexity, peer group difficulty and firm risk varies with other relative performance plan characteristics, based on the idea that other characteristics define whether the relative performance plan provides "pure" RPE incentives, vis-à-vis noisier variants of RPE incentives. "Pure" RPE incentives refer to those plans that compensate managers for idiosyncratic performance (i.e., shield managers from systematic performance), whereas in noisier RPE plans managers' payout is still a function of systematic performance (e.g., Holmström, 1982). I focus on two other plan characteristics - the type of payouts (i.e., dollar-based payouts versus sharebased payouts) and the level of systematic risk filtration-and provide some intuition for their moderating effects by amending the analytical model (see Appendix I and Figure 1.6 for details on the analytical model and the amendments, respectively).

With regard to the type of payouts, Panel A of Figure 1.6 shows that the incentives stemming from relative performance plans are stronger for dollar-based plans than for share-based plans. This effect manifests because awarding pre-specified amounts of cash based on relative performance is not the same as awarding performance shares based on relative performance. Intuitively, if managers are awarded based on pre-specified amounts of cash, then managers' payout simply equals the cash associated with the relative performance percentile. However, if managers are awarded with shares, then

36. In addition, to the extent that the empirical evidence is consistent with my additional theoretical predictions, these cross-sectional tests help to further reduce concerns that an omitted correlated variable is behind my results. That is to say that if a correlated omitted variable were to explain my results, it should not only be correlated with the choice for payout convexity and peer group difficulty but should also be differentially correlated with the dimensions examined in these cross-sectional tests. I acknowledge this approach is not a panacea for resolving all issues of endogeneity, but-in conjunction with all preceding analyses-certainly narrows the set of plausible alternative explanations for my story. 
Figure 1.6. Moderating effects of other plan characteristics on the idiosyncratic risk properties of relative performance plans

Panel A. Share-based payouts

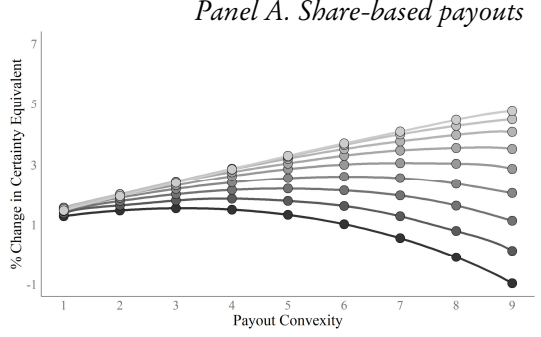

Panel C. Low risk filtration

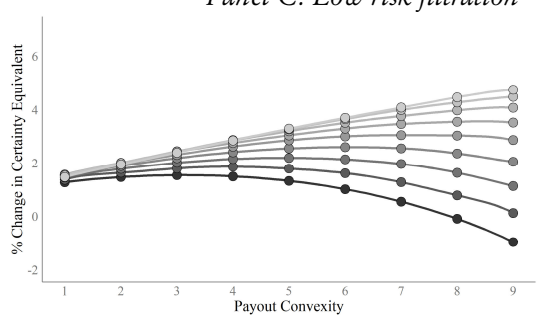

Panel B. Dollar-based payouts

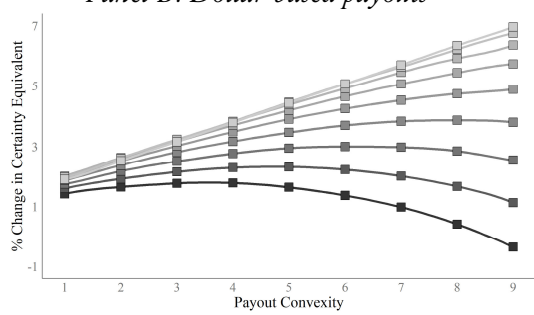

Panel D. High risk filtration

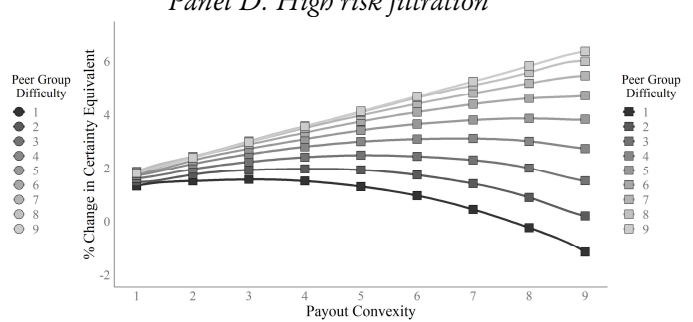

This figure illustrates a risk-averse agent's incentives to increase idiosyncratic risk in response to changes in payout convexity and peer group difficulty as well as changes in other plan characteristics in a long-term incentive plan based on relative performance that strips away a portion of the systematic component of performance. Risk-taking incentives are measured as the percentage change in the subjective value (i.e., certainty equivalent) of the agent's incentive plan for a 0.1 change in the idiosyncratic volatility of the firm's stock returns, computed by simulating the model described in Appendix I for one holding period. Panels A and B alter the payout scheme and illustrate the incentives for share-based payouts and dollar-based payouts, respectively. Panels $\mathrm{C}$ and $\mathrm{D}$ alter the level of systematic risk filtration and illustrate the incentives for low and high risk filtration, respectively. That is, in Panels A, B and C, the relative nature of the incentive plan decreases the sensitivity of the agent's utility to systematic performance by $20 \%$, whereas the plan in Panel D decreases this sensitivity by $80 \%$; in Panels A, C and D, the incentive plan is based on share payouts, whereas the plan in Panel B is based on dollar payouts. Each panel also alters payout convexity and peer group difficulty, while holding the market value of the agent's total wealth constant at $\$ 15$ million. Thus, for a given level of payout convexity and peer group difficulty, the agent's outside wealth is determined such that his/her total wealth is equal to $\$ 15$ million. All other parameters are consistent with the main simulations presented in Figure 1.2.

managers' payout equals the number of shares granted (which is a function of relative performance) multiplied by the firm's stock price. Because the firm's stock price is still a function of systematic performance, managers' payout is still a function of systematic performance. As a result, managers who do well relative to peers (and thus are granted many shares) could still receive relatively low dollar payouts if systematic performance has a large negative impact on the firm's stock price. In other words, share-based relative performance plans do not fully shield managers from systematic performance and are, therefore, noisier variants of RPE incentives than dollar-based plans.

With regard to the level of systematic risk filtration, Panel B of Figure 1.6 shows that the incentives stemming from relative performance plans are stronger for relative 
Table 1.7. Cross-sectional predictions-other plan characteristics

Panel A. Payout schemes

\begin{tabular}{|c|c|c|c|}
\hline \multirow[b]{2}{*}{ Variable } & \multicolumn{2}{|c|}{$\begin{array}{l}(1) \\
\text { Dependent variable: } \\
\text { Idiosyncratic Risk }\end{array}$} & \multirow[b]{2}{*}{$(2)>(1)$} \\
\hline & $R P E^{\text {cash }}=0$ & $R P E^{\text {cash }}=1$ & \\
\hline Convexity & $\begin{array}{c}0.024 \\
(0.047)\end{array}$ & $\begin{array}{l}-0.023 \\
(0.059)\end{array}$ & -0.047 \\
\hline Convexity ${ }^{2}$ & $\begin{array}{l}-0.015 \\
(0.017)\end{array}$ & $\begin{array}{c}0.008 \\
(0.025)\end{array}$ & 0.023 \\
\hline Peer Difficulty & $\begin{array}{c}0.212 \\
(0.167)\end{array}$ & $\begin{array}{c}0.734 \\
(0.351)\end{array}$ & 0.522 \\
\hline Convexity $\times$ Peer Difficulty & $\begin{array}{l}-0.385^{\dagger} \\
(0.248)\end{array}$ & $\begin{array}{l}-1.308^{3 *} \\
(0.613)\end{array}$ & -0.923 \\
\hline Convexity $^{2} \times$ Peer Difficulty & $\begin{array}{c}0.163^{*} \\
(0.092)\end{array}$ & $\begin{array}{c}0.535^{* *} \\
(0.251)\end{array}$ & 0.372 \\
\hline Controls & yes & yes & \\
\hline Year effects & yes & yes & \\
\hline Industry effects & yes & yes & \\
\hline Observations & 1,185 & 421 & \\
\hline Estimator & tsls & tsls & \\
\hline Endogeneity test (Durbin-Wu-Hausman statistic) & $2.912^{*, 3 *}$ & $4.179^{* * \%}$ & \\
\hline$(p$-value $)$ & 0.006 & 0.000 & \\
\hline Overidentifying test (Sargan-Hansen $J$-statistic) & 2.892 & 12.219 & \\
\hline (p-value) & 0.968 & 0.201 & \\
\hline
\end{tabular}

performance plans that filter a larger portion of the firm's systematic performance. The intuition is similar to the intuition with respect to differing payout schemes, in that if the relative performance plan filters relatively more systematic risk, the incentive to increase risk through the idiosyncratic component of risk is stronger.

Following the above discussion, I examine whether the relation between payout convexity, peer group difficulty and firm risk is stronger for dollar-based plans (vis-à-vis share-based plans) and plans that filter relatively more systematic risk (vis-à-vis low risk filtration plans). To examine this, I partition my sample based on the categories/median of the following variables: (1) $R P E^{\text {cash }}$, which equals one if the relative performance payout is not determined based on the firm's stock price, zero otherwise; and (2) Peer Group Synchronicity, which is the firm's three-year monthly stock return synchronicity with its relative performance peers and captures the amount of systematic volatility in the stock returns of the focal firm and its peers (see Table 1.1 for descriptive statistics). ${ }^{37}$ I then estimate Equation (1.4.1) separately for each subsample and test for a difference in the coefficients between the subsamples. Table 1.7 presents results of these analyses.

Panel A of Table 1.7 presents results of estimating the relation between payout convexity, peer group difficulty and firm risk after partitioning on $R P E^{c a s h}$. For share-

37. With regard to $R P E^{\text {cash }}$, it is important to note that not all plans that "payout in cash" are dollar-based RPE plans. That is, there is a subtle difference between plans that payout: (1) pre-specified amounts of cash that are unrelated to the firm's stock price (i.e., dollar-based RPE); and (2) ex post amounts of cash that are determined on the firm's stock price (i.e., not dollar-based RPE) (see Panels A and B in Appendix III for examples of both types, respectively). With regard to Peer Group Synchronicity, I use a three-year period, because the performance period in the vast majority of relative performance plans is three year (e.g., De Angelis and Grinstein, 2019, Gong et al., 2011). 
Table 1.7. Cross-sectional predictions—other plan characteristics (continued)

Panel B. Filtering of systematic risk

\begin{tabular}{|c|c|c|c|}
\hline \multirow[b]{2}{*}{ Variable } & \multicolumn{2}{|c|}{$\begin{array}{l}\text { (1) } \\
\text { Dependent variable: } \\
\text { Idiosyncratic Risk }\end{array}$} & \multirow[b]{2}{*}{$(2)>(1)$} \\
\hline & $\begin{array}{c}\text { Low } \\
\text { Peer Syncbronicity }\end{array}$ & $\begin{array}{c}\text { High } \\
\text { Peer Synchronicity }\end{array}$ & \\
\hline Convexity & $\begin{array}{l}0.017 \\
(0.063)\end{array}$ & $\begin{array}{l}-0.046 \\
(0.047)\end{array}$ & -0.063 \\
\hline Convexity $^{2}$ & $\begin{array}{l}-0.010 \\
(0.023)\end{array}$ & $\begin{array}{l}0.012 \\
(0.017)\end{array}$ & 0.022 \\
\hline Peer Difficulty & $\begin{array}{l}0.186 \\
(0.207)\end{array}$ & $\begin{array}{l}0.444^{\prime \prime} \\
(0.193)\end{array}$ & 0.258 \\
\hline Convexity $\times$ Peer Difficulty & $\begin{array}{l}-0.406 \\
(0.332)\end{array}$ & $\begin{array}{l}-0.699 \\
(0.293)\end{array}$ & -0.293 \\
\hline Convexity $^{2} \times$ Peer Difficulty & $\begin{array}{r}0.189^{\dagger} \\
(0.130) \\
\end{array}$ & $\begin{array}{l}0.267^{\prime \prime} \\
(0.111) \\
\end{array}$ & 0.078 \\
\hline Controls & yes & yes & \\
\hline Year effects & yes & yes & \\
\hline Industry effects & yes & yes & \\
\hline Observations & 674 & 674 & \\
\hline Estimator & tsls & tsls & \\
\hline $\begin{array}{l}\text { Endogeneity test (Durbin-Wu-Hausman statistic) } \\
\text { ( } p \text {-value) }\end{array}$ & $\begin{array}{l}2.502^{* *} \\
0.015\end{array}$ & $\begin{array}{l}4.730^{3} \\
0.000\end{array}$ & \\
\hline $\begin{array}{l}\text { Overidentifying test (Sargan-Hansen } J \text {-statistic) } \\
(p \text {-value) }\end{array}$ & $\begin{array}{l}2.414 \\
0.983\end{array}$ & $\begin{array}{l}5.666 \\
0.773\end{array}$ & \\
\hline
\end{tabular}

This table presents results of estimating whether the relation between payout convexity, peer group difficulty and firms' risk profiles varies in the cross-section of firms with differing other relative performance plan characteristics, using two-stage least squares estimation ("tsls"). Panel A presents results of estimating whether the relation varies with differing payout schemes $\left(R P E^{\text {cash }}\right)$. Panel B presents results of estimating whether the relation varies with differing levels of systematic risk filtration (Peer Synchronicity). Standard errors are in parentheses and are adjusted for within cluster correlation by firm and year. The industry indicators follow the 48 industry groups identified by Fama and French (1997). ${ }^{\dagger}, ",{ }^{*}$ and ${ }^{* 3 *}$ indicate significance at two-tailed probability levels of $15 \%$, $10 \%, 5 \%$, and $1 \%$, respectively. Equality of coefficients across columns is tested for two-tailed statistical significance, whereby the standard error of the difference between the coefficients is calculated by pooling the standard errors across subsamples. All variables are defined in the caption of Table 1.1 .

based RPE, I find that the coefficients decrease compared to the "average coefficients" in Table 1.4 and become, by and large, statistically insignificant. In contrast, for dollarbased RPE, I find that the coefficients increase compared to the "average coefficients" in Table 1.4 and also increase in statistical significance. In economic terms, I find that the coefficients in the dollar-based RPE column are approximately three times larger than the coefficients in the share-based RPE column. These differences are statistically significant at conventional levels.

Panel B of Table 1.7 presents results of estimating the relation between payout convexity, peer group difficulty and firm risk after partitioning on Peer Group Synchronicity. For low risk filtration plans, I find that the coefficients decrease compared to the "average coefficients" in Table 1.4 and are statistically insignificant. In contrast, for high risk filtration plans, I find that the coefficients increase compared to the "average 
coefficients" in Table 1.4. In economic terms, I find that the coefficients in the high risk filtration column are approximately one and a half times larger than the coefficients in the low risk filtration column. These differences are, however, not statistically significant at conventional levels (two-tailed $p$-values range between 0.205 and 0.534 ).

Collectively, these findings demonstrate that the incentive effects of payout convexity and peer group difficulty vary with other relative performance plan characteristics that define whether the plan provides "pure" RPE incentives, vis-à-vis noisier variants of RPE incentives. In particular, the evidence suggests that the incentive effects are stronger in dollar-based RPE plans (vis-à-vis share-based RPE plans). In addition, I find weak evidence that the incentive effects are stronger in plans that filter relatively more systematic risk (vis-à-vis low risk filtration plans).

\section{V.B. Contextual Factors}

I examine whether the relation between payout convexity, peer group difficulty and firm risk varies with contextual factors that alter the incentive to increase risk. In particular, I examine whether this relation is stronger among: (1) managers with investment opportunities that have a relatively higher rate of return per unit of risk; (2) managers facing relatively fewer career concerns; and (3) managers whose stock options' payoffs have a relatively high sensitivity to return volatility. The intuition behind examining these settings is as follows: (1) for firms operating in environments with higher returns to risk it seems reasonable-from the board's perspective-to impose steeper idiosyncratic risk-taking incentives on their managers, as this would lead to, all else equal, more value for shareholders; (2) managers facing fewer career concerns are more likely to take greater risks; therefore, it also seems reasonable-from the board's perspective-to impose steeper idiosyncratic risk-taking incentives on such managers; and (3) managers who besides relative incentives also have stock options for which the payout is sensitive to return volatility, the incentive to increase risk through the idiosyncratic component of risk is stronger (e.g., Park and Vrettos, 2015).

To examine whether the relation between payout convexity, peer group difficulty and firm risk varies with these contextual factors, I partition my sample based on the medians of the following variables: (1) Industry $\theta$, which is the slope coefficient from an industry-year specific regression of buy-and-hold return over the year on the natural log of 1 plus the variance of monthly returns ${ }^{38}$; (2) Age, which is the age of the CEO (in years) with larger values corresponding to smaller parameters of career concerns; ${ }^{39}$ and (3) Vega, which is the sensitivity of the risk-neutral value of the CEO's portfolio of stock and stock options to a 0.01 change in the volatility of the underlying stock (see Table 1.1 for descriptive statistics). I then estimate Equation (1.4.1) separately for each subsample

38. This measure is grounded in first principles of theories of asset pricing (e.g., Sharpe, 1964) and captures returns per unit of risk in terms of the slope of the efficient frontier within firms' investment opportunity sets (e.g., Armstrong et al., 2019). The set of available projects, or investment opportunities, is defined in a meanvariance space. Let this set of projects be given by a concave efficient frontier that takes the form: $\mu(i)=\varphi+$ $\theta \log \left(1+\sigma^{2}(i)\right)$, where $\log (\cdot)$ is the natural $\log$ operator, $\varphi$ represents the payoff to the risk-free project where $\sigma^{2}(i)=0$, and $\theta$ determines the slope of the frontier-i.e., the returns per unit of risk.

39. Prior literature shows analytically and empirically that younger managers face greater career concerns and undertake projects that are easier for the market to evaluate in lieu of more risky and innovative investments (e.g., Holmström, 1999, Scharfstein and Stein, 1990, Zwiebel, 1995). 
and test for a difference in the coefficients between the subsamples. Table 1.8 presents results of these analyses.

Panel A of Table 1.8 presents results of estimating the relation between payout convexity, peer group difficulty and firm risk after partitioning on Industry $\theta$. For low $\theta$ firms, I find that the coefficients decrease compared to the "average coefficients" in Table 1.4 and are statistically insignificant. In contrast, for high $\theta$ firms, I find that the coefficients increase compared to the "average coefficients" in Table 1.4. In economic terms, I find that the coefficients (on the key variables of interest) in the high $\theta$ column are approximately ten times larger than the coefficients in the low $\theta$ column. These differences are statistically significant at conventional levels.

Panel B of Table 1.7 presents results of estimating the relation between payout convexity, peer group difficulty and firm risk after partitioning on Age. For younger managers, I find that the coefficients decrease compared to the "average coefficients" in Table 1.4 and are statistically insignificant. In contrast, for older managers, I find that the coefficients increase compared to the "average coefficients" in Table 1.4. In economic terms, I find that the coefficients (on the key variables of interest) in the older managers column are approximately two times larger than the coefficients in the younger managers column. These differences are, however, not statistically significant at conventional levels (two-tailed $p$-values range between 0.250 and 0.386 ).

Panel C of Table 1.7 presents results of estimating the relation between payout convexity, peer group difficulty and firm risk after partitioning on Vega. For low vega managers, I find that the coefficients decrease compared to the "average coefficients" in Table 1.4 and are statistically insignificant. In contrast, for high vega managers, I find that the coefficients increase compared to the "average coefficients" in Table 1.4. In economic terms, I find that the coefficients (on the key variables of interest) in the high vega column are approximately three times larger than the coefficients in the low vega column. These differences are, however, not statistically significant at conventional levels (two-tailed $p$-values range between 0.156 and 0.201 ).

Collectively, these findings demonstrate that the incentive effects of payout convexity and peer group difficulty vary with contextual factors. In particular, the evidence suggests that the incentive effects are stronger among managers with investment opportunities that have a relatively higher rate of return per unit of risk. In addition, I find weak evidence that the incentive effects are stronger among managers facing relatively fewer career concerns and managers whose stock options' payoffs have a relatively high sensitivity to return volatility.

\section{Summary and Conclusion}

The use of incentive plans based on relative performance in large U.S. firms has grown dramatically in the last decade. Since many investors, regulators and practitioners argue that misaligned incentive-compensation contracts induce managers to take inappropriate risks, it is crucial to understand how this boom affects managerial risktaking. In this study, I develop a numerical model and test an empirical model of relative risk-taking incentives.

My numerical model predicts that these incentive plans give undiversified, riskaverse managers an incentive to pursue projects characterized by idiosyncratic rather 
Table 1.8. Cross-sectional predictions-contextual factors

Panel A. Returns to an additional unit of risk

\begin{tabular}{|c|c|c|c|}
\hline \multirow[b]{2}{*}{ Variable } & \multicolumn{2}{|c|}{$\begin{array}{l}(1) \\
\text { Dependent variable: } \\
\text { Idiosyncratic Risk }\end{array}$} & \multirow[b]{2}{*}{$(2)>(1)$} \\
\hline & $\begin{array}{l}\text { Low } \\
\text { Industry } \theta\end{array}$ & $\begin{array}{l}\text { High } \\
\text { Industry } \theta\end{array}$ & \\
\hline Convexity & $\begin{array}{r}0.063^{\dagger} \\
(0.041)\end{array}$ & $\begin{array}{l}-0.111^{*} \\
(0.066)\end{array}$ & $-0.174^{* * \cdots}$ \\
\hline Convexity $^{2}$ & $\begin{array}{c}-0.027^{\dagger} \\
(0.017)\end{array}$ & $\begin{array}{c}0.041^{\dagger} \\
(0.025)\end{array}$ & $0.068^{* * *}$ \\
\hline Peer Difficulty & $\begin{array}{c}-0.066 \\
(0.206)\end{array}$ & $\begin{array}{c}0.644^{*} \\
(0.290)\end{array}$ & $0.710^{* * *}$ \\
\hline Convexity $\times$ Peer Difficulty & $\begin{array}{l}-0.001 \\
(0.325)\end{array}$ & $\begin{array}{l}-0.954^{* *} \\
(0.458)\end{array}$ & $-0.953^{* *}$ \\
\hline Convexity $^{2} \times$ Peer Difficulty & $\begin{array}{c}0.037 \\
(0.124) \\
\end{array}$ & $\begin{array}{c}0.344^{*} \\
(0.180) \\
\end{array}$ & $0.307^{*}$ \\
\hline $\begin{array}{l}\text { Controls } \\
\text { Year effects } \\
\text { Industry effects } \\
\text { Observations } \\
\text { Estimator } \\
\text { Endogeneity test (Durbin-Wu-Hausman statistic) } \\
\quad(p \text {-value) } \\
\text { Overidentifying test (Sargan-Hansen } J \text {-statistic) } \\
\text { (p-value) }\end{array}$ & $\begin{array}{l}\text { yes } \\
\text { yes } \\
\text { yes } \\
781 \\
\text { tsls } \\
2.521^{* *} \\
0.015 \\
16.422^{*} \\
0.059 \\
\end{array}$ & $\begin{array}{l}\text { yes } \\
\text { yes } \\
\text { yes } \\
825 \\
\text { tsls } \\
3.720^{* * 5} \\
0.001 \\
7.054 \\
0.632 \\
\end{array}$ & \\
\hline \multicolumn{4}{|c|}{ Panel B. Career concerns } \\
\hline & $\begin{array}{l}\text { (1) } \\
\text { Depende } \\
\text { Idiosync }\end{array}$ & $\begin{array}{l}\quad(2) \\
\text { variable: } \\
\text { atic Risk }\end{array}$ & (3) \\
\hline Variable & $\begin{array}{l}\text { Low } \\
\text { Age }\end{array}$ & $\begin{array}{l}\text { High } \\
\text { Age }\end{array}$ & $(2)>(1)$ \\
\hline Convexity & $\begin{array}{c}0.089 \\
(0.048)\end{array}$ & $\begin{array}{c}-0.053 \\
(0.060)\end{array}$ & $-0.142^{* 50}$ \\
\hline Convexity $^{2}$ & $\begin{array}{c}-0.039^{*} \\
(0.020)\end{array}$ & $\begin{array}{c}0.013 \\
(0.020)\end{array}$ & $0.052^{* *}$ \\
\hline Peer Difficulty & $\begin{array}{c}0.223 \\
(0.220)\end{array}$ & $\begin{array}{c}0.425 \\
(0.244)\end{array}$ & 0.202 \\
\hline Convexity $\times$ Peer Difficulty & $\begin{array}{c}-0.305 \\
(0.349)\end{array}$ & $\begin{array}{c}-0.675 \\
(0.347)\end{array}$ & -0.370 \\
\hline Convexity $^{2} \times$ Peer Difficulty & $\begin{array}{c}0.107 \\
(0.134) \\
\end{array}$ & $\begin{array}{c}0.256 \\
(0.125) \\
\end{array}$ & 0.149 \\
\hline Controls & yes & yes & \\
\hline Year effects & yes & yes & \\
\hline Industry effects & yes & yes & \\
\hline Observations & 730 & 876 & \\
\hline Estimator & tsls & tsls & \\
\hline $\begin{array}{l}\text { Endogeneity test (Durbin-Wu-Hausman statistic) } \\
(p \text {-value) }\end{array}$ & $\begin{array}{l}2.443^{*} \\
0.018\end{array}$ & $\begin{array}{l}4.648^{* \ldots} \\
0.000\end{array}$ & \\
\hline $\begin{array}{l}\text { Overidentifying test (Sargan-Hansen } J \text {-statistic) } \\
(p \text {-value) }\end{array}$ & $\begin{array}{l}4.823 \\
0.849\end{array}$ & $\begin{array}{l}5.644 \\
0.775\end{array}$ & \\
\hline
\end{tabular}


Table 1.8. Cross-sectional predictions-contextual factors (continued)

Panel C. Sensitivity of stock options' payoff to return volatility

\begin{tabular}{|c|c|c|c|}
\hline \multirow[b]{2}{*}{ Variable } & $\begin{array}{c}(1) \\
\text { Dependen } \\
\text { Idiosyncr }\end{array}$ & \begin{tabular}{l}
\multicolumn{1}{c}{$(2)$} \\
ariable: \\
c Risk
\end{tabular} & \multirow[b]{2}{*}{$(2)>(1)$} \\
\hline & $\begin{array}{l}\text { Low } \\
\text { Vega }\end{array}$ & $\begin{array}{l}\text { High } \\
\text { Vega }\end{array}$ & \\
\hline Convexity & $\begin{array}{c}0.030 \\
(0.035)\end{array}$ & $\begin{array}{l}-0.029 \\
(0.064)\end{array}$ & -0.059 \\
\hline Convexity $^{2}$ & $\begin{array}{l}-0.011 \\
(0.015)\end{array}$ & $\begin{array}{l}0.016 \\
(0.025)\end{array}$ & 0.027 \\
\hline Peer Difficulty & $\begin{array}{c}0.260 \\
(0.235)\end{array}$ & $\begin{array}{c}0.613^{3} \\
(0.310)\end{array}$ & 0.353 \\
\hline Convexity $\times$ Peer Difficulty & $\begin{array}{c}-0.382 \\
(0.334)\end{array}$ & $\begin{array}{c}-0.996 \\
(0.526)\end{array}$ & -0.614 \\
\hline Convexity $^{2} \times$ Peer Difficulty & $\begin{array}{c}0.136 \\
(0.119)\end{array}$ & $\begin{array}{c}0.382^{*} \\
(0.212) \\
\end{array}$ & 0.246 \\
\hline Controls & yes & yes & \\
\hline Year effects & yes & yes & \\
\hline Industry effects & yes & yes & \\
\hline Observations & 803 & 803 & \\
\hline Estimator & tsls & tsls & \\
\hline $\begin{array}{l}\text { Endogeneity test (Durbin-Wu-Hausman statistic) } \\
\text { ( } p \text {-value) }\end{array}$ & 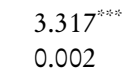 & $\begin{array}{l}2.556^{* *} \\
0.013\end{array}$ & \\
\hline $\begin{array}{l}\text { Overidentifying test (Sargan-Hansen } J \text {-statistic) } \\
(p \text {-value) }\end{array}$ & $\begin{array}{r}14.966 * \\
0.092\end{array}$ & $\begin{array}{l}1.578 \\
0.997\end{array}$ & \\
\hline
\end{tabular}

This table presents results of estimating whether the relation between payout convexity, peer group difficulty and firms' risk profiles varies in the cross-section of firms with differing contextual factors, using two-stage least squares estimation ("tsls"). Panel A presents results of estimating whether the relation varies with differing returns to an additional unit of risk (Industry $\theta$ ). Panel B presents results of estimating whether the relation varies with differing career concerns (Age). Panel $\mathrm{C}$ presents results of estimating whether the relation varies with differing sensitivity of stock options' payoff to return volatility (Vega). Standard errors are in parentheses and are adjusted for within cluster correlation by firm and year. The industry indicators follow the 48 industry groups identified by Fama and French (1997). ${ }^{\dagger},{ }^{* * *}$ and ${ }^{* * *}$ indicate significance at two-tailed probability levels of $15 \%, 10 \%, 5 \%$, and $1 \%$, respectively. Equality of coefficients across columns is tested for two-tailed statistical significance, whereby the standard error of the difference between the coefficients is calculated by pooling the standard errors across subsamples. All variables are defined in the caption of Table 1.1.

than systematic risk. The reason for this incentive is that the relative nature of these incentive plans strips away a portion of the systematic component of performance. I use the numerical model to form empirical predictions about the plan characteristics through which this incentive arises. I present robust empirical evidence consistent with the model's central prediction that this effect manifests synergistically through two plan characteristics: payout convexity and peer group difficulty. I further show that boards' contract-design choices with respect to combinations of payout convexity and peer group difficulty in managers' incentive-compensation contracts are consistent with moral hazard considerations. That is to say that boards impose steeper relative performance incentives on managers that have access to a sufficiently large array of idiosyncratic investment projects. Finally, in additional analyses I show that the relation between payout convexity, peer group difficulty and firm risk varies with the "pureness" 
of the relative performance plan as well as with contextual factors. One noteworthy finding is that dollar-based plans provide "purer" RPE incentives than share-based plans.

Collectively, the evidence in this study provides insights into the risk-taking properties of incentive plans based on relative performance. The synergistic effect of payout convexity and peer group difficulty on firm risk provides investors, regulators and practitioners with additional dimensions to consider in assessing whether incentivecompensation contracts expose firms to risks. To the extent that peer group difficulty is not directly observed from firms' proxy statements, one important takeaway from my study is that solely relying on information in firms' proxy statements yields an incomplete picture of the risk-taking properties of incentive-compensation contracts.

My study also makes several important contributions to the academic literature. First, in developing my model of risk-taking incentives, I have adjusted-and, in doing so, advanced-the traditional "certainty equivalent framework" to match my setting of incentive-compensation plans that strip away a portion of the firm's systematic performance. Second, I develop measurement approaches to empirically calculate payout convexity and peer group difficulty in relative performance plans. These measurement approaches are easily implemented for a large sample of firms, and the intuition of both the model and the measurement approaches can also be applied to other (i.e., nonrelative) incentives of executives as well as lower-level employees. As such, my hope is that these advancements inspire future work on incentive-compensation. I outline several open research questions below.

First, one promising avenue for future research includes extending my work by moving beyond firm decisions and examining whether these risk decisions induced by relative performance plans are optimal in a value-enhancing sense. It is not clear to what extent the inferred implications for firm value using the evidence presented in this paper in conjunction with first principles from theories of asset pricing generalize to performance in this setting. Furthermore, my finding that peer group difficulty is an important driver of firm risk opens many doors for future research. On the one hand, this finding recognizes that there are-and in doing so, highlights the potential to further studying-risk-taking incentives embedded in incentive-compensation contracts that are not directly observable from proxy statements. On the other hand, this finding shows that there are many opportunities for future research to link explicit (e.g., relative performance plans) and implicit (e.g., product market competition) interactions among firms. In addition, there is much room for future work on better understanding the dynamics of-explicit and implicit-peer effects. Another interesting avenue for future research might include improving our understanding of how relative performance plans fit into an efficient risk-taking governance framework by, for example, examining the complex interactions between relative performance plans, payout convexity, peer group difficulty and other governance choices, such as the board's structure, investor monitoring, shareholder rights, etc. Examining these interactions might provide novel insights into why firms do-and, perhaps more importantly, do not-use relative performance plans. Finally, although the focus in this study is on explicit grants for CEOs, there is much room to apply this study's intuition and measurement approaches to other levels of managers as well as to implicit relative performance settings, such as internal labor markets. 


\section{Appendix I: The Model of Risk-Taking Incentives}

This appendix describes the model (based closely on Armstrong and Vashishtha (2012) and Tian (2004)) and the numerical procedure used to calculate the certainty equivalent of an agent's incentive plan for generating Figure 1.2. Consistent with prior literature, I begin by assuming that the agent is risk-averse and his/her preferences can be represented with the power utility function:

$$
U(W)= \begin{cases}\frac{W^{(1-\rho)}}{(1-\rho)} & \text { if } \rho \neq 1 \\ \ln W & \text { otherwise }\end{cases}
$$

where $W$ is the agent's terminal wealth and $\rho$ is the agent's coefficient of relative risk aversion (where a larger $\rho$ indicates a greater degree of risk aversion).

The agent's terminal wealth consists of both firm-unrelated (i.e., private) initial cash wealth and firm-related wealth from future relative performance provisions. Formally, let $w$ denote the agent's initial outside wealth and $n$ denote the number of shares the agent receives for relative firm performance (for now I assume payouts are in shares; in Section V, I examine dollar-based payout schemes). The agent may invest his/her outside wealth between the risk-free asset (e.g., a money-market fund) and the market portfolio (e.g., an index fund tracking the performance of a market index). Given the structure of the relative performance plan and the firm's risk profile, the agent maximizes his/her expected utility from terminal wealth by optimally allocating (both long and short) private wealth between the risk-free asset and the market portfolio. Let $\theta$ denote the portion of the agent's outside wealth that he/she invests in the market portfolio. Then, the agent's end-of-period wealth can be expressed as:

$$
W_{T}=\theta w M_{T}+(1-\theta) w\left(1+r_{f}\right)^{T}+n P_{T},
$$

where $M_{T}$ is the realized market price at time $T, r_{f}$ is the return on the risk-free asset, and $P_{T}$ is the firm's realized stock price at time $T$.

The number of shares the agent receives for relative firm performance, $n$, are determined based on a standard relative performance plan. This plan has the following payout structure:

\begin{tabular}{l|ccccccc} 
Rank & 7 & 6 & 5 & 4 & 3 & 2 & 1 \\
\hline Awards $(n)$ & 0 & $t$ & $1.2 c t$ & $1.4 c t$ & $1.6 c t$ & $1.8 c t$ & $2 c t$
\end{tabular}

where $t$ is the target award, and $c$ is payout convexity. For larger values of $c$, the number of shares the agent receives is larger. Thus, holding constant the agent's wealth, the plan's convexity (or curvature of the wealth-performance relation) is larger for larger values of c. To model peer group difficulty, I vary the performance level that is required for each rank with a parameter $d$. For larger values of $d$, the agent must generate greater returns to end up at a specific rank in the peer group. Thus, holding constant the agent's own parameters that generate his/her firm's end-of-period stock price, the difficulty in beating the peer group is larger for larger values of $d$.

As is standard in the literature (e.g., Armstrong and Vashishtha, 2012, e.g., Tian, 2004), I assume that the firm's end-of-period stock price and the market portfolio follow 
a joint geometric Brownian motion with parameters $\mu$ and $\sigma$ for the expected value and standard deviation of the distributions, respectively. In particular, the firm's stock price and unit value of the market portfolio at time $T$ are joint log-normally distributed and are described by:

$$
\begin{aligned}
& P_{T}=P_{0} \exp \left(\left[\mu_{p}-\frac{1}{2} \sigma_{p}^{2}\right] T+\sigma_{p} \varepsilon_{p} \sqrt{T}\right) \\
& M_{T}=M_{0} \exp \left(\left[\mu_{m}-\frac{1}{2} \sigma_{m}^{2}\right] T+\sigma_{m} \varepsilon_{m} \sqrt{T}\right)
\end{aligned}
$$

where $P_{0}$ and $M_{0}$ are the firm's initial stock price and the initial value of the market portfolio, respectively. $\mu_{p}$ and $\sigma_{p}$ are the expected return and expected return volatility of the firm's stock, whereby the latter can be further decomposed into two distinct components: systematic risk $(\beta)$ and idiosyncratic risk $\left(\sigma_{p_{i d i o}}\right)$ (e.g., Tian, 2004). $\mu_{m}$ and $\sigma_{m}$ are the expected return and expected return volatility of the market portfolio. $\varepsilon_{p}$ and $\varepsilon_{m}$ are joint normal shocks with correlation $\eta$.

To focus on the impact of payout convexity and peer group difficulty, I follow prior literature and make a simplifying assumption that the firm's expected return of the firm's stock, $\mu_{p}$, is a function of systematic risk and is given by the Capital Asset Pricing Model (e.g., Armstrong and Vashishtha, 2012, Hall and Murphy, 2000, Hall and Murphy, 2002, Kahl, Liu, and Longstaff, 2003, Lewellen, 2006, Meulbroek, 2001, Tian, 2004):

$$
\mu_{p}=r_{f}+\beta\left(\mu_{m}-r_{f}\right)
$$

where $\beta=\eta \sigma_{p} / \sigma_{m}$.

The unique feature of relative performance evaluation is that it shields the agent from systematic risk/performance (i.e., $\beta$ ). In other words, the relative performance plan decreases the firm's return-sensitivity to systematic risk, thereby reducing the agent's incentive to increase risk through the systematic component of risk. I model the degree of this risk filtration using a parameter called $\gamma$ (for now I hold this parameter constant; in Section V, I vary this parameter). In this regard, note that in a perfect RPE world, all of $\beta$ is filtered so that the firm's end-of-period stock price becomes a function of only the idiosyncratic component of expected return volatility-i.e., $\sigma_{p_{i d i o}}$ in Equation (1.A.3).

As the agent cannot sell his/her firm-related wealth, his/her optimal portfolio allocation may differ from the portfolio allocation of other investors who do not face such constraints. As a result, the agent may subjectively discount the value of incentives from its market value. With a portion of his/her wealth tied to the firm, the agent may therefore choose to invest a smaller proportion of his/her total wealth in the market portfolio than he/she otherwise would if no restriction is imposed. The agent's objective is to maximize the expected utility of his/her terminal wealth, by optimally allocating (both long and short) his/her cash between the risk-free asset and the market portfolio (given the risk profile of the firm). Formally, the agent chooses $\theta$ to maximize his/her expected utility, $E U^{*}$, which is expressed as:

$$
E U^{*}=\max _{\theta} E\left[\iint U\left(W_{T}\right) f\left(M_{T}, P_{T}\right) d M_{T} d P_{T}\right] .
$$


As discussed in Section II.B, the value of the relative performance plan (to the undiversified, risk-averse agent who may discount its value) is equal to an immediate cash payment that provides the same expected utility as the uncertain relative performance plan does. This certainty equivalent value of the agent's incentive plan, $C E$, can be expressed as:

$$
C E=E U^{*(1-\rho)} /(1-\rho) .
$$

The main goal of this model is to examine the agent's incentives for altering the firm's idiosyncratic risk profile caused by changes in payout convexity and peer group difficulty. As is standard in the literature (e.g., Armstrong and Vashishtha, 2012, Tian, 2004), I define the agent's idiosyncratic risk-taking incentives as the percentage change in the certainty equivalent for an exogenous change in the idiosyncratic volatility of the firm's stock returns, while holding constant the systematic volatility of the firm's stock returns. The greater the percentage change from moving from the safe to the risky state of the world, the greater an agent's incentive to pursue idiosyncratic risk.

The optimization problem of the agent's certainty equivalent does not have a closedform solution. Therefore, I follow prior literature and solve for the agent's certainty equivalent of his/her incentive plan numerically. Specifically, I simulate the price process for the market portfolio and the firm's stock and add wealth to the agent's initial outside wealth to keep the objective value of the agent (i.e., the expected value of the incentive plan and the initial cash) constant. ${ }^{40}$ Figure 1.2 graphically summarizes the results of these simulations. Below I discuss the specific parameterization of the above model used to generate Figure 1.2, which is also described in its caption.

To make sure that the model remains sensible, and the intuition does not become too murky, I rely on very standard modeling choices and assumptions which closely follow prior literature. The agent is assumed to have power utility with a coefficient of relative risk aversion of three (e.g., Hall and Murphy, 2000, 2002, Lambert et al., 1991). The annualized parameters for the stock-price process and the market-value process are as follows: stock price is $\$ 30$, idiosyncratic-return volatility is $20 \%$, systematic-return volatility is $20 \%$, market-return volatility is $20 \%$, market-risk premium is $7 \%$, and riskfree rate is $2 \%$. With regard to the relative performance plan, I assume that the plan decreases the sensitivity of the agent's utility to systematic performance by $40 \%$, which is approximately the median weight on an RPE grant (e.g., De Angelis and Grinstein, 2019)(In Section V, I explore cross-sectional variation in the relative incentives-risk relation and allow this parameter to vary.) For both payout convexity and peer group difficulty, I simulate nine increasing levels to analyze their impact on risk-averse agent's incentives to increase idiosyncratic risk in response to the relative performance plan. Different levels of payout convexity are simulated by increasing the number of shares the agent receives after each performance threshold (which is one of key determinants of payout convexity, holding constant the agent's total wealth; see Section III.C for

40. For simplicity and to focus on the impact of payout convexity and peer group difficulty, I abstract away from other incentive-compensation components than the relative performance plan. In my empirical design, I likewise control for alternative incentives. In the presence of more complex incentive-compensation structures, the optimal risk-taking contract could endogenize the utility the agent receives from other incentives. 
details). I follow Lambert et al. (1991) and estimate a range of payout convexity levels such that the sensitivity of the wealth-performance relation ranges between $10 \%$ and $100 \%$ of the agent's total wealth. Thus, in the lowest convexity world, the agent receives 50,000 shares (i.e., $t$, which, multiplied by the firm's initial share price of $\$ 30$, equals $\$ 1.5$ million or $10 \%$ of the agent's total wealth), which increases for higher convexity worlds. Different levels of peer group difficulty are simulated by increasing performance levels that are required for each performance threshold, holding constant the agent's own performance-generating process. This modeling technique is similar to how out-themoney and in-the-money stock options are modeled (e.g., Lewellen, 2006). For the simulated one holding period, I simulate the differing performance levels to be within a $[-15 \% ; 15 \%]$ range of the focal firm's initial stock price, which represents a credible range of annualized stock returns.

\section{Appendix II: Systematic Risk Properties of Relative Performance Plans}

This appendix illustrates a risk-averse agent's incentives to increase systematic risk in response to changes in payout convexity and peer group difficulty in a long-term incentive plan based on relative performance that strips away a portion of the systematic component of performance. The agent's risk-taking incentives are numerically estimated using the model and parameterization described in Appendix I.

Figure 1.B1 illustrates the effects of increasing payout convexity and peer group difficulty on an agent's incentives to alter his/her firm's systematic risk profile by providing plots of the percentage change in the certainty equivalent of his/her incentive plan. Panel A of Figure 1.B1 shows that the percentage increase in an agent's certainty equivalent caused by payout convexity is nonlinear with increasing marginal returns. This implies that if payout convexity is sufficiently large, then relative performance plans do give agents an incentive to increase the systematic component of risk. Intuitively, an agent can still outperform his/her peers by increasing systematic risk relatively more than his/her peers. This numerical estimation shows that this strategy becomes more lucrative the greater the prizes are that the agent can win. ${ }^{41}$ Panel B of Figure 1.B1 shows that increasing peer group difficulty has little effect on an agent's certainty equivalent with respect to systematic risk (the shape is concave, but the differences across different levels of peer group difficulty are very small). Finally, Panels C and D of Figure 1.B1 show that payout convexity and peer group difficulty interact with respect to systematic risk. However, these interaction effects are much less pronounced compared to the effect with respect to idiosyncratic risk.

Collectively, these numerical simulations confirm that payout convexity and peer group difficulty give an agent barely an incentive to increase the systematic component of risk. These findings are consistent with the notion that by reducing the sensitivity of an agent's pay to systematic performance, the incentive to increase risk through the systematic component of risk is likewise reduced. Thus, in relative terms, relative performance plans give an agent more of an incentive to increase risk through the idiosyncratic component of risk.

41. Further (unreported) simulations indicate that this incentive depends on the amount of systematic risk that is stripped away by the relative performance plan. If the filtration of systematic risk is sufficiently large, then the incentive to increase systematic risk can be zero (or even negative). 
Figure 1.B1. Systematic risk properties of relative performance plans

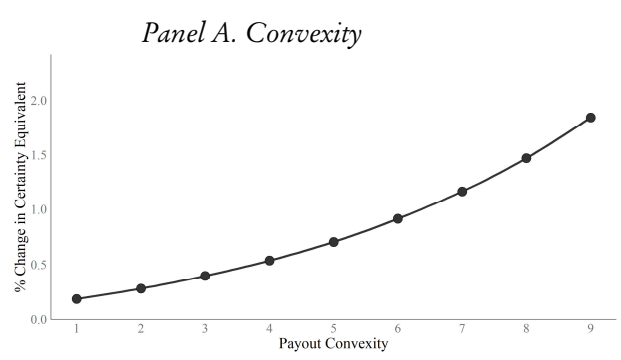

Panel C. Interactions
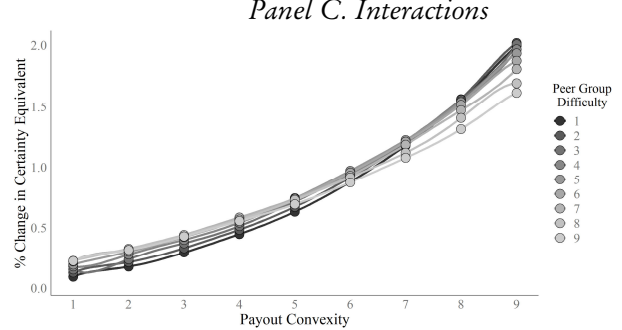

Panel B. Peer group difficulty

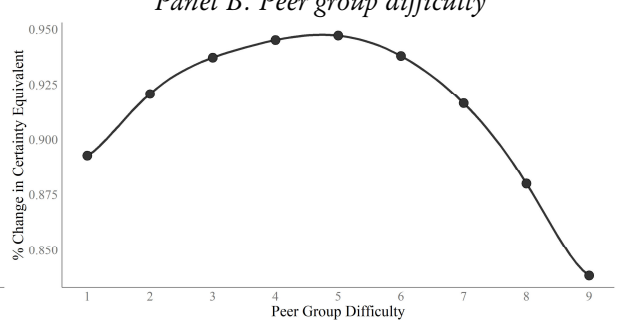

Panel D. Interactions

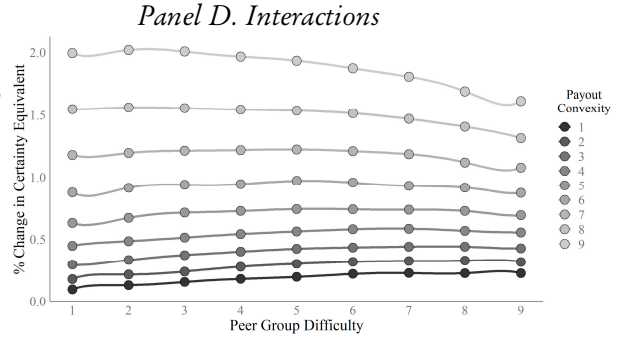

This figure illustrates a risk-averse agent's incentives to increase systematic risk in response to changes in payout convexity and peer group difficulty in a long-term incentive plan based on relative performance that strips away a portion of the systematic component of performance. Risk-taking incentives are measured as the percentage change in the subjective value (i.e., certainty equivalent) of the agent's incentive plan for a 0.1 change in the systematic volatility of the firm's stock returns for different levels of payout convexity and peer group difficulty, computed by simulating the model described in Appendix I for one holding period. Panels A and $\mathrm{B}$ alter payout convexity and peer group difficulty, respectively, while holding both the other constant (at its mean level) and the market value of the agent's total wealth constant at $\$ 15$ million. Panels C and D alter payout convexity and peer group difficulty, respectively, while also varying the other characteristic but holding the market value of the agent's total wealth constant at $\$ 15$ million. Thus, for a given level of payout convexity and peer group difficulty, the agent's outside wealth is determined such that his/her total wealth is equal to $\$ 15$ million. The agent is assumed to have power utility with a coefficient of relative risk aversion of three, and to optimally allocate his/her outside wealth (both long and short) between the risk-free asset and the market portfolio to maximize his/her expected utility. Different levels of payout convexity are simulated by increasing the number of shares the agent receives after each performance threshold, holding constant the agent's total wealth. Different levels of peer group difficulty are simulated by increasing performance levels that are required for each performance threshold, holding constant the agent's own performance-generating process. For both payout convexity and peer group difficulty, I simulate nine increasing levels to analyze their impact on risk-averse agent's incentives to increase systematic risk in response to the relative performance plan. The relative nature of the incentive plan decreases the sensitivity of the agent's utility to systematic performance by $40 \%$. The annualized parameters for the stock-price process and the market-value process are as follows: stock price is $\$ 30$, idiosyncratic-return volatility is $20 \%$, systematic-return volatility is $20 \%$, market-return volatility is $20 \%$, market-risk premium is $7 \%$, and risk-free rate is $2 \%$. 


\section{Appendix III: Example Relative Performance Plan}

The following text is an excerpt from the DEF 14a filings of AT\&T Inc. (2019, pp. 43-49) and United Parcel Service Inc. (2019, pp. 36-38), where both firms describe their relative performance plans. Panel A presents AT\&T Inc.'s plan, which is a relative performance plan with share-based payouts (i.e., the payouts are in cash but based on the share price). Panel B presents United Parcel Service Inc.'s plan, which is a relative performance plan with dollar-based payouts.

Panel A. Share-based plan of ATET Inc. (2019)

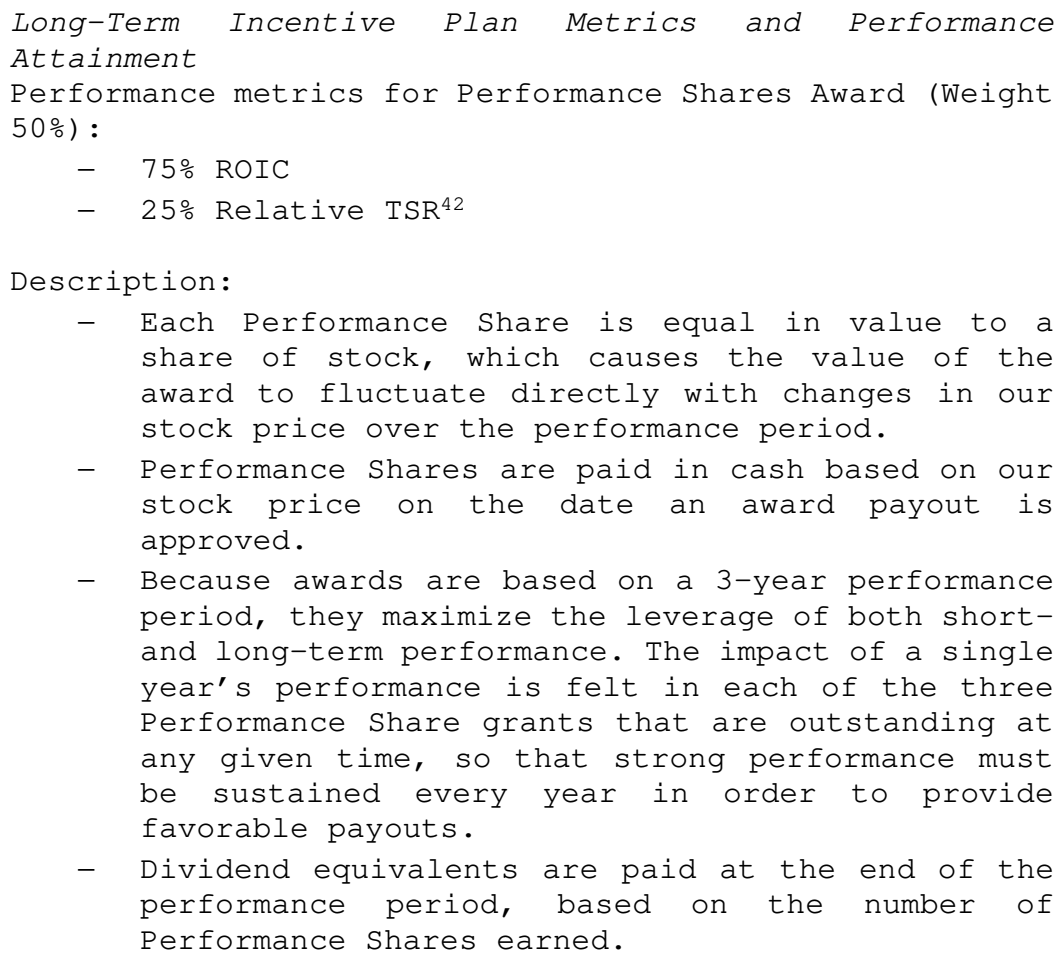

42. TSR was measured relative to the following 37 companies:

$\begin{array}{lll}\text { Alphabet } & \text { Gilead Sciences } & \text { PepsiCo } \\ \text { Amazon } & \text { Hewlett Packard } & \text { Pfizer } \\ \text { Apple } & \text { Home Depot } & \text { Philip Morris Intl } \\ \text { Boeing } & \text { Honeywell } & \text { Procter \& Gamble } \\ \text { CenturyLink } & \text { IBM } & \text { Qualcomm } \\ \text { Charter Communications Intel } & \text { Sprint } \\ \text { Chevron } & \text { Johnson \& Johnson } & \text { T-Mobile } \\ \text { Cisco } & \text { Johnson Controls } & \text { Twenty-First Century Fox } \\ \text { Coca-Cola } & \text { Lockheed Martin } & \text { United Technologies } \\ \text { Comcast } & \text { Merck } & \text { Verizon } \\ \text { Exxon Mobil } & \text { Microsoft } & \text { Wal-Mart } \\ \text { Facebook } & \text { Oracle } & \text { Walt Disney } \\ \text { General } & & \end{array}$


Panel B. Dollar-based plan of United Parcel Service Inc. (2019)

Relative Total Shareowner Return

Relative TSR is measured by covering our TSR to the TSR a peer group of companies during a three-year performance period. The Compensation Committee evaluates the peer group annually to determine if the companies included in the group are the most appropriate comparators for measuring the success of our executives in delivering shareowner value. ${ }^{43}$

$\begin{array}{cc}\text { Three-Year TSR Compared to } & \begin{array}{c}\text { Percentage of Target Earned for } \\ \text { Peer Group }\end{array} \\ \text { TSR Portion of LTIP Award) }\end{array}$

The maximum payout for the TSR portion of the award is capped at $200 \%$ of target. If our TSR over the three-year measurement period is negative, even if it exceeds the median of the peer group, the maximum payout percentage for the TSR portion of LTIP awards is capped at $100 \%$ of target.

\section{LTIP Awards}

The performance measures selected by the Compensation Committee for the 2018 LTIP awards are:

- Growth in Adjusted Consolidated Revenue;

- Adjusted Operating Return on Invested Capital ("ROIC"); and

- Relative Total Shareowner Return ("TSR").

Each goal is measured independently and applied equally in determining final payouts.

The Compensation Committee approved the following target values as a percent of base salary for the 2018 LTIP awards:

43. The peer group considered by the Compensation Committee for 2018 compensation purposes (the "2018 Peer Group") is unchanged from the peer group used for 2017 compensation, and consisted of the companies below:

The Boeing Company

Caterpillar Inc.

The Coca-Cola Company

Costco Wholesale Corporation

FedEx Corporation

The Home Depot, Inc.

Johnson \& Johnson

The Kroger Co.

Lockheed Martin Corporation
The Procter \& Gamble Company

Sysco Corporation

Target Corp.

Lowe's Companies, Inc.

McDonald's Corp.

Pepsico, Inc.

United Technologies Corporation

Walgreen Boots Alliance, Inc. 


\begin{tabular}{ccc} 
Executive officers & $\begin{array}{c}\text { LTIP Target } \\
\text { (\% Base Salary) }\end{array}$ & Base Salary \\
\hline Chief Executive Officer & 700 & $1,234,992$ \\
Chief Operating Officer & 575 & 693,676 \\
Chief Financial Officer & 450 & 552,654 \\
Chief Strategy Officer & 450 & 613,500 \\
Other executive officers & 350 &
\end{tabular}

Target values are based on internal pay comparison considerations and market data regarding total compensation of comparable positions at similarly sized companies. Differences in the target award values are based on increasing levels of responsibility among the executive officers.

\section{Appendix IV: Model Identification}

This appendix discusses the identification tests of the two-stage least squares equations briefly described in Section V. In employing two-stage least squares, I acknowledge that the identification assumptions are more stringent than under ordinary least squares (e.g., Larcker and Rusticus, 2010). That is, conventional two-stage least squares requires strong and perfectly exogenous instruments for the endogenous variables, which-admittedly_are difficult to find. To ensure that weak and invalid instruments are not behind my results, I undertake separate analyses in which I turn to "weak-instrument-robust confidence sets" (Andrews, 2018) and "modified-biascorrected-two-stage least squares” (Anatolyev, 2013, Kolesár et al., 2015), respectively. Furthermore, as I discuss below, models that are nonlinear in endogenous variables require different treatment of identification (e.g., Angrist and Pischke, 2009a, Wooldridge, 2010).

Let me emphasize that I rely on this multitude of techniques not to circumvent standard assumptions, but rather as a safeguard to comfort readers who have concerns about certain parameter estimates. In this regard, the combined set of tests should reduce concerns related to: (1) endogeneity, through two-stage least squares; (2) instrument exogeneity, through modified-bias-corrected-two-stage least squares; and (3) weak instruments, through weak-instrument-robust confidence sets. Another reason that I present this "menu" of parameter estimates is to treat identification as a continuum rather than a binary phenomenon. ${ }^{44}$ To the extent that different estimates are produced by alternative sets of identifying assumptions that differ in their degree of plausibilityand, inversely, in their degree of credibility-this menu of parameter estimates allows different readers with different priors to update differently based on the same data and tests. With regard to two-stage least squares, two of such tests relate to: (1) weak instruments; and (2) instrument exogeneity. I discuss each test in turn below, after which I discuss identification of nonlinear models.

44. Treating identification (of causal effects) as a continuum rather than a binary phenomenon is a form of "partial identification." This framework-pioneered by Manski (1989, 1990, 1993, 2003) and Horowitz and Manski $(1995,1998,2000)$-took shape in the 1990s, and its use has since grown rapidly in fields such as economics, political science and sociology. These techniques ask how much we can learn from a regression of observed outcomes on observed conditioning variables under additional assumptions (e.g., in my case, assumptions related to the exogeneity and the strength of instruments). Also see, for example, Armstrong (2013) for a brief discussion of partial identification in accounting. 
Regarding weak instruments, a formal test for weak identification when there are more than three endogenous variables in the presence of heteroskedasticity, autocorrelation, and clustering is-at current date-nonexistent (Andrews, Stock, and Sun, 2019, p. 739, Sun, 2018)..$^{45}$ Therefore, I am unable to perform a formal test for weak identification. Nevertheless, to ensure reliable inference, I can adopt estimation techniques that are robust to weak instruments. I follow current recommendations by Andrews et al. (2019, p. 748) and calculate "weak-instrument-robust confidence sets" based on Andrews (2018). ${ }^{46}$ These confidence sets represent a credible range in which the parameters of interest should lie. Most importantly, these ranges are robust to heteroskedasticity, autocorrelation, clustering, and weak instruments.

Regarding instrument exogeneity, I report, in all tables that present second-stage results, Sargan (1958)-Hansen (1982) J-statistics to test instrument exogeneity using overidentifying restrictions. In addition, to more rigorously reduce concerns that invalid instruments are behind my results, I also report parameter estimates based on modifiedbias-corrected-two-stage least squares (Anatolyev, 2013, Kolesár et al., 2015). Unlike conventional two-stage least squares, this estimator allows instruments to have direct effects on the outcome-i.e., a relaxation of the strict exogeneity assumption. The identifying assumption in this regard is that the direct effects of these "invalid" instruments are uncorrelated with the effects of the instruments on the endogenous treatment variable of interest. But even if these forces are correlated-which I cannot completely rule out - the asymptotic bias will be small under standard two-stage least squares estimation assumptions. ${ }^{47}$

45. In the case of a single endogenous variable, one would test for identification of the instruments by a simple comparison of the first-stage $F$-statistic to the thresholds put forward by Staiger and Stock (1997) (which rely on the assumption of homoskedasticity). In the presence of heteroskedasticity and a single endogenous variable, the current recommendation is to compare the "effective $F$-statistic" to the thresholds of Montiel Olea and Pflueger (2013) (e.g., Andrews et al., 2019). This effective $F$-statistic incorporates a multiplicative correction that depends on the robust variance estimate. In the case of homoskedasticity, this statistic therefore reduces to the "traditional $F$-statistic." These methods are, however, not sufficient to test for identification when there are multiple endogenous variables. Rather, the set of instruments must be tested for identification, jointly (Stock, Wright, and Yogo, 2002, p. 522). In the case of multiple endogenous variables, one could compute the Kleibergen and Paap (2006) Wald $r k F$-statistic, which is a robust analog of-and therefore in the case of homoskedasticity reduces to-the Cragg and Donald (1993) Wald F-statistic (e.g., Andrews et al., 2019, Baum, Schaffer, and Stillman, 2007). However, the Kleibergen and Paap (2006) Wald rk $F$-statistic cannot be compared to the critical values based on Stock and Yogo (2005), because the latter assumes homoskedastic errors. As such, these statistics are not informative and have no theoretical justification in the presence of heteroskedasticity, autocorrelation and clustering (e.g., Andrews et al., 2019, Baum et al., 2007, Sun, 2018)—and even less in the presence of nonlinear models (e.g., Andrews, 2018, p. 337).

46. Andrews' (2018) weak-instrument-robust confidence sets are estimated in a two-step process. One first assesses instrument strength and then reports conventional confidence sets if the instruments appear strong and a robust confidence set if they appear weak. This approach is applicable to both homoskedastic and heteroskedastic settings, including settings with multiple endogenous variables. It also allows for nonlinear functional forms, which is especially relevant in my setting.

47. Another advantage of the modified-bias-corrected-two-stage least squares estimator is that it is based on methods for just-identified settings. Such estimates are approximately median-unbiased and, thus, less likely subject to weak instruments (e.g., Angrist and Pischke, 2009b). More precisely, the modified-bias-correctedtwo-stage least squares estimator is based on a single instrument constructed as a function of only instruments and endogenous regressors, which is then used in the second stage to estimate the parameter of interest (using methods for just-identified settings). Since these estimates are based only a single instrument, I present 
While obtaining instruments for the continuous endogenous variables Convexity, Peer Difficulty, Delta and Vega is relatively straightforward, instrumenting the endogenous interaction variables "entails a different treatment of identification" (Wooldridge, 2010, p. 263), because "naively plugging in first-stage fitted values in a nonlinear models is a bad idea” (Angrist and Pischke, 2009a, p. 143). Regarding identification in nonlinear models, Wooldridge (2010, pp. 262-268) and Angrist and Pischke (2009a, pp. 141-144) recommend to always add some squares and cross products of the instruments as additional terms to the instrument list. In fact, as noted by Wooldridge (2010, p. 261), for models "nonlinear in endogenous variables [...] adding nonlinear functions of the exogenous variables to the instruments not only is desirable but is often needed to achieve identification." Following this approach, I add the nonlinear endogenous terms (i.e., Convexity ${ }^{2}$, Convexity $\times$ Peer Difficulty and Convexity ${ }^{2}$ $\times$ Peer Difficulty) to the list of endogenous variables. Next, I add products of the instruments for Convexity to instrument Convexity ${ }^{2}$, and products of the instruments for Convexity, Convexity ${ }^{2}$ and Peer Difficulty to instrument Convexity $\times$ Peer Difficulty and Convexity ${ }^{2} \times$ Peer Difficulty. I then estimate the equations using two-stage least squares. ${ }^{48}$

coefficient estimates for the key variables of interest based on a series of estimations that treat each variable separately as endogenous.

48. Wooldridge (2010) notes that it is crucial to add separate nonlinear endogenous terms to the list of endogenous variables to avoid estimating "the forbidden regression." In the forbidden regression, one would replace the separate nonlinear endogenous terms with the same nonlinear function of fitted values from a firststage estimation. The mistake is in the thinking that the linear projection of the nonlinear term is equivalent to the nonlinear project of the linear term, leading to invalid estimates. Furthermore, he notes that the efficiency of this estimation technique does not fall by adding more nonlinear functions to the instrument list. 

"Every firm is vulnerable to attack by competitors. [... A well implemented offensive strategy constitutes the single best defense against attack by a challenger. A firm that continuously invests to gain competitive advantage by improving its relative [position] will be difficult to challenge successfully. Even with a vigorous offensive strategy, however, an important role remains for defensive strategy. A firm can make it harder for challengers to attack it through the way it chooses to compete.

-Michael E. Porter, Harvard Business School Professor of Strategy (in Competitive Advantage, 1998) 


\title{
Relative Performance Evaluation and Competitive Aggressiveness
}

\begin{abstract}
We examine the relation between incentive plans based on relative performance and competitive aggressiveness. Using data on executive incentivecompensation contracts in large U.S. firms, we find a positive association between competitive aggressiveness and peer group overlap-i.e., the extent to which two firms select each other as peers in these incentive plans. Our findings indicate that managers of such firms take more frequent as well as more complex competitive actions, relative to managers evaluated on relative performance without peer group overlap. Moreover, we show that these competitive tactics are more pronounced when: (1) managers compete against peers with similar grant sizes; (2) managers compete against peers on similar performance metrics; and (3) managers compete against larger peer groups. Collectively, our findings provide evidence on how widely used incentive-compensation practices impact strategic firm decisions.
\end{abstract}

\section{Introduction}

The usage of incentive plans based on relative performance in large U.S. firms has grown from 22 to 67 percent from 2006 to 2019 (e.g., Equilar, 2020, Meridian Compensation Partners LLC., 2019). Given the ubiquity of relative performance plans, it is of paramount interest to investors, regulators, and practitioners to understand how these incentive plans affect firm decisions. However, empirical evidence on the implications of relative performance plans for firm decisions is limited. We address this

t5 Christoph Feichter (Vienna University) and Frank Moers (Maastricht University) coauthored this chapter. We gratefully acknowledge comments from Martin Artz, Iwan Bos, Isabella Grabner, Melissa Martin, Jae Yong Shin, Regina Wittenberg-Moerman, Aner Zhou, and an anonymous referee. We further thank workshop participants at Alliance Manchester Business School, Maastricht University, Open University of the Netherlands, Seoul National University, Vienna University of Economics and Business, and conference participants at the 11th Conference on New Directions in Management Accounting, the 2nd Swiss Winter Accounting Conference, and the 2020 Management Accounting Section Midyear Meeting for their valuable comments. We also would like to thank Brian Connelly for sharing his code to classify competitive actions into types. Finally, we thank The Wharton School for access to ISS Incentive Lab and RavenPack News Analytics. 
important void by examining how these incentive-compensation practices relate to competitive actions that aim to directly challenge rivals. In particular, we relate the extent to which firms select each other as peers to their competitive aggressiveness.

A key purpose of relative performance evaluation (hereafter "RPE") is to improve risk-sharing between the principal and the agent by benchmarking the agent's performance against peers that are affected by common shocks. This allows the principal to provide more efficient incentives (e.g., Holmström, 1982). However, basing pay on relative performance at the same time puts the agent in direct competition to its peers. An agent can respond to this competition in two ways, i.e., (i) sabotage and (ii) collusion (e.g., Gibbons and Murphy, 1990). In terms of competitive aggressiveness, sabotage implies more competitive aggressiveness, whereas collusion implies less competitive aggressiveness. This suggests that RPE incentive plans can increase or decrease competitive aggressiveness. Below we explain the rationale for each scenario in detail.

The reason why RPE incentive plans can increase competitive aggressiveness is fairly intuitive. The manager of the focal firm has an incentive to gain an advantage over competitors and improve the firm's relative position, which he/she can achieve by engaging in competitive actions. This intuition is formalized in a simple theoretical framework developed by Aggarwal and Samwick (1999). This framework predicts that, in a setting with two competing agents, the incentives to act aggressively are greatest if both agents are evaluated based on own- and peer performance, because both agents then have an incentive to outperform each other. Such "duality" is not necessarily present in relative performance plans of large U.S. firms-a focal firm's peers need not use RPE themselves or, if they use RPE, they need not select the focal firm as their own peer. Throughout the paper, we refer to such an overlapping peer relationship as "peer group overlap." There are no economic forces that either prohibit or require firms to select each other as peers, and as such there is variation in the degree to which competing firms are evaluated based on each other's performance. As a result, if relative performance plans increase competitive aggressiveness, this increase is proportional to the extent to which two firms select each other as peers in these incentive plans.

The reason why RPE incentive plans can decrease competitive aggressiveness is also intuitive but less straightforward. It is typically the case that all firms would be better off when none of them are competitively aggressive compared to when all of them are (e.g., Aggarwal and Samwick, 1999). In the presence of RPE, a necessary condition for the latter is a commitment to abstain from being competitively aggressive. Such commitment can be created through collusion. If firms using RPE incentive plans collude, they are less competitively aggressive than firms that do not use these incentive plans. Moreover, if relative performance plans decrease competitive aggressiveness, then this decrease is also proportional to the extent to which two firms select each other as peers in these incentive plans.

At the end of the day, both scenarios are plausible. The goal of this paper is to test which scenario plays out in practice. Strictly speaking, our question is therefore an empirical question.

We empirically examine the relation between peer group overlap in relative performance plans and competitive aggressiveness using a large sample of U.S. firms over the period 2006 through 2017. We identify peer group overlap in managers' incentivecompensation contracts based on the Compensation Discussion and Analysis (CD\&A) 
section of the proxy statement. To measure competitive aggressiveness, we follow a rich literature on competitive actions in strategic management, and use structured content analysis of competitive actions identified by news events. Examples of such actions are the introduction of new products in an attempt to steal market share from a peer, the launch of a new marketing campaign, price cuts, and the initiation of a joint venture. Our first measure of competitive aggressiveness is the firm's action volume, which captures the number of competitive actions for a given period. Our second measure is the firm's action complexity. This measure embraces the fact that not all actions are identical-it exploits variation in firms' competitive repertoires across multiple action types, such as, new products, pricing, marketing and joint ventures. A key advantage of using these two measures is that they allow us to capture a broad and comprehensive set of relevant and impactful competitive actions. Nevertheless, to ensure that our inferences are not unique to these specific measures of competitive aggressiveness, we triangulate and confirm that our results are robust to using accounting-based input (i.e., advertisement expenditures) and output (i.e., operating margins) measures of competitive aggressiveness.

We test for a relation between peer group overlap and competitive aggressiveness using multiple specifications, including a difference-in-differences design. In our first set of tests, we examine the relation between peer group overlap and competitive aggressiveness using variation in peer group overlap. Consistent with the sabotage hypothesis, we find that peer group overlap is positively associated with competitive aggressiveness. Our findings suggest that firms with peer group overlap act more aggressively by taking more frequent as well as more complex competitive actions than do firms without peer group overlap.

In our second set of tests, we estimate a staggered continuous difference-indifferences specification. We exploit the idea that if a firm is added to one of its peers' peer group, it receives a conditionally exogenous peer group overlap treatment in that year. In this specification, the treatment effect is identified from variation in peers' incentive-compensation choices. As such, this design rules out many alternative explanations related to firms' own incentive-compensation choices. We find that in the year a focal firm gets added to one of its peers' peer group, the focal firm increases its competitive aggressiveness on both the volume and the complexity dimension. This finding strengthens our inference that managers consider peer group overlap in shaping their firms' repertoire of competitive actions.

Our evidence is consistent with the sabotage hypothesis, which suggests that peer group overlap in relative performance plans increases firms' competitive aggressiveness. To further mitigate concerns that a correlated omitted variable is behind our results, we conduct an extensive battery of robustness tests. Specifically, in our third set of tests, we assess the robustness of the overlap-aggressiveness association to: (i) using two alternative measures of competitive aggressiveness, (ii) using two alternative measures of competitive environment, (iii) rigorously controlling for a common time and industry trend in competitive aggressiveness using Fama and MacBeth (1973) regressions, and (iv) controlling for manager's equity incentives. In addition, we: (v) assess the impact of unobservable factors on the overlap-aggressiveness association by applying the bounding technique put forward by Oster (2019). We find that our results are robust. Although we cannot completely rule out the possibility that a correlated omitted variable explains our results, these robustness tests help us to strengthen our main inference that peer 
group overlap is positively associated with firms' competitive aggressiveness-on average.

In our fourth set of tests, we explore whether the overlap-aggressiveness association varies with characteristics of relative performance plans. In these tests, we show that the association is more pronounced when: (i) managers compete against peers with similar grant sizes, (ii) managers compete against peers on similar performance metrics, and (iii) managers compete against larger peer groups. Collectively, these findings indicate that characteristics of relative performance plans matter for competitive aggressiveness. In addition-because these tests link the relation between peer group overlap and competitive aggressiveness to characteristics of managers' incentive-compensation contracts-these findings implicitly strengthen our inference that the relation is attributable to the decisions of managers.

Collectively, we provide empirical evidence on the relation between relative performance plans-and, in particular, peer group overlap-and competitive aggressiveness. Our study provides investors, regulators and practitioners with insights into the implications of contemporary incentive-compensation contracts for firm decisions. While prior research has mainly focused on the adoption and the risk reduction properties of RPE (e.g., Albuquerque, 2009, 2014, Gibbons and Murphy, 1990, Gong et al., 2011, Janakiraman et al., 1992) we provide evidence on the economic consequences of relative performance evaluation. In light of the public debate on the structure of executive incentive-compensation contracts, these insights are of paramount interest to these parties, because they can be used to assess whether these contracts expose firms to material risks.

Moreover, we provide important insights into the discussion as to whether competition among large U.S. firms induces firms to sabotage or collude. For example, in related work, Bloomfield et al. (2020) posit that cartel membership increases the likelihood that a firm uses RPE. Through cartel membership firms could get the risk reduction benefits of RPE without sabotaging each other. Similarly, $\mathrm{Ha}, \mathrm{Ma}$, and Žaldokas (2020) show that after four regional offices of Department of Justice closed down, some firms put a positive weight on peer performance in their executive incentivecompensation contracts. Our story is not mutually exclusive to these stories. Whereas these studies focus on how the existence of collusive agreements affects the use of RPE and how firms abstain from using RPE to enter into collusive agreements, we focus on how explicit RPE plans relate to firms' competitive actions. The evidence we present is in favor of the "sabotage hypothesis," and-in conjunction with prior studies' findingshighlights the complex nature of the relation between RPE and competitive behavior. Our study thus improves the understanding of the economics of relative performance plans.

Finally, our study has two important academic takeaways. First, our study documents considerable differential implications of relative performance plans with peer group overlap and relative performance plans without peer group overlap. This has significant implications for the transferability of research results from within-firm RPE plans, which typically has $100 \%$ overlap, to executive RPE plans, and vice versa. As such, future academic studies that examine the relation between executive RPE plans and firm decisions benefit from considering the specific characteristics of RPE plans, rather than pooling all plans into one construct. 
Second, we draw from - and, in doing so, help bridge-the strategic management and accounting literatures. Even though accountants have a great interest in understanding how competition affects accounting-related issues (e.g., Harris, 1998, Li, Lundholm, and Minnis, 2013), the accounting literature largely ignored the reverse association between accounting-related choices and competitive actions. We bring in the perspective that incentive-compensation choices relate to such competitive actions. Moreover, we introduce measurement techniques from strategic management to measure competitive aggressiveness. To the extent that competitive aggressiveness is an established and validated construct in strategic management (e.g., Connelly, Lee, Tihanyi, Certo, and Johnson, 2019, Connelly, Tihanyi, Ketchen, Carnes, and Ferrier, 2017, Ferrier, 2001, Ferrier and Lyon, 2004, Ferrier, Smith, and Grimm, 1999), it provides ample opportunity for future accounting research.

The paper proceeds as follows. Section II discusses related literature and develops hypotheses. Section III discusses variable measurement, sample selection and descriptive statistics. Section IV presents our main tests and results. Section V discusses our crosssectional tests. Section VI discusses our additional test. Section VII concludes.

\section{Related Literature and Hypothesis Development}

\section{II.A. Related Literature}

In his seminal paper, Holmström (1982) develops an economic theory of relative performance evaluation. Analyzing a setting with multiple agents, he argues that if an agent's performance and performance of his/her peers are exposed to common shocks, it is optimal to use peer performance as an instrument to filter this risk from performance. This improves the efficiency of incentives. This strong theoretical argument triggered a large stream of empirical research in the mid-1980s and 90s examining the use of RPE in executive incentive-compensation contracts (e.g., Antle and Smith, 1986, Barro and Barro, 1990, Gibbons and Murphy, 1990, Janakiraman et al., 1992). These studies find mixed evidence for the use of RPE.

One potential reason for this mixed evidence is the researcher's (in)ability to identify the peer group used in relative performance plans. Prior to the introduction of the CD\&A disclosure in firms' proxy statements in 2006, there was no publicly available data on peer groups used by firms. The absence of this information is a key obstacle in identifying the use of RPE with an implicit approach (e.g., Black, Dikolli, and Hofmann, 2015, Dikolli, Hofmann, and Pfeiffer, 2013). ${ }^{49}$ In line with this conjecture, recent studies using more fine-grained peer groups than market-wide indices or industry classifications do detect RPE using the implicit approach. Such peer groups include, for example, matched size-industry peers (e.g., Albuquerque, 2009), life cycle peers (e.g., Drake and Martin, 2020) and product market peers (e.g., Jayaraman, Milbourn, Peters, and Seo, 2020).

CD\&A disclosures in firms' proxy statements reveal that the use of RPE in executive incentive-compensation contracts is omnipresent and increasing rapidly. For example, in the period 2006 through 2019, the use of RPE has more than doubled. Nowadays,

49. The implicit approach refers to tests whereby one estimates a regression of total compensation on firm performance and market and/or industry performance to detect the use of RPE (e.g., Antle and Smith, 1986, Gibbons and Murphy, 1990, Janakiraman et al., 1992). 
approximately two-thirds of S\&P 500 firms use some form of RPE in their incentivecompensation contracts (e.g., Bizjak et al., 2021, Equilar, 2020, Meridian Compensation Partners LLC., 2019). These CD\&A disclosures also detail the award structures of these RPE plans and provide insights into the associated peer groups used as the benchmark to evaluate managers' relative performance. Importantly, peers used in these RPE plans differ from peers used to benchmark managers' compensation levels-there is relatively little overlap between these groups. For example, in our sample, we find that only about $35 \%$ of the peers that are selected as compensation-benchmarking peers are also selected as a relative performance peer in our sample. This statistic is consistent with the statistic reported in prior studies (e.g., Albuquerque, De Franco, and Verdi, 2013, Gong et al., 2011).

With the improved ability to assess whether a firm uses RPE, empirical research shifted toward examining the antecedents of RPE, among which the determinants of peer selection. For example, consistent with Holmström's (1982) risk reduction argument, Gong et al. (2011) show that common risk exposure is an important determinant of firmlevel RPE use. ${ }^{50}$ They also show that industry composition and firm size play a crucial role in peer selection; this is in line with Albuquerque (2009), who is able to detect RPE with the implicit approach using matched size-industry peers. Drake and Martin (2020) add that boards also consider life cycle stages when constructing peer groups. Albuquerque (2014) also finds that the firm's life cycle is an important determinant of using RPE and concludes that firms with high growth opportunities often lack the availability of suitable peers-hindering them from using RPE. Taken together, these studies provide evidence that firms construct peer groups with the goal of filtering common shocks. In this regard, Bloomfield et al. (2021) and Ma, Shin, and Wang (2019) show that the self-selected peer groups that firms construct do a good job in filtering systematic performance. ${ }^{51}$

The combined evidence thus suggests that firms construct peer groups with the goal of risk-filtration-à la Holmström (1982). Nevertheless, Holmström (1982, p. 335) also points out that this efficient use of information induces competition between agents. While he argues that such competition is valueless beyond information extraction purposes, analytical frameworks that model interactions between agents show that RPE incentives can induce strategic interaction. Thereby, RPE incentives can expose the principal to potentially unintended-and costly-consequences (e.g., Aggarwal and Samwick, 1999, Sklivas, 1987, Vickers, 1985). Below we discuss these costs in more detail.

\section{II.B. Hypothesis Development}

The two most important costs associated with the use of RPE relate to actions a firm can take to affect performance of the peer group, i.e., (i) sabotage and (ii) collusion (e.g., Gibbons and Murphy, 1990).

50. In an analytical model, Dikolli, Diser, Hofmann, and Pfeiffer (2018) show that CEO power can also influence the use of RPE and the choice of the peer group.

51. Ma et al. (2019) conclude that firms' self-selected peer groups exhibit a return beta of 1 with the focal firm-on average. Bloomfield et al. (2021) develop an algorithm that mimics the RPE peer selection process and constructs optimal peer groups (from the standpoint of risk-filtration). They find that firms construct selfselected peer groups that filter similar magnitudes of risk (out-of-sample) as their algorithmically-constructed peer groups. 
Regarding sabotage, RPE puts a firm in direct competition to its peers. To gain an advantage over competitors and improve the relative position, firms engage in competitive actions (e.g., aggressive pricing strategies, the introduction of a new promotional campaign, or the acquisition of another firm in order to gain synergistic benefits). For example, Ferrier (2001) states that: "As they navigate the competitive landscape, firms often directly and aggressively challenge competitors in an effort to improve relative performance." Aggarwal and Samwick (1999) formalize this intuition and show analytically that RPE affects firms' competitive actions. Their model demonstrates that if managers work under a relative performance plan in an imperfect competitive product market, they will act more competitively aggressive than if they would work under an absolute performance plan.

While these competitive actions can improve relative performance, they are also costly-and potentially value-destroying. In essence, RPE gives managers incentives to engage in competitive actions, as long as these actions destroy peer value relatively more than own value (e.g., Bloomfield et al., 2020, Gibbons and Murphy, 1990). In environments where products are strategic complements, competitive aggressiveness is always value-destroying and firms are typically better off not using RPE (e.g., Vrettos, 2013). In environments where products are strategic substitutes, the situation is different: one firm may-individually-be better off using RPE so to commit the manager to competitive actions while at the same time shield him/her from common risk.

But even in the absence of common risk, Aggarwal and Samwick (1999, p. 2012) demonstrate that the use of RPE can be an equilibrium outcome of a prisoner's dilemma problem. Under a relative performance plan, a manager is incentivized to act aggressively and improve the firm's relative position compared to peer firms. However, this implies that a peer firm loses value relative to the focal firm. To counteract this tendency-and improve its own relative position-that peer firm would also be better off to use RPE itself. This in turn increases that peer firm's competitive aggressiveness, leading to an equilibrium where both firms use RPE and act aggressively, even though collectively they would be better off had they commit to not being aggressive (e.g., Aggarwal and Samwick, 1999, p. 2012). Thus, the incentives to act aggressively are greatest when "all agents" are evaluated based on own- and peer performance. However, while having each other as peers is typical for RPE and other tournament-like schemes within firms, this need not be the case for RPE schemes between firms. A focal firm's peers need not use RPE themselves or, if they use RPE, they need not select the focal firm as their own peer. The extent to which the focal firm's peers use RPE and have the focal firm as a peer, is what we dub "peer group overlap."

The above sabotage discussion implies that if RPE gives managers incentives to act aggressively, economic theory predicts a firm's competitive aggressiveness is increasing in a firm's peer group overlap. We label this prediction the "sabotage hypothesis."

The second commonly discussed consequence from using RPE is the concern that it can give agents incentives to collude (e.g., Dye, 1984, Mookherjee, 1984). While collusion creates its own problems (e.g., potential inefficiencies), it could also create the commitment necessary to escape from the previously discussed prisoner's dilemma problem-in which all firms act aggressively to improve their relative position. When firms collude, they could collectively agree on product market strategies. Thereby, firms avoid the costs of sabotage, but still benefit from risk filtration. Consistent with this 
argument, Bloomfield et al. (2020) find that RPE is used frequently in firms that have been convicted to violate antitrust laws.

Besides these explicit collusive agreements, collusion might also go undetected or take a more tacit form. In the latter case, firms do not communicate privately to exchange information and, thus, do not violate antitrust laws. For example, Bourveau, She, and Žaldokas (2020) provide evidence that firms publicly share detailed information about their customers, contracts and products so to potentially tacitly coordinate actions in product markets with peers. Even though these collusive agreements are more tacit, they still have real effects on firm policies (e.g., Bertomeu, Evans, Feng, and Tseng, 2020, Bertomeu and Liang, 2015).

There is further evidence that suggests that firms coordinate with peers. For example, in a sample of Japanese firms, Joh (1999) tests how peer performance affects the structure of incentive-compensation contracts. She finds that managers' pay is positively related to industry profit, which suggests a commitment to product market collusion. More recently in the U.S. setting, Ha et al. (2020) show that after four regional offices of Department of Justice closed down-and, thus, after collusion oversight weakens-a subset of firms puts a positive weight on peer performance in their executive incentive-compensation contracts. This similarly suggests a commitment to product market collusion.

Although these studies do not explicitly examine firms' choices after they adopt RPE, the evidence suggests that a subset of firms motivates managers to collude through their incentive-compensation contracts. Given our focus, the question is whether firms commit to product market collusion through relative performance plans. If RPE gives managers incentives to enter into collusive agreements with peers, then peer group overlap decreases a firm's competitive aggressiveness. We label this prediction the "collusion hypothesis."

Collectively, the above discussion implies that RPE incentives can either: (i) increase competitive aggressiveness-through sabotage-or (ii) decrease competitive aggressiveness - through collusion. At the end of the day, it is an empirical question which hypothesis dominates.

Note that both predictions hinge on the assumption that firms act in product markets with imperfect competition (e.g., Aggarwal and Samwick, 1999). In a perfectly competitive product market, actions of one firm do not affect performance of other firms, and consequently, competitive aggressiveness does not impact a firm's relative performance. In contrast, in imperfect competitive product markets, actions of one firm do influence both own- and peer performance. This implies that the associations between peer group overlap and competitive aggressiveness is likely to be stronger in settings with relatively more imperfect competition than in settings with relatively more perfect competition. In our empirical analysis, we explore this point by partitioning our sample into observations operating in relatively imperfect and perfect competitive product markets.

\section{Variable Measurement and Sample Selection}

In this section, we define our data sources, sample selection procedures, and variable construction process. 
Table 2.1. News event examples

\begin{tabular}{|c|c|c|}
\hline Action type & Firm & Example \\
\hline New product actions & Barnes \& Noble Inc. & Barnes E Nobel Studio Debuts New Series: Mr. Literary \\
\hline Pricing actions & Atmel Corp. & $\begin{array}{l}\text { Atmel Reduces System Cost in Industrial Applications with High- } \\
\text { Quality Video Decoding ARM926-based Microprocessor }\end{array}$ \\
\hline Marketing actions & United Parcel Service Inc. & $\begin{array}{l}\text { UPS Racing Unveils Commercials and Online Sweepstakes to } \\
\text { Launch } 2010 \text { NASCAR Season }\end{array}$ \\
\hline Acquisitions & Bio-Rad Laboratories Inc. & $\begin{array}{l}\text { Bio-Rad Complete the Purchase of Certain Diagnostics Businesses } \\
\text { of Biotest AG }\end{array}$ \\
\hline Equity joint ventures & Scientific Games Corp. & Playtech Signs Joint Venture with Scientific Games \\
\hline Strategic alliances & McAfee Inc. & $\begin{array}{l}\text { Brocade and McAfee Enter Strategic Partnership to Deliver } \\
\text { Comprehensive Network Security Solutions }\end{array}$ \\
\hline Market expansion & Texas Instruments Inc. & Texas Instruments to Enter E-Reader Market \\
\hline
\end{tabular}

This table presents example events for each action category.

\section{III.A. Measurement of Competitive Aggressiveness}

One key construct in all our tests is competitive aggressiveness. Following an extensive prior literature in strategic management, we construct our primary measures of competitive aggressiveness using the firm's competitive action repertoire identified through structured content analysis of news events. ${ }^{52}$ In Appendix I, we detail all steps to compute our primary measures of competitive aggressiveness as well as their interpretation. Below, we present a synopsis of their computation and interpretation.

To identify competitive actions, we rely on news events identified by RavenPack News Analytics (hereafter "RavenPack"). RavenPack develops proprietary algorithms that identify events (e.g., new product offerings of firms, price actions, strategic alliances, etc.) in unstructured text published by reputable content sources, such as the Dow Jones Newswires, the Wall Street Journal and over 19,000 other traditional and social media sites.

For each news event, RavenPack identifies a "type," a "relevance score," and a "novelty score." The type refers to a class of events that share similar characteristics; the relevance score indicates the relevance of the focal firm in the event, where greater values imply more relevant events; and the novelty score indicates the novelty of a news event and helps to distinguish duplicate events, where greater values imply more unique events. We follow prior literature (e.g., Connelly et al., 2019, Connelly et al., 2017), and examine seven major action types, including: (i) new product actions, (ii) pricing actions, (iii) marketing actions, (iv) acquisitions, (v) equity joint ventures, (vi) strategic alliances, and (vii) market expansion. ${ }^{53}$ Table 2.1 presents example events for each action type. We limit our analyses to events for which the relevance score is 100 (i.e., the maximum) and the novelty score is 100 (i.e., the maximum), to ensure that we: (i) assign news events to the correct firm, and (ii) do not double-count events.

52. While new in accounting, this approach has a long-standing history in the strategic management literature (e.g., Chen, Katila, McDonald, and Eisenhardt, 2010, Connelly et al., 2019, Connelly et al., 2017, Ferrier, 2001, Ferrier and Lyon, 2004, Ferrier et al., 1999, Nadkarni, Chen, and Chen, 2016, Ndofor, Sirmon, and He, 2011, Rindova, Ferrier, and Wiltbank, 2010).

53. We thank Brian Connelly for providing his decision tree to classify competitive actions into types. 
Using these competitive actions, we follow the strategic management literature and construct two empirical measures of competitive aggressiveness: (i) action volume and (ii) action complexity.

The volume dimension measures how many competitive actions a firm takes. It counts the number of actions for each firm-year, irrespective of the action type. The interpretation of this measure is straightforward: the more actions a firm takes, the greater its competitive aggressiveness. Formally, we define Action Volume as follows:

$$
\text { Action Volume }=\sum_{i=1}^{7} a_{i j}=V_{j}
$$

where $a_{j}$ is the number of firm $j$ 's actions in the $i$ th action type in a given year.

The complexity dimension considers that not all actions are identical (e.g., launching a new marketing campaign is a fundamentally different action than performing an acquisition) and that firms act more aggressively if they spread their actions across multiple dimensions. It thus measures the breadth of competitive actions across different action types. We relate the actions in the different action types to the overall number of actions for each firm-year. The interpretation of this measure is as follows: the more equally distributed the actions are across the different action types, the more complex and, hence, the greater a firm's competitive aggressiveness. Formally, we define Action Complexity as follows:

$$
\text { Action Complexity }=1-\sum_{i=1}^{7}\left(a_{i j} / V_{j}\right)^{2}
$$

where $a_{i j}$ is the number of firm $j$ 's actions in the $i$ th action type and $V_{j}$ is the total number of actions carried out by firm $j$ in a given year (i.e., Action Volume).

A key advantage of using these measures of competitive aggressiveness is that they allow us to capture a broad and comprehensive set of relevant and impactful firm actions. Nevertheless, to ensure that our inferences are not unique to one specific measure of competitive aggressiveness-but rather apply to this theoretical construct more generally-we also triangulate our main analyses in robustness tests with more traditional accounting-based input and output measures of competitive behavior, including the firm's advertisement expenditures and operating margin.

\section{III.B. Measurement of Peer Group Overlap}

To measure peer group overlap in relative performance plans, we first identify usage of relative performance plans in executive incentive-compensation contracts based on data from the ISS Incentive Lab database. We identify the presence of a relative performance plan if the Compensation Discussion and Analysis section of the firm's proxy statement states that: (i) at least one component of executive compensation is determined based on the firm's performance relative to performance of other firms, and (ii) the firm uses and explicitly states the self-selected performance peer group. We exclude firms that use an index as peer group from the sample, because we are primarily interested in firms that explicitly select their own set of peers to compete with. Appendix II exemplifies the relative performance plan of United Parcel Service Inc. (2019). 
Figure 2.1. Peer group overlap

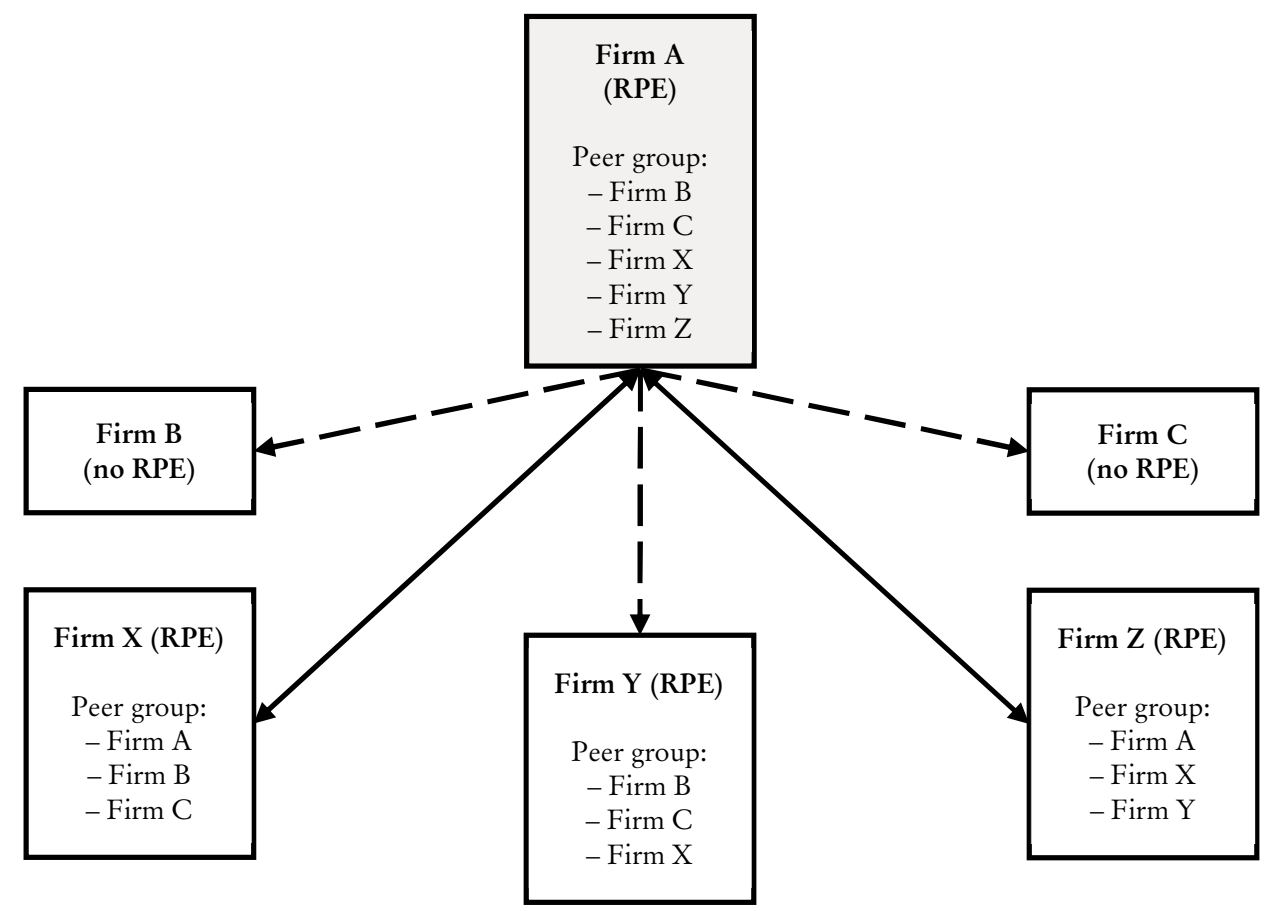

This figure illustrates the peer group overlap concept. The focal firm A has five peers. Of these five peers, two peers $(B$ and $C)$ do not have a relative performance plan themselves and three peers $(\mathrm{X}, \mathrm{Y}$ and $\mathrm{Z})$ do have a relative performance plan. Peers $\mathrm{X}$ and $\mathrm{Z}$ also have firm $\mathrm{A}$ selected as their peer, resulting in an overlap in peer selection—as indicated by the solid lines. From firm A's viewpoint, there are thus two (out of five) overlapping peer relations. As such, in this example, peer group overlap for firm $\mathrm{A}$ is $40 \%$.

We then analyze all firm-peer relationships and record which relationships are "singular" and which are "dual." Singular peer relationships are those relationships whereby the focal firm has another firm selected as a peer, but this peer firm does not have the focal firm as an RPE peer (or does not use RPE at all). In a dual peer relationship, the peer firm also has the focal firm selected as peer. Thus, if a relationship is dual, there is a "peer group overlap." We then count the number of overlapping peer relationships per firm-year and scale that by the peer group size for that firm-year. We label this variable Peer Group Overlap. The higher the fraction of dual relationships in a relative performance plan, the greater peer group overlap. Figure 2.1 illustrates the concept of peer group overlap.

\section{III.C. Sample Selection and Descriptive Statistics}

We construct our sample using data from Compustat, CRSP, ExecuComp, RavenPack, ISS Incentive Lab, and the Hoberg-Philips Data Library. Our sample begins in 2006, when data on relative performance plans and associated peer groups for the largest 750 firms by market capitalization first becomes available in ISS Incentive Lab, 
and ends in 2017. The final sample contains 1,623 firm year observations with nonmissing values for all required variables. ${ }^{54}$

Table 2.2 presents descriptive statistics for the primary variables in our design. Table 2.3 presents the year and industry distribution of Peer Group Overlap. In addition, we provide more details about the characteristics of relative performance plans used by firms in our sample in Section IV.A. Table 2.2 shows that the mean (median) of Action Volume is 33 (17), which implies that the average (typical) firm takes about 33 (17) actions per year. The mean (median) of Action Complexity is 0.438 (0.500), which implies that there is considerable variation in firms' action repertoires across action types. In total, the firms in our full sample engage in 53,732 competitive actions (untabulated). Regarding Peer Group Overlap, Table 2.2 shows that the mean is 15 percent. This implies that on average approximately one in seven firm-peer relationships is a dual peer relationship. Table 2.3 further shows that the mean peer group overlap has grown from 8 to 21 percent from 2006 to 2017.

\section{Empirical Analysis}

\section{IV.A. What do RPE Plans with Self-Selected Peers Look Like?}

Before we test the associations between peer group overlap and competitive aggressiveness, we first provide more details about the characteristics of these relative performance plans. Specifically, in this section, we provide additional descriptive statistics on: (i) the level of relative performance incentives, (ii) the performance criteria used in these plans, (iii) the size and dynamics of the peer group, and (iv) the type of peers chosen. We further test whether these characteristics differ between RPE firms without peer group overlap and RPE firms with peer group overlap. We tabulate these results in Table 2.4 .

Panel A in Table 2.4 presents additional descriptive statistics on the level of relative performance incentives. We estimate the level of incentives by measuring the "riskneutral value" of the RPE plan-i.e., the current dollar amount the manager can maximally receive from his/her RPE plan. For RPE grants with equity awards, the dollar amount equals the maximum number of shares the manager can receive multiplied by the firm's current share price; for RPE grants with cash awards, the dollar amount simply equals the maximum cash the manager can receive. We scale this variable by the manager's previous year's total compensation, so it expresses a percentage of total compensation. We label this variable Grant Size. The mean (median) Grant Size is $77.1 \%$ (59.4\%), which implies that the average (typical) RPE plan provides the manager with the possibility to earn a RPE grant worth $77.1 \%(59.4 \%)$ of his/her previous year's total compensation. This indicates that, for firms that use RPE plans, the grants from these plans provide significant incentives to managers. This finding is in line with De Angelis and Grinstein (2019). Finally, we note that the level of incentives does not differ, on average, between RPE without overlap and RPE with overlap (76.3\% vs. $77.8 \%$; two-tailed $p=0.614$ for the difference).

54. In untabulated analyses, we find that, when including non-RPE firms in ISS Incentive Lab in our sample, approximately $25 \%$ of the firms in our sample use a relative performance plan with self-selected peers as part of its executive incentive-compensation contract. This statistic is consistent with previous studies that use data from ISS Incentive Lab (e.g., De Angelis and Grinstein, 2019, Gong et al., 2011). 
Table 2.2. Sample descriptive statistics

\begin{tabular}{lrrrrr}
\multicolumn{7}{c}{ Panel A. Full sample } \\
\hline \multicolumn{7}{c}{ Mean } & Std. Dev. & \multicolumn{1}{c}{ 10th } & \multicolumn{1}{c}{ 50th } & \multicolumn{1}{c}{90 th } \\
\hline Action Volume & 33.107 & 45.698 & 3.000 & 17.000 & 79.800 \\
Action Complexity & 0.438 & 0.233 & 0.000 & 0.500 & 0.690 \\
Peer Group Overlap & 0.150 & 0.181 & 0.000 & 0.087 & 0.400 \\
New Exogenous Overlap & 0.266 & 0.597 & 0.000 & 0.000 & 1.000 \\
Peer Group Synchronicity & 0.480 & 0.208 & 0.192 & 0.497 & 0.741 \\
Market Value (Rank) & 0.510 & 0.212 & 0.222 & 0.500 & 0.800 \\
Book-to-Market (Rank) & 0.512 & 0.263 & 0.150 & 0.500 & 0.875 \\
Leverage (Rank) & 0.517 & 0.261 & 0.154 & 0.500 & 0.869 \\
Sales Growth (Rank) & 0.492 & 0.270 & 0.143 & 0.500 & 0.875 \\
Return (Rank) & 0.519 & 0.260 & 0.160 & 0.526 & 0.867 \\
HEP Number of Competitors (Rank) & 0.501 & 0.248 & 0.167 & 0.500 & 0.833 \\
HEP Competitor Similarity (Rank) & 0.499 & 0.265 & 0.143 & 0.500 & 0.857 \\
HEP Number of Competitors & 63.087 & 81.822 & 4.000 & 25.000 & 199.800 \\
\hline
\end{tabular}

Panel B. Subsamples

\begin{tabular}{lrrrrrr}
\hline & \multicolumn{1}{c}{ RPE firms without overlap } & \multicolumn{3}{c}{ RPE firms with overlap } \\
& Mean & Std. Dev. & Median & Mean & Std. Dev. & Median \\
\hline Action Volume & 27.867 & 36.570 & 13.000 & 35.726 & 49.444 & 18.000 \\
Action Complexity & 0.443 & 0.227 & 0.500 & 0.436 & 0.235 & 0.498 \\
Peer Group Overlap & 0.000 & 0.000 & 0.000 & 0.225 & 0.180 & 0.179 \\
New Exogenous Overlap & 0.000 & 0.000 & 0.000 & 0.398 & 0.694 & 0.000 \\
Peer Group Synchronicity & 0.420 & 0.195 & 0.429 & 0.509 & 0.208 & 0.537 \\
Market Value (Rank) & 0.483 & 0.218 & 0.484 & 0.523 & 0.208 & 0.500 \\
Book-to-Market (Rank) & 0.505 & 0.261 & 0.500 & 0.515 & 0.264 & 0.500 \\
Leverage (Rank) & 0.539 & 0.258 & 0.548 & 0.506 & 0.262 & 0.500 \\
Sales Growth (Rank) & 0.486 & 0.272 & 0.476 & 0.495 & 0.269 & 0.500 \\
Return (Rank) & 0.511 & 0.251 & 0.500 & 0.524 & 0.264 & 0.533 \\
HEP Number of Competitors (Rank) & 0.489 & 0.246 & 0.500 & 0.507 & 0.250 & 0.500 \\
HEP Competitor Similarity (Rank) & 0.487 & 0.270 & 0.500 & 0.505 & 0.262 & 0.500 \\
HEP Number of Competitors & 56.425 & 79.146 & 22.000 & 66.418 & 82.964 & 26.000 \\
\hline
\end{tabular}

This table presents descriptive statistics. Panel A presents descriptive statistics for the full sample. Panel B presents descriptive statistics grouped by RPE firms without and with peer group overlap. The sample contains 1,623 observations for all RPE firms with self-selected peers in ISS Incentive Lab from 2006 to 2017 with non-missing values for all required variables. We exclude financial service firms and utilities. Action Volume is the total number of competitive actions. Action Complexity is the variation in competitive actions across seven types of competitive actions. Peer Group Overlap is the number of overlapping peer relationships scaled by the peer group size. New Exogenous Overlap is the number of overlapping peer relationships that were not overlapping peer relationships in the previous year, for which the overlap was initiated by the peer. Peer Group Synchronicity is the firm's stock return synchronicity with its peers. Market Value (Rank) is the firm's peer group-rank of market value. Book-to-Market (Rank) is the firm's peer group-rank of the ratio of book value of total assets to the firm's market value. Leverage (Rank) is the firm's peer group-rank of the book value of total long-term debt, scaled by total assets. Sales Growth (Rank) is the firm's peer group-rank of growth in annual revenue over the prior year. Return (Rank) is the firm's peer group-rank of cumulative stock return. HEP Number of Competitors (Rank) is the firm's peer group-rank of number of product market competitors. HEP Competitor Similarity (Rank) is the firm's peer group-rank of similarity to its product market competitors. HEP Number of Competitors is the firm's number of product market competitors. 
Table 2.3. Year and industry distribution of Peer Group Overlap

\begin{tabular}{|c|c|c|c|c|c|c|c|c|c|c|c|c|}
\hline & 2006 & 2007 & 2008 & 2009 & 2010 & 2011 & 2012 & 2013 & 2014 & 2015 & 2016 & 2017 \\
\hline (1) & 0.101 & 0.227 & 0.198 & 0.270 & 0.200 & 0.192 & 0.162 & 0.167 & 0.136 & 0.187 & 0.137 & 0.203 \\
\hline (2) & 0.083 & 0.056 & 0.036 & 0.064 & 0.119 & 0.087 & 0.045 & 0.011 & 0.048 & 0.120 & 0.036 & 0.107 \\
\hline (3) & 0.050 & 0.132 & 0.118 & 0.145 & 0.117 & 0.124 & 0.150 & 0.141 & 0.138 & 0.199 & 0.140 & 0.179 \\
\hline (4) & 0.102 & 0.228 & 0.145 & 0.122 & 0.243 & 0.224 & 0.242 & 0.315 & 0.303 & 0.302 & 0.423 & 0.391 \\
\hline (5) & 0.104 & 0.061 & 0.000 & 0.029 & 0.049 & 0.023 & 0.024 & 0.044 & 0.043 & 0.115 & 0.075 & 0.139 \\
\hline (6) & 0.039 & 0.065 & 0.050 & 0.075 & 0.106 & 0.042 & 0.102 & 0.085 & 0.115 & 0.081 & 0.071 & 0.084 \\
\hline (7) & 0.000 & 0.067 & 0.195 & 0.111 & 0.056 & 0.033 & 0.000 & 0.035 & 0.051 & 0.054 & 0.029 & 0.231 \\
\hline (8) & NA & NA & NA & NA & NA & NA & NA & NA & NA & NA & NA & NA \\
\hline (9) & 0.022 & 0.000 & 0.000 & 0.032 & 0.030 & 0.051 & 0.107 & 0.092 & 0.078 & 0.106 & 0.075 & 0.075 \\
\hline (10) & 0.231 & 0.209 & 0.180 & 0.008 & 0.097 & 0.098 & 0.116 & 0.073 & 0.103 & 0.086 & 0.109 & 0.117 \\
\hline (11) & NA & NA & NA & NA & NA & NA & NA & NA & NA & NA & NA & NA \\
\hline (12) & 0.036 & 0.129 & 0.087 & 0.054 & 0.075 & 0.090 & 0.168 & 0.089 & 0.130 & 0.126 & 0.200 & 0.206 \\
\hline
\end{tabular}

This table presents mean descriptive statistics on Peer Group Overlap across time and industries. The sample contains 1,623 observations for all RPE firms with self-selected peers in ISS Incentive Lab from 2006 to 2017 with non-missing values for all required variables. We exclude financial service firms and utilities. The industry classification follows the 12 industry groups identified by Fama and French (1997): (1) Consumer Non-Durables; (2) Consumer Durables; (3) Manufacturing; (4) Oil, Gas, and Coal Extraction; (5) Chemicals and Allied Products; (6) Business Equipment; (7) Telephone and Television Transmission; (8) Utilities; (9) Wholesale and Retail; (10) Healthcare and Medical Equipment; (11) Finance; and (12) Other. All variables are defined in the caption of Table 2.2.

Panel B in Table 2.4 presents additional descriptive statistics on the performance criteria used in relative performance plans. In our sample, $80.4 \%$ of the relative performance plans is price-based whereas $32.8 \%$ is accounting-based. ${ }^{55}$ These percentages indicate a predominance of price-based criteria (e.g., total shareholder return), which is in line with prior studies (e.g., Bizjak et al., 2021, Gong et al., 2011, Gong et al., 2019). Consistent with Bizjak et al. (2021), we also find that the predominance of price-based plans is increasing over time. For example, in untabulated analyses we find that in $201789.1 \%$ of the RPE plans is price-based, vis-a-vis $26.3 \%$ of RPE plans is accounting-based. When comparing RPE without overlap to RPE with overlap, we find that the use of accounting-based RPE is similar for these two groups (33.8\% vs. $32.2 \%$; two-tailed $p=0.527$ for the difference). In contrast, the use of pricebased RPE is significantly (two-tailed $p<0.001$ ) higher for RPE with overlap $(82.4 \%$ ) compared to RPE without overlap (76.3\%). In line with the increasing predominance of price-based plans, this difference is negligible in more recent years (e.g., $91.4 \%$ vs. $88.6 \%$ in 2017; two-tailed $p=0.606$ for the difference).

Panel C in Table 2.4 presents additional descriptive statistics on the size and dynamics of the peer group in relative performance plans. Regarding size, the mean (median) peer group contains 14.670 (12) peers. In untabulated analyses, we find that there is significant variability in peer group size, e.g., the 10 th percentile being 5 peers and the 90 th percentile being 25 peers. The average peer group for RPE firms without overlap is slightly larger than the average peer group for RPE firms with overlap (15.640 vs. 14.180, respectively). The typical peer group, however, is similar in size across RPE

55. Note that these percentages add up to more than $100 \%$ because some firms use both price-based and accounting-based metrics. 
Table 2.4. Additional descriptive statistics on relative performance plans

\begin{tabular}{|c|c|c|c|c|c|c|c|}
\hline \multicolumn{8}{|c|}{$(2) \quad(3) \quad(4)$} \\
\hline & \multicolumn{2}{|c|}{ All RPE firms } & \multicolumn{2}{|c|}{$\begin{array}{c}\text { RPE firms } \\
\text { without overlap }\end{array}$} & \multicolumn{3}{|c|}{$\begin{array}{l}\text { RPE firms } \\
\text { with overlap }\end{array}$} \\
\hline & Mean & Median & Mean & Median & Mean & Median (5) & $5)-(3)$ \\
\hline Grant Size & 0.771 & 0.594 & 0.763 & 0.563 & 0.778 & 0.617 & 0.015 \\
\hline \multicolumn{8}{|c|}{ Panel B. Performance criteria } \\
\hline & (1) & $(2)$ & (3) & $(4)$ & (5) & $(6)$ & (7) \\
\hline & \multicolumn{2}{|c|}{ All RPE firms } & \multicolumn{2}{|c|}{$\begin{array}{l}\text { RPE firms } \\
\text { without overlap }\end{array}$} & \multicolumn{2}{|c|}{$\begin{array}{l}\text { RPE firms } \\
\text { with overlap }\end{array}$} & \\
\hline & Mean & Median & Mean & Median & Mean & Median & $(5)-(3)$ \\
\hline RPE-price & 0.804 & 1.000 & 0.763 & 1.000 & 0.824 & 1.000 & $0.061^{\text {s.mp }}$ \\
\hline RPE-accounting & 0.328 & 0.000 & 0.338 & 0.000 & 0.322 & 0.000 & -0.016 \\
\hline \multicolumn{8}{|c|}{ Panel C. Peer group size and dynamics } \\
\hline & (1) & $(2)$ & (3) & $(4)$ & (5) & (6) & (7) \\
\hline & \multicolumn{2}{|c|}{ All RPE firms } & \multicolumn{2}{|c|}{$\begin{array}{l}\text { RPE firms } \\
\text { without overlap }\end{array}$} & \multicolumn{2}{|c|}{$\begin{array}{l}\text { RPE firms } \\
\text { with overlap }\end{array}$} & \\
\hline & Mean & Median & Mean & Median & Mean & Median & $(5)-(3)$ \\
\hline Deer Group Size & 14.670 & 12.000 & 015.640 & 12.000 & 14.180 & 12.000 & $-1.461^{* n}$ \\
\hline Duration Firm-Peer & 0.572 & 0.543 & 0.593 & 0.558 & 0.562 & 0.530 & $-0.031^{* * n}$ \\
\hline \multicolumn{8}{|c|}{ Panel D. Peers chosen from same product market } \\
\hline & (1) & $(2)$ & (3) & (4) & (5) & (6) & (7) \\
\hline & \multicolumn{2}{|c|}{ All RPE firms } & \multicolumn{2}{|c|}{$\begin{array}{c}\text { RPE firms } \\
\text { without overlap }\end{array}$} & \multicolumn{2}{|c|}{$\begin{array}{c}\text { RPE firms } \\
\text { with overlap }\end{array}$} & \\
\hline & Mean & Median & Mean & Median & Mean & Median & $(5)-(3)$ \\
\hline$\%$ Peers in HEP & 0.425 & 0.364 & 0.405 & 0.385 & 0.435 & 0.353 & $0.030^{*}$ \\
\hline
\end{tabular}

This table presents additional descriptive statistics on relative performance plans. Panel A presents descriptive statistics on the level of relative performance incentives. Panel B presents descriptive statistics on the performance criteria used in these plans. Panel C presents descriptive statistics on the size and dynamics of the peer group. Panel D presents descriptive statistics on the type of peers chosen. Grant Size is the "risk-neutral value" of the RPE plan, scaled by the manager's previous year's total compensation. $R P E$-price restricts $R P E$ to firms with price-based metrics. $R P E$ accounting restricts $R P E$ to firms with accounting-based metrics. Peer Group Size is the total number of firms in the peer group. Duration Firm-Peer is the time a firm-peer relationship lasts, expressed as a percentage of the time the focal firm uses RPE. \%Peers in HEP is the overlap with product market competitors, identified by Hoberg and Phillips (2010, 2016), scaled by the peer group size. "* and ${ }^{* * *}$ indicate significance at two-tailed probability levels of $10 \%, 5 \%$, and $1 \%$, respectively.

firms without overlap and RPE firms with overlap and contains 12 peers. In terms of dynamics, we note that peer groups for relative performance evaluation are quite sticky over time. For example, in our sample we find that the mean (median) firm-peer relationship lasts for $57.2 \%(54.3 \%)$ of the time the focal firm uses RPE. ${ }^{56}$ This statistic implies that, for a firm that uses RPE for, e.g., 10 years, the mean and median peer is in the peer group for at least 5.5 of those 10 years. In untabulated analyses, we further find this statistic is fairly right skewed: the first quartile of this statistic is $42.2 \%$. This then

56. Note that this statistic is quite difficult to express in-and relatively uninformative when expressed in-actual years, because there is much variation in how long firms themselves use RPE. Hence, it is more convenient to express this statistic as a percentage of the time the focal firm uses RPE. 
implies that for a firm that uses RPE for, e.g., 10 years, at least $75 \%$ of the mean peer group remains unchanged for at least 4.2 years. We further note that when a new firm is added to a RPE peer group, it typically replaces another firm (e.g., that firm ceased to exist, got acquired or did not match the focal firm's operations anymore).$^{57}$ Thus, even though peer groups are quite sticky over time, firms do change them. We exploit such variation in a staggered continuous difference-in-differences design in Section IV.C.

Panel D in Table 2.4 presents additional descriptive statistics on the type of peers chosen in relative performance plans. In this regard, we examine what portion of a focal firm's peers operates in the same product market as the focal firm. To do so, we construct a variable that measures the percentage of RPE peers that are in the focal firm's peer group defined by Hoberg and Phillips $(2010,2016)$. We refer to this variable as \%Peers in HEP. For this measure, larger values correspond to more product market competitors in the peer group (or less cross-industry RPE peers). We find that the mean (median) $\%$ Peers in HEP is $42.5 \%$ (36.4\%), which implies that for the average (typical) peer group, somewhat less than half (more than a third) of the peer group consists of product market competitors. When comparing RPE without overlap to RPE with overlap, we find that the mean overlap with product market competitors is $40.5 \%$ and $43.5 \%$, respectively. The difference is statistically significant at the 7\% level, which implies that RPE firms with overlap have $3 \%$ more peers (i.e., roughly 0.4 peer) operating in their own product market than do RPE firms without overlap.

\section{IV.B. Peer Group Overlap and Competitive Aggressiveness}

In this section, we examine the association between peer group overlap and competitive aggressiveness, by estimating the following equation:

$$
\left[\text { Aggressiveness }_{i j t}\right]=\alpha+\beta_{1} \text { Peer GroupOverla } p_{i j t}+\gamma^{\prime} X_{i j t}+\theta^{\prime} \mu_{j}+\phi^{\prime} v_{t}+\varepsilon_{i j t}
$$

where the indices $i, j$ and $t$ correspond to firm, industry and time, respectively. The dependent variable is either Action Volume or Action Complexity (see Section III.A for details). $X$ is a vector that includes a battery of control variables, which we describe below. Lastly, $\mu_{j}$ are industry fixed effects (based on the 48 industry groups identified by Fama and French (1997)), $v_{t}$ are year fixed effects, and $\varepsilon_{i j t}$ is the firm-year specific error. To correct for any residual cross-sectional and time-series dependence in the firm-year specific error term, $\varepsilon_{i j t}$, we base inferences throughout all our analyses on standard errors clustered by firm and year (e.g., Gow et al., 2010).

We control for the "level of risk reduction" in relative performance plans to ensure that Peer Group Overlap strictly captures a relative performance plan's competitive incentives, rather than a blend of competitive incentives and risk reduction incentives. ${ }^{58}$

57. For example, in their most recent proxy statement, Johnson \& Johnson (2020, p. 68) reports that: "for 2020, the Medical Devices Competitor Composite was updated to more accurately reflect changes in its business mix, the evolution of the competitive landscape, and newly public companies. Alcon Inc. and Intuitive Surgical, Inc. were added while Abbott Laboratories, Becton Dickinson, Edwards Lifesciences, and Roche Holding AG (Diabetes) were removed."

58. Peers that are selected for competitive reasons are very likely to have a strong performance correlation with the focal firm. For example, in our sample, the cross-sectional correlation between Peer Group Overlap and Peer Group Synchronicity is $\mathbf{0 . 4 0 6}$. Because relative performance plans filter this correlation (i.e., "risk") 
We estimate each plan's risk reduction properties by measuring the focal firm's threeyear monthly stock return synchronicity with its actual RPE peers (e.g., Morck, Yeung, and $\mathrm{Yu}, 2000) .{ }^{59} \mathrm{We}$ label this variable Peer Group Synchronicity. In addition, we control for various firm fundamentals that impact competitive aggressiveness, including the firm's market value of equity, book-to-market ratio, leverage, past sales growth and returns (e.g., Covin and Covin, 1990, Ferrier, 2001, Ferrier et al., 1999). We also include two measures of competition, because prior literature suggests that competitive environments can shape firms' competitive repertoires (e.g., Covin and Covin, 1990, Eisenhardt and Martin, 2000). We measure competition as the number of competitors in the product market and their similarity with the focal firm, as identified by Hoberg and Phillips $(2010,2016)$. We measure these fundamentals as a percentile rank relative to the firm's RPE peers at the beginning of the period (suffixed with (Rank)). We do so because, for a firm's competitive repertoire of actions, the relative standing to competitors is more important than the firm's absolute fundamentals (e.g., Ferrier, 2001, Ferrier et al., 1999).

Finally, to account for the fact that both the sabotage and collusion predictions are more likely to be observable in product markets with imperfect competition, we split our sample based on the type of competition. ${ }^{60}$ Because no commonly accepted metric or threshold to define "perfect competition" exists, we rely on the notion that a product market characteristic reflective of relatively more perfect competition is a large number of firms (e.g., Robinson, 1934). Therefore, we split our sample based on the median number of product market competitors as defined by Hoberg and Phillips (2010, 2016), and estimate our equation separately for the two subsamples. ${ }^{61} \mathrm{We}$ tabulate these results in Table 2.5.

from performance, we control for these risk reduction incentives to ensure that Peer Group Overlap strictly captures competitive incentives.

59. We use a three-year period, because the performance period in the vast majority of relative performance plans is three years (e.g., Gong et al., 2011).

60. Controlling for the Hoberg and Philips' $(2010,2016)$ measures of competition in addition to our sample split based on the number of competitors in the product market as identified by Hoberg and Phillips $(2010,2016)$ is a deliberate choice. We split our specifications to "interact" all variables with the type of competition, because economic theory predicts differential relationships between relative performance plans, peer group overlap and competitive aggressiveness, conditional on the type of competition (i.e., relatively more perfect/imperfect competition). We control for competition in our specifications to estimate the relation between peer group overlap and competitive aggressiveness over and above regular product market competition. The split sample analysis additionally allows product market competition to have a differential association with competitive aggressiveness conditional on the number of competitors. For example, the number of competitors might itself be nonlinearly related to competitive aggressiveness.

61. We rely on the number of product market competitors as identified by Hoberg and Phillips (2010, 2016) as our primary measure of competitive environment, because this measure of competition has several benefits over alternative measures. First, because Hoberg and Phillips (2010, 2016) define competitors using a text-based algorithm that relies on product market descriptions in firms' 10 -Ks their classification is a firmspecific measure. As such, their measure more accurately captures a firm's direct competitors, compared to industry-based measures (e.g., the Herfindahl-Hirschman Index). Second, their measure takes into account that firms can operate in different competitive environments simultaneously. This is important as firms likely consider their conglomerate structures when acting aggressively. Nevertheless, to ensure that our inferences are not unique to one specific measure of competitive environment, we also triangulate our main analyses with two additional measures of competitive environment, including the Herfindahl-Hirschman Index and the maximum similarity score as identified by Hoberg and Phillips $(2010,2016)$. 
Table 2.5. Peer group overlap and competitive aggressiveness

\begin{tabular}{|c|c|c|c|c|c|c|c|c|}
\hline \multirow[b]{2}{*}{ Variable } & \multicolumn{4}{|c|}{$\begin{array}{c}\text { (1) } \\
\text { Low HEP Number of Competitors } \\
\text { Dependent variable: }\end{array}$} & \multicolumn{4}{|c|}{$\begin{array}{c}(3) \\
\text { High HEP Number of Competitors } \\
\text { Dependent variable: }\end{array}$} \\
\hline & \multicolumn{2}{|c|}{$\log ($ Action Volume $)$} & \multicolumn{2}{|c|}{ Action Complexity } & \multicolumn{2}{|c|}{$\log ($ Action Volume $)$} & \multicolumn{2}{|c|}{ Action Complexity } \\
\hline Peer Group Overlap & $0.816^{* 6}$ & $(0.276)$ & $0.219^{* * n}$ & $(0.062)$ & $0.504^{*}$ & $(0.232)$ & -0.007 & $(0.058)$ \\
\hline Peer Group Synchronicity & -0.009 & $(0.215)$ & -0.029 & $(0.050)$ & 0.100 & $(0.202)$ & -0.005 & $(0.045)$ \\
\hline Market Value & $0.940^{* \ldots *}$ & $(0.241)$ & $0.176^{* * a}$ & $(0.049)$ & $1.024^{* * *}$ & $(0.236)$ & 0.103 & $(0.061)$ \\
\hline Book-to-Market & 0.231 & $(0.230)$ & $0.104 \%$ & $(0.037)$ & 0.333 & $(0.204)$ & $0.092^{*}$ & $(0.041)$ \\
\hline Leverage & 0.022 & $(0.214)$ & 0.048 & $(0.054)$ & $0.509^{* * * 3}$ & $(0.151)$ & $0.078^{*}$ & $(0.035)$ \\
\hline Sales Growth & $-0.341^{* *}$ & $(0.131)$ & $-0.100^{*}$ & $(0.032)$ & -0.010 & $(0.094)$ & -0.059 & $(0.034)$ \\
\hline Return & -0.129 & $(0.137)$ & -0.017 & $(0.030)$ & -0.055 & $(0.151)$ & -0.030 & $(0.024)$ \\
\hline HEP Number of Competitors & $-0.338^{*}$ & $(0.186)$ & -0.051 & $(0.038)$ & -0.018 & $(0.154)$ & 0.045 & $(0.048)$ \\
\hline HEP Competitor Similarity & 0.173 & $(0.108)$ & 0.036 & $(0.021)$ & -0.207 & $(0.195)$ & -0.023 & $(0.042)$ \\
\hline Year and industry effects & \multicolumn{2}{|c|}{ Yes } & \multicolumn{2}{|c|}{ Yes } & \multicolumn{2}{|c|}{ Yes } & \multicolumn{2}{|c|}{ Yes } \\
\hline Observations & \multicolumn{2}{|c|}{795} & \multicolumn{2}{|c|}{795} & \multicolumn{2}{|c|}{828} & \multicolumn{2}{|c|}{828} \\
\hline Adjusted $R^{2}$ & \multicolumn{2}{|c|}{$53.505 \%$} & \multicolumn{2}{|c|}{$24.731 \%$} & \multicolumn{2}{|c|}{$54.819 \%$} & \multicolumn{2}{|c|}{$25.360 \%$} \\
\hline
\end{tabular}

This table presents results examining the association between peer group overlap and competitive aggressiveness, split by the number of product market competitors identified by Hoberg and Phillips $(2010,2016)$. The sample contains 1,623 observations for all RPE firms with self-selected peers in ISS Incentive Lab from 2006 to 2017 with non-missing values for all required variables. The industry indicators follow the 48 industry groups identified by Fama and French (1997). All control variables are measured as the firm's peer group-rank of that control variable-i.e., Variable (Rank). Standard errors are in parentheses and are adjusted for within cluster correlation by firm and time conform Gow et al. (2010). ", and " indicate significance at two-tailed probability levels of $10 \%$, $5 \%$, and $1 \%$, respectively. All variables are defined in the caption of Table 2.2 .

Columns (1) and (2) in Table 2.5 presents the results for the subsample with low number of product market competitors, and Columns (3) and (4) presents the results for the subsample with high number of product market competitors. In Columns (1) and (2), we find that the coefficient on Peer Group Overlap is positive and both statistically and economically significant in Columns (1) and (2). In economic terms, these coefficients imply that in environments with a low number of product market competitors, RPE firms with peer group overlap at the 90 th percentile have $36 \%$ greater action volume and $19 \%$ greater action complexity than RPE firms with peer group overlap at the 10 th percentile. ${ }^{62,63} \mathrm{We}$ also find that the coefficient on Peer Group Overlap is positive and significant in Column (3), which implies an association between peer group overlap and action volume for firms operating in environments with a high number

62. We calculate the economic magnitudes as follows. For the volume dimension: $\exp ($ Peer Group Overlap

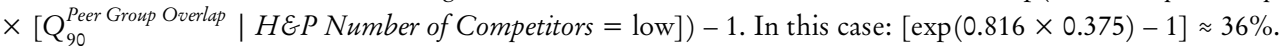
For the complexity dimension, we compare the magnitude to the (unconditional) mean value of Action Complexity for RPE firms with Peer Group Overlap at the 10th percentile operating in environments with a

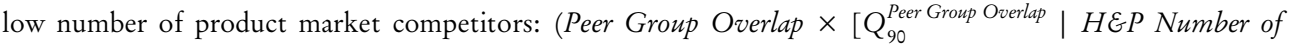
Competitors $=\mathrm{low}]) / \overline{\text { Action Complexity }}_{\text {Peer Group Overlap }=0 \& \text { \& H P Number of Competitors }=1 \text { low }}$ in this case: $(0.219 \times$ 0.375 ) / $0.434 \approx 19 \%$.

63. We also compare the economic magnitudes of peer group overlap to economic magnitudes of other significant control variables using a specification whereby we use the decile ranks of each independent variable to ensure all variables are of similar scale. In these comparisons, we find that the economic magnitude of moving from the bottom decile to the top decile of peer group overlap is of similar magnitude as moving from the bottom decile to the top decile of the firm's relative size-i.e., Market Value (Rank). 
of product market competitors. This finding may seem counterintuitive at first glance. However, additional analyses discussed in Section IV reconcile these findings; there we show that these actions are primarily related to acquisitions-actions that distort perfect competition.

Collectively, these findings are consistent with the sabotage hypothesis and indicate that peer group overlap in relative performance plans is positively associated with competitive aggressiveness. Our findings suggest that managers of such firms take more frequent as well as more complex competitive actions compared to managers not facing peer group overlap. ${ }^{64}$

\section{IV.C. Peer Group Overlap and Competitive Aggressiveness: Exogenous Variation}

In this section, we examine the association between peer group overlap and competitive aggressiveness using exogenous variation in peer group overlap. Specifically, we layer a staggered continuous difference-in-differences design on top of Equation (2.3.3) (e.g., Atanasov and Black, 2016, pp. 253-254). We do so to reduce concerns that our earlier findings are driven by firms' endogenous choices regarding managers' incentive-compensation contracts.

Our difference-in-differences design exploits the idea that if a firm is added to one of its peers' peer group, it receives an exogenous peer group overlap treatment in that year. Although this treatment requires that the focal firm heretofore endogenously chose that peer, the initiation of an overlapping peer relationship in this way is "conditionally exogenous" to the focal firm-it is plausible to assume that the focal firm cannot manipulate its peers' peer selection. Thus, the treatment effect is identified from variation in peers' incentive-compensation choices. As such, we eliminate at least half-and arguably more than half-of the endogenous variation associated with firms' own incentive-compensation practices. We acknowledge this test is not a panacea for resolving all issues of endogeneity, but it certainly narrows the set of plausible alternative explanations for our story.

Our treatment variable is staggered as well as continuous, because firms receive treatment at different points in time and we allow treatment to vary with the number of exogenous overlap additions in the year. To control for observable contextual differences in covariates between treated firms and control firms and mitigate concerns regarding non-parallel trends, we use an entropy balancing approach (e.g., Atanasov and Black, 2016, pp. 258-259) Specifically, we balance on the first and second moments of the distributions of all control variables of Equation (2.3.3). Figure 2.2 illustrates a love plot that visualizes the covariate balance between firms in the pre-period and firms in the post-period after entropy balancing the first and second moments of the distributions of groups are insignificant (i.e., all two-tailed $p$-values $>0.999$ ). In addition, Figure 2.3 plots

64. In untabulated analyses, we also examine the association between relative performance plans, peer group overlap and competitive aggressiveness, in a broader sample of firms using RPE and firms not using RPE. In these analyses, we continue to find that the association with competitive aggressiveness is concentrated in the subsample of firms using RPE with peer group overlap. These findings corroborate the notion that peer group overlap-and not plain-vanilla relative performance evaluation-is associated with competitive aggressiveness. 
Figure 2.2. Covariate balance

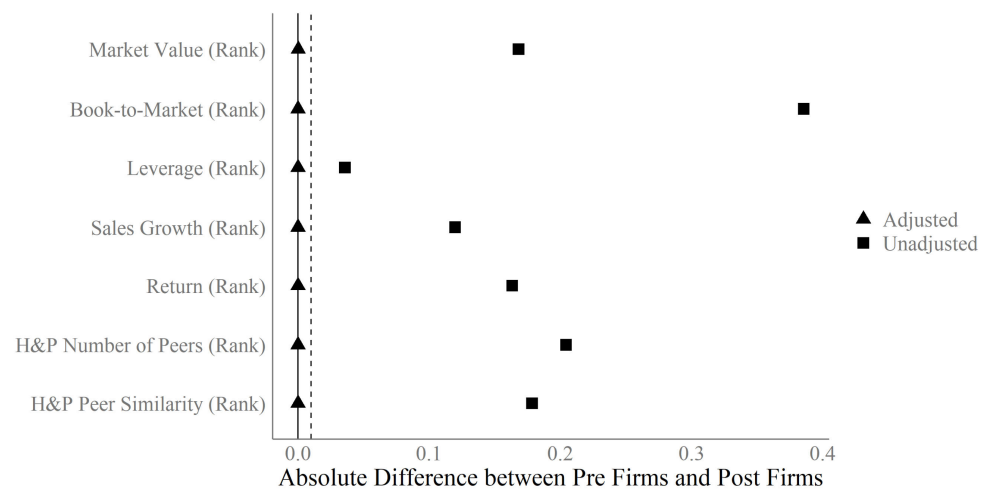

This figure illustrates love plots that visualize covariate balance between treated RPE firms in the pre-period and treated RPE firms in the post-period after entropy balancing the first and second moments of the distributions of all covariates in Equation (2.3.3). For parsimony, this figure does not visualize the covariate balance for the year and industry indicators.

Figure 2.3 New overlapping relationships

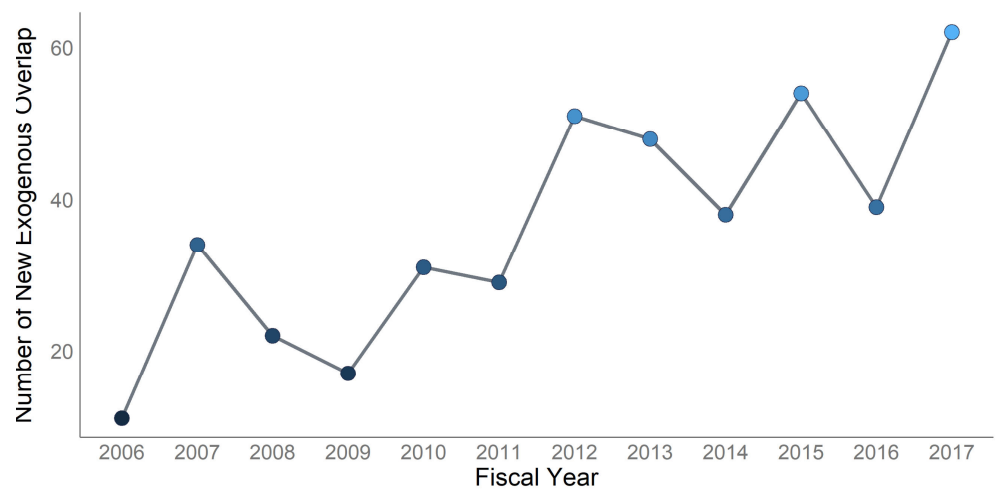

This figure plots the total new overlapping peer relationships that are exogenous for each fiscal year.

all covariates. This figure shows that, after balancing, all differences between the two the total new overlapping peer relationships that are exogenous for each fiscal year-i.e., the "treatment events." This figure shows a linear trend in the number of total new overlapping peer relationships across time.

Table 2.6 presents results of our difference-in-differences analysis. In this table, Post is an indicator variable equal to one for years after the first treatment, and New Exogenous Overlap is the number of overlapping peer relationships that were not overlapping peer relationships in the previous year, for which the overlap was initiated by the peer. Note that the main coefficient on New Exogenous Overlap is omitted, because it has a perfect correlation with its interaction with Post. The primary variable of interest is Post $\times$ New 
Table 2.6. Exogenous peer group overlap and competitive aggressiveness

\begin{tabular}{|c|c|c|c|c|c|c|c|c|}
\hline \multirow[b]{2}{*}{ Variable } & \multicolumn{4}{|c|}{$\begin{array}{c}(1) \\
\text { Low HEP Number of Competitors } \\
\text { Dependent variable: }\end{array}$} & \multicolumn{4}{|c|}{$\begin{array}{c}(3) \\
\text { High } H E P \text { Number of Competitors } \\
\text { Dependent variable: }\end{array}$} \\
\hline & \multicolumn{2}{|c|}{$\log ($ Action Volume $)$} & \multicolumn{2}{|c|}{ Action Complexity } & \multicolumn{2}{|c|}{$\log ($ Action Volume $)$} & \multicolumn{2}{|c|}{ Action Complexity } \\
\hline Post & 0.045 & $(0.141)$ & -0.046 & $(0.034)$ & -0.023 & $(0.133)$ & -0.026 & $(0.036)$ \\
\hline Post $\times$ New Exogenous Overlap & $0.112^{* *}$ & $(0.056)$ & $0.037^{*}$ & $(0.019)$ & -0.013 & $(0.048)$ & 0.005 & $(0.018)$ \\
\hline Market Value & $-0.739^{* * * \%}$ & $(0.270)$ & $-0.168^{*}$ & $(0.093)$ & 0.197 & $(0.274)$ & 0.009 & $(0.092)$ \\
\hline Book-to-Market & 0.453 & $(0.316)$ & 0.089 & $(0.072)$ & $1.494^{* \ldots:}$ & $(0.318)$ & 0.120 & $(0.084)$ \\
\hline Leverage & 0.149 & $(0.281)$ & $0.121^{* * *}$ & $(0.051)$ & 0.221 & $(0.284)$ & 0.107 & $(0.066)$ \\
\hline Sales Growth & 0.338 & $(0.220)$ & $0.155^{* *}$ & $(0.061)$ & 0.316 & $(0.223)$ & $0.105^{*}$ & $(0.063)$ \\
\hline Return & $-0.783^{* \ldots}$ & $(0.161)$ & -0.176 & $(0.057)$ & 0.015 & $(0.148)$ & -0.011 & $(0.047)$ \\
\hline$H E P N u m$ & -0.094 & $(0.161)$ & $-0.104^{3}$ & $(0.044)$ & -0.205 & $(0.146)$ & -0.046 & $(0.046)$ \\
\hline HEP Competitor Similari & -0.108 & $(0.254)$ & -0.075 & $(0.058)$ & -0.095 & $(0.260)$ & -0.053 & $(0.072)$ \\
\hline Year and in & \multicolumn{2}{|c|}{ Yes } & \multicolumn{2}{|c|}{ Yes } & \multicolumn{2}{|c|}{ Yes } & \multicolumn{2}{|l|}{ Yes } \\
\hline Obse & \multirow{2}{*}{\multicolumn{2}{|c|}{$\begin{array}{c}519 \\
54.474 \%\end{array}$}} & \multicolumn{2}{|c|}{519} & \multicolumn{2}{|c|}{545} & \multicolumn{2}{|l|}{545} \\
\hline Adjusted $R^{2}$ & & & \multicolumn{2}{|c|}{$20.069 \%$} & \multicolumn{2}{|c|}{$59.204 \%$} & \multicolumn{2}{|c|}{$29.392 \%$} \\
\hline
\end{tabular}

This table presents staggered continuous difference-in-differences results examining the association between exogenous peer group overlap and competitive aggressiveness, split by the number of product market competitors identified by Hoberg and Phillips $(2010,2016)$. The sample contains 1,064 observations for all RPE firms with self-selected peers in ISS Incentive Lab from 2006 to 2017 with non-missing values for all required variables that are at least once treated. The post subsample is entropy balanced to the pre subsample using all control variables, including year and industry indicators. Post is an indicator variable equal to one for years after the first treatment. New Exogenous Overlap is the number of overlapping peer relationships that were not overlapping peer relationships in the previous year, for which the overlap was initiated by the peer. The main coefficient on New Exogenous Overlap is omitted, because it has a perfect correlation with its interaction with Post. The industry indicators follow the 48 industry groups identified by Fama and French (1997). All control variables are measured as the firm's peer group-rank of that control variable-i.e., Variable (Rank). Standard errors are in parentheses and are adjusted for within cluster correlation by firm and time conform Gow et al. (2010). ", and ${ }^{m, * m}$ indicate significance at two-tailed probability levels of $10 \%$, $5 \%$, and $1 \%$, respectively. All variables are defined in the caption of Table 2.2 .

Exogenous Overlap, which measures the continuous effect of each additional exogenous addition in peer group overlap on competitive aggressiveness in the year in which the exogenous addition is initiated. ${ }^{65}$ In other words, Post $\times$ New Exogenous Overlap measures the average treatment effect on the treated-the impact of exogenous variation in peer group overlap on competitive aggressiveness.

In Columns (1) and (2) of Table 2.6, we find that the coefficient on Post $\times$ New Exogenous Overlap is positive and both statistically and economically significant. This finding implies that in the year a focal firm gets added to one of its peers' peer group, the focal firm-if operating in environments with a low number of product market competitors-increases competitive aggressiveness on both dimensions of aggressiveness. In economic terms, these coefficients imply that for each incremental exogenous addition to a peers' peer group, the focal firm increases action volume by $12 \%$ and action complexity by $10 \%$, relative to firms that are not added to their peers' peer group. The statistically insignificant coefficient on Post $\times$ New Exogenous Overlap in

65. Unlike Peer Group Overlap, New Exogenous Overlap is not scaled by the firm's peer group size. We do so to improve the economic interpretation of the estimated coefficient. In untabulated analyses, we confirm that the staggered continuous difference-in-differences results are robust to controlling for the firm's peer group size. 
Figure 2.4. Exogenous peer group overlap and competitive aggressiveness
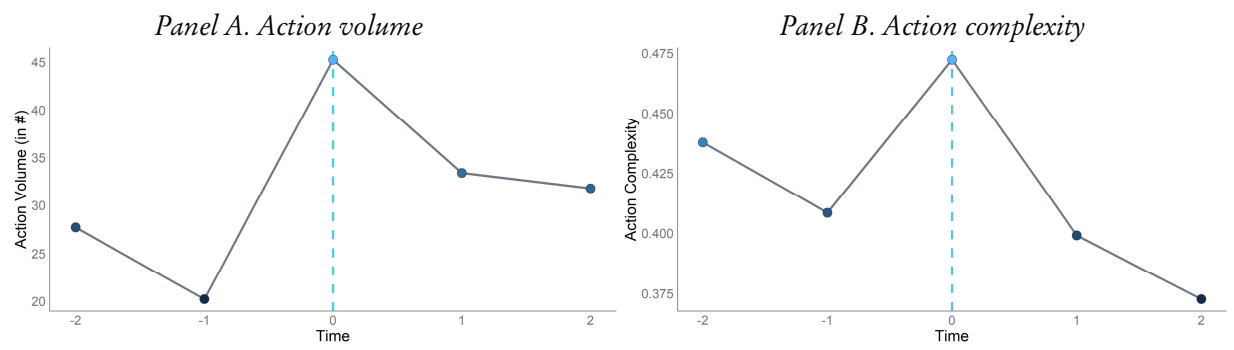

This figure illustrates levels of competitive aggressiveness around the time firms receive exogenous peer group overlap treatments in their incentive-compensation contracts. Panel A displays the volume dimension of aggressiveness. Panel B displays the complexity dimension of aggressiveness. In this figure, $t=0$ refers to the year in which managers receive exogenous peer group overlap treatments in their incentive-compensation contracts. Each data point represents the time-average level of competitive aggressiveness in the cross-section of firms that receive exogenous peer group overlap treatment.

Columns (3) and (4) of Table 2.6 suggests that exogenous additions for firms operating in environments with relatively more perfect competition are not associated with changes in competitive aggressiveness.

To shed more light on the dynamics of exogenous additions on competitive aggressiveness, we illustrate levels of competitive aggressiveness around the time firms receive exogenous peer group overlap treatments in their incentive-compensation contracts in Figure 2.4. Panel A displays the volume dimension of aggressiveness and shows that the effect on action volume is immediate and quite sustainable. Panel B displays the complexity dimension of aggressiveness and shows that the effect on action complexity is immediate but less sustainable. The combined pattern displayed in Figure 2.4 suggests: (i) that these first-year actions are one-time actions that deviate from the firm's typical repertoire of actions, and thus that: (ii) these actions are indeed "new" competitive actions toward peer firms.

Although the increase in overlap that we examine here is exogenous to the focal firm, it is possible that some firms are more likely to be subject to this exogenous treatment. Untabulated results show that, of all the firm characteristics that we control for in our analyses, only the firm's relative size is associated with being exogenously chosen into a new dual relationship (i.e., a New Exogenous Overlap relationship) - the larger the focal firm's size relative to its peers the more likely that firm is to receive an exogenous dual relationship. Therefore, we also examine whether relatively larger firms respond differently to exogenous dual relationships than do relatively smaller firms. We explore this question by including an interaction term between the treatment variable and Market Value (Rank). In untabulated analyses, we do not find a differential response to exogenous peer group overlap based on the focal firm's size relative to its peers. In other words, relatively small firms respond similarly to exogenous peer group overlap as do relatively large firms.

Collectively, the results of our staggered continuous difference-in-differences estimation strengthen our inferences in two ways. First, this test allows us to isolate the effect of exogenous variation in peer group overlap on competitive aggressiveness. The 
results provide evidence that managers consider peer group overlap in shaping their firm's repertoire of competitive actions. Second, these findings help to alleviate concerns that a correlated omitted variable is behind our main results-e.g., that our results are an artifact of firms' own incentive-compensation choices.

\section{IV.D. Robustness Tests}

In this section, we examine the robustness of our key finding-the peer group overlap-competitive aggressiveness association. In particular, we examine the robustness of this finding to: (i) using two alternative measures of competitive aggressiveness, (ii) using two alternative measures of competitive environment, controlling for a (iii) common time and (iv) common industry trend in competitive aggressiveness using Fama and MacBeth (1973) regressions and (v) controlling for manager's equity incentives. Below, we discuss the first robustness check as it-in addition to being a robustness check-also helps us to interpret the economic significance of the peer group overlapcompetitive aggressiveness association more clearly. In Appendix III, we discuss the remaining robustness checks, and show that our main findings are robust to all these alternative specifications.

Alternative Measures of Competitive Aggressiveness. This In our main analyses, we identify competitive actions through news events. The main advantage of using these competitive actions is that they allow us to capture a broad and comprehensive set of relevant and impactful firm actions. In this robustness check, we triangulate our analyses with more traditional accounting-based input and output measures of competitive behavior, using the firm's advertisement expenditures and operating margin. ${ }^{66}$ In terms of aggressiveness, greater advertisement expenditures and smaller operating margins imply greater competitive aggressiveness (e.g., Fombrun and Ginsberg, 1990, Vilcassim, Kadiyali, and Chintagunta, 1999).

We re-estimate Equation (2.3.3) and replace the dependent variable with the firm's advertisement expenditures, scaled by average total assets (Advertisement), and the firm's average revenue minus cost of goods sold and selling, general and administrative expenditures, scaled by average revenue (Operating Margin). We tabulate these results in Table 2.7.

In Columns (1) and (2), we find that the coefficient on Peer Group Overlap is both statistically and economically significant. These findings indicate that peer group overlap is positively associated with firms' annual advertisement expenditures, and negatively associated with firms' operating margins within the subsample with low number of product market competitors. In economic terms, these coefficients imply that in environments with a low number of product market competitors, RPE firms with peer group overlap at the 90 th percentile have $76 \%$ higher advertising expenditures and $17 \%$

66. We focus on these accounting-based measures as they represent competitive actions and are readily available for a large sample of firms. In contrast, price and quantity measures are not readily available for a large sample of firms. Moreover, price and quantity measures are difficult to interpret without knowing the nature of the strategic game between firms. 
Table 2.7. Peer group overlap and competitive aggressiveness—alternative measures for competitive aggressiveness

\begin{tabular}{|c|c|c|c|c|c|c|c|c|}
\hline \multirow{3}{*}{$\frac{\text { Variable }}{\text { Peer Group Overlap }}$} & \multicolumn{4}{|c|}{$\begin{array}{c}(1) \\
\text { Low HEP Number of Competitors } \\
\text { Dependent variable: }\end{array}$} & \multicolumn{4}{|c|}{$\begin{array}{c}(3) \\
\text { High } H \mathcal{E} P \text { Number of Competitors } \\
\text { Dependent variable: }\end{array}$} \\
\hline & \multicolumn{2}{|c|}{ Advertisement } & \multicolumn{2}{|c|}{ Operating Margin } & \multicolumn{2}{|c|}{ Advertisement } & \multicolumn{2}{|c|}{ Operating Margin } \\
\hline & $0.024^{* * 4}$ & $(0.009)$ & $-0.084^{3}$ & $(0.037)$ & 0.002 & $(0.004)$ & 0.028 & $(0.075)$ \\
\hline Peer Group Synchronicity & -0.009 & $(0.006)$ & 0.002 & $(0.047)$ & -0.005 & $(0.009)$ & -0.019 & $(0.052)$ \\
\hline Market Value & -0.004 & $(0.005)$ & -0.009 & $(0.034)$ & $0.013^{* *}$ & $(0.006)$ & -0.021 & $(0.073)$ \\
\hline Book-to-Market & -0.009 & $(0.006)$ & -0.047 & $(0.028)$ & 0.000 & $(0.005)$ & -0.002 & $(0.066)$ \\
\hline Leverage & 0.002 & $(0.004)$ & -0.017 & $(0.021)$ & -0.002 & $(0.005)$ & -0.033 & $(0.057)$ \\
\hline Sales Growth & -0.001 & $(0.003)$ & 0.010 & $(0.015)$ & -0.009 & $(0.005)$ & 0.011 & $(0.019)$ \\
\hline Return & -0.003 & $(0.003)$ & 0.018 & $(0.017)$ & 0.003 & $(0.003)$ & 0.033 & $(0.042)$ \\
\hline HEP Number of Competitors & -0.002 & $(0.004)$ & $0.070 *$ & $(0.026)$ & 0.003 & $(0.005)$ & $-0.147^{*}$ & $(0.078)$ \\
\hline HEP Competitor Similarity & $0.007^{* *}$ & $(0.003)$ & 0.012 & $(0.021)$ & -0.002 & $(0.004)$ & 0.080 & $(0.074)$ \\
\hline Year and industry effect & $\mathrm{Ye}$ & & $\mathrm{Ye}$ & & Yes & & Yes & \\
\hline Observations & 77 & & 77 & & 810 & & 810 & \\
\hline Adjusted $R^{2}$ & 57.61 & $3 \%$ & 37.39 & $1 \%$ & 34.71 & & 12.74 & $1 \%$ \\
\hline
\end{tabular}

This table presents results examining the robustness of the association between peer group overlap and competitive aggressiveness, split by the number of product market competitors identified by Hoberg and Phillips (2010, 2016) to using alternative proxies for competitive aggressiveness. Advertisement is the firm's advertisement expenditures, scaled by average total assets. Operating Margin is the firm's average revenue minus cost of goods sold and selling, general and administrative expenditures, scaled by average revenue. The sample contains 1,586 observations for all RPE firms with self-selected peers in ISS Incentive Lab from 2006 to 2017 with non-missing values for all required variables. The industry indicators follow the 48 industry groups identified by Fama and French (1997). All control variables are measured as the firm's peer group-rank of that control variable-i.e., Variable (Rank). Standard errors are in parentheses and are adjusted for within cluster correlation by firm and time conform Gow et al. (2010). ", ${ }^{* *}$ and ${ }^{* * *}$ indicate significance at twotailed probability levels of $10 \%, 5 \%$, and $1 \%$, respectively. All variables are defined in the caption of Table 2.2.

lower operating margins than RPE firms with peer group overlap at the 10 th percentile. ${ }^{67}$ These magnitudes reveal economically relevant differences in competitive behavior between firms with low and high peer group overlap. Moreover, these tests alleviate concerns that our findings are driven by specific measurement choices related to competitive aggressiveness, but rather apply to the theoretical construct more generally.

Additional Robustness Tests. Appendix III discusses and reports results of the remaining robustness checks. In these checks, we show that our main findings are robust to these specifications.

\section{IV.E. Oster Bounds: The Impact of Unobservables}

Our empirical strategy is designed to minimize the threat that a correlated omitted variable explains our results. For example, we base our inferences on a staggered

67. We calculate the economic magnitudes in the same way as the economic magnitudes for the complexity dimension of competitive aggressiveness. That is, we compare the magnitude to the (unconditional) mean value of Advertisement and Operating Margin for RPE firms with Peer Group Overlap at the 10th percentile operating in environments with a low number of product market competitors. In absolute terms, the $76 \%$ higher advertising expenditures and 17\% lower operating margins imply 1\% higher advertising expenditures (as a percentage of total assets) and 3\% lower operating margins, respectively. 
continuous difference-in-differences estimation and an extensive battery of robustness checks. Strictly speaking, we cannot completely rule out the possibility that an omitted correlated variable is behind our results. Nevertheless, we can formally assess the impact of unobservable factors on our main findings by applying the bounding technique put forward by Oster (2019), which builds on the intuition by Altonji, Elder, and Taber (2005).

This technique is a form of partial identification and can be used in two ways. ${ }^{68}$ First, it provides an estimate for the bounds on the coefficient of interest, based on estimated coefficients, $R^{2}$ values, and assumptions related to the omitted variable bias. Here we follow Altonji et al. (2005) and Oster (2019), consider $R_{\max }^{2}=\min \left(1.3 \widetilde{R}^{2}, 1\right)$ and $\delta=1$, which implies that we assume: (i) that our equations are misspecified by $30 \%$, and (ii) a situation in which unobservable factors have a similar effect on our results as do observable factors. We also consider $\delta=-1$, which implies a situation in which the impact of unobservable factors is of similar magnitude, but correlates in the opposite way as do observable factors. Second, this technique allows us to estimate how large the impact of unobservable factors relative to observable factors-i.e., $\delta$-needs to be to drive our coefficients of interest to zero.

We apply this technique to our key finding - the peer group overlap-competitive aggressiveness association in Table 2.5. In this regard, the Oster bounds indicate that if unobservable factors have a similar effect on the association between peer group overlap and competitive aggressiveness as do observables (i.e., $\delta=1$ ), the estimated coefficient on Peer Group Overlap on Action Volume for the subsample with low number of product market competitors in Column (1) of Table 2.5 increases by approximately $5 \%$-from 0.816 to $0.855 .{ }^{69}$ If we assume that unobservable factors have the opposite effect as do observable factors, this coefficient decreases to 0.777 . This implies that a reasonable range in which the "true" coefficient lies, is the interval $[0.777,0.855]$. A similar exercise with respect to Action Complexity reveals that such a reasonable interval is $[0.163,0.274]$. Most importantly, these bounds do not include zero. Thus, unobservable factors need to have a larger impact on the observed relationship between RPE and competitive aggressiveness than observable factors for the Peer Group Overlap coefficients to be zero. To be more precise, the Oster (2019) bounds indicate that the impact of unobservable

68. Partial identification techniques treat identification (of causal effects) as a continuum rather than a binary phenomenon. This framework-pioneered by Manski (1989, 1990, 1993, 2003) and Horowitz and Manski $(1995,1998,2000$ ) - took shape in the 1990s, and its use has since grown rapidly in fields such as economics, political science and sociology. These techniques ask how much we can learn from a regression of observed outcomes on observed conditioning variables under additional assumptions (e.g., in our case, assumptions related to the structure of unobservables). Instead of traditional point estimates, we then obtain a credible range of values in which the parameter of interest lies. The credibility of inference in this regard decreases with the strength of the assumptions maintained (e.g., Manski, 2003). Also see, for example, Armstrong (2013) for a brief discussion of partial identification in accounting.

69. The coefficient increases because if we estimate a univariate regression between $\log$ (Action Volume) and Peer Group Overlap, the coefficient on Peer Group Overlap is 0.689 (compared to 0.816 with controls). Hence, if unobservable factors are correlated in the same direction as observable factors, then the coefficient increases further. 
factors needs to be at least twenty (four) times the impact of observable factors to drive the coefficient on Peer Group Overlap to zero in the volume (complexity) specification. ${ }^{70}$

While we cannot completely rule out the possibility that a correlated omitted variable is behind our results, we argue-based on our main tests, robustness checks and the Oster (2019) bounds - that the likelihood that such a correlated omitted variable exists is negligible. Taking all tests together, for an omitted variable to explain our results, it would need to: (i) be correlated with all dimensions of competitive aggressiveness, (ii) differentially affect firms using RPE with peer group overlap and firms using RPE without peer group overlap, conditional on the firm's competitive environment, (iii) differentially affect firms using RPE with exogenous peer group overlap and firms using RPE with endogenous peer group overlap, conditional on the firm's competitive environment, (iv) be unexplained by common time and industry trends, and (v) impact the peer group overlap-competitive aggressiveness association more than all observable factors combined in our research design. We assess the likelihood of all these conditions being present as low and, therefore, conclude that it seems implausible that a correlated omitted variable is behind our results.

\section{Cross-Sectional Variation in the Overlap-Aggressiveness Association}

While the previous analyses show that there is, on average, a positive association between peer group overlap and competitive aggressiveness that is unlikely to be driven by a correlated omitted variable, we expect that this association varies in the crosssection. We specifically conjecture that the association varies with other characteristics of relative performance plans. In this section, we therefore examine whether and how the overlap-aggressiveness association is moderated by the following characteristics of relative performance plans: (i) the level of relative performance incentives, (ii) the performance criteria used in these plans, (iii) the size and dynamics of the peer group, and (iv) the type of peers chosen (see Section IV.A for details about the measurement of these variables). To test these moderations, we re-estimate Equation (2.3.3) and include an interaction term between Peer Group Overlap and each respective characteristic. We tabulate these results in Table 2.8. Below we discuss each cross-sectional test in turn.

\section{V.A. The Level of Incentives}

We examine whether the overlap-aggressiveness association varies with level of RPE incentives. In this regard, economic theory predicts that the incentive to act aggressively does not only depend on the level of incentives of the focal manager, but also depends on peer managers' incentives. That is, the more homogenous the RPE "tournament," the greater the competitive equilibrium (e.g., Lazear and Rosen, 1981). Intuitively, if managers indeed take competitive actions to target firms in the peer group, then we expect the association between peer group overlap and competitive aggressiveness to be stronger in settings where the tournament between firm-peer pairs is "relatively more homogenous" than in settings where the tournament is "relatively less homogenous."

70. Even if we increase the degree to which our equations are misspecified-e.g., by assuming that the theoretical maximum $R^{2}$ is twice that of our equations-the impact of unobservable factors still needs to be at least five times (one time) the impact of observable factors to drive the coefficient on Peer Group Overlap to zero in the volume (complexity) specification. 
Table 2.8. Peer group overlap and competitive aggressiveness-cross-sectional variation

Panel A. Incentive strength similarity

\begin{tabular}{|c|c|c|c|c|}
\hline \multirow[b]{3}{*}{ Variable } & \multirow{2}{*}{\multicolumn{2}{|c|}{$\begin{array}{c}\text { (1) } \\
\text { Low HEP Number of Competitors } \\
\text { Dependent variable: }\end{array}$}} & \multirow{2}{*}{\multicolumn{2}{|c|}{$\begin{array}{c}\text { High } H E P \text { Number of Competitors } \\
\text { Dependent variable: }\end{array}$}} \\
\hline & & & & \\
\hline & \multicolumn{2}{|c|}{$\log ($ Action Volume $) \quad$ Action Complexity } & \multicolumn{2}{|c|}{$\log ($ Action Volume $) \quad$ Action Complexity } \\
\hline Peer Group Overlap & $0.970^{* * 3 *} \quad(0.237)$ & $0.158^{* * 2}(0.070)$ & $0.676^{30}(0.224)$ & $-0.045(0.064)$ \\
\hline Grant Size Distance & $0.014^{*} \quad(0.006)$ & $-0.003 \quad(0.002)$ & $0.009 \quad(0.013)$ & $0.001(0.003)$ \\
\hline $\begin{array}{c}\text { Peer Group Overlap } \times \\
\text { Grant Size Distance }\end{array}$ & $-0.049^{* * *}(0.013)$ & $0.010^{* *}(0.005)$ & $-0.009 \quad(0.029)$ & $0.003(0.010)$ \\
\hline Controls & Yes & Yes & Yes & Yes \\
\hline Year and industry effects & Yes & Yes & Yes & Yes \\
\hline Observations & 795 & 795 & 828 & 828 \\
\hline Adjusted $R^{2}$ & $59.182 \%$ & $28.966 \%$ & $56.547 \%$ & $32.627 \%$ \\
\hline \multicolumn{5}{|c|}{ Panel B. Performance criteria similarity } \\
\hline \multirow[b]{3}{*}{ Variable } & $(1)$ & & \multicolumn{2}{|l|}{$(3)$} \\
\hline & \multicolumn{2}{|c|}{$\begin{array}{c}\text { Low HEP Number of Competitors } \\
\text { Dependent variable: }\end{array}$} & \multicolumn{2}{|c|}{$\begin{array}{c}\text { High } H E P \text { Number of Competitors } \\
\text { Dependent variable: }\end{array}$} \\
\hline & $\log ($ Action Volume $)$ & Action Complexity & $\log ($ Action Volume $)$ & Action Complexity \\
\hline Peer Group Overlap & $1.142^{*}(0.280)$ & $0.308^{2}(0.063)$ & $0.631^{* 3 *}(0.272)$ & $0.005(0.069)$ \\
\hline Criteria Distance & $0.213 \quad(0.135)$ & $0.016 \quad(0.039)$ & $-0.053 \quad(0.180)$ & $-0.019(0.040)$ \\
\hline $\begin{array}{l}\text { Peer Group Overlap } \times \\
\text { Criteria Distance }\end{array}$ & $-0.984^{* *} \quad(0.366)$ & $-0.184 \quad(0.112)$ & $-0.353 \quad(0.496)$ & $-0.016(0.089)$ \\
\hline Controls & Yes & Yes & Yes & Yes \\
\hline Year and industry effects & Yes & Yes & Yes & Yes \\
\hline Observations & 795 & 795 & 828 & 828 \\
\hline Adjusted $R^{2}$ & $53.946 \%$ & $25.212 \%$ & $54.956 \%$ & $25.290 \%$ \\
\hline & & C. Peer group size & & \\
\hline & (1) & (2) & (3) & (4) \\
\hline & $\begin{array}{r}\text { Low } H E P \text { Num } \\
\text { Depende }\end{array}$ & $\begin{array}{l}\text { r of Competitors } \\
\text { variable: }\end{array}$ & $\begin{array}{r}\text { High } H \mathcal{E P} \text { Numbe } \\
\text { Dependent }\end{array}$ & $\begin{array}{l}\text { r of Competitors } \\
\text { variable: }\end{array}$ \\
\hline Variable & $\log ($ Action Volume $)$ & Action Complexity & $\log ($ Action Volume $)$ & Action Complexity \\
\hline Peer Group Overlap & $0.147 \quad(0.441)$ & $0.129(0.094)$ & $0.371 \quad(0.470)$ & $-0.034(0.101)$ \\
\hline Peer Group Size & $-0.007 \quad(0.008)$ & $0.000(0.002)$ & $0.000 \quad(0.003)$ & $0.000(0.001)$ \\
\hline $\begin{array}{l}\text { Peer Group Overlap } \times \\
\text { Peer Group Size }\end{array}$ & $0.084^{*} \quad(0.043)$ & $0.008(0.008)$ & $0.037 \quad(0.055)$ & $-0.001 \quad(0.008)$ \\
\hline Controls & Yes & Yes & Yes & Yes \\
\hline Year and industry effects & Yes & Yes & Yes & Yes \\
\hline Observations & 795 & 795 & 828 & 828 \\
\hline Adjusted $R^{2}$ & $59.136 \%$ & $28.599 \%$ & $56.553 \%$ & $32.149 \%$ \\
\hline
\end{tabular}

Following this intuition, we examine whether the overlap-aggressiveness association is moderated by the similarity in the level of incentives across firms facing peer group overlap. We measure the similarity in the level of incentives using Grant Size Distance, with larger values corresponding to less similar incentive structures. Grant Size Distance is the Euclidean distance between Grant Size of the focal firm and each of its overlapping peers.

Panel A in Table 2.8 presents results from allowing the overlap-aggressiveness association to vary with the similarity in the level of incentives. We find that the actions managers take are moderated by the similarity with peer managers' incentives. These results show that more homogenous tournaments are associated with more homogeneity in the type of competitive actions-firms act highly competitive (i.e., higher action 
Table 2.8. Peer group overlap and competitive aggressiveness—cross-sectional variation (continued)

Panel D. Peers chosen from same product market

\begin{tabular}{|c|c|c|c|c|}
\hline \multirow[b]{2}{*}{ Variable } & \multicolumn{2}{|c|}{$\begin{array}{c}(1) \\
\text { Low } H E P \text { Number of Competitors } \\
\text { Dependent variable: }\end{array}$} & \multicolumn{2}{|c|}{$\begin{array}{c}\text { (3) } \\
\text { High HEP Number of Competitors } \\
\text { Dependent variable: }\end{array}$} \\
\hline & $\log ($ Action Volume $)$ & Action Complexity & $\log ($ Action Volume $)$ & Action Complexity \\
\hline Peer Group Overlap & $1.292^{*} \quad(0.422)$ & $0.221^{* 3 *}(0.091)$ & $1.425^{*} \quad(0.710)$ & -0.035 \\
\hline$\%$ Peers in HEP & $-0.146 \quad(0.213)$ & $-0.169^{*}(0.070)$ & $-1.039^{* * *}(0.252)$ & $-0.187^{* * *}(0.051)$ \\
\hline $\begin{array}{l}\text { Peer Group Overlap } \times \\
\% \text { Peers in HEP }\end{array}$ & $(0.789)$ & $(0.159)$ & -1.073 & $(0.300)$ \\
\hline Controls & Yes & Yes & Yes & Yes \\
\hline Year and industry effects & Yes & Yes & Yes & Yes \\
\hline Observations & 795 & 795 & 828 & 828 \\
\hline Adjusted $R^{2}$ & $53.871 \%$ & $26.172 \%$ & $60.644 \%$ & $28.106 \%$ \\
\hline
\end{tabular}

This table presents results examining cross-sectional variation in the association between peer group overlap and competitive aggressiveness, split by the number of product market competitors identified by Hoberg and Phillips $(2010,2016)$. Panel A presents results examining cross-sectional variation in the similarity of the strength of incentives. Panel B presents results examining crosssectional variation in the similarity of performance criteria. Panel $\mathrm{C}$ presents results examining cross-sectional variation in the size of the peer group. Panel D presents results examining crosssectional variation in the type of peers chosen. Grant Size Distance is the Euclidean distance between the "risk-neutral value" of the RPE plan, scaled by the manager's previous year's total compensation (i.e., Grant Size) of the focal firm and each of its overlapping peers. Criteria Distance is the Euclidean distance between the performance criteria of the RPE plan (i.e., RPE-price) of the focal firm and each of its overlapping peers. Peer Group Size is the total number of firms in the peer group. \%Peers in HEP is the overlap with product market competitors, identified by Hoberg and Phillips (2010, 2016), scaled by the peer group size. The industry indicators follow the 48 industry groups identified by Fama and French (1997). Standard errors are in parentheses and are adjusted for within cluster correlation by firm and time conform Gow et al. (2010). ", ${ }^{* *}$ and ${ }^{* * *}$ indicate significance at twotailed probability levels of $10 \%, 5 \%$, and $1 \%$, respectively. ${ }^{\dagger}$ indicates significance at two-tailed probability levels of $12 \%$, and is only reported for the main variables of interest. All variables are defined in the caption of Table 2.2.

volume), but focus on fewer dimensions (i.e., lower action complexity). Collectively, these findings indicate that homogeneity in RPE incentives across firms matters for competitive aggressiveness.

\section{V.B. The Performance Criteria}

We examine whether the overlap-aggressiveness association varies with performance criteria in relative performance plans. Descriptive statistics discussed in Section IV.A reveal variation in the measures used in relative performance plans. Although there is a predominance of price-based metrics, there is also a significant portion that is based on accounting numbers. Following the tournament homogeneity intuition from Section V.A, we examine whether a manager's incentive to act aggressively is moderated by the similarity in performance criteria across firms facing peer group overlap. We measure the similarity in performance criteria using Criteria Distance, with larger values corresponding to less similar performance criteria. Criteria Distance is the Euclidean distance between RPE-price of the focal firm and each of its overlapping peers. ${ }^{71}$

71. Strictly speaking, we empirically observe three categories of criteria: (i) only price-based measures, (ii) only accounting-based measures, and (iii) both price-based and accounting-based measures. Given the 
Panel B in Table 2.8 presents results from allowing the overlap-aggressiveness association to vary with performance criteria similarity. We find that the actions managers take are indeed moderated by the similarity with peer managers' performance criteria. Consistent with the findings in Panel A in Table 2.8, we find that more homogenous tournaments are associated with more competitive aggressiveness. Collectively, these findings corroborate the notion that homogeneity in RPE plans across firms matters for competitive aggressiveness.

\section{V.C. The Size of the Peer Group}

We examine whether the overlap-aggressiveness association varies with the size of the peer group, as it might requires more aggressiveness to outperform a larger group of peers than a smaller group of peers. We measure the size of peer group using Peer Group Size.

Panel C in Table 2.8 presents results from allowing the overlap-aggressiveness association to vary with peer group size. We find that managers' action volume is increasing in the size of the peer group while leaving the complexity unaffected. This finding implies that the number of peers in the peer group matter for competitive aggressiveness associated with peer group overlap.

\section{V.D. The Type of Peers Chosen}

We examine whether the overlap-aggressiveness association varies with the composition of the peer group. Specifically, we examine whether peers from the same versus different product markets give managers a differential incentive to act aggressively. On the one hand, it could be that managers act particularly aggressive towards peers operating in their own product market. On the other hand, it could be that relative performance plans provide managers with an incentive to act aggressively towards peers irrespective of industry membership. We measure peers operating in a firm's own product market using \%Peers in HEP.

Panel D in Table 2.8 presents results from allowing the overlap-aggressiveness association to vary with peers operating in a firm's own product market. We do not find a statistically significant interaction between Peer Group Overlap and \%Peers in HEP. These insignificant findings suggest that managers with peer group overlap act aggressively independent of how many peers operate within their direct product market.

\section{Additional Analysis: Competitive Action Types}

In this section, we examine the association between peer group overlap and the types of competitive actions. To do so, we split our aggregated volume measure into underlying action types and provide insights into which competitive actions managers take.

predominance of price-based measures and the last category being relatively small, we use RPE-price, which captures (i) and (ii), to measure Criteria Distance. The relevance of using RPE-price is also revealed in an untabulated analysis in which we allow the overlap-aggressiveness association to vary with $R P E$-price. Here we find that managers indeed take more actions under price-based RPE, compared to only accounting-based RPE, but with similar complexity. To the extent that price-based metrics reflect valuation implications of competitive actions more quickly than do accounting-based metrics, this finding suggests that the faster actions are reflected in performance, the more managers are inclined to act aggressively in the presence of peer group overlap. 
Specifically, we re-estimate Equation (2.3.3) and replace the dependent variable with the action volume within each of the following types: (i) new product actions (New Products), (ii) pricing actions (Pricing), (iii) marketing actions (Marketing), (iv) acquisitions (Acquisitions), (v) equity joint ventures (Joint Ventures), (vi) strategic alliances (Strategic Alliances), and (vii) market expansion (Market Expansion). We tabulate these results in Table 2.9.

Panel A in Table 2.9 presents results for the subsample with low number of product market competitors. These results show that the association between peer group overlap and competitive aggressiveness is primarily driven by actions related to the release of new products, acquisitions, joint ventures, and strategic alliances. The significant association between peer group overlap and the release of new products is consistent with the association between peer group overlap and advertisement expenditures documented in Table 2.7. Panel B in Table 2.9 presents results for the subsample with high number of product market competitors. Here we also find an association between peer group overlap and acquisitions.

Collectively, these findings provide more insights into which competitive actions firms take. We interpret these findings as follows. In settings with relatively less perfect competition, any action could in principle have an impact on performance. Consistent with this notion, we find that firms' competitive action repertoire consists of an extensive set of actions. In contrast, in settings with relatively more perfect competition, only competitive actions that distort perfect competition-such as acquisitions-likely have an impact on performance. Consistent with this notion, we find that firms with peer group overlap primarily rely on this type of actions.

\section{Conclusion}

This study examines the relation between incentive plans based on relative performance and competitive aggressiveness. Theoretically, relative performance evaluation puts agents into direct competition with each other, which can either increase or decrease competitive aggressiveness. On the one hand, direct competition can give managers an incentive to act aggressively towards peers, because managers can gain an advantage over competitors and improve their firm's relative position by engaging in competitive actions. We label this prediction the "sabotage hypothesis." On the other hand, because being aggressive can be costly to the firm, direct competition can give managers an incentive to collude so to commit to abstain from being competitively aggressive. We label this prediction the "collusion hypothesis."

We empirically examine the relation between direct competition, which we label peer group overlap, and competitive aggressiveness using a large sample of U.S. firms over the period 2006 through 2017 and using a variety of tests that exploit various forms of variation in peer group overlap. Across all specifications, we present evidence consistent with the sabotage hypothesis. That is, we find a positive association between peer group overlap and competitive aggressiveness. This evidence is robust to a battery of tests designed to mitigate concerns that correlated omitted variables explain our results.

Collectively, our study contributes to both practice and academia. For example, our study provides investors, regulators and practitioners with insights into how contemporaneous incentive-compensation contracts impact firm decisions. The finding that peer group overlap is positively associated with competitive aggressiveness provides 
Table 2.9. Peer group overlap and competitive action types

Panel A. Low HEP Number of Competitors

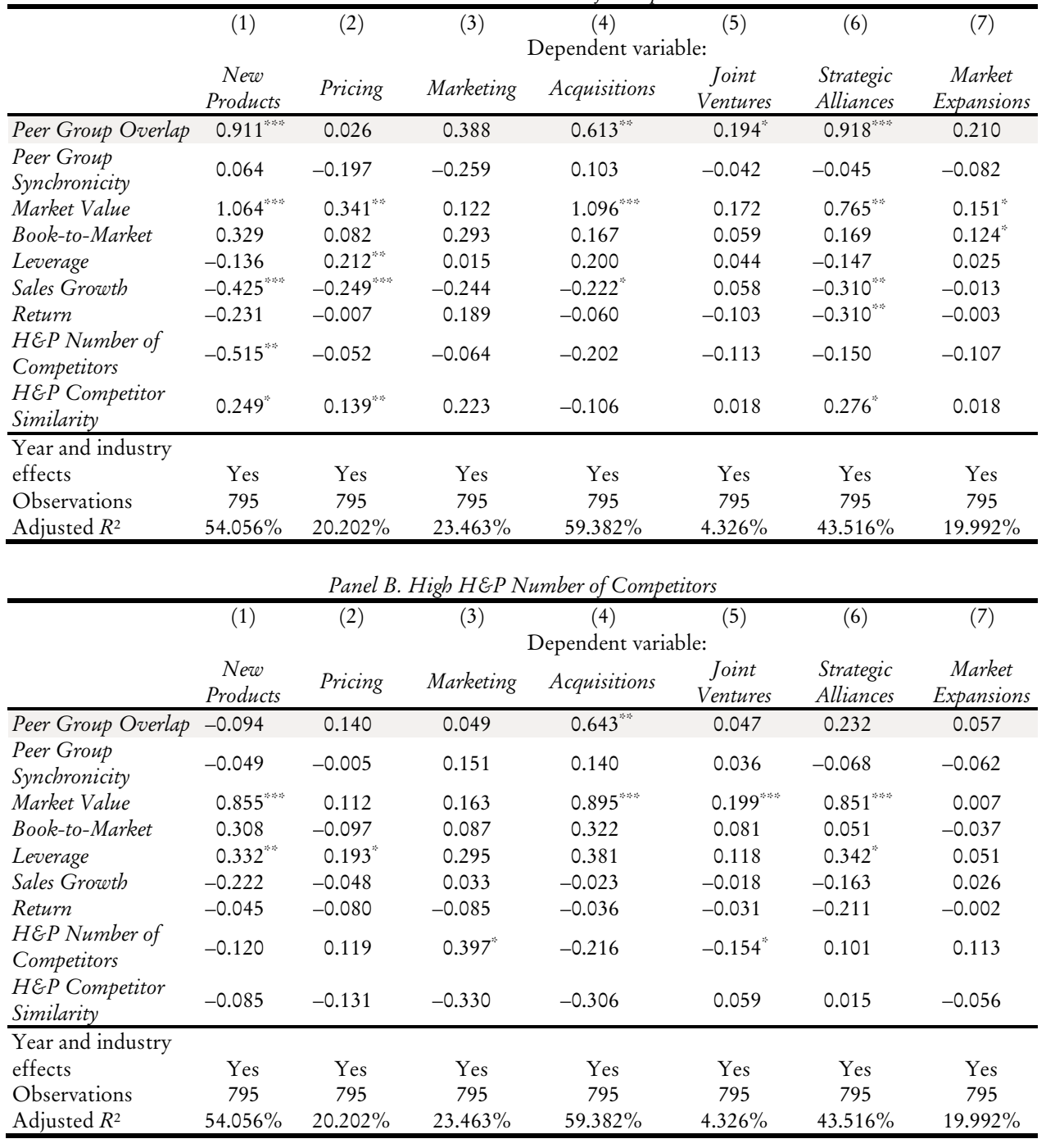

This table presents results examining the association between peer group overlap and the types of competitive actions, split by the number of product market competitors identified by Hoberg and Phillips $(2010,2016)$. The sample contains 1,623 observations for all RPE firms with self-selected peers in ISS Incentive Lab from 2006 to 2017 with non-missing values for all required variables. All dependent variables are measured in natural logarithms. The industry indicators follow the 48 industry groups identified by Fama and French (1997). All control variables are measured as the firm's peer group-rank of that control variable-i.e., Variable (Rank). Standard errors (omitted for brevity) are adjusted for within cluster correlation by firm and time conform Gow et al. (2010). ", and indicate significance at two-tailed probability levels of $10 \%, 5 \%$, and $1 \%$, respectively. All variables are defined in the caption of Table 2.2.

investors, regulators and practitioners with additional dimensions to consider in assessing whether incentive-compensation contracts expose firms to material risks. 
Moreover, to the extent that peer group overlap is not directly observed from one firm's proxy statement-as this requires a set of proxy statements-one important takeaway from our study is that solely relying on information in one firm's proxy statement may yield an incomplete picture of the incentive properties of executive incentivecompensation contracts. With respect to academia, we draw from-and, in doing so, help bridge-related literatures. For example, we bring measurement techniques from strategic management to the accounting literature so to clearly answer our research question. These measurement approaches have a long-standing history in that field and are easily implemented for a large sample of firms. Our hope is that this approach sparks much future research in accounting.

\section{Appendix I: Discussion of Competitive Aggressiveness Measures}

This appendix discusses in more detail our measures of competitive aggressiveness. In particular, this appendix discusses: (i) the construction these measures and (ii) the interpretation of these measures as well as each underlying dimension.

\section{A.I.A. Construction}

Following an extensive prior literature in strategic management, we measure competitive aggressiveness using the firm's competitive actions (e.g., Ferrier, 2001, Ferrier and Lyon, 2004, Ferrier et al., 1999, Rindova et al., 2010). To identify these competitive actions, we use structured content analysis of news events identified by RavenPack. A key advantage of using these news events is that they allow us to capture relevant and impactful firm decisions. Such actions are typically difficult to quantify when strictly relying on accounting-based measures.

RavenPack develops proprietary algorithms that identify events in the unstructured text published by reputable content sources, such as the Dow Jones Newswires, the Wall Street Journal and over 19,000 other traditional and social media sites. The database records an entry any time one of these sources reports on a company. RavenPack covers over 36,000 companies (e.g., Connelly et al., 2017). The database identifies the first mention of any given competitive action in order to eliminate duplication (e.g., Drake, Guest, and Twedt, 2014).

The first step in constructing the measures of competitive aggressiveness is to download the news events from RavenPack. For each news event, RavenPack identifies a "type"-i.e., a class of events that share similar characteristics. For our study, we follow prior literature and examine seven major "types" of competitive actions (e.g., Connelly et al., 2019, Connelly et al., 2017). These types include: (i) new product actions, (ii) pricing actions, (iii) marketing actions, (iv) acquisitions, (v) equity joint ventures, (vi) strategic alliances, and (vii) market expansion. In total, the size of the raw data for the period 2006 to 2018 is 4.31 GB. Table 2.1 in the main body presents example events for each action type.

The second step in constructing the measures of competitive aggressiveness is to structure the news events data. To precisely categorize each news event, RavenPack assigns "relevance" and "novelty" scores to each news event. The relevance score indicates the relevance of the focal firm in the event, where greater values imply more relevant events. The novelty score indicates the novelty of a news event and helps to distinguish duplicate events, where greater values imply more unique events. Both scores 
are measured on a scale from 0 to 100 . Consistent with prior literature, we filter events based on the relevance and novelty scores assigned by RavenPack (e.g., Connelly et al., 2019, Connelly et al., 2017). In particular, we limit our analyses to events for which the relevance score is 100 (i.e., the maximum) and the novelty score is 100 (i.e., the maximum). This constraint ensures that we: (i) assign news events to the correct firm, and (ii) do not double-count events.

The third step in constructing the measures of competitive aggressiveness is to link each news event to a firm in our sample. The firm identifier in RavenPack is the International Securities Identification Number (ISIN) code. We use Compustat's Capital IQ database to transform ISIN codes to Compustat's GVKEY codes. After linking all news events to GVKEY codes, we link the news events to our sample (using the GVKEY code). Using the above relevance and novelty constraints, the firms in our full ISS Incentive Lab sample (i.e., firms using RPE and firms not using RPE) engage in a total of 264,597 competitive actions from 2006 to 2017. In the sample of firms using RPE, this statistic equals 53,732 competitive actions.

The final step in constructing the measures of competitive aggressiveness is to transform the individual news events into empirical measures. Following an extensive and long-standing prior literature in strategic management (e.g., Ferrier, 2001, Ferrier and Lyon, 2004, Ferrier et al., 1999), we construct two empirical measures of competitive aggressiveness: "action volume" and "action complexity."

The volume dimension captures the number of actions a firm takes in one year. In terms of aggressiveness, the more actions a firm takes, the greater its competitive aggressiveness. However, not all actions are identical; distinct actions can be classified into different action types (e.g., launching a new marketing campaign is a fundamentally different action than performing an acquisition). And to the extent that taking actions from various types can be more harmful for competitors than merely focusing on one action type, another commonly used measure of competitive aggressiveness is complexity. The complexity dimension captures the breadth of a firm's repertoire of competitive actions across different action types. In terms of aggressiveness, the greater a firm's action complexity, the greater its competitive aggressiveness.

To measure the volume dimension of competitive aggressiveness, we count the number of actions for each firm-year. To measure the complexity dimension of competitive aggressiveness, we exploit variation in the different "types" of action typesi.e., (i) new product actions, (ii) pricing actions, (iii) marketing actions, (iv) acquisitions, (v) equity joint ventures, (vi) strategic alliances, and (vii) market expansion. In particular, we relate the actions in the different types to the overall number of actions. Formally, both measures are defined as follows:

$$
\begin{aligned}
& \text { Action Volume }=\sum_{i=1}^{7} a_{i j}=V_{j} \\
& \text { Action Complexity }=1-\sum_{i=1}^{7}\left(a_{i j} / V_{j}\right)^{2}
\end{aligned}
$$

where $a_{i j}$ is the number of firm $j$ 's actions in the $i$ th action type and $V_{j}$ is the total number of actions carried out by firm $j$ in a given year (i.e., Action Volume). 


\section{A.I.B. Interpretation}

To improve the interpretation of our measures, we first report extensive descriptive statistics for all measures. Table 2.A.I.A presents descriptive statistics for the competitive aggressiveness measures.

Panel A in Table 2.A.I.A presents mean statistics across time. This panel shows that there exists a significant time trend in firms' competitive aggressiveness. For example, the average firm takes 15 actions in 2006, whereas nowadays the average firm takes over 74 actions per year. Furthermore, this panel shows that this increase in the number of actions goes hand in hand with a decrease in the complexity of actions. In other words, nowadays firms take relatively more similar actions than in 2006.

Panel B in Table 2.A.I.A presents mean statistics across industries. This panel shows that there also exist significant industry effects in firms' competitive aggressiveness. For example, firms operating in more technology-heavy industries (e.g., "Business Equipment," and "Telephone and Television Transmission") are much more aggressive than firms operating in non-technology industries (e.g., "Manufacturing," and "Oil, Gas, and Coal Extraction"). And even though firms operating in more technology-heavy industries take more actions, these firms also take more complex actions than their counterparts in non-technology industries (e.g., more new products, more strategic alliances, and more market expansions).

We next report correlation coefficients between all measures. Table 2.A.I.B presents Pearson's (above diagonal) and Spearman's (below diagonal) correlation coefficients between the competitive aggressiveness measures. This table shows that the correlation between Action Volume and Action Complexity is positive (e.g., Pearson's correlation coefficient is 0.170 ). This suggests that, in the cross-section, firms that take more actions also take more complex actions. Furthermore, the strong correlation coefficients between Action Volume and, for example, New Products, Acquisitions and Strategic Alliances, suggest that those firms that take many actions do so via these dimensions. This is consistent with the pattern that we observed in Table 2.A.I.A for firms operating in more technology-heavy industries. We also observe some noteworthy-and intuitive-correlation coefficients between the underlying action dimensions. For example, the strong correlation between New Products and Pricing suggests that new products go hand in hand with pricing strategies. Another intuitive correlation is between New Products and Strategic Alliances, which suggests that new products stem from strategic alliances. 
Table 2.A.I.A. Descriptive statistics on competitive aggressiveness measures

Panel A. Year distribution

\begin{tabular}{ccccccccccc}
\hline & $\begin{array}{c}\text { Action } \\
\text { Year }\end{array}$ & $\begin{array}{c}\text { Volume } \\
\text { Complexity }\end{array}$ & $\begin{array}{c}\text { Products } \\
\text { Cricing Marketing }\end{array}$ & Acquisitions & \multicolumn{3}{c}{$\begin{array}{c}\text { Joint } \\
\text { Ventures }\end{array}$} & $\begin{array}{c}\text { Strategic } \\
\text { Alliances }\end{array}$ & $\begin{array}{c}\text { Market } \\
\text { Expansions }\end{array}$ \\
\hline 2006 & 14.800 & 0.411 & 6.070 & 0.194 & 2.220 & 3.940 & 0.167 & 2.210 & 0.014 \\
2007 & 23.600 & 0.469 & 10.100 & 0.495 & 2.390 & 6.580 & 0.369 & 3.590 & 0.058 \\
2008 & 23.300 & 0.442 & 10.300 & 0.541 & 3.170 & 5.700 & 0.387 & 3.130 & 0.090 \\
2009 & 21.200 & 0.433 & 9.230 & 0.830 & 3.420 & 4.440 & 0.348 & 2.830 & 0.098 \\
2010 & 25.600 & 0.466 & 10.600 & 0.575 & 4.140 & 6.470 & 0.333 & 3.390 & 0.117 \\
2011 & 26.200 & 0.503 & 10.100 & 0.906 & 3.120 & 7.680 & 0.471 & 3.820 & 0.065 \\
2012 & 26.800 & 0.492 & 11.200 & 0.500 & 3.410 & 6.830 & 0.507 & 4.240 & 0.127 \\
2013 & 26.500 & 0.498 & 11.000 & 0.394 & 3.810 & 6.490 & 0.256 & 4.380 & 0.156 \\
2014 & 28.900 & 0.460 & 12.200 & 0.321 & 3.270 & 7.460 & 0.259 & 5.220 & 0.080 \\
2015 & 31.100 & 0.482 & 12.700 & 0.366 & 3.320 & 8.130 & 0.323 & 5.990 & 0.256 \\
2016 & 48.800 & 0.363 & 5.920 & 0.282 & 4.830 & 33.400 & 0.250 & 3.920 & 0.218 \\
2017 & 74.000 & 0.265 & 4.890 & 0.286 & 5.220 & 58.500 & 0.303 & 4.430 & 0.377 \\
\hline
\end{tabular}

Panel B. Industry distribution

\begin{tabular}{|c|c|c|c|c|c|c|c|c|c|}
\hline Industry & $\begin{array}{l}\text { Action } \\
\text { Volume }\end{array}$ & $\begin{array}{c}\text { Action } \\
\text { Complexity }\end{array}$ & $\begin{array}{c}\text { Neww } \\
\text { Products }\end{array}$ & Pricing & Marketing & Acquis & $\begin{array}{c}\text { Joint } \\
\text { Ventures }\end{array}$ & $\begin{array}{l}\text { Strategic } \\
\text { Alliances }\end{array}$ & $\begin{array}{c}\text { Market } \\
\text { Expansions }\end{array}$ \\
\hline (1) & 27.600 & 0.467 & 4.890 & 0.450 & 2.600 & 15.800 & 0.212 & 3.460 & 0.199 \\
\hline (2) & 37.200 & 0.427 & 13.000 & 0.578 & 3.340 & 14.900 & 0.297 & 4.660 & 0.469 \\
\hline (3) & 19.300 & 0.426 & 4.770 & 0.189 & 2.640 & 9.740 & 0.343 & 1.550 & 0.060 \\
\hline (4) & 19.100 & 0.367 & 1.220 & 0.197 & 3.570 & 12.700 & 0.442 & 0.933 & 0.016 \\
\hline (5) & 24.000 & 0.421 & 2.450 & 1.530 & 2.560 & 15.400 & 0.360 & 1.690 & 0.027 \\
\hline (6) & 50.300 & 0.504 & 24.000 & 0.295 & 3.650 & 13.900 & 0.176 & 8.100 & 0.214 \\
\hline (7) & 157.000 & 0.518 & 69.700 & 4.820 & 10.300 & 48.700 & 0.675 & 22.000 & 0.850 \\
\hline (8) & NA & NA & NA & NA & NA & NA & NA & NA & NA \\
\hline (9) & 21.500 & 0.452 & 4.770 & 0.204 & 3.100 & 9.300 & 0.044 & 3.880 & 0.204 \\
\hline (10) & 50.000 & 0.554 & 7.570 & 0.330 & 7.800 & 24.700 & 0.311 & 9.170 & 0.126 \\
\hline (11) & NA & NA & NA & NA & NA & NA & NA & NA & NA \\
\hline (12) & 38.000 & 0.423 & 12.900 & 0.437 & 3.370 & 16.200 & 0.463 & 4.380 & 0.221 \\
\hline
\end{tabular}

This table presents descriptive statistics for the competitive aggressiveness measures. Panel A presents mean statistics across time. Panel B presents mean statistics across industries. The sample contains 1,623 observations for all RPE firms with self-selected peers in ISS Incentive Lab from 2006 to 2017 with non-missing values for all required variables. We exclude financial service firms and utilities. The industry classification follows the 12 industry groups identified by Fama and French (1997): (1) Consumer Non-Durables; (2) Consumer Durables; (3) Manufacturing; (4) Oil, Gas, and Coal Extraction; (5) Chemicals and Allied Products; (6) Business Equipment; (7) Telephone and Television Transmission; (8) Utilities; (9) Wholesale and Retail; (10) Healthcare and Medical Equipment; (11) Finance; and (12) Other. Action Volume is the total number of competitive actions. Action Complexity is the variation in competitive actions across seven types of competitive actions. New Products is the total number of competitive actions in the new product actions type. Pricing is the total number of competitive actions in the pricing actions type. Marketing is the total number of competitive actions in the marketing actions type. Acquisitions is the total number of competitive actions in the acquisitions actions type. Joint Ventures is the total number of competitive actions in the equity joint ventures actions type. Strategic Alliances is the total number of competitive actions in the strategic alliances actions type. Market Expansions is the total number of competitive actions in the market expansion actions type. 
Table 2.A.I.B. Correlations between competitive aggressiveness measures

\begin{tabular}{|c|c|c|c|c|c|c|c|c|c|c|}
\hline & & A & B & C & D & $\bar{E}$ & F & $\bar{G}$ & $\mathrm{H}$ & I \\
\hline Action Volume & A & & 0.170 & 0.793 & 0.524 & 0.496 & 0.751 & 0.266 & 0.816 & 0.470 \\
\hline Action Complexity & B & 0.261 & & 0.249 & 0.181 & 0.259 & -0.089 & 54 & 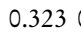 & 0.155 \\
\hline New Products & $\mathrm{C}$ & 0.582 & 0.545 & & 0.549 & 0.321 & 0.225 & 0.225 & 0.776 & 0.416 \\
\hline Pricing & $\mathrm{D}$ & 0.308 & 0.269 & 0.270 & & 0.253 & 0.202 & 0.213 & 0.468 & 0.306 \\
\hline Marketing & $\mathrm{E}$ & 0.473 & 0.303 & 0.183 & 0.120 & & 0.327 & 0.083 & 0.34 & 0.203 \\
\hline$A c$ & $\mathrm{~F}$ & 0.78 & 0.088 & 0.191 & 0.218 & 0.232 & & 0.137 & 0.381 & 0.275 \\
\hline Joint Ventures & G & 0.227 & 0.325 & 0.193 & 0.201 & 0.047 & 0.181 & & 0.262 & 0.187 \\
\hline Strategic Alliances & $\mathrm{H}$ & 0.628 & 0.548 & 0.675 & 0.299 & 0.232 & 0.310 & 0.236 & & 0.431 \\
\hline Market Expansions & I & 0.33 & 0.162 & 0.289 & 0.232 & 0.162 & 0.250 & 0.125 & 0.305 & \\
\hline
\end{tabular}

This table presents Pearson's (above diagonal) and Spearman's (below diagonal) correlation coefficients between the competitive aggressiveness measures. The sample contains 1,623 observations for all RPE firms with self-selected peers in ISS Incentive Lab from 2006 to 2017 with non-missing values for all required variables. We exclude financial service firms and utilities. All correlation coefficients are significant at the $1 \%$. All variables are defined in the caption of Table 2.A.I.A.

\section{Appendix II: Example Relative Performance Plan}

The following text is an excerpt from the DEF 14a filing of United Parcel Service Inc. (2019, pp. 36-38), where the firm describes its relative performance plan.

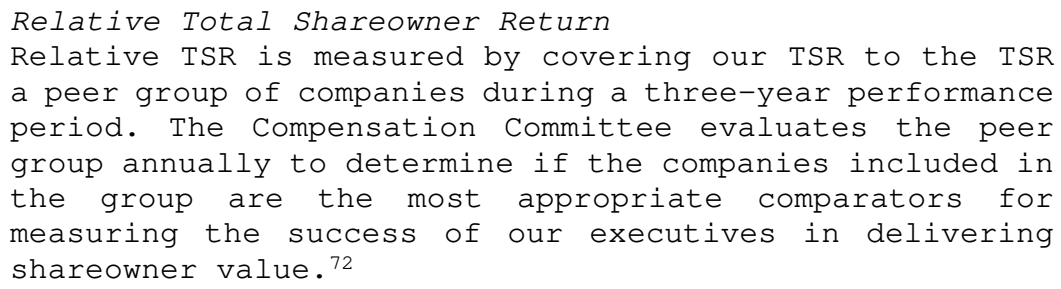

$\begin{array}{cc}\begin{array}{c}\text { Three-Year TSR Compared to } \\ \text { Peer Group }\end{array} & \begin{array}{c}\text { Percentage of Target Earned for } \\ \text { TSR Portion of LTIP Award) }\end{array} \\ \text { Greater than 75th Percentile } & 200 \% \\ \text { Median } & 100 \% \\ \text { 25th Percentile } & 50 \% \\ \text { Less than 25th Percentile } & 0 \%\end{array}$

72. The peer group considered by the Compensation Committee for 2018 compensation purposes (the "2018 Peer Group") is unchanged from the peer group used for 2017 compensation, and consisted of the companies below:

The Boeing Company

Caterpillar Inc.

The Coca-Cola Company

Costco Wholesale Corporation

FedEx Corporation

The Home Depot, Inc.

Johnson \& Johnson

The Kroger Co.

Lockheed Martin Corporation

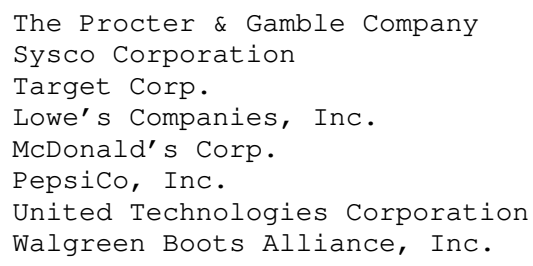


The maximum payout for the TSR portion of the award is capped at $200 \%$ of target. If our TSR over the three-year measurement period is negative, even if it exceeds the median of the peer group, the maximum payout percentage for the TSR portion of LTIP awards is capped at $100 \%$ of target.

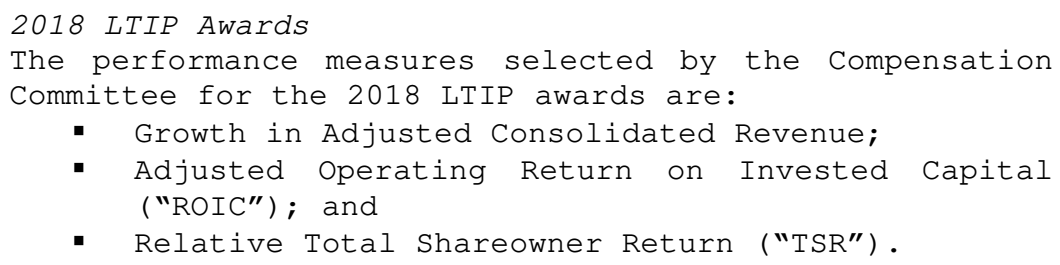

Each goal is measured independently and applied equally in determining final payouts.

The Compensation Committee approved the following target values as a percent of base salary for the 2018 LTIP awards:

\begin{tabular}{ccc} 
Executive officers & $\begin{array}{c}\text { LTIP Target } \\
\text { (\%) }\end{array}$ & Base Salary) \\
\hline Chief Executive Officer & 700 & $1,234,992$ \\
Chief Operating Officer & 575 & 693,676 \\
Chief Financial Officer & 450 & 552,654 \\
Chief Strategy Officer & 450 & 613,500 \\
Other executive officers & 350 &
\end{tabular}

Target values are based on internal pay comparison considerations and market data regarding total compensation of comparable positions at similarly sized companies. Differences in the target award values are based on increasing levels of responsibility among the executive officers.

\section{Appendix III: Robustness Tests}

This appendix elaborates on and reports results for the robustness tests briefly described in the paper in Section IV.D.

\section{A.III.A. Alternative Measures of Competitive Environment}

We assess the robustness of our main results to using alternative measures of competitive environment: (i) the sales Herfindahl-Hirschman Index, and (ii) the maximum similarity score as identified by Hoberg and Phillips (2010, 2016). We do so to mitigate concerns with respect to our empirical proxy for the firm's competitive environment. We partition our sample into observations with relatively low and high values of these characteristics, and re-estimate Equation (2.3.3) separately for each subsample.

Panels $\mathrm{A}$ and $\mathrm{B}$ in Table 2.A.III presents these results, respectively. Across all specifications, we continue to find results in line with our main results. Specifically, we find that in environments with relatively more imperfect competition (i.e., high 
Table 2.A.III. Peer group overlap and competitive aggressiveness—robustness checks

Panel A. Alternative measure for competitive environment-Herfindabl-Hirschman index

\begin{tabular}{|c|c|c|c|c|}
\hline \multirow[b]{2}{*}{ Variable } & \multicolumn{2}{|c|}{$\begin{array}{l}\text { (1) } \\
\text { High Herfindabl-Hirschman Index } \\
\text { Dependent variable: }\end{array}$} & \multicolumn{2}{|c|}{$\begin{array}{l}(3) \\
\text { Low Herfindabl-Hirschman Index } \\
\text { Dependent variable: }\end{array}$} \\
\hline & $\log ($ Action Volume $)$ & Action Complexity & $\log ($ Action Volume $)$ & Action Complexity \\
\hline Peer Group Overlap & $0.855^{* * *}$ & $0.130^{* *} \quad(0.058)$ & $(0.349)$ & $(0.069)$ \\
\hline Controls & Yes & Yes & Yes & Yes \\
\hline Year and industry effects & Yes & Yes & Yes & Yes \\
\hline Observations & 805 & 805 & 818 & 818 \\
\hline Adjusted $R^{2}$ & $51.438 \%$ & $22.894 \%$ & $51.015 \%$ & $26.080 \%$ \\
\hline
\end{tabular}

Panel B. Alternative measure for competitive environment-Hoberg and Philips similarity

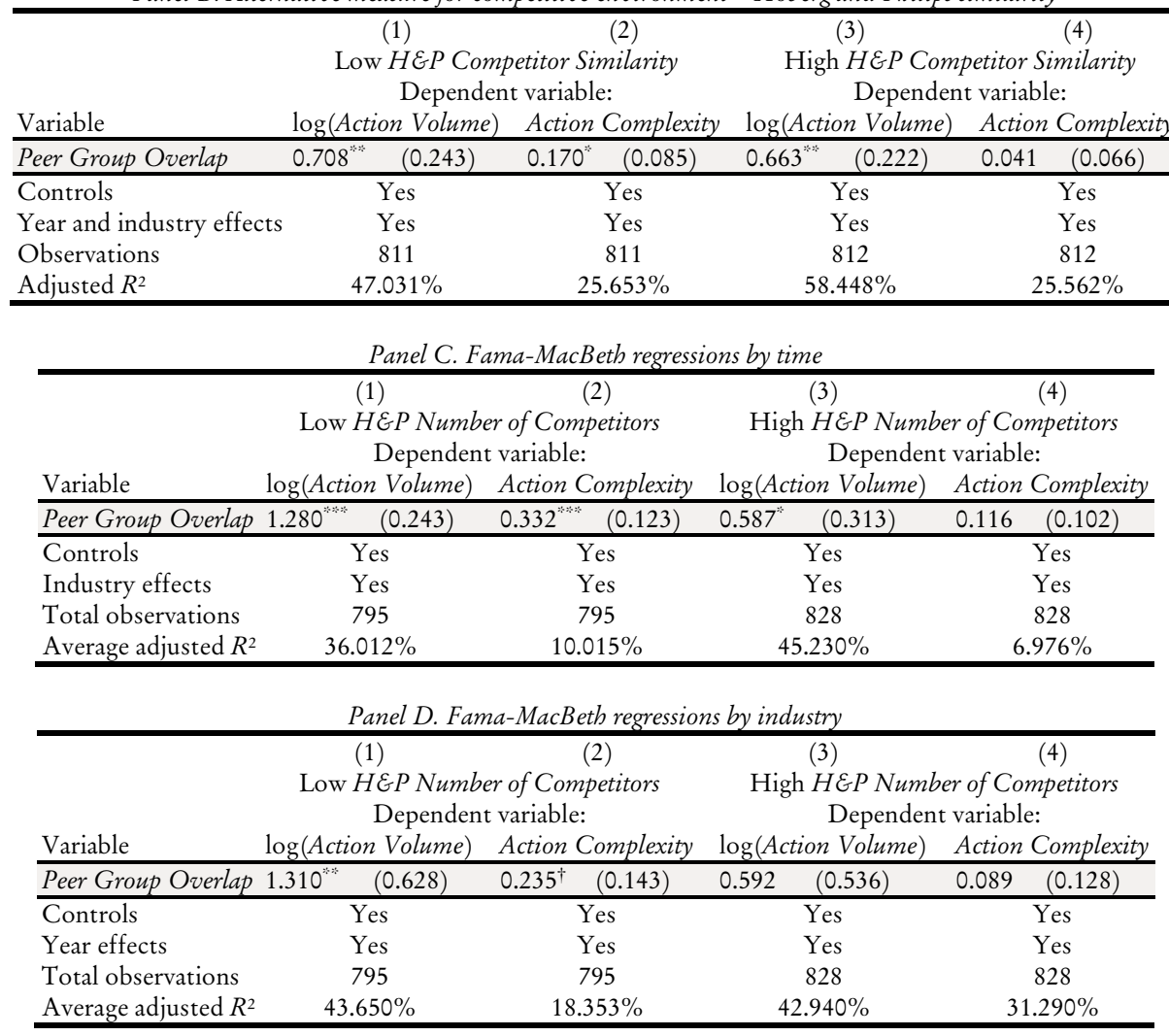

Herfindabl-Hirschman Index and low HEP Competitor Similarity), the coefficient on Peer Group Overlap is positive and significant. Hence, we conclude that our main results are robust to using alternative measures of competitive environment.

\section{A.III.B. Controlling for a Common Time Trend}

We assess the robustness of our main results to controlling for a common time trend in competitive aggressiveness, because firms likely operate in different economic cycles which may impact their aggressiveness decisions. Although our main specifications include year fixed effects, we now re-estimate Equation (2.3.3) using Fama and MacBeth 
Table 2.A.III. Peer group overlap and competitive aggressiveness—robustness checks (continued)

Panel E. Controlling for equity incentives

\begin{tabular}{|c|c|c|c|c|c|c|c|c|}
\hline \multirow[b]{2}{*}{ Variable } & \multicolumn{4}{|c|}{$\begin{array}{c}(1) \\
\text { Low HEP Number of Competitors } \\
\text { Dependent variable: }\end{array}$} & \multicolumn{4}{|c|}{$\begin{array}{l}(3) \\
\text { High } H E P \text { Number of Competitors } \\
\text { Dependent variable: }\end{array}$} \\
\hline & \multicolumn{2}{|c|}{$\log ($ Action Volume $)$} & \multicolumn{2}{|c|}{ Action Complexity } & \multicolumn{2}{|c|}{$\log ($ Action Volume $)$} & \multicolumn{2}{|c|}{ Action Complexity } \\
\hline Peer Group Overlap & $0.725^{3 * 3}$ & $(0.231)$ & $0.174^{* 20}$ & $(0.070)$ & 0.208 & $(0.231)$ & 0.076 & $(0.063)$ \\
\hline $\log ($ Delta $)$ & 0.073 & $(0.044)$ & -0.006 & $(0.009)$ & $0.131^{* \ldots}$ & $(0.039)$ & $0.019^{*}$ & $(0.009)$ \\
\hline $\log (V e g a)$ & 0.039 & $(0.023)$ & 0.006 & $(0.006)$ & $0.069^{* *}$ & $(0.029)$ & 0.009 & $(0.008)$ \\
\hline Controls & \multicolumn{2}{|c|}{ Yes } & \multicolumn{2}{|c|}{ Yes } & \multicolumn{2}{|c|}{ Yes } & \multicolumn{2}{|c|}{ Yes } \\
\hline Year and industry effects & \multicolumn{2}{|c|}{ Yes } & \multicolumn{2}{|c|}{ Yes } & \multicolumn{2}{|c|}{ Yes } & \multicolumn{2}{|c|}{ Yes } \\
\hline Observations & \multicolumn{2}{|c|}{700} & \multicolumn{2}{|c|}{700} & \multicolumn{2}{|c|}{793} & \multicolumn{2}{|c|}{793} \\
\hline Adjusted $R^{2}$ & \multicolumn{2}{|c|}{$55.554 \%$} & \multicolumn{2}{|c|}{$24.842 \%$} & \multicolumn{2}{|c|}{$59.463 \%$} & \multicolumn{2}{|c|}{$29.300 \%$} \\
\hline
\end{tabular}

This table presents results examining the robustness of the association between peer group overlap and competitive aggressiveness, split by the number of product market competitors identified by Hoberg and Phillips $(2010,2016)$. Panel A presents results examining the robustness to using the Herfindahl-Hirschman index as a proxy for competitive environment. Panel B presents results examining the robustness to using the maximum similarity score as identified by Hoberg and Phillips $(2010,2016)$ as proxy for competitive environment. Panel C presents results examining the robustness to using Fama and MacBeth (1973) regressions by time. Panel D presents results examining the robustness to using Fama and MacBeth (1973) regressions by industry. Panel E presents results examining the robustness to controlling for equity incentives. The industry indicators follow the 48 industry groups identified by Fama and French (1997). Standard errors are in parentheses and are adjusted for within cluster correlation by firm and time conform Gow et al. (2010). ", " and indicate significance at two-tailed probability levels of $10 \%, 5 \%$, and $1 \%$, respectively. ${ }^{\dagger}$ indicates significance at two-tailed probability levels of $11 \%$, and is only reported for the main variables of interest.

(1973) regressions, which allows the coefficients on all variables to vary for each year. Specifically, we estimate Equation (2.3.3) on an annual basis, and compute coefficients and standard errors based on the distributions of the year-specific cross-sectional regressions.

Panel C in Table 2.A.III presents these results. We report the time-series average of the estimated coefficients and the corresponding standard errors, which are based on the standard deviation of the error in the time-series average estimated coefficients. We continue to find that the coefficient on Peer Group Overlap is positive and significant in environments with relatively more imperfect competition. Hence, we conclude that our main results are robust to rigorously controlling for a common time trend.

\section{A.III.C. Controlling for a Common Industry Trend}

We assess the robustness of our main results to controlling for a common industry trend in competitive aggressiveness, to address concerns that industry characteristics are behind our results. Although our main specifications include industry fixed effects, we now re-estimate Equation (2.3.3) using Fama and MacBeth (1973) regressions, which allows the coefficients on all variables to vary for each industry. Specifically, we estimate Equation (2.3.3) on an industry basis, and compute coefficients and standard errors based on the distributions of the industry-specific time-series regressions.

Panel D in Table 2.A.III presents these results. We report the industry average of the estimated coefficients and the corresponding standard errors, which are based on the standard deviation of the error in the industry average estimated coefficients. We 
continue to find that the coefficient on Peer Group Overlap is positive and significant in environments with relatively more imperfect competition (albeit at attenuated significance levels for the complexity specification). Hence, we conclude that our main results are robust to rigorously controlling for a common industry trend.

\section{A.III.D. Controlling for Equity Incentives}

We assess the robustness of our main results to controlling for managers' equity incentives, because prior literature documents an interdependence between relative performance plans and equity incentives (e.g., Park and Vrettos, 2015, Timmermans, 2021). We measure the manager's equity incentives through delta and vega. Delta is the sensitivity of the risk-neutral value of the CEO's portfolio of stock and stock options to a $1 \%$ change in the price of the underlying stock. Vega is the sensitivity of the risk-neutral value of the CEO's portfolio of stock options to a 0.01 change in the volatility of the underlying stock (e.g., Core and Guay, 2002, Guay, 1999). We estimate the risk-neutral value of the manager's option portfolio using the Black and Scholes (1973) model, as modified by Merton (1973b) to account for dividend payouts. We then re-estimate Equation (2.3.3) and include Delta and Vega.

Panel $\mathrm{E}$ in Table 2.A.III presents these results. We continue to find that the coefficient on Peer Group Overlap is positive and significant in environments with relatively more imperfect competition. Hence, we conclude that our main results are not an artifact of equity incentives in executive incentive-compensation contracts. 

"The existence of asymmetric information can enable market participants to engage in deleterious strategic behaviors that would be impossible in a world of complete information. For example, an auditor's knowledge of audit processes and efforts is superior to that of management and boards, or third parties like investors, which can lead the auditor to act strategically in his or her own self-interest. [...] in the SEC's space, the lack of symmetric information between a buyer and a seller can lead to adverse selection, or even to complete market failure. Hidden information or hidden actions may also permit a firm to substitute more risky assets without bondholders' knowledge, or permit executives to collect unwarranted rents for themselves. at the expense of shareholders."

-Mark J. Flannery, Chief Economist and Director of the U.S. Securities and Exchange Commission (speech to the Public Company Accounting Oversight Board's Center for Economic Analysis, October 22, 2015) 


\title{
Managerial Incentives and Disclosure: Evidence from Relative Performance Evaluation ${ }^{\text {मै }}$
}

\begin{abstract}
We examine the relation between managers' incentive-compensation contracts and their disclosure decisions. Specifically, we examine how contracts that explicitly evaluate managers on peer performance are associated with: (1) the transparency of mandatory disclosure; (2) the provision of voluntary disclosure; and (3) the substitution between the two. We find a negative relation between relative performance plans in which competition with peers is strong and both the transparency of mandatory disclosure and the provision of voluntary disclosure. Moreover-and consistent with our theoretical prediction-we show that the substitution between the two depends critically on whether managers compete with peers for market prices or accounting numbers. We further show that boards' choices for relative performance plan characteristics are consistent with proprietary cost considerations. Collectively, our findings suggest that disclosure-specific costs should be interpreted more broadly, as proprietary costs to one manager may arise-or perhaps more importantly, not arisebecause of characteristics of managers at other firms.
\end{abstract}

\section{Introduction}

Information disclosure is crucial to maintain fair, orderly, and efficient markets. However, as SEC Chief Economist and Director Kothari (2020) notes: "while companies might report some information on their own, it is largely down to the materiality-based disclosure system that [helps investors understand the economics of firms]." The need for this system is driven substantially by the proprietary costs of disclosure-competition-

is Melissa Martin (University of Illinois at Chicago) coauthored this chapter. We gratefully acknowledge comments from Peter Demerjian, Mirko Heinle, Frank Moers, Patrick Vorst, and seminar participants at the Executive Compensation and Corporate Governance Brown Bag, the Journal of Management Accounting Research online brownbag program and University of Munich, and conference participants at the 2021 Management Accounting Section Midyear Meeting for their valuable comments. We thank our respective schools for generous support. 
related costs that arise because the revelation of sensitive information can jeopardize the firm's competitive position. ${ }^{73}$ These costs are associated with a reduction in both the quality of mandatory disclosure and the probability of voluntary disclosure (see, e.g., Heinle, Samuels, and Taylor (2020) for a review of this literature). While the impact of firm-level product market competition on firm-level disclosure has been studied extensively, little is known about how managers' perception of competition relates to their disclosure decisions. Given managers' unique position as primary decision-makers at the firm and the role their preferences play in shaping disclosure decisions (e.g., Bamber, John, and Wang, 2010, Brochet, Faurel, and McVay, 2011, Dedman and Lennox, 2009), it is important to understand how perceptions of competition shape proprietary costs. In this study, we aim to provide more insights into this relation by examining how managers' incentive-compensation contracts shape both mandatory and voluntary disclosure decisions.

Specifically, we examine how incentive-compensation contracts that explicitly evaluate managers on their performance relative to peer performance relate to disclosure decisions. Relative performance evaluation (RPE) is a useful tool that allows boards to contract with their managers more efficiently by shielding them from systematic performance trends. However, by measuring performance in a relative manner, these performance plans also directly incentivize managers to outperform the listed set of competitor firms. ${ }^{74}$ One consequence of this direct competition is that managers' evaluation of the proprietary costs of disclosure increase: revealing information to peers is more costly to the manager when evaluated based on relative performance than on individual performance. As a result, we expect that managers evaluated on relative performance provide more opaque mandatory disclosure and less voluntary disclosure, compared to managers evaluated on individual performance, ceteris paribus.

Identifying a relation between disclosure and managerial incentives, such as relative performance incentives, is, however, complicated by the fact that disclosure policies are endogenously determined by the same forces that shape managerial incentives (e.g., Core, 2001). To formalize the intuition for how and why relative performance plans relate to disclosure decisions, we explore this incentive equilibrium in two stages in the standard backward fashion (e.g., Gibbons, 1992). In the first stage, we consider the response of the manager to an-from his/her perspective-exogenous relative performance plan. In the second stage, we examine in more detail which firms wouldfrom the board's perspective-endogenously choose which type of relative performance plan, given managers' anticipated responses to the-from the managers' perspectiveexogenous incentive plan.

73. Graham, Harvey, and Rajgopal (2005, p. 63) document, based on a survey of 401 financial executives, that "giving away company secrets is an important barrier to more voluntary disclosure-managers do not want to explicitly reveal sensitive proprietary information 'on a platter' to competitors."

74. De Angelis and Grinstein (2019) show that relative performance plans provide managers with strong economic incentives to compete with peer firms. They show that relative awards account for nearly $50 \%$ of the value of performance-based awards in incentive-compensation contracts. In our sample, we similarly find that the incentives stemming from relative performance plans are strong: the average (typical) RPE plan provides the manager with the possibility to earn a RPE grant worth $77.4 \%(61.0 \%)$ of his/her previous year's total compensation (see Section IV for details). 
Regarding the first stage, the extent to which a relative performance plan influences salience of competition - and, thus, the manager's disclosure decision-depends on the intensity of the strategic interactions between the focal manager and each of his/her peers. In our context of relative performance plans, the intensity of such strategic interactions hinges on the intersection of two channels: peer group overlap and product market overlap. In a setting with two competing agents, the incentives to act strategically are greatest when: (1) both agents are evaluated based on own- and peer performance (i.e., "peer group overlap")—because both agents then have an incentive to outperform each other; and (2) both agents operate within the same product market (i.e., "product market overlap")-because both principals signal to their agents that existing product market competition is a priority (e.g., Aggarwal and Samwick, 1999, Feichter et al., 2021). Thus, we predict that the manager's evaluation of the proprietary costs of disclosure is amplified by the extent to which peer firms are from the same product market and, if using RPE, have also selected the focal firm in their own relative performance plan. This in turn incentivizes managers to provide even more opaque mandatory disclosure and less voluntary disclosure.

Departing from prior literature which defines proprietary costs as a firm-level attribute that affects all disclosures decisions similarly, Heinle et al. (2020) put forth the idea that different disclosures are subject to different frictions and thus subject to different proprietary costs—-termed "disclosure-specific costs." As the proprietary costs of mandatory disclosure increase, managers respond by reducing the information content of these required disclosures. But at the same time, to minimize the resulting increase in information asymmetry with the market, managers increase voluntary disclosure of "less proprietary" information to compensate for decreased disclosure of costlier proprietary information. This implies that the way in which a relative performance plan relates to mandatory and voluntary disclosure jointly depends on the differential frictions it induces. These frictions are affected by the metric underlying relative performance.

If managers are evaluated on relative price-based metrics (e.g., stock returns), they have strong incentives to withhold proprietary information from their peers, but also to ensure investors have adequate pricing information. ${ }^{75} \mathrm{In}$ this case we predict that managers substitute increased voluntary disclosure of less proprietary information (e.g., summary earnings guidance) for decreased transparency of proprietary information in mandatory disclosures. This allows managers to continue to signal the valuation implications of their proprietary information without relinquishing their competitive advantage. In contrast, if managers are evaluated on relative accounting-based metrics (e.g., earnings), they still have incentives to withhold proprietary information but have little-or, at least at the margin less-incentives to ensure investors have adequate pricing information. In addition-and perhaps more importantly-providing enhanced voluntary disclosure of less proprietary information through summary earnings guidance may provide peer firms with a performance target. Knowing this target allows peers to either make real adjustments to or "manage" their accounting numbers so to outperform the focal firm. Therefore, when accounting-based relative performance metrics are used,

75. If managers fail to provide investors with adequate pricing information, the average precision of investors' information decreases. This reduction in the average precision of investors' information has real implications for the firm's stock price in the capital market (e.g., Lambert, Leuz, and Verrecchia, 2011). 
we predict that managers do not substitute increased voluntary disclosure of less proprietary summary earnings information when withholding proprietary information in mandatory disclosures from competitors.

Regarding the second stage of the incentive equilibrium, we examine in more detail which firms would - from the board's perspective-endogenously choose to evaluate their managers based on relative accounting-based metrics (vis-à-vis relative price-based metrics or no relative metrics), given managers' anticipated responses to the-from the managers' perspective-exogenous incentive plan. Our predictions above suggest that plans based on relative accounting metrics encourage more withholding of information by the manager. Such a disclosure policy can be desired when firms have: (1) close rivals that can more completely exploit the focal firm's proprietary information; or (2) significant proprietary investments. As such, in these cases, we predict boards want to give their managers stronger incentives to withhold this proprietary information and, thus, choose relative performance plans based on accounting metrics.

To test our predictions, we use a large sample of U.S. firms covered by the ISS Incentive Lab database over the period 2006 through 2017. We follow Heinle et al. (2020), and focus on decreased quality of mandatory disclosure through redactions of required public filings in the form of confidential treatment orders approved by the SEC. ${ }^{76}$ We measure voluntary disclosure in the form of management guidance. These disclosure decisions are relevant for two reasons. First, mandatory disclosures have a direct impact on the amount of available information in capital markets. Second, managers can directly and relatively effortlessly (compared to, for example, operational decisions) impact both the quality of information in mandatory disclosures as well as voluntary disclosure decisions.

In our first set of tests, we examine whether and how the existence of relative performance plans is associated with managers' disclosure decisions by examining both confidential treatment orders and management guidance independently. We find that, on average, managers evaluated on RPE provide fewer voluntary earnings guidance but do not redact more in their mandatory disclosures, compared to a matched sample of managers not evaluated on RPE. This pattern is consistent with the idea that different incentive plans differentially affect managers' perception of competition and, thus, their disclosure decisions. In this case: managers evaluated on relative performance have stronger incentives to withhold voluntary information from peers.

In our second set of tests, we examine whether and how strategic interaction intensity, our proxy for salience of competition, moderates the relation between relative performance evaluation and mandatory and voluntary disclosure decisions. Consistent with our theoretical predictions, we find strong evidence that the relation between

76. Through these confidential treatment orders approved by the SEC, firms can redact sections of their mandatory disclosures. The SEC (2010a, p. 2) provides the following guidance regarding these redactions in mandatory disclosures: "Sometimes disclosure of information required by the disclosure rules (e.g., Regulation S$K)$ can negatively affect a company's business and financial condition because of the competitive harm that could result from the disclosure. [...] To address the potential disclosure hardship, the Commission has established a system that allows companies to request confidential treatment of information filed under the Securities Act and the Exchange Act." If a request is denied, the firm must publish the unredacted version of its disclosure. In this regard, however, Heinle et al. (2020) note that confidential treatment orders are rarely denied (i.e., less than $0.12 \%$ of all orders in their sample). 
relative performance plans and managers' disclosure decisions is moderated by both peer group overlap and product market overlap. Consistent with the salience of competition altering managers perceptions of the proprietary costs of disclosure, we find that the reduction in voluntary earnings guidance is concentrated in those firms with high levels of strategic interaction intensity (i.e., either high peer group overlap, high product market overlap, or high peer group overlap and high product market overlap). Moreover, we also find that managers with high levels of strategic interaction intensity redact more in their mandatory disclosures, compared to a matched sample of managers not evaluated on RPE. Collectively, these findings corroborate the notion that relative performance plans induce competition which differentially affects managers' disclosure decisions, and that this competition is related to strategic interaction intensity.

In our third set of tests, we examine whether and how the existence of relative performance plans is associated with firms' disclosure substitution-i.e., confidential treatment orders and management guidance jointly. Confirming the idea of disclosurespecific costs put forward by Heinle et al. (2020), we document that the substitution effect indeed depends on the metric underlying relative performance. We find that managers who are evaluated on relative price metrics, more fully substitute opaque mandatory disclosure with summary earnings guidance than managers who are not evaluated on relative performance. In contrast, managers who are evaluated on relative accounting metrics, less fully substitute opaque mandatory disclosure with summary earnings guidance than managers who are not evaluated on relative performance. In fact, our evidence suggests managers evaluated on relative accounting metrics increase withholding of both mandatory and voluntary information. Collectively, our findings suggest that relative performance plans matter for the quality of information in capital markets.

In our fourth set of tests, we confirm that boards' choices for relative performance plans based on relative accounting-based metrics vis-à-vis relative price-based metrics or no use of relative metrics are consistent with proprietary cost considerations. In this regard, we show that the probability of using relative accounting-based metrics is increasing in the extent to which the focal firm: (1) has close rival firms that can exploit the focal firm's proprietary information; and (2) makes significant investments in proprietary innovations. This finding suggests that boards: (1) are aware of disclosurespecific costs; (2) anticipate managers' differential disclosure response to alternative relative performance metrics; and (3) exploit this in incentive-compensation design to minimize disclosure. Together, these contract-design findings complete the puzzle and strengthen the economic intuition for why we observe the relation between relative performance plans and managerial disclosure decisions.

Collectively, our findings are consistent with our incentive equilibrium predictions. While we cannot completely rule out the possibility that an omitted correlated variable is behind our results, we assess this likelihood as negligible for two reasons. First, the economic intuition behind our predictions is closely tied to two theoretical frameworks which are grounded in theories of asset pricing, competition, and disclosure. Second, our differential theoretical predictions and empirical evidence on the relation between disclosure, disclosure substitution and relative performance plans conditional on the intensity of strategic interactions and the metric underlying performance, mitigate concerns about correlated omitted variables that are inherent in typical research designs. 
That is to say that if a correlated omitted variable were to explain our results, it would need to: (1) be correlated with redactions; (2) be correlated with voluntary disclosure; (3) be correlated with the choice to adopt a relative performance plan; (4) differentially affect firms that adopted RPE conditional on the firm's peer group overlap and product market overlap (which are semi-exogenous to the focal firm); and (5) differentially affect firms that adopted RPE conditional on whether the plan is based on price or accounting metrics. Although this variable may exist, these requirements preclude many typical candidates such as the degree of product market competition, the manager's risk aversion, or the level of firms' trade secrecy.

In this study, we provide empirical evidence on the implications of managers' relative performance incentive-compensation contracts for the quality of information in capital markets. Our study should therefore be of interest to both practitioners and academics.

With respect to practitioners, our work highlights a new channel through which information asymmetry in capital markets arises. This is important, since information asymmetry is a direct threat to the SEC's (2021) mission to protect investors, to maintain fair, orderly, and efficient markets, and to facilitate capital formation. The channel we highlight is especially intriguing, as it is further compounded by disclosure requirements mandated by the SEC (2006) which were aimed to reduce asymmetric information issues related to executive and director compensation. ${ }^{77}$ In particular, these amendments require firms to unveil to investors - and by extension to competing firms - the details of managers' incentive-compensation structures. Thereby, these enhanced disclosures make it crystal clear to managers whether-and, if so, to what degree and on which dimension-competing managers similarly have strong and explicit incentives to strategically interact with them. While incentive plans based on explicit relative performance give managers an incentive to behave strategically even without disclosing the details of the plan, these increased disclosure requirements enable managers to quantify strategic intensity and, thereby, magnify the importance of strategic behavior (e.g., Berger and Hann, 2003, Bloomfield, 2021, Fershtman and Judd, 1987, Katz, 1991). Despite our evidence, let us emphasize that the point of this paper is not to criticize these disclosure amendments, but rather to shed light on the complex cost-benefit tradeoff in setting standards that address asymmetric information issues (e.g., SEC, 2000, 2003, 2006, 2010b). In this regard, we show that even a standard as vital as the Compensation, Discussion, and Analysis section of the proxy statement has its cost. Finally, to the extent that strategic interactions embedded in incentive-compensation contracts are not directly observable from a single firm's proxy statement-but rather from multiple firms' proxy statements-one key takeaway from our study is that proprietary costs to one manager may arise-or perhaps more importantly, not arise-because of characteristics (e.g., incentive-compensation contracts) of managers at other firms.

77. The SEC adopted amendments to the disclosure requirements in proxy and information statements for executive and director compensation. The amendments are intended to "make proxy and information statements, reports and registration statements easier to understand. They are also intended to provide investors with a clearer and more complete picture of the compensation earned by a company's principal executive officer, principal financial officer and highest paid executive officers and members of its board of directors. In addition, they are intended to provide better information about key financial relationships among companies and their executive officers, directors, significant shareholders and their respective immediate family members" (SEC, 2006, p. 1). 
We contribute to the rich literature that examines how proprietary costs and agency costs simultaneously affect disclosure decisions (e.g., Bens, Berger, and Monahan, 2011, Berger and Hann, 2007) (also see, e.g., Beyer, Cohen, Lys, and Walther (2010) for a recent review). Whereas most studies explicitly focus on the proprietary costs of disclosure-modeled through the intensity of product market competition-we show that agency benefits may incentivize managers to disclose information even when proprietary costs are non-trivial. This agency perspective is an overlooked perspective in many empirical studies that examine the role of proprietary costs on disclosure decisions (e.g., Berger, 2011, p. 207). More recently, the disclosure literature has shifted away from the effects of product market competition and shifted toward examining how voluntary disclosure is affected by factors other than competition, such as trade secrets (e.g., Glaeser, 2018), common ownership (e.g., Bourveau et al., 2020, Park, Sani, Shroff, and White, 2019), and mandatory disclosure (e.g., Barth, Landsman, Tian, and Yu, 2021, Heinle et al., 2020, Noh, So, and Weber, 2019). Taken together, this recent literature corroborates the importance of considering other factors in shaping disclosure-specific proprietary costs.

Our evidence bridges these two perspectives on proprietary costs of disclosure, suggesting that boards are both aware of the firm-level proprietary costs driven by firmlevel product market competition but also acknowledge that contractual incentives are an important driver of disclosure specific costs. Taking managers' perceptions of proprietary costs of disclosure into account, boards thus design incentive-compensation contracts that constrain managers to follow desired disclosure policy (e.g., Core, 2001, Shleifer and Vishny, 1997, Zingales, 1998).

We also contribute to the growing literature that examines the use of relative performance plans in executive incentive-compensation contracts. While most studies in this line of research examine characteristics and determinants of relative performance plans (e.g., Albuquerque, 2009, 2014, Drake and Martin, 2020, Gong et al., 2011, Ma et al., 2019, Park and Vrettos, 2015, Vrettos, 2013), a handful of studies provide empirical evidence on the effects of these incentive plans on managers' strategic decisions (e.g., Bloomfield et al., 2020, Feichter et al., 2021, Gong et al., 2019, Timmermans, 2021) (also see studies 1 and 2 or Chapters 2 and 3 in this dissertation). By investigating how relative performance plans alter managers' disclosure decisions, we add to this stream of literature by improving our understanding of how RPE encourages strategic disclosure. Our evidence suggests that relative performance plans-which serve mainly to improve contracting efficiency-have significant implications for peer-relevant disclosures and, thereby, information asymmetry with market participants. More generally, we highlight the importance of considering how contractual managerial incentives affect disclosure policies when designing incentive-compensation contracts for executives of large U.S. firms.

\section{Related Literature and Hypothesis Development}

\section{II.A. Information Disclosure}

In making disclosure decisions, managers face a tradeoff between: (1) reducing information asymmetry with investors; and (2) revealing private information to peers (e.g., Hayes and Lundholm, 1996, Wagenhofer, 1990). An important determinant in this 
tradeoff is the proprietary cost associated with the disclosure of private information (e.g., Healy and Palepu, 2001, Verrecchia, 2001). Because withholding private information from peers comes at the cost of increasing information asymmetry with investors, managers complement their concealments with additional "less proprietary" information so as not to harm price formation in the market (e.g., Barth et al., 2021, Glaeser, 2018, Glaeser and landsman, 2019, Noh et al., 2019). Heinle et al. (2020) formalize this intuition by theoretically modeling the notion of "disclosure substitution." They highlight that mandatory and voluntary disclosures have separate and distinct disclosurespecific costs, such that a single uniform disclosure policy is suboptimal. Heinle et al. (2020) also provide empirical evidence on the substitution between opaque mandatory disclosures, 10-K redactions, and enhanced voluntary earnings guidance.

Both prior literature and Heinle et al.'s (2020) theoretical framework highlight the important role competition plays in the disclosure tradeoff decision. However, studies in this realm typically refer to the proprietary costs of disclosure at the firm-level and overlook the role of the manager in this decision. Heinle et al. (2020) refine this notion by identifying the important role of disclosure-specific costs, but caveat they do not model individual manager characteristics. To the extent managers' contractual incentives alter the proprietary costs of specific disclosures, we argue they likely also influence disclosure decisions. ${ }^{78}$ In this regard, we study managers' incentives in the form of incentivecompensation contracts based on relative performance, because these plans directly alter the salience of competition.

\section{II.B. Relative Performance Evaluation}

A relative performance plan refers to a performance-contingent incentive compensation-contract where performance is not evaluated in absolute levels, but relative to competitors. Holmström (1982) shows that when performance outcomes of various homogenous agents are affected by common exogenous shocks, relative performance contracts are preferable to individual incentive contracts. The notion behind this optimality is that peer performance can be used to filter these common exogenous shocks, thereby isolating managers' idiosyncratic actions and performance. This filtering is beneficial from a contracting perspective, as it reduces compensation risk associated with systematic performance.

Consistent with these theoretical benefits, the use of relative performance plans has become increasingly prevalent in practice over the last decade: more than half of U.S. executive incentive-compensation contracts contain some form of RPE (e.g., Equilar, 2020, Meridian Compensation Partners LLC., 2019). Further, in terms of economic incentives, relative performance incentives account for nearly $50 \%$ of the value of performance-based awards in a manager's annual incentive-compensation contract (e.g., De Angelis and Grinstein, 2019). In our sample, we find that the average (typical) RPE plan provides the manager with the possibility to earn a RPE grant worth $77.4 \%(61.0 \%)$

78. As a recent example, Edmans, Goncalves-Pinto, Groen-Xu, and Wang (2018) show that managers strategically time their voluntary disclosures in months in which they are expected to sell their firm-related equity holdings. Aboody and Kasznik (2000), Noe (1999) and Cheng and Lo (2006) provide similar evidence that managers time their disclosures to benefit personally. 
of his/her previous year's total compensation (see Section IV for details). As such, these incentive plans provide economically significant incentives to managers.

However, while RPE provides efficiency-enhancing advantages for contracting purposes, it simultaneously increases competition imposed on the manager (e.g., Aggarwal and Samwick, 1999, Vrettos, 2013). In particular, these plans give managers explicit incentives to strategically interact with competitors. To illustrate such incentives, consider Chevron Corporation (2019). If Chevron outperforms all of its peers, the CEO receives $\$ 15$ million, but if all peers outperform Chevron, the CEO receives $\$ 0$. These explicit incentives to outperform peers alter the (strategic) decisions of the manager. For example, Gong et al. (2019) show that managers strategically time mandatory disclosures based on their RPE peers' fiscal-year ends, and strategically choose RPE peers based on their own fiscal-year ends. In the same vein, Timmermans (2021) (i.e., study 1 or Chapter 2 in this dissertation) provides empirical evidence that relative performance plans affect managers' risk taking differently than stock option contracts.

\section{II.C. Hypothesis Development}

In this section, we build our predictions for the relation between relative performance plans and managerial disclosure. We note that disclosure policies are endogenously determined by the same forces that shape managerial incentives (e.g., Core, 2001). Therefore, we examine this incentive equilibrium in two stages. In the first stage, we consider how a manager responds to an-from his/her perspective-exogenous relative performance plan. In the second stage, we examine which firms would-from the board's perspective-endogenously choose which type of relative performance plan, given managers' anticipated responses to the-from the managers' perspectiveexogenous incentive plan.

First Stage-Relative Performance Plans and Information Disclosure. One consequence of RPE's strong and explicit incentives to strategically interact with competitors is that the manager's evaluation of proprietary costs of disclosure increases: revealing information to peers is more costly when evaluated based on relative performance than on individual performance. As a result, we expect that managers evaluated on relative performance decrease information disclosure, compared to managers evaluated on individual performance. That is, we predict that RPE is associated with: (1) more opaque mandatory disclosure; and (2) fewer voluntary disclosure.

We further argue that these associations are increasing in the salience of competition induced by the RPE contract. In our context, the intensity of such competition hinges on the intersection of two channels: (1) peer group overlap; and (2) product market overlap. Economic theory predicts that in a setting with two competing agents, the incentives to act strategically are greatest when: (1) both agents are evaluated based on own- and peer performance (i.e., we label this "peer group overlap")-because both agents then have an incentive to outperform each other; and (2) both agents operate within the same product market (i.e., we label this "product market overlap")—because both principals signal to their agents that existing product market competition is a 
priority (e.g., Aggarwal and Samwick, 1999, Feichter et al., 2021). ${ }^{79}$ This implies that, in our setting of relative performance plans, the incentives to act strategically are greatest when two firms from the same product market select each other as peers in these incentive plans. ${ }^{80}$ We use the intuition of this simple theoretical framework developed by Aggarwal and Samwick (1999), and posit that if strategic interactions stemming from relative performance plans give managers incentives to act strategically on operational dimensions, managers are also incentivized to act strategically in their disclosure decisions.

Following the above discussion, we therefore predict that the incentives to decrease disclosure (i.e., more opaque mandatory disclosure and fewer voluntary disclosure) stemming from relative performance plans are, in the cross-section, proportional to strategic interaction intensity.

First Stage-Relative Performance Plans and Disclosure Substitution. In the previous section, we discussed how relative performance plans impact mandatory disclosure and voluntary disclosure separately. In this section, we discuss how these incentive plans relate to mandatory disclosure and voluntary disclosure jointly. In Heinle et al.'s (2020) general setting of disclosure-specific costs, the disclosure-specific cost of mandatory operational disclosure is increasing in the presence of competition. This leads to more opaque mandatory filings. In their setting, managers substitute this opaque mandatory disclosure for less costly voluntary disclosure because: (1) the manager is cautious of increasing information asymmetry with investors; and (2) the disclosure-specific cost of voluntarily disclosing "less proprietary" information (e.g., summary performance expectations that reveal to investors the valuation implications of their proprietary information) is relatively low.

In contrast to the general setting, in relative performance settings the willingness to bear the costs of information asymmetry and/or the costs of disclosing less-proprietary summary information vary. That is, (1) depending on the metric underlying relative performance, the manager may be more, or less, cautious of increasing information asymmetry with investors; and (2) summary performance expectations are not costless since such information may provide peers with a performance benchmark to beat; if peers successfully act on this benchmark, relative performance-and thus compensation-for managers of the focal firm may suffer.

Thus, in the presence of RPE, the disclosure-specific costs of voluntary disclosure may be sufficiently high so as to outweigh the benefit of substitution and maintaining the overall level of information asymmetry with the market. As we discuss below, this depends on the metric underlying relative performance. Commonly used performance

79. Feichter et al. (2021) (i.e., study 2 or Chapter 3 in this dissertation) empirically show that when two firms include each other as RPE peers in their respective relative performance plans (i.e., "peer group overlap"), managers make more aggressive strategic decisions (e.g., increasing advertisement costs, launching new products, or cutting prices).

80. Note that these conditions need not be the case in relative performance plans of large U.S. firms: one firm's peers need not use RPE themselves or, if they use RPE, they need not select the focal firm as their own peer. Nevertheless, this variation in peer selection allows us to tease out variation in the intensity of strategic interactions-and, thus, more convincingly test our theoretical predictions in the setting of relative performance plans. 
metrics in relative incentive plans include: (1) price-based metrics, such as stock returns; and (2) accounting-based metrics, such as return on equity or earnings (e.g., De Angelis and Grinstein, 2019, Gong et al., 2011). ${ }^{81}$ We discuss each metric-type in turn below.

Managers evaluated based on relative price metrics have incentives to both: (1) withhold proprietary operational information from peers to maintain their competitive advantage; and (2) ensure investors have adequate information to correctly price the firm. This suggests that consistent with the substitution model in Heinle et al. (2020), managers evaluated on relative price metrics have an incentive to manage the overall level of information asymmetry and, thus, will substitute their reduced quality mandatory disclosure with less costly voluntary disclosure. Further, to the extent price-based metrics heighten the awareness of the cost of withholding information from market participants, managers may be even more likely to substitute reduced mandatory disclosure with increased voluntary disclosure to signal the valuation implications of their proprietary information. Therefore, we predict that managers evaluated on relative price metrics substitute opaque mandatory disclosure to a greater extent with voluntary summary earnings guidance than managers not evaluated on relative metrics.

In contrast, when managers are evaluated based on relative accounting metrics, market expectations are irrelevant for performance on the RPE metric. Hence, managers evaluated on relative accounting metrics are-at the margin-less concerned with reducing information asymmetry with investors, since a significant fraction of their compensation is not affected by market expectations. In fact, disclosing expectations of performance on these accounting metrics to the market, in the form of earnings guidance, may enable peer firms to make adjustments such that they can outperform the focal firm. This implies that managers evaluated on relative accounting metrics provide less informative mandatory disclosures-without substituting voluntary disclosure. Further, to the extent that the cost of offsetting this reduction with increased voluntary disclosure in the form of summary performance information may be sufficiently high, the proprietary cost of such an additional voluntary disclosure may even completely negate the substitution effect. Therefore, we predict that managers evaluated on relative accounting metrics substitute opaque mandatory disclosure to a lesser extent with summary earnings guidance, compared to managers not evaluated on relative metrics.

Second stage-Who Chooses What? In this section, we examine which firms would choose which relative performance plan-given managers' anticipated responses. If firms take the classical perspective that proprietary costs of disclosure are a firm-level construct, and as we argue relative performance contracts increase the salience of competition, then implementing any RPE contract results in the withholding of proprietary information. If, however, firms are aware of the differential disclosurespecific costs, the above discussion implies that: (1) managers evaluated on relative price metrics substitute opaque mandatory disclosure to a greater extent with voluntary summary earnings guidance than managers not evaluated on relative metrics; and (2)

81. Gong et al. (2011) show that in 2006 approximately $73 \%$ and $24 \%$ of the RPE contracts are pricebased and accounting-based, respectively. Bizjak et al. (2021) present descriptive evidence that the predominance of price-based RPE contracts is even increasing in recent years- $87 \%(22 \%)$ of the RPE contracts contain price-based (accounting-based) metrics. 
managers evaluated on relative accounting metrics substitute opaque mandatory disclosure to a lesser extent with summary earnings guidance, compared to managers not evaluated on relative metrics. The remaining question in this incentive equilibrium is for which type of firms these choices (i.e., managers' anticipated disclosure responses) are optimal. Phrased differently: conditional on evaluating managers on their relative performance, which type of firms would give their managers relatively strong incentives to withhold information?

Economic theory predicts that firms that redact information are those firms for which such information would jeopardize their competitive advantage (e.g., Boone, Floros, and Johnson, 2016, Verrecchia and Weber, 2006). Therefore, we predict that firms that use relative performance evaluation to give their managers incentives to withhold information operate in competitive markets and/or work on proprietary innovations (e.g., Glaeser, 2018). To be more precise, we predict that firms using relative accounting metrics: (1) operate in environments where there are relatively more close peers; and (2) have large investments in research and development, compared to both firms using relative price metrics and firms not using relative performance metrics.

\section{Variable Measurement}

\section{III.A. Measures of Disclosure}

Regarding mandatory disclosure, we follow Heinle et al. (2020) and examine the transparency of mandatory disclosure through redactions in the form of confidential treatment orders approved by the SEC. These redactions allow managers to redact parts of their SEC filings, primarily to conceal information that would otherwise harm their competitive advantage. Confidential treatment orders thus capture the most direct form of competitor relevant proprietary information (e.g., Boone et al., 2016, Verrecchia and Weber, 2006). We obtain firms' confidential treatment redactions (CTO) through searching their $10-\mathrm{K}$ and $10-\mathrm{Q}$ filings via SeekINF. Specifically, we use the phrases "confidential treatment has been ... ," "Rule 24b-2," "Rule 406" and "CT Order," to identify CTO redactions (e.g., Glaeser, 2018). We use a frequency variable that counts the number of redactions in firms' mandatory disclosures (Redactions).

Regarding voluntary disclosure, we also follow Heinle et al. (2020) and focus on voluntary disclosure in the form of management provided earnings guidance. These forecasts are relevant because managers provide forecasts, among other reasons, to reduce information asymmetry with investors. We obtain data on management forecasts from IBES Guidance. Similar to our redaction variable, we use a frequency variable that counts the number of earnings guidance the firm issues during the year (Earnings Guidance).

\section{III.B. Measures of Relative Performance Plans}

We follow De Angelis and Grinstein (2019) and Gong et al. (2019), and obtain data on relative performance plans for the largest 750 firms by market capitalization from ISS Incentive Lab. We create an indicator variable for the presence of relative performance plans $(R P E)$. The existence of a relative performance plan is identified if the Compensation, Discussion, and Analysis section of the firm's proxy statement states that executive compensation is determined based on the firm's performance relative to 
performance of a pre-specified set of peer firms. ${ }^{82} \mathrm{We}$ also generate separate indicator variables (RPE-price and $R P E$-accounting), taking the value of one for firm-years that use price-based metrics or accounting-based metrics in their relative performance plan, and zero otherwise. Appendix A exemplifies a (price-based) relative performance plan for United Parcel Service Inc. (2019).

\section{III.C. Measures of Strategic Interaction Intensity}

Peer Group Overlap. To measure peer group overlap in relative performance plans, we follow Feichter et al. (2021) (i.e., study 2 or Chapter 3 in this dissertation) and analyze all firm-peer relationships and record which relationships are "singular" and which are "dual." Singular peer relationships are those relationships whereby the focal firm has selected a given firm as a performance peer, but this peer firm does not have the focal firm as an RPE peer (or does not use RPE at all). In a dual peer relationship, the peer firm also has the focal firm selected as peer. Thus, if a relationship is dual, there is a "peer group overlap." Figure 3.1 illustrates this concept. We then count the number of overlapping peer relationships per firm-year and scale that by the peer group size for that firm-year (Peer Group Overlap). The higher the fraction of dual relationships in a relative performance plan, the higher the peer group overlap. We set this variable to zero for nonRPE firms, because these firms do not have a peer group.

Product Market Overlap. To examine the impact of peer relationships stemming from within the product market, we construct a variable similar to the peer group overlap variable. In this variable, we define a product market overlapping peer relationship as those relationships whereby the focal firm has selected a given firm as a peer and that peer firm operates within the same product market, as defined by Hoberg and Phillips (2010, 2016). We then count the number of overlapping product market-peer relationships per firm-year and scale that by the peer group size for that firm-year (Product Market Overlap). The higher the fraction of product market-peer relationships in a relative performance plan, the higher the overlap stemming from regular product market competition. Again, we set this variable to zero for non-RPE firms, because these firms do not have a peer group.

\section{III.D. Measuring Rival Similarity}

To examine our second stage prediction of whether firms using relative accounting metrics operate in environments where there are relatively more close peers than firms using relative price metrics, we use two proxies for competition. These measures for competition, Product Market Size and Rival Similarity, are the firm's number of product market peers and the firm's mean similarity to its product market peers, respectively. Product market peers are as defined by Hoberg and Phillips $(2010,2016)$. In this regard, Rival Similarity is the variable of interest, which captures how "close" peers are to the focal firm. We include Product Market Size to control for the size of the product market.

82. Firms can also use relative performance plans, but choose an index of firms as the performance benchmark (e.g., S\&P 500 firms). Because we are interested in the tournament-style incentives induced by listing a set of performance peers, we exclude these firms from our analysis. 
Figure 3.1. Peer group overlap

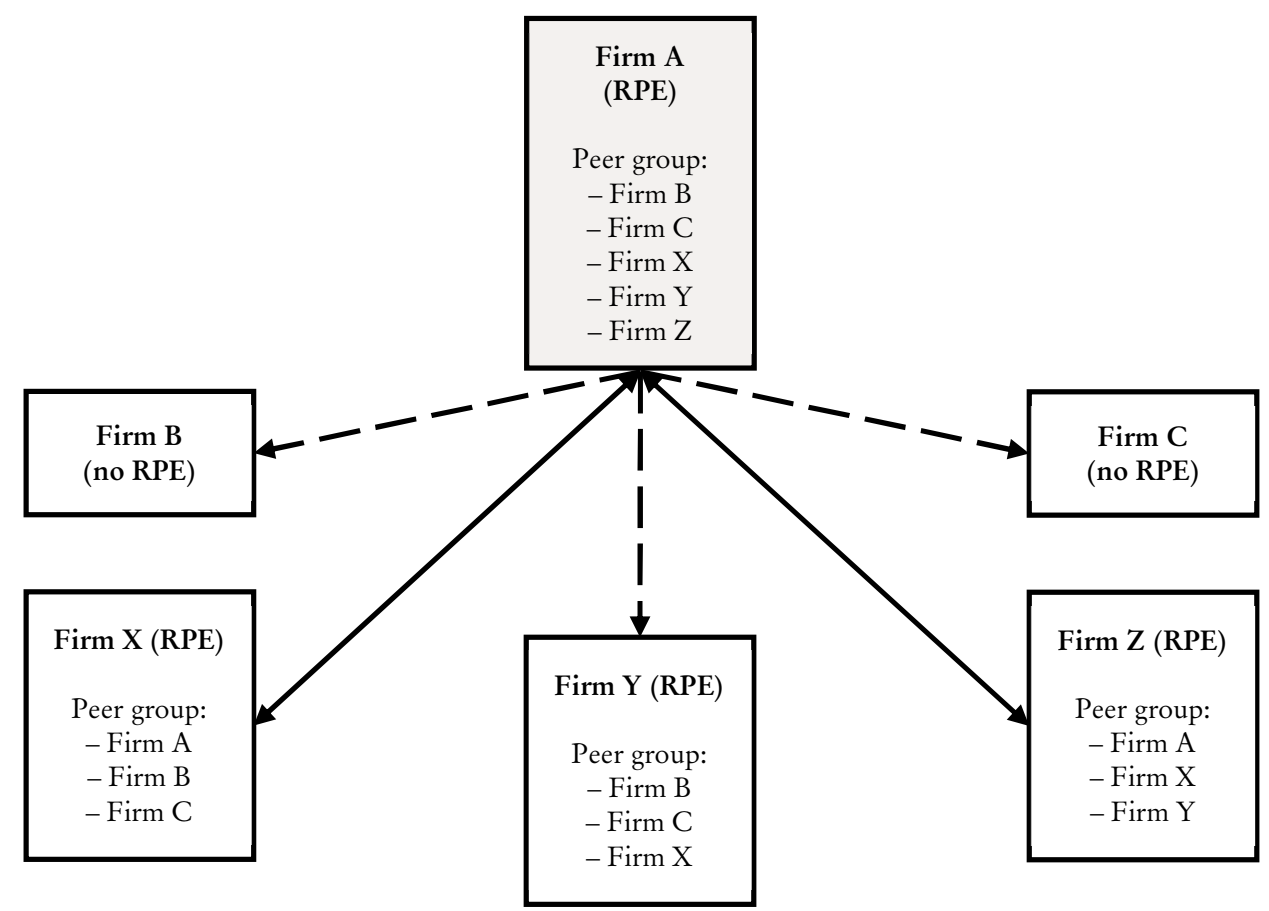

This figure illustrates the peer group overlap concept. The focal firm A has five peers. Of these five peers, two peers (B and $\mathrm{C}$ ) do not have a relative performance plan themselves and three peers (X, Y and Z) do have a relative performance plan. Peers X and Z also have firm A selected as their peer, resulting in an overlap in peer selection-as indicated by the solid lines. From firm A's viewpoint, there are thus two (out of five) overlapping peer relations. As such, in this example, peer group overlap for firm A is $40 \%$.

\section{III.E. Measuring Research and Development Intensity}

To examine our second stage prediction of whether firms using relative accounting metrics have large investments in research and development, we follow Glaeser (2018) and measure the firm's annual research and development expenditures, scaled by total assets. We label this variable $R E D$ Intensity.

\section{Descriptive Statistics}

Table 3.1 presents descriptive statistics for the primary variables in our design for both our full sample (Panel A), as well as separately in non-RPE, RPE, RPE-price, and RPE-accounting firms (Panel B). The sample contains 9,451 observations for all firms in ISS Incentive Lab from 2006 to 2017 with non-missing values for all required variables. This table shows that $27 \%$ of firm-years in our sample use a relative performance plan (with self-selected peers). Among the firms using RPE, we identify approximately $76 \%$ using relative price-based performance metrics and 36\% employing relative accountingbased performance metrics. These statistics are consistent with previous studies that rely 
Table 3.1. Descriptive statistics

\begin{tabular}{|c|c|c|c|c|c|}
\hline & Mean & Std. Dev. & $25 \mathrm{th}$ & $50 \mathrm{th}$ & 75 th \\
\hline Earnings Guidance & 7.893 & 14.345 & 0.000 & 4.000 & 10.000 \\
\hline Redactions & 0.174 & 0.554 & 0.000 & 0.000 & 0.000 \\
\hline$R P E$ & 0.271 & 0.445 & 0.000 & 0.000 & 1.000 \\
\hline$R P E$-price & 0.206 & 0.404 & 0.000 & 0.000 & 0.000 \\
\hline$R P E$-accounting & 0.098 & 0.298 & 0.000 & 0.000 & 0.000 \\
\hline Peer Group Overlap & 0.036 & 0.108 & 0.000 & 0.000 & 0.000 \\
\hline Product Market Overlap & 0.115 & 0.271 & 0.000 & 0.000 & 0.000 \\
\hline Size & 8.488 & 1.235 & 7.701 & 8.440 & 9.368 \\
\hline$R O A$ & 0.053 & 0.095 & 0.017 & 0.051 & 0.096 \\
\hline Leverage & 0.294 & 0.337 & 0.110 & 0.243 & 0.387 \\
\hline$M T B$ & 1.976 & 1.319 & 1.175 & 1.568 & 2.267 \\
\hline Loss & 0.142 & 0.349 & 0.000 & 0.000 & 0.000 \\
\hline Returns & 1.140 & 0.441 & 0.903 & 1.110 & 1.320 \\
\hline Volatility & 0.094 & 0.060 & 0.056 & 0.079 & 0.114 \\
\hline Nanalysts & 10.445 & 3.918 & 12.000 & 12.000 & 12.000 \\
\hline Ninstitutions & 2.898 & 1.912 & 1.619 & 2.605 & 4.225 \\
\hline Big4 & 0.975 & 0.156 & 1.000 & 1.000 & 1.000 \\
\hline
\end{tabular}

on ISS Incentive Lab (e.g., Bizjak et al., 2021, De Angelis and Grinstein, 2019, Gong et al., 2019).

Table 3.1 also shows that sample firms on average provide eight earning-related forecasts and redact approximately 0.174 times per year. Untabulated descriptive statistics indicate that $61 \%$ of firm-years provide at least one earnings-related guidance and $12 \%$ of firm-years redact to conceal proprietary information. The redactions statistic is consistent with previous studies that employ this measure (e.g., Glaeser, 2018, Heinle et al., 2020). However, we note the sample of firms covered by ISS Incentive Lab are larger and better performing than the Compustat universe (e.g., Albuquerque, Chen, Dong, and Riedl, 2019). We also note that the ISS Incentive Lab sample (i.e., S\&P 500 and 400 firms) consists heavily of firms with significant market demand for earnings guidance, consistent with the notion that earnings guidance is de facto mandatory for market leaders. In our sample, the likelihood of earnings-related guidance for a firm-year (i.e., $61 \%$ ) is significantly high than the general population of Compustat firms over the same time period (i.e., $26 \%$ ).

Table 3.2 presents descriptive statistics on the distributions of RPE plans, as well as RPE metrics, across time and industries. This table shows that, for firms using RPE, approximately $14 \%$ of their peers "overlap" - this statistic is increasing over time: $7 \%$ in 2006 and $24 \%$ in 2017. In addition, this table shows that, for firms using RPE, approximately $40 \%$ of their peers operate in the same product market-we do not identify a time trend for this variable. These statistics are consistent with previous studies that employ these measures (e.g., Feichter et al., 2021) (i.e., study 2 or Chapter 3 in this dissertation).

Table 3.3 presents additional descriptive statistics on the relative performance plans that we study. Panel A in Table 3.3 presents additional descriptive statistics on the level of relative performance incentives. We estimate the level of incentives by measuring the "risk-neutral value" of the RPE plan-i.e., the current dollar amount the manager can maximally receive from his/her RPE plan. For RPE grants with equity awards, the dollar 
Table 3.1. Descriptive statistics (continued)

Panel B. Descriptives for subsamples

\begin{tabular}{lrrrrrr}
\hline \multicolumn{7}{c}{ Panel B. Descriptives for subsamples } \\
& \multicolumn{2}{c}{ Non-RPE } & \multicolumn{2}{c}{ RPE-price } & \multicolumn{2}{c}{ RPE-accounting } \\
& Mean & Median & Mean & Median & Mean & Median \\
\hline Earnings Guidance & 8.235 & 4.000 & 7.530 & 5.000 & 4.364 & 0.000 \\
Redactions & 0.188 & 0.000 & 0.120 & 0.000 & 0.156 & 0.000 \\
Peer Group Overlap & 0.000 & 0.000 & 0.139 & 0.077 & 0.137 & 0.059 \\
Product Market Overlap & 0.000 & 0.000 & 0.418 & 0.357 & 0.475 & 0.500 \\
Size & 8.349 & 8.296 & 8.848 & 8.809 & 8.957 & 8.940 \\
ROA & 0.055 & 0.055 & 0.044 & 0.039 & 0.054 & 0.044 \\
Leverage & 0.288 & 0.226 & 0.320 & 0.294 & 0.276 & 0.225 \\
MTB & 2.090 & 1.649 & 1.649 & 1.400 & 1.714 & 1.388 \\
Loss & 0.149 & 0.000 & 0.129 & 0.000 & 0.102 & 0.000 \\
Returns & 1.144 & 1.107 & 1.130 & 1.122 & 1.131 & 1.114 \\
Volatility & 0.098 & 0.082 & 0.082 & 0.069 & 0.082 & 0.070 \\
Nanalysts & 10.314 & 12.000 & 10.756 & 12.000 & 11.073 & 12.000 \\
Ninstitutions & 2.701 & 2.396 & 3.440 & 3.355 & 3.539 & 3.300 \\
Big4 & 0.972 & 1.000 & 0.983 & 1.000 & 0.990 & 1.000 \\
\hline
\end{tabular}

This table presents descriptive statistics. Panel A presents descriptive statistics for the full sample. Panel B presents descriptive statistics grouped by RPE firms and non-RPE firms. The sample contains 9,451 observations for all firms in ISS Incentive Lab from 2006 to 2017 with non-missing values for all required variables. Earnings Guidance is the number of earnings guidance issued by the firm during the fiscal year. Redactions is the number of redactions in firms' mandatory disclosures. $R P E$ is an indicator variable equal to one if the firm's proxy statement explicitly states that executive compensation is determined based on the firm's performance relative to the performance of other firms, zero otherwise. $R P E$-price restricts $R P E$ to firms with price-based metrics. $R P E$-accounting restricts $R P E$ to firms with accounting-based metrics. Peer Group Overlap is the number of overlapping peer relationships, scaled by the peer group size. Product Market Overlap is the overlap with product market competitors, identified by Hoberg and Phillips (2010, 2016), scaled by the peer group size. Size is the natural logarithm of market value of equity. $R O A$ is income before extraordinary items scaled by total assets. Leverage is long term debt plus short term debt, scaled by total assets. $M T B$ is market value of equity plus book value of liabilities divided by total assets. Loss is an indicator variable equal to one if income before extraordinary items is negative, and zero otherwise. Returns is the buy and hold return over the fiscal year. Volatility is the standard deviation of monthly returns over the fiscal year. NAnalysts is the number of analysts that issue one-year ahead earnings forecasts during the fiscal year. NInstitutions is the number of institutional investors during the fiscal year, in hundreds. Big4 is an indicator variable equal to one if the firm has a Big 4 auditor, and zero otherwise.

amount equals the maximum number of shares the manager can receive multiplied by the firm's current share price; for RPE grants with cash awards, the dollar amount simply equals the maximum cash the manager can receive. We scale this variable by the manager's previous year's total compensation, so it expresses a percentage of total compensation. We label this variable Grant Size. The mean (median) Grant Size is $77.4 \%$ (61.0\%), which implies that the average (typical) RPE plan provides the manager with the possibility to earn a RPE grant worth $77.4 \%(61.0 \%)$ of his/her previous year's total compensation. This indicates that, for firms that use RPE plans, the grants from these plans provide significant incentives to managers. This finding is in line with De Angelis and Grinstein (2019). Finally, we note that the level of incentives does not differ, on average, between price-based RPE plans and accounting-based RPE plans $(78.3 \%$ vs. $77.6 \%$; two-tailed $p$ $=0.771$ for the difference). 
Table 3.2. Relative performance plans by year and industry

Panel A. Year distribution

\begin{tabular}{|c|c|c|c|c|c|}
\hline & $R P E$ & RPE-price & RPE-accounting & g Peer Group Overlap & Product Market Overlap \\
\hline 2006 & $16.00 \%$ & $9.90 \%$ & $7.50 \%$ & $7.40 \%$ & $41.60 \%$ \\
\hline 2007 & $17.90 \%$ & $12.00 \%$ & $7.90 \%$ & $11.90 \%$ & $43.40 \%$ \\
\hline 2008 & $18.10 \%$ & $12.00 \%$ & $7.50 \%$ & $10.10 \%$ & $45.60 \%$ \\
\hline 2009 & $19.80 \%$ & $13.30 \%$ & $8.50 \%$ & $9.20 \%$ & $45.40 \%$ \\
\hline 2010 & $24.30 \%$ & $17.40 \%$ & $9.80 \%$ & $11.60 \%$ & $45.10 \%$ \\
\hline 2011 & $26.40 \%$ & $19.40 \%$ & $10.10 \%$ & $10.00 \%$ & $43.00 \%$ \\
\hline 2012 & $32.50 \%$ & $24.90 \%$ & $11.10 \%$ & $12.80 \%$ & $38.80 \%$ \\
\hline 2013 & $33.60 \%$ & $27.40 \%$ & $10.80 \%$ & $14.20 \%$ & $43.70 \%$ \\
\hline 2014 & $36.70 \%$ & $30.00 \%$ & $11.90 \%$ & $14.00 \%$ & $43.80 \%$ \\
\hline 2015 & $38.10 \%$ & $31.40 \%$ & $11.90 \%$ & $14.70 \%$ & $41.40 \%$ \\
\hline 2016 & $37.80 \%$ & $31.20 \%$ & $12.20 \%$ & $16.20 \%$ & $37.10 \%$ \\
\hline 2017 & $38.30 \%$ & $32.20 \%$ & $11.40 \%$ & $23.90 \%$ & $43.70 \%$ \\
\hline \multicolumn{6}{|c|}{ Panel B. Industry distribution } \\
\hline & $R P E$ & RPE-price & RPE-accounting & Peer Group Overlap & Product Market Overlap \\
\hline (1) & $16.00 \%$ & $9.90 \%$ & $7.50 \%$ & $7.40 \%$ & $41.60 \%$ \\
\hline$(2)$ & $17.90 \%$ & $12.00 \%$ & $7.90 \%$ & $11.90 \%$ & $43.40 \%$ \\
\hline (3) & $18.10 \%$ & $12.00 \%$ & $7.50 \%$ & $10.10 \%$ & $45.60 \%$ \\
\hline (4) & $19.80 \%$ & $13.30 \%$ & $8.50 \%$ & $9.20 \%$ & $45.40 \%$ \\
\hline$(5)$ & $24.30 \%$ & $17.40 \%$ & $9.80 \%$ & $11.60 \%$ & $45.10 \%$ \\
\hline (6) & $26.40 \%$ & $19.40 \%$ & $10.10 \%$ & $10.00 \%$ & $43.00 \%$ \\
\hline (7) & $32.50 \%$ & $24.90 \%$ & $11.10 \%$ & $12.80 \%$ & $38.80 \%$ \\
\hline$(8)$ & $33.60 \%$ & $27.40 \%$ & $10.80 \%$ & $14.20 \%$ & $43.70 \%$ \\
\hline (9) & $36.70 \%$ & $30.00 \%$ & $11.90 \%$ & $14.00 \%$ & $43.80 \%$ \\
\hline$(10)$ & $38.10 \%$ & $31.40 \%$ & $11.90 \%$ & $14.70 \%$ & $41.40 \%$ \\
\hline (11) & $37.80 \%$ & $31.20 \%$ & $12.20 \%$ & $16.20 \%$ & $37.10 \%$ \\
\hline$(12)$ & $38.30 \%$ & $32.20 \%$ & $11.40 \%$ & $23.90 \%$ & $43.70 \%$ \\
\hline
\end{tabular}

This table presents descriptive statistics about the RPE plans (with self-selected peers) and characteristics. Panel A presents mean statistics across time. Panel B presents mean statistics across industries. The sample contains 9,451 observations for all firms in ISS Incentive Lab from 2006 to 2017 with non-missing values for all required variables. The industry classification follows the 12 industry groups identified by Fama and French (1997): (1) Consumer Non-Durables; (2) Consumer Durables; (3) Manufacturing; (4) Oil, Gas, and Coal Extraction; (5) Chemicals and Allied Products; (6) Business Equipment; (7) Telephone and Television Transmission; (8) Utilities; (9) Wholesale and Retail; (10) Healthcare and Medical Equipment; (11) Finance; and (12) Other. Row and column totals may not always total to $100 \%$, because some firms use multiple mechanisms. All variables are defined in the caption of Table 3.1 .

Panel B in Table 3.3 presents additional descriptive statistics on the size and dynamics of the peer group in relative performance plans. Regarding size, the mean (median) peer group contains 15.430 (13) peers. In untabulated analyses, we find that there is significant variability in peer group size, e.g., the 10th percentile being 5 peers and the 90 th percentile being 25 peers. The average peer group for price-based RPE plans is slightly larger than the average peer group for accounting-based RPE plans (16.670 vs. 11.940 , respectively). In terms of dynamics, we note that peer groups for relative performance evaluation are quite sticky over time. For example, in our sample we find that the mean (median) firm-peer relationship lasts for $59.6 \%(57.4 \%)$ of the time the 
Table 3.3. Additional descriptive statistics on relative performance plans

Panel A. Level of incentives

\begin{tabular}{|c|c|c|c|c|c|c|c|}
\hline & (1) & (2) & (3) & (4) & (5) & (6) & (7) \\
\hline & All RI & PE firms & RPE & Erice & \multicolumn{3}{|c|}{ RPE-accounting } \\
\hline & Mean & Median & Mean & Median & Mean & Median & $(5)-(3)$ \\
\hline Grant Size & 0.774 & 0.610 & 0.783 & 0.645 & 0.776 & 0.557 & 0.007 \\
\hline
\end{tabular}

Panel B. Peer group size and dynamics

\begin{tabular}{|c|c|c|c|c|c|c|c|}
\hline & $(1)$ & $(2)$ & $(3)$ & $(4)$ & $(5)$ & (6) & $(7)$ \\
\hline & \multicolumn{2}{|c|}{ All RPE firms } & \multicolumn{2}{|c|}{ RPE-price } & \multicolumn{2}{|c|}{ RPE-accounting } & \\
\hline & Mean I & Median $\mathrm{N}$ & Mean & Median & Mean & Median & $(5)-(3)$ \\
\hline Peer Group Size & 15.430 & 13.0001 & 16.670 & 14.000 & 11.940 & 11.000 & $-4.728^{* * * 2}$ \\
\hline Duration Firm-Peer & 0.596 & 0.574 & 0.585 & 0.558 & 0.602 & 0.589 & $-0.017^{* *}$ \\
\hline \multicolumn{8}{|c|}{ Panel C. Overlap } \\
\hline & (1) & $(2)$ & (3) & (4) & $(5)$ & (6) & (7) \\
\hline & \multicolumn{2}{|c|}{ All RPE firms } & \multicolumn{2}{|c|}{ RPE-price } & \multicolumn{2}{|c|}{ RPE-accounting } & \\
\hline & Mean & n Median & Mean & Median & Mean & Median & $(5)-(3)$ \\
\hline Peer Group Overlap & 0.13 & 0.067 & 0.139 & 0.077 & 70.137 & 0.059 & -0.002 \\
\hline Product Market Overlap & ap 0.42 & 0.364 & 0.418 & 0.357 & $7 \quad 0.475$ & 0.500 & $0.057^{* \ldots:}$ \\
\hline
\end{tabular}

This table presents additional descriptive statistics on relative performance plans. Panel A presents descriptive statistics on the level of relative performance incentives. Panel B presents descriptive statistics on the size and dynamics of the peer group. Panel C presents descriptive statistics on the type of peers chosen. Grant Size is the "risk-neutral value" of the RPE plan, scaled by the manager's previous year's total compensation. The "risk-neutral value" of the RPE plan equals the current dollar amount the manager can maximally receive from his/her RPE plan-for RPE grants with equity awards, the dollar amount equals the maximum number of shares the manager can receive multiplied by the firm's current share price; for RPE grants with cash awards, the dollar amount simply equals the maximum cash the manager can receive. Peer Group Size is the total number of firms in the peer group. Duration Firm-Peer is the time a firm-peer relationship lasts, expressed as a percentage of the time the focal firm uses RPE. Peer Group Overlap is the number of overlapping peer relationships, scaled by the peer group size. Product Market Overlap is the overlap with product market competitors, identified by Hoberg and Phillips $(2010,2016)$, scaled by the peer group size. " $"$ and ${ }^{* * *}$ indicate significance at two-tailed probability levels of $10 \%, 5 \%$, and $1 \%$, respectively.

focal firm uses RPE. ${ }^{83}$ This statistic implies that, for a firm that uses RPE for 10 years, the mean (median) peer is in the peer group for at least 6 (5.75) of those 10 years. In untabulated analyses, we further find this statistic is fairly right skewed: the first quartile of this statistic is $44.4 \%$. This then implies that for a firm that uses RPE for 10 years, at least $75 \%$ of the mean peer group remains unchanged for at least 4.4 years.

Panel $\mathrm{C}$ in Table 3.3 presents additional descriptive statistics on the type of peers chosen in relative performance plans. In this regard, we focus on Peer Group Overlap and Product Market Overlap. We find that price-based RPE plans and accounting-based RPE plans have similar peer group overlap $(13.9 \%$ vs. $13.7 \%$, respectively), but different product market overlap ( $41.8 \%$ vs. $47.5 \%$, respectively).

83. Note that this statistic is quite difficult to express in-and relatively uninformative when expressed in-actual years, because there is much variation in how long firms themselves use RPE. Hence, it is more convenient to express this statistic as a percentage of the time the focal firm uses RPE. 


\section{Multivariate Tests}

\section{V.A. Relative Performance Plans and Information Disclosure}

In this section, we examine how relative performance plans relate to managers' mandatory and voluntary disclosure behavior. To do so, we estimate the following equation using both a Poisson regression and an OLS regression: ${ }^{84}$

$$
\left[\text { Disclosure }_{i j t}\right]=\alpha+\beta_{1}\left[R P E_{i j t}\right]+\gamma^{\prime} X_{i j t}+\theta^{\prime} \mu_{j}+\phi^{\prime} v_{t}+\varepsilon_{i j t}
$$

In this equation, $i, j$ and $t$ index firm, industry, and year, respectively. Disclosure is either Redactions or Earnings Guidance. We include a variety of control variables in $X$ that closely follow Heinle et al. (2020); specifically, we control for firm size (Size), leverage (Leverage), growth opportunities $(M T B)$, accounting and stock performance (ROA, Loss, and Returns), stock return volatility (Volatility), the number of analysts covering the firm (NAnalysts), the number of institutional investors (NInstitutions), an indicator variable for whether the firm has a Big 4 auditor (Big4). We also include and industry fixed effects (based on the 48 industry groups identified by Fama and French (1997)), $\mu_{j}$, and year fixed effects, $v_{t}$. Finally, we base all inferences on two-way cluster-robust standard errors (by firm and year), following Gow et al. (2010).

Furthermore, to mitigate potential confounding effects of observable factors between firms using relative performance plans and firms not using relative performance plans, we use an entropy balancing approach in all our specifications (e.g., Hainmueller, 2017). Specifically, we balance on the first moment of the distributions of all control variables of Equation (3.5.1). Figure 3.2 illustrates a love plot that visualizes the covariate balance between RPE firms and non-RPE firms. This figure shows that after balancing all differences between the two groups are insignificant (i.e., all two-tailed $p$-values $>$ $0.999)$.

If, as we predict, RPE highlights competition with peers, we expect managers to increase the opacity of mandatory operational disclosures by more frequently redacting their mandatory disclosures. In addition, we expect managers evaluated on RPE to reduce voluntary disclosure by providing less frequent earnings guidance.

We report the results of these tests in Table 3.4. In Panel A, we do not find that managers evaluated on RPE redact more frequently in their mandatory disclosures, compared to a matched sample of managers not evaluated on RPE. However, in Panel B, we do find that managers evaluated on RPE provide fewer voluntary earnings guidance than do their non-RPE counterparts. Collectively, these results provide some evidence that RPE incentive-compensation contracts differentially affect firms' disclosure behavior-on average. Below we examine whether these average associations are moderated by strategic interaction intensity.

84. We also use a Poisson regression because, strictly speaking, we estimate count data (i.e., disclosure is never negative). This technique is particularly designed to model such count data, and is also used in prior literature on disclosure in accounting (e.g., Balakrishnan, Billings, Kelly, and Ljungqvist, 2014, Bamber et al., 2010, Lennox and Park, 2006). 
Figure 3.2. Covariate entropy balance

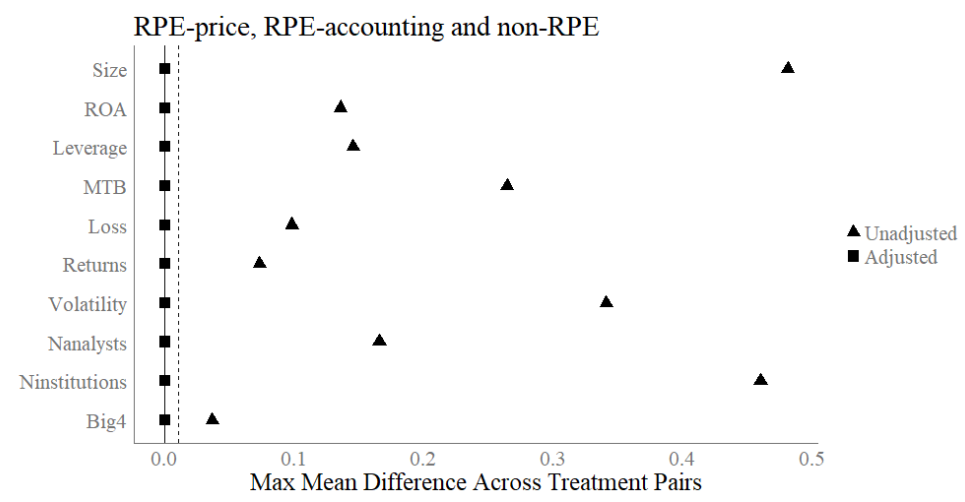

This figure illustrates a love plot that visualizes the multinomial covariate balance between RPEprice, RPE-accounting, and non-RPE firms after entropy balancing the first moment of the distributions of all covariates in Equation (3.5.1). For parsimony, this figure does not visualize the covariate balance for the year and industry indicators.

\section{V.B. Strategic Interaction Intensity and Information Disclosure}

In this section, we examine how strategic interaction intensity moderates the relation between relative performance plans and mandatory and voluntary disclosure decisions. To do so, we estimate a modified version of Equation (3.5.1), in which we include indicator variables for firms with high strategic interaction intensity. ${ }^{85}$

Specifically, we re-estimate Equation (3.5.1) and include: (1) High PGO, which is an indicator variable equal to one if the firm's Peer Group Overlap is greater than the median of Peer Group Overlap in the subsample of RPE firms, zero otherwise; (2) High PMO is an indicator variable equal to one if the firm's Product Market Overlap is greater than the median of Product Market Overlap in the subsample of RPE firms, zero otherwise; and (3) High Overlap is an indicator equal to one if both High PGO and High PMO are one, zero otherwise. As such, RPE estimates an effect between non-RPE firms and RPE with low strategic interaction intensity, and the interaction estimates the differential effect for RPE firms with high strategic interaction intensity. Note that the main effects of the indicator variables are omitted, because they have a perfect correlation with their interaction with $R P E$.

Table 3.5 presents results estimating the association between relative performance evaluation, peer group overlap, product market overlap and disclosure. In Panel A, we find that, compared to RPE managers with low strategic interaction intensity, RPE managers with high strategic interaction intensity redact more frequently in their

85. We include these indicator variables to avoid estimating excessive high-level interaction models-to ease the interpretation of the results. Specifically, this approach allows us, without much loss of information, to avoid estimating a three-way interaction and the respective lower-level two-way interactions. Moreover, in our disclosure substitution analyses (see Sections V.C and V.D for details), we avoid including a four-way interaction and numerous lower-level three-way and two-way interactions. 
Table 3.4. Relative performance evaluation and disclosure

\begin{tabular}{|c|c|c|c|c|}
\hline \multirow{3}{*}{$\frac{\text { Variable }}{R P E}$} & \multicolumn{2}{|l|}{ (1) } & \multicolumn{2}{|c|}{$(2)$} \\
\hline & \multicolumn{4}{|c|}{$\begin{array}{c}\text { Dependent variable: } \\
\text { Redactions }\end{array}$} \\
\hline & -0.060 & $(0.187)$ & -0.010 & $(0.026)$ \\
\hline Size & 0.042 & $(0.085)$ & 0.007 & $(0.017)$ \\
\hline$R O A$ & -0.387 & $(0.694)$ & -0.030 & $(0.116)$ \\
\hline Leverage & -0.159 & $(0.236)$ & -0.016 & $(0.026)$ \\
\hline$M T B$ & -0.050 & $(0.087)$ & -0.005 & $(0.012)$ \\
\hline Loss & $0.188^{\dagger}$ & $(0.130)$ & 0.038 & $(0.025)$ \\
\hline Returns & -0.119 & $(0.128)$ & -0.018 & $(0.021)$ \\
\hline Volatility & $4.156^{* * *}$ & $(1.268)$ & $0.773^{* *}$ & $(0.253)$ \\
\hline Nanalysts & 0.000 & $(0.025)$ & 0.000 & $(0.004)$ \\
\hline Ninstitutions & -0.051 & $(0.060)$ & -0.009 & $(0.012)$ \\
\hline Big4 & -0.487 & $(0.412)$ & -0.064 & $(0.066)$ \\
\hline Year effects & \multicolumn{2}{|l|}{ yes } & \multicolumn{2}{|c|}{ yes } \\
\hline Industry effects & \multicolumn{2}{|l|}{ yes } & \multicolumn{2}{|c|}{ yes } \\
\hline Estimator & \multicolumn{2}{|c|}{ Poisson } & \multicolumn{2}{|c|}{ OLS } \\
\hline Observations & \multicolumn{2}{|c|}{9,451} & \multicolumn{2}{|c|}{9,451} \\
\hline Adjusted (pseudo) $R^{2}$ & \multicolumn{2}{|c|}{$2.944 \%$} & \multicolumn{2}{|c|}{$3.545 \%$} \\
\hline \multicolumn{5}{|c|}{ Panel B. Management earnings guidance } \\
\hline & \multicolumn{2}{|c|}{ (1) } & \multicolumn{2}{|c|}{$(2)$} \\
\hline Variable & \multicolumn{4}{|c|}{ Dependent variable: } \\
\hline$R P E$ & $-0.147^{\circ}$ & $(0.075)$ & $-1.163^{*}$ & $(0.583)$ \\
\hline Size & $0.208^{* * *}$ & $(0.065)$ & $1.697^{* *}$ & $(0.574)$ \\
\hline$R O A$ & $-0.837^{*}$ & $(0.469)$ & $-5.771^{*}$ & $(2.777)$ \\
\hline Leverage & 0.213 & $(0.193)$ & 0.879 & $(0.951)$ \\
\hline$M T B$ & $-0.090^{*}$ & $(0.055)$ & $-0.674^{\dagger}$ & $(0.397)$ \\
\hline Loss & -0.009 & $(0.165)$ & 0.059 & $(1.075)$ \\
\hline Returns & 0.037 & $(0.053)$ & 0.343 & $(0.403)$ \\
\hline Volatility & 0.135 & $(0.790)$ & 0.693 & $(5.429)$ \\
\hline Nanalysts & -0.012 & $(0.012)$ & -0.117 & $(0.120)$ \\
\hline Ninstitutions & $-0.075^{*}$ & $(0.037)$ & $-0.696^{*}$ & $(0.348)$ \\
\hline Big4 & 0.149 & $(0.457)$ & 0.684 & (2.087) \\
\hline Year effects & \multicolumn{2}{|l|}{ yes } & \multicolumn{2}{|c|}{ yes } \\
\hline Industry effects & \multicolumn{2}{|c|}{ yes } & \multicolumn{2}{|c|}{ yes } \\
\hline Estimator & \multicolumn{2}{|c|}{ Poisson } & \multicolumn{2}{|c|}{ OLS } \\
\hline Observations & \multicolumn{2}{|c|}{9,451} & \multicolumn{2}{|c|}{9,451} \\
\hline Adjusted (pseudo) $R^{2}$ & \multicolumn{2}{|c|}{$11.837 \%$} & 9.781 & \\
\hline
\end{tabular}

This table presents results examining the association between relative performance evaluation and disclosure. Panel A presents results for redactions in mandatory disclosures. Panel B presents results for management earnings guidance. The subsample of non-RPE firms is entropy balanced to the subsample of RPE firms using all control variables, including year and industry indicators. The industry classification follows the 48 industry groups identified by Fama and French (1997). Standard errors are in parentheses and are adjusted for within cluster correlation by firm and year conform Gow et al. (2010). ${ }^{\dagger}, ", \cdots$ and ${ }^{* * *}$ indicate significance at two-tailed probability levels of $15 \%$, $10 \%, 5 \%$, and $1 \%$, respectively. All variables are defined in the caption of Table 3.1. 
Table 3.5. Peer group overlap, product market overlap and disclosure

Panel A. Redactions in mandatory disclosures

\begin{tabular}{|c|c|c|c|c|c|c|}
\hline Variable & (1) & (2) & $\begin{array}{c}(3) \\
\text { Dependen } \\
\text { Reda }\end{array}$ & $\begin{array}{l}\quad(4) \\
\text { variable: } \\
\text { tions }\end{array}$ & (5) & (6) \\
\hline$\overline{R P E}$ & $\begin{array}{c}-0.260 \\
(0.206)\end{array}$ & $\begin{array}{c}-0.035 \\
(0.027)\end{array}$ & $\begin{array}{c}-0.239 \\
(0.205)\end{array}$ & $\begin{array}{c}-0.032 \\
(0.026)\end{array}$ & $\begin{array}{c}-0.284^{\dagger} \\
(0.191)\end{array}$ & $\begin{array}{c}-0.037 \\
(0.024)\end{array}$ \\
\hline$R P E \times$ High $P G O$ & $\begin{array}{c}0.428^{*} \\
(0.249)\end{array}$ & $\begin{array}{c}0.051 \\
(0.034)\end{array}$ & & & & \\
\hline$R P E \times$ High $P M O$ & & & $\begin{array}{c}0.326 \\
(0.263)\end{array}$ & $\begin{array}{c}0.043 \\
(0.038)\end{array}$ & & \\
\hline$R P E \times$ High Overlap & & & & & $\begin{array}{c}0.611^{*} \\
(0.258)\end{array}$ & $\begin{array}{c}0.079^{*} \\
(0.040)\end{array}$ \\
\hline Controls & yes & yes & yes & yes & $\overline{\text { yes }}$ & yes \\
\hline Year effects & yes & yes & yes & yes & yes & yes \\
\hline Industry effects & yes & yes & yes & yes & yes & yes \\
\hline Estimator & Poisson & OLS & Poisson & OLS & Poisson & OLS \\
\hline Observations & 9,451 & 9,451 & 9,451 & 9,451 & 9,451 & 9,451 \\
\hline Adjusted (pseudo) $R^{2}$ & $2.750 \%$ & $3.620 \%$ & $3.111 \%$ & $3.646 \%$ & $2.965 \%$ & $3.708 \%$ \\
\hline
\end{tabular}

Panel B. Management earnings guidance

\begin{tabular}{|c|c|c|c|c|c|c|}
\hline Variable & (1) & (2) & $\begin{array}{c}(3) \\
\text { Dependen } \\
\text { Earnings }\end{array}$ & $\begin{array}{c}\text { (4) } \\
\text { t variable: } \\
\text { Guidance }\end{array}$ & (5) & (6) \\
\hline$\overline{R P E}$ & $\begin{array}{c}-0.064 \\
(0.091)\end{array}$ & $\begin{array}{c}-0.536 \\
(0.749)\end{array}$ & $\begin{array}{c}0.010 \\
(0.089)\end{array}$ & $\begin{array}{c}0.052 \\
(0.739)\end{array}$ & $\begin{array}{c}-0.066 \\
(0.083)\end{array}$ & $\begin{array}{c}-0.546 \\
(0.672)\end{array}$ \\
\hline$R P E \times$ High $P G O$ & $\begin{array}{c}-0.195^{\prime \prime} \\
(0.110)\end{array}$ & $\begin{array}{c}-1.272^{\dagger} \\
(0.788)\end{array}$ & & & & \\
\hline$R P E \times$ High $P M O$ & & & $\begin{array}{c}-0.359^{3 *} \\
(0.106)\end{array}$ & $\begin{array}{c}-2.438^{*} \\
(0.831)\end{array}$ & & \\
\hline$R P E \times$ High Overlap & & & & & $\begin{array}{c}-0.318^{\ldots} \\
(0.114) \\
\end{array}$ & $\begin{array}{c}-1.838^{*} \\
(0.747) \\
\end{array}$ \\
\hline Controls & yes & yes & $\overline{\text { yes }}$ & yes & yes & yes \\
\hline Year effects & yes & yes & yes & yes & yes & yes \\
\hline Industry effects & yes & yes & yes & yes & yes & yes \\
\hline Estimator & Poisson & OLS & Poisson & OLS & Poisson & OLS \\
\hline Observations & 9,451 & 9,451 & 9,451 & 9,451 & 9,451 & 9,451 \\
\hline Adjusted (pseudo) $R^{2}$ & $11.907 \%$ & $9.895 \%$ & $12.573 \%$ & $9.971 \%$ & $12.103 \%$ & $9.941 \%$ \\
\hline
\end{tabular}

This table presents results examining the association between relative performance evaluation, peer group overlap, product market overlap and disclosure. Panel A presents results for redactions in mandatory disclosures. Panel B presents results for management earnings guidance. High PGO is an indicator variable equal to one if the firm's Peer Group Overlap is greater than the median of Peer Group Overlap in the subsample of RPE firms, zero otherwise. High PMO is an indicator variable equal to one if the firm's Product Market Overlap is greater than the median of Product Market Overlap in the subsample of RPE firms, zero otherwise. High Overlap is an indicator equal to one if both High PGO and High PMO are one, zero otherwise. The main effects of High PGO, High $P M O$ and High Overlap are omitted, because they have a perfect correlation with their interaction with $R P E$. The subsample of non-RPE firms is entropy balanced to the subsample of RPE firms using all control variables, including year and industry indicators. The industry classification follows the 48 industry groups identified by Fama and French (1997). Standard errors are in parentheses and are adjusted for within cluster correlation by firm and year conform Gow et al. (2010). $\dagger$, ", , and ${ }^{* *}$ indicate significance at two-tailed probability levels of $15 \%, 10 \%, 5 \%$, and $1 \%$, respectively. All variables are defined in the caption of Table 3.1 . 
mandatory disclosures. In addition, in Panel $\mathrm{B}$, we find that the reduction in voluntary earnings guidance is concentrated in those firms with high levels of strategic interaction intensity.

Collectively, these findings corroborate the notion that relative performance plans induce competition which differentially affects managers' disclosure decisions, and that this competition is related to strategic interaction intensity.

\section{V.C. Relative Performance Plans and Disclosure Substitution}

In this section, we test the association between relative performance evaluation and disclosure substitution (i.e., the association between management earnings guidance and redactions in mandatory disclosures). We estimate "disclosure substitution" by modifying the version of Equation (3.5.1) where the dependent variable is Earnings Guidance to include Redactions as an independent variable (e.g., Heinle et al., 2020).

If, as we predict, managers evaluated on relative price-based metrics have strong incentives to ensure investors have adequate pricing information, we expect that RPEprice managers increase voluntary disclosure when withholding proprietary information in mandatory disclosures from competitors. This implies that disclosure substitution for $\mathrm{RPE}$-price managers is stronger than for managers not evaluated on RPE. We predict the opposite is true for RPE-accounting managers, that RPE-accounting managers decrease voluntary disclosure when withholding proprietary information in mandatory disclosures from competitors. This implies that disclosure substitution for RPEmanagers firms is weaker than for managers not evaluated on RPE. To test these differential disclosure substitution predictions, we partition our sample into RPE-price and RPE-accounting firms and compare their disclosure substitution against non-RPE firms, by including an interaction term between the $R P E$ variables (i.e., $R P E$-price and $R P E$-accounting) and Redactions. For completeness, we also estimate the pooled effect of all RPE plans (i.e., $R P E$ ).

Table 3.6 presents results examining the association between the existence of a relative performance contract and disclosure substitution. In Columns (1) and (2), we are unable to document evidence of disclosure substitution for either RPE firms or nonRPE firms included in our ISS Incentive Lab sample. In Appendix II, we explore this insignificant effect in more detail and find that it is an artifact of the ISS Incentive Lab sample (i.e., S\&P 500 and 400 firms), for which earnings guidance is de facto mandatory for market leaders. ${ }^{86}$ In a broader Compustat sample, we replicate the main inferences in Heinle et al. (2020) and document evidence of disclosure substitution.

86. Specifically, we investigate a boundary condition to the substitution effect documented in Heinle et al. (2020) because, for a subset of firms closely followed by market participants (i.e., firms in our ISS Incentive Lab sample), the high demand for earnings guidance alters the costs of non-disclosure so as to result in a de facto mandatory nature of earnings guidance. In this Appendix, we: (1) replicate the main inferences in Heinle et al. (2020) (in a "Compustat sample"); and (2) show that there exists a boundary condition to the substitution effect conditional on firms' guidance history-for "always-guiders" there is little room to supplement redactions in mandatory disclosures with incremental earnings guidance. Hence, we conclude that the absence of this disclosure substitution in firms in the ISS Incentive Lab universe in our main analysis is likely not due to coding mistakes, but rather due to economic differences between these firms and firms that are not part of a S\&P index. 
Table 3.6. Relative performance evaluation and disclosure substitution

\begin{tabular}{|c|c|c|c|c|c|c|}
\hline \multirow[b]{3}{*}{ Variable } & \multicolumn{2}{|c|}{$R P E$} & \multicolumn{2}{|c|}{ RPE-price } & \multicolumn{2}{|c|}{$R P E$-accounting } \\
\hline & (1) & $(2)$ & (3) & $(4)$ & $(5)$ & $(6)^{\circ}$ \\
\hline & & & $\begin{array}{l}\text { Dependen } \\
\text { Earnings }\end{array}$ & $\begin{array}{l}\text { variable: } \\
\text { vidance }\end{array}$ & & \\
\hline$\overline{R P E}$ & $\begin{array}{c}-0.186 \\
(0.083)\end{array}$ & $\begin{array}{c}-1.455^{3} \\
(0.655)\end{array}$ & & & & \\
\hline$R P E$-price & & & $\begin{array}{c}-0.089 \\
(0.079)\end{array}$ & $\begin{array}{c}-0.830 \\
(0.677)\end{array}$ & & \\
\hline$R P E$-accounting & & & & & $\begin{array}{c}-0.404^{*} \\
(0.177)\end{array}$ & $\begin{array}{c}-2.838^{*} \\
(1.219)\end{array}$ \\
\hline Redactions & $\begin{array}{c}-0.085 \\
(0.095)\end{array}$ & $\begin{array}{c}-0.595 \\
(0.740)\end{array}$ & $\begin{array}{c}-0.123 \\
(0.097)\end{array}$ & $\begin{array}{c}-0.997 \\
(0.781)\end{array}$ & $\begin{array}{c}0.035 \\
(0.113)\end{array}$ & $\begin{array}{c}0.291 \\
(0.908)\end{array}$ \\
\hline$R P E \times$ Redactions & $\begin{array}{c}0.185 \\
(0.168)\end{array}$ & $\begin{array}{c}1.353 \\
(1.299)\end{array}$ & & & & \\
\hline$R P E$-price $\times$ Redactions & & & $\begin{array}{c}0.410 \\
(0.190)\end{array}$ & $\begin{array}{c}3.951^{*} \\
(2.174)\end{array}$ & & \\
\hline$R P E$-accounting $\times$ Redactions & & & & & $\begin{array}{c}-0.350^{*} \\
(0.174) \\
\end{array}$ & $\begin{array}{c}-1.179 \\
(0.975) \\
\end{array}$ \\
\hline Controls & yes & yes & yes & yes & yes & yes \\
\hline Year effects & yes & yes & yes & yes & yes & yes \\
\hline Industry effects & yes & yes & yes & yes & yes & yes \\
\hline Estimator & Poisson & OLS & Poisson & OLS & Poisson & OLS \\
\hline Observations & 9,451 & 9,451 & 8,504 & 8,504 & 7,504 & 7,504 \\
\hline Adjusted (pseudo) $R^{2}$ & $13.586 \%$ & $5.461 \%$ & $12.742 \%$ & $2.867 \%$ & $8.589 \%$ & $1.265 \%$ \\
\hline
\end{tabular}

This table presents results examining the association between relative performance evaluation and disclosure substitution (i.e., the association between management earnings guidance and redactions in mandatory disclosures). The subsample of non-RPE firms is entropy balanced to the subsample of RPE firms using all control variables, including year and industry indicators. The industry classification follows the 48 industry groups identified by Fama and French (1997). Standard errors are in parentheses and are adjusted for within cluster correlation by firm and year conform Gow, Ormazabal, and Taylor (2010). ${ }^{\dagger}, ",{ }^{*}$ and ${ }^{* * *}$ indicate significance at two-tailed probability levels of $15 \%, 10 \%, 5 \%$, and $1 \%$, respectively. All variables are defined in the caption of Table 3.1 .

In Columns (3) and (4), we find that the coefficient on RPE-price $\times$ Redactions is positive and statistically significant. This coefficient implies that, compared to non-RPE managers, $R P E$-price managers provide more guidance upon redacting their mandatory disclosures. This finding is consistent with our prediction that price-based RPE contracts highlight both the cost of mandatory operational disclosures, as well as the importance of minimizing information asymmetry with the market, resulting in an enhanced substitution effect relative to managers not evaluated on RPE.

In Column (5), we find that the coefficient on RPE-accounting $\times$ Redactions is negative and statistically significant. This coefficient implies that, compared to managers not evaluated on RPE, $R P E$-accounting managers provide fewer guidance upon redacting their mandatory disclosures. This finding implies that $R P E$-accounting firms-firms that benefit from concealing earnings performance benchmarks from peers-do not substitute with additional voluntary earnings guidance. In fact, the disincentive to provide performance peers an earnings target to beat results not in substitution at all; instead, managers increase withholding of both mandatory and voluntary disclosure. 
Table 3.7. Peer group overlap, product market overlap and disclosure substitution

\begin{tabular}{|c|c|c|c|c|c|c|}
\hline \multirow[b]{2}{*}{ Variable } & \multicolumn{6}{|c|}{ Panel A. RPE-price } \\
\hline & $(1)$ & $(2)$ & $\begin{array}{c}\text { (3) } \\
\text { Dependen } \\
\text { Earnings }\end{array}$ & $\begin{array}{c}\text { (4) } \\
\text { t variable: } \\
\text { Guidance }\end{array}$ & $(5)$ & $(6)$ \\
\hline RPE-price & $\begin{array}{c}-0.038 \\
(0.100)\end{array}$ & $\begin{array}{c}-0.388 \\
(0.890)\end{array}$ & $\begin{array}{l}0.05 \\
(0.087)\end{array}$ & $\begin{array}{c}0.346 \\
(0.807)\end{array}$ & $\begin{array}{c}-0.025 \\
(0.081)\end{array}$ & $\begin{array}{c}-0.298 \\
(0.728)\end{array}$ \\
\hline Redactions & $\begin{array}{c}-0.116 \\
(0.096)\end{array}$ & $\begin{array}{c}-0.939 \\
(0.780)\end{array}$ & $\begin{array}{l}-0.127 \\
(0.099)\end{array}$ & $\begin{array}{c}-1.000 \\
(0.796)\end{array}$ & $\begin{array}{c}-0.124 \\
(0.099)\end{array}$ & $\begin{array}{c}-0.990 \\
(0.793)\end{array}$ \\
\hline$R P E$-price $\times$ Redactions & $\begin{array}{c}0.733^{*} \\
(0.305)\end{array}$ & $\begin{array}{r}9.590^{\dagger} \\
(5.782)\end{array}$ & $\begin{array}{c}0.350 \\
(0.197)\end{array}$ & $\begin{array}{c}3.901 \\
(2.585)\end{array}$ & $\begin{array}{c}0.632^{3} \\
(0.281)\end{array}$ & $\begin{array}{r}7.807^{\dagger} \\
(4.763)\end{array}$ \\
\hline RPE-price $\times$ High $P G O$ & $\begin{array}{c}-0.139 \\
(0.126)\end{array}$ & $\begin{array}{c}-1.124 \\
(0.996)\end{array}$ & & & & \\
\hline RPE-price $\times$ High $P M O$ & & & $\begin{array}{c}-0.314^{*} \\
(0.131)\end{array}$ & $\begin{array}{l}-2.508^{*} \\
(1.191)\end{array}$ & & \\
\hline RPE-price $\times$ High Overlap & & & & & $\begin{array}{c}-0.278^{*} \\
(0.115)\end{array}$ & $\begin{array}{c}-1.996 \\
(0.837)\end{array}$ \\
\hline RPE-price $\times$ Redactions $\times$ High $P G O$ & $\begin{array}{c}-0.550 \\
(0.262)\end{array}$ & $\begin{array}{c}-8.104 \\
(5.462)\end{array}$ & & & & \\
\hline RPE-price $\times$ Redactions $\times$ High $P M O$ & & & $\begin{array}{c}0.115 \\
(0.240)\end{array}$ & $\begin{array}{c}0.268 \\
(3.276)\end{array}$ & & \\
\hline RPE-price $\times$ Redactions $\times$ High Overlap & & & & & $\begin{array}{r}-0.397^{*} \\
(0.227) \\
\end{array}$ & $\begin{array}{c}-6.038 \\
(4.382) \\
\end{array}$ \\
\hline Controls & yes & yes & yes & yes & yes & yes \\
\hline Year effects & yes & yes & yes & yes & yes & yes \\
\hline Industry effects & yes & yes & yes & yes & yes & yes \\
\hline Estimator & Poisson & OLS & Poisson & OLS & Poisson & OLS \\
\hline Observations & 9,451 & 9,451 & 8,504 & 8,504 & 7,504 & 7,504 \\
\hline Adjusted (pseudo) $R^{2}$ & $11.148 \%$ & $8.624 \%$ & $11.667 \%$ & $8.542 \%$ & $11.269 \%$ & $8.623 \%$ \\
\hline
\end{tabular}

Collectively, these findings suggest that relative performance plans matter for the quality of information in capital markets.

\section{V.D. Strategic Interaction Intensity and Disclosure Substitution}

In this section, we examine how strategic interaction intensity moderates the relation between relative performance evaluation and disclosure substitution. To do so, we include the indicator variables for firms with high strategic interaction intensity in the disclosure substitution equation (see Sections V.B and V.C for details). We tabulate these results in Table 3.7. Panel A presents results for RPE-price firms. Panel B presents results for RPE-accounting firms.

In Panel $\mathrm{A}$, we find that the disclosure substitution effect for $R P E$-price firms depends on strategic interaction intensity. Specifically, we find that the increase in guidance upon redacting their mandatory disclosures is concentrated in those RPE-price firms with low levels of peer group overlap. For RPE-price with high levels of peer group overlap, we find that disclosure substitution decreases (i.e., nullifies). We do not find evidence that product market overlap influences the relation between RPE-price incentives and disclosure substitution. Together, these findings imply that when competition induced by peer group overlap is perceived to be sufficiently high, the benefit of reducing information asymmetry with the market is lower than-and thus outweighed by-the proprietary cost of additional voluntary disclosure-even for managers who have significant price-based incentives. 
Table 3.7. Peer group overlap, product market overlap and disclosure substitution (continued)

Panel B. RPE-accounting

\begin{tabular}{|c|c|c|c|c|c|c|}
\hline Variable & (1) & (2) & $\begin{array}{c}(3) \\
\text { Dependen } \\
\text { Earnings }\end{array}$ & $\begin{array}{l}\text { (4) } \\
\text { variable: } \\
\text { uidance }\end{array}$ & $(5)$ & (6) \\
\hline RPE-accounting & $\begin{array}{c}-0.363^{*} \\
(0.193)\end{array}$ & $\begin{array}{c}-2.796^{*} \\
(1.460)\end{array}$ & $\begin{array}{l}-0.121 \\
(0.213)\end{array}$ & $\begin{array}{c}-0.915 \\
(1.674)\end{array}$ & $\begin{array}{c}-0.331^{\prime \prime} \\
(0.188)\end{array}$ & $\begin{array}{c}-2.491 \\
(1.424)\end{array}$ \\
\hline Redactions & $\begin{array}{c}0.036 \\
(0.112)\end{array}$ & $\begin{array}{c}0.296 \\
(0.912)\end{array}$ & $\begin{array}{c}0.023 \\
(0.110)\end{array}$ & $\begin{array}{c}0.263 \\
(0.895)\end{array}$ & $\begin{array}{c}0.034 \\
(0.112)\end{array}$ & $\begin{array}{c}0.312 \\
(0.912)\end{array}$ \\
\hline$R P E$-accounting $\times$ Redactions & $\begin{array}{c}-0.329^{*} \\
(0.190)\end{array}$ & $\begin{array}{c}-1.282 \\
(1.131)\end{array}$ & $\begin{array}{l}-0.390 \\
(0.181)\end{array}$ & $\begin{array}{r}-1.831^{\dagger} \\
(1.069)\end{array}$ & $\begin{array}{c}-0.351^{\prime \prime} \\
(0.181)\end{array}$ & $\begin{array}{c}-1.446 \\
(1.096)\end{array}$ \\
\hline$R P E$-accounting $\times$ High $P G O$ & $\begin{array}{c}-0.131 \\
(0.266)\end{array}$ & $\begin{array}{c}-0.092 \\
(1.422)\end{array}$ & & & & \\
\hline$R P E$-accounting $\times$ High $P M O$ & & & $\begin{array}{l}-0.705^{3} \\
(0.233)\end{array}$ & $\begin{array}{l}-3.596 \\
(1.591)\end{array}$ & & \\
\hline RPE-accounting $\times$ High Overlap & & & & & $\begin{array}{c}-0.455^{*} \\
(0.274)\end{array}$ & $\begin{array}{c}-1.146 \\
(1.241)\end{array}$ \\
\hline$R P E$-accounting $\times$ Redactions $\times$ High $P G O$ & $\begin{array}{c}-0.122 \\
(0.215)\end{array}$ & $\begin{array}{c}0.242 \\
(0.834)\end{array}$ & & & & \\
\hline$R P E$-accounting $\times$ Redactions $\times$ High $P M O$ & & & $\begin{array}{c}0.088 \\
(0.204)\end{array}$ & $\begin{array}{c}1.104 \\
(0.743)\end{array}$ & & \\
\hline RPE-accounting $\times$ Redactions $\times$ High Overlap & & & & & $\begin{array}{c}-0.044 \\
(0.279)\end{array}$ & $\begin{array}{c}0.651 \\
(0.831)\end{array}$ \\
\hline Controls & yes & yes & yes & yes & yes & yes \\
\hline Year effects & yes & yes & yes & yes & yes & yes \\
\hline Industry effects & yes & yes & yes & yes & yes & yes \\
\hline Estimator & Poisson & OLS & Poisson & OLS & Poisson & OLS \\
\hline Observations & 9,451 & 9,451 & 8,504 & 8,504 & 7,504 & 7,504 \\
\hline Adjusted (pseudo) $R^{2}$ & $8.666 \%$ & $1.270 \%$ & $8.725 \%$ & $1.178 \%$ & $8.670 \%$ & $1.304 \%$ \\
\hline
\end{tabular}

This table presents results examining the association between relative performance evaluation, peer group overlap, product market overlap and disclosure substitution (i.e., the association between management earnings guidance and redactions in mandatory disclosures). Panel A presents results for RPE-price firms. Panel B presents results for RPE-accounting firms. High PGO is an indicator variable equal to one if the firm's Peer Group Overlap is greater than the median of Peer Group Overlap in the subsample of RPE firms, zero otherwise. High PMO is an indicator variable equal to one if the firm's Product Market Overlap is greater than the median of Product Market Overlap in the subsample of RPE firms, zero otherwise. High Overlap is an indicator equal to one if both High PGO and High PMO are one, zero otherwise. The main effects of High PGO, High PMO and High Overlap are omitted, because they have a perfect correlation with their interaction with $R P E$. The subsample of non-RPE firms is entropy balanced to the subsample of RPE firms using all control variables, including year and industry indicators. The industry classification follows the 48 industry groups identified by Fama and French (1997). Standard errors are in parentheses and are adjusted for within cluster correlation by firm and year conform Gow et al. (2010). ", ", significance at two-tailed probability levels of $15 \%, 10 \%, 5 \%$, and $1 \%$, respectively. All variables are defined in the caption of Table 3.1 .

In Panel $\mathrm{B}$, we find that the decrease in guidance upon redacting their mandatory disclosures in $R P E$-accounting firms does not vary by strategic interaction intensity. In other words, the decrease in disclosure substitution for $R P E$-accounting firms relates the performance criteria (i.e., the accounting metric) and not necessarily to the strategic interaction intensity. This finding is intuitive, because the accounting metric already completely negates the benefit of reducing information asymmetry with the market. In contrast, for RPE-price firms there is a benefit of reducing information asymmetry with the market which becomes costly when strategic interaction intensity is high. 
Collectively, these findings are consistent with our theoretical predictions, and corroborate the notion that strategic interaction intensity matters for the quality of information in capital markets and that different incentive plans, due to different frictions, differentially affect managers' disclosure decisions.

\section{V.E. Who Chooses What?}

In this section, we examine firms' choices with respect to their relative performance plans. To do so, we estimate a multinomial probit equation in which we analyzejointly-boards' choices between: (1) not using RPE; (2) using RPE with price-based metrics; and (3) using RPE with accounting-based metrics. Specifically, we estimate:

$$
\operatorname{Pr}\left(\left[R P E \text { Cboice }_{i j t}\right]\right)=\alpha+\beta_{1}\left[\text { Force }_{i j t}\right]+\gamma^{\prime} X_{i j t}+\theta^{\prime} \mu_{j}+\phi^{\prime} v_{t}+\varepsilon_{i j t}
$$

where RPE Choice is one of the three choices for relative performance plans (where not using RPE is the baseline). Force is one of the economic forces that we predict relates to the choice of using RPE with accounting-based metrics, i.e., either: (1) Rival Similarity, which captures how "close" peers are to the focal firm; or (2) RED Intensity, which captures the firm's research and development investments. In the specification where we examine Rival Similarity, we additionally include Product Market Size to control for the size of the product market (see Sections III.D and III.E for details).

Table 3.8 presents results of examining, jointly, the probability of choosing one of the three choices for relative performance plans. Panel A presents results of examining the role of close rivals. In Column (1), we find that the coefficient on Rival Similarity is positive and both economically and statistically significant, whereas the coefficient on Rival Similarity in Column (2) is negative and both economically and statistically significant. These coefficients imply that as the similarity of a focal firm to its rivals increases and thus peer firms can more completely exploit the focal firm's proprietary information, then the focal firm is more likely to use a relative performance plan with accounting-based metrics (which incentivizes managers to withhold information). In economic terms, a shift in the firm's rival similarity from the 10 th to the 90 th $(90$ th to the 10 th) percentile is associated with a $18 \%(17 \%)$ increase in the probability that the firm uses a relative performance plan with accounting-based (price-based) metrics.

Panel B presents results of examining the role of research and development expenditures. In Column (1), we find that the coefficient on $R E D$ Intensity is positive and both economically and statistically significant. This coefficient implies that as the firm's investments in research and development increase and thus the firm's proprietary cost of disclosure increases, the focal firm is more likely to use a relative performance plan with accounting-based metrics (which incentivizes managers to withhold information). In economic terms, a shift in the firm's research and development intensity from the 10 th to the 90 th percentile is associated with a $33 \%$ increase in the probability that the firm uses a relative performance plan with accounting-based metrics. ${ }^{87}$

87. In untabulated analyses we also find that both economic forces interact in predicting the use of relative performance plans with accounting-based metrics. In particular, we find a positive and significant interaction between Rival Similarity and RED Intensity regarding the use of accounting-based metrics, whereas we find a negative and significant interaction between Rival Similarity and $R E D$ Intensity regarding the use of price- 
Table 3.8. Choices for relative performance plans

Panel A. Close rivals

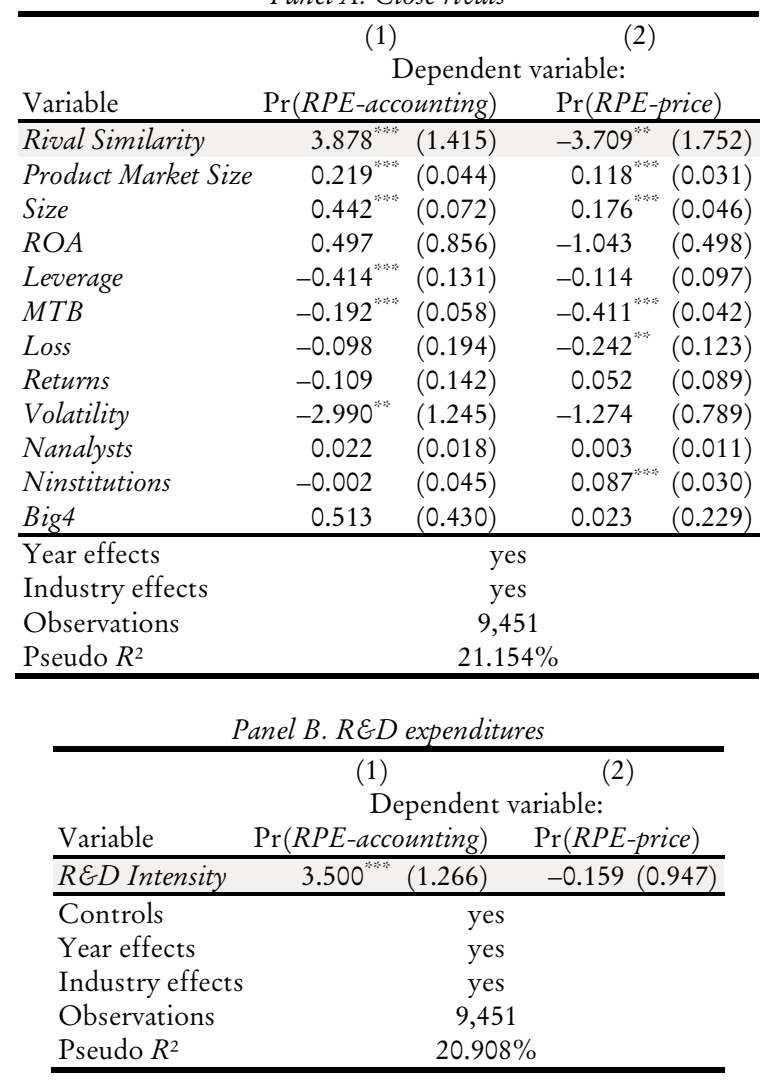

This table presents results of estimating, jointly, the probability of choosing one of the three choices for relative performance plans: (1) not using RPE (i.e., the baseline); (2) using RPE with price-based metrics; and (3) using RPE with accounting-based metrics, using a multinomial probit estimation Panel A presents results of examining the role of close rivals (Rival Similarity). Panel B presents results of examining the role of research and development expenditures (RED Intensity). The industry classification follows the 48 industry groups identified by Fama and French (1997). Standard errors are in parentheses and are adjusted for within cluster correlation by firm and year conform Gow et al. (2010). ${ }^{\dagger}, ", *$ and ${ }^{* * *}$ indicate significance at two-tailed probability levels of $15 \%$, $10 \%, 5 \%$, and $1 \%$, respectively. All variables are defined in the caption of Table 3.1.

Collectively, these findings provide evidence for our prediction that firms anticipate managers' differential disclosure response to alternative relative performance metrics and design these contracts to give their managers incentives to withhold information when operating in competitive markets. If firms only viewed proprietary costs of disclosure as a firm-level construct, we would expect to see increased use of RPE contracts regardless of the underlying RPE metric. However, our findings bridge this classical view with more modern views of disclosure specific costs and suggest that firms both recognize the firm- 
level proprietary costs of disclosure driven by product-market competition but also the disclosure-specific costs arising from differential compensation contracting choices.

\section{Additional Analyses}

\section{VI.A. Controlling for Product Market Competition}

Similar to Heinle et al. (2020), we assess robustness of our main results to controlling for traditional competition incentives. Specifically, we re-estimate all equations and control for two measures of product market competition: the number of product market competitors and their similarity with the focal firm, as defined by Hoberg and Phillips (2010, 2016) (Product Market Size and Rival Similarity, respectively; see Section III.D for details). In untabulated analyses, we find that inclusion of these two variables does not alter preceding inferences with respect to the association between relative performance plans and disclosure.

\section{VI.B. Controlling for Individual Incentives}

We also assess robustness of our main results to controlling for the manager's individual incentives. Specifically, we re-estimate all equations and control for the CEO's tenure and equity delta-i.e., the sensitivity of the risk-neutral value of the CEO's portfolio of stock and stock options to a $1 \%$ change in the price of the underlying stock (e.g., Core and Guay, 1999, 2002). We estimate the risk-neutral value of the CEO's option portfolio using the Black and Scholes (1973) model, as modified by Merton (1973b) to account for dividend payouts. In untabulated analyses, we find that inclusion of these two variables does not alter preceding inferences with respect to the association between relative performance plans and disclosure.

\section{Summary and Conclusion}

In this study, we explore the relation between managers' incentive plans based on relative performance and their disclosure decisions. To formalize the intuition for how and why relative performance plans relate to disclosure decisions, we explore this relation in two stages. We first examine the response of the manager to an-from his/her perspective-exogenous relative performance plan. Given managers' anticipated responses to the-from the managers' perspective-exogenous incentive plan, we examine in more detail which firms would-from the board's perspectiveendogenously choose which type of relative performance plan.

With regard to the first stage, we provide evidence that managers' relative incentivecompensation contracts systematically relate to: (1) the transparency of mandatory disclosure; (2) the provision of voluntary disclosure; and (3) the substitution between the two. Specifically, we document that these incentive plans motivate managers who have concerns about the proprietary cost of disclosure due to strategic interactions with peers to: (1) reduce the quality of mandatory disclosure; and (2) reduce voluntary disclosure. These effects manifest because managers cannot publicly disclose proprietary information to investors without also revealing that information to peers. Managers can, however, substitute voluntary disclosure of "less proprietary" information to inform investors about the valuation implications of "more proprietary" information. In this regard, we show that this substitution effect critically depends on the metric underlying 
relative performance. If managers are competing on price, they do substitute increased voluntary disclosure of less proprietary information for decreased disclosure of proprietary information-e.g., through earnings guidance. However, if managers are competing on accounting numbers, they do not substitute disclosure after increasing the opacity of their mandatory disclosures. In fact, our evidence suggests managers evaluated on relative accounting metrics increase withholding of both mandatory and voluntary information.

With regard to the second stage, we provide evidence that boards' choices for relative performance plans are consistent with proprietary cost considerations. Specifically, we show that boards are more likely to evaluate their managers based on relative accountingbased metrics (vis-à-vis relative price-based metrics or no relative metrics) when the firm has: (1) close rivals that can more completely exploit the focal firm's proprietary information; or (2) significant proprietary investments. These contract-design findings complete the puzzle and strengthen the economic intuition for why we observe the relation between relative performance plans and managerial disclosure decisions.

Collectively, our findings indicate that different incentive plans, due to different frictions, differentially affect managers' disclosure decisions. These differential disclosure patterns matter for several reasons. First, these patterns suggest that disclosure-specific costs should be interpreted more broadly, as proprietary costs to one manager may arise-or perhaps more importantly, not arise-because of characteristics of managers at other firms. Relatedly, these patterns-in conjunction with our second stage findings - suggest that boards are both aware of the firm-level proprietary costs driven by firm-level product market competition but also acknowledge that contractual incentives are an important driver of disclosure specific costs. As such, our evidence corroborates the notion that disclosure policies are endogenously determined by the same forces that shape managerial incentives (e.g., Core, 2001, Shleifer and Vishny, 1997, Zingales, 1998), and highlights the benefit in taking a more "endogenous perspective" in painting a picture of the relation between managerial incentives and disclosure. Finally, although our evidence suggests that boards design incentive-compensation contracts that benefit the firm, these patterns also highlight a new channel through which information asymmetry at the capital market-level arises This is a noteworthy finding considering the SEC's (2021) mission to protect investors, to maintain fair, orderly, and efficient markets, and to facilitate capital formation.

\section{Appendix I: Example Relative Performance Plan}

The following text is an excerpt from the DEF 14a filing of United Parcel Service Inc. (2019, pp. 36-38), where the firm describes its relative performance plan.

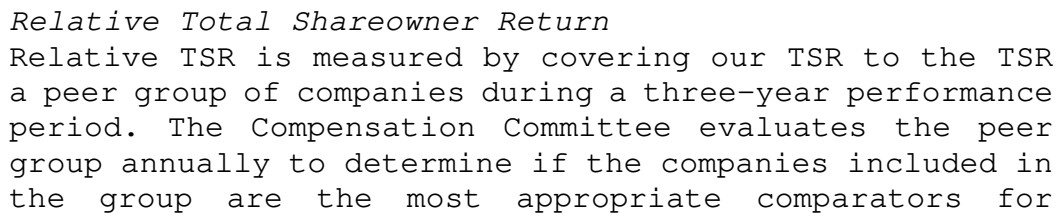


measuring the success of our executives in delivering shareowner value. ${ }^{88}$

\begin{tabular}{cc}
$\begin{array}{c}\text { Three-Year TSR Compared to } \\
\text { Peer Group }\end{array}$ & $\begin{array}{c}\text { Percentage of Target Earned for } \\
\text { TSR Portion of LTIP Award) }\end{array}$ \\
\hline Greater than 75th Percentile & $200 \%$ \\
Median & $100 \%$ \\
25th Percentile & $50 \%$ \\
Less than 25th Percentile & $0 \%$
\end{tabular}

The maximum payout for the TSR portion of the award is capped at $200 \%$ of target. If our TSR over the three-year measurement period is negative, even if it exceeds the median of the peer group, the maximum payout percentage for the TSR portion of LTIP awards is capped at $100 \%$ of target.

2018 LTIP Awards

The performance measures selected by the Compensation Committee for the 2018 LTIP awards are:

- Growth in Adjusted Consolidated Revenue;

- Adjusted Operating Return on Invested Capital ("ROIC"); and

- Relative Total Shareowner Return ("TSR").

Each goal is measured independently and applied equally in determining final payouts.

The Compensation Committee approved the following target values as a percent of base salary for the 2018 LTIP awards:

\begin{tabular}{ccc} 
Executive officers & $\begin{array}{c}\text { LTIP Target } \\
\text { (\% Base Salary) }\end{array}$ & Base Salary \\
\hline Chief Executive Officer & 700 & $1,234,992$ \\
Chief Operating Officer & 575 & 693,676 \\
Chief Financial Officer & 450 & 552,654 \\
Chief Strategy Officer & 450 & 613,500 \\
Other executive officers & 350 &
\end{tabular}

Target values are based on internal pay comparison considerations and market data regarding total compensation of comparable positions

88. The peer group considered by the Compensation Committee for 2018 compensation purposes (the "2018 Peer Group") is unchanged from the peer group used for 2017 compensation, and consisted of the companies below:

The Boeing Company

Caterpillar Inc.

The Coca-Cola Company

Costco Wholesale Corporation

FedEx Corporation

The Home Depot, Inc.

Johnson \& Johnson

The Kroger Co.

Lockheed Martin Corporation
The Procter \& Gamble Company

Sysco Corporation

Target Corp.

Lowe's Companies, Inc.

McDonald's Corp.

Pepsico, Inc.

United Technologies Corporation

Walgreen Boots Alliance, Inc. 
at similarly sized companies. Differences in the target award values are based on increasing levels of responsibility among the executive officers.

\section{Appendix II: Replication of Heinle, Samuels and Taylor (2020)}

This appendix elaborates on the boundary condition to the substitution effect and reports results for the replication of the inferences in Heinle et al. (2020).

\section{A.II.A. Boundary Condition to the Substitution Effect}

We first investigate a boundary condition to the substitution effect documented in Heinle et al. (2020). For a subset of firms closely followed by market participants the high demand for earnings guidance alters the costs of non-disclosure so as to result in a de facto mandatory nature of earnings guidance. For example, Apple, Inc. departed from their standard guidance behavior and did not provide traditional earnings guidance to investors for fiscal Q3 2020, which troubled market participants.

Firms for which earnings guidance is de facto mandatory include the most heavily followed firms in the economy-which are also the firms in our (ISS Incentive Lab) sample. We note that these firms are significantly different from both the general population of (Compustat) firms used in Heinle et al. (2020) as well as from the set of firms making up the largest decile of market value in their sample in terms of the frequency of earnings guidance. To empirically identify the substitution effect documented in Heinle et al. (2020), firms must have the ability to begin offering earnings guidance in response to providing opaque mandatory disclosure. If over a recent window firms consistently offer earnings guidance to the market, it is unlikely that we will observe incremental earnings guidance associated with redactions in their mandatory disclosures.

To empirically test for a potential boundary condition to the substitution effect, we estimate the disclosure substitution equation in Heinle et al. (2020), and interact Redact with an indicator equal to one if the firm issued at least one management earnings forecast during each of the three prior fiscal years, and zero otherwise (AlwaysGuider). This allows us to estimate disclosure substitution conditional on firms' earnings guidance history. This is important, because our (ISS Incentive Lab) sample differs significantly from the (Compustat) sample in Heinle et al. (2020). In this regard, we also replicate the main inferences in Heinle et al. (2020). We document the results of these analyses in Table 3.A.II.A.

Panel $\mathrm{A}$ in Table 3.A.II.A shows that there exists significant variation in the frequency-i.e., consistency-of earnings guidance based on firms' earnings guidance history. For example, in the sample of firms that issued at least one management earnings forecast during each of the three prior fiscal years, we show they provide earnings guidance on average 8.5 times in a fiscal year. For these "always-guiders" there is thus little room to supplement redactions in mandatory disclosures with incremental earnings guidance. In contrast, "not-always-guiders" are more flexible to provide incremental earnings guidance, as these firms only provide earnings guidance approximately 0.7 times in a fiscal year.

Panel A in Table 3.A.II.A also shows that 50 percent of the firms that consistently provide earnings guidance are covered by ISS Incentive Lab-and are thus part of our 
Table 3.A.II.A. Boundary condition to the substitution effect

Panel A: Descriptive statistics

\begin{tabular}{lrrrrrrrr}
\hline & \multicolumn{3}{c}{ AlwaysGuider $=1$} & \multicolumn{4}{c}{ AlwaysGuider $=0$} \\
& Mean & Std. Dev. & 25th & 75th & Mean & Std. Dev. & 25th & 75th \\
\hline VolDisc & 0.974 & 0.160 & 1.000 & 1.000 & 0.355 & 0.479 & 0.000 & 1.000 \\
VolDisc Earn & 0.935 & 0.247 & 1.000 & 1.000 & 0.146 & 0.353 & 0.000 & 0.000 \\
\# VolDisc & 15.898 & 10.129 & 9.000 & 21.000 & 2.576 & 5.336 & 0.000 & 3.000 \\
\# VolDisc Earn & 8.574 & 6.419 & 4.000 & 11.000 & 0.758 & 2.659 & 0.000 & 0.000 \\
Redact & 0.134 & 0.431 & 0.000 & 0.000 & 0.123 & 0.329 & 0.000 & 0.000 \\
IncentiveLab & 0.507 & 0.500 & 0.000 & 1.000 & 0.184 & 0.387 & 0.000 & 0.000 \\
\hline
\end{tabular}

Panel B. Regression output

\begin{tabular}{|c|c|c|c|c|}
\hline \multirow[b]{2}{*}{ Variable } & \multicolumn{2}{|l|}{$(1)$} & \multicolumn{2}{|c|}{$(2)$} \\
\hline & \multicolumn{4}{|c|}{ Dependent variable: } \\
\hline Redact & $0.053^{* \% 5}$ & $(0.011)$ & $0.037^{*:=4}$ & $(0.010)$ \\
\hline AlwaysGuider & $0.749^{* * *}$ & $(0.016)$ & $0.708^{*}$ & $(0.017)$ \\
\hline Always Guider $\times$ Redact & $-0.042^{* * *}$ & $(0.012)$ & $-0.031^{* *}$ & $(0.013)$ \\
\hline Size & $0.006^{* * * *}$ & $(0.002)$ & $0.010^{*}$ & $(0.002)$ \\
\hline$R O A$ & $0.089^{* * *}$ & $(0.017)$ & $0.065^{* \ldots *}$ & $(0.011)$ \\
\hline Leverage & -0.006 & $(0.008)$ & 0.007 & $(0.010)$ \\
\hline$M T B$ & 0.001 & $(0.001)$ & $-0.002^{*}$ & $(0.001)$ \\
\hline Loss & 0.000 & $(0.011)$ & -0.003 & $(0.008)$ \\
\hline Returns & 0.000 & $(0.008)$ & -0.003 & $(0.004)$ \\
\hline Volatility & -0.020 & $(0.101)$ & -0.002 & $(0.064)$ \\
\hline Nanalysts & $0.006^{* \ldots * *}$ & $(0.001)$ & $0.005^{* \ldots+n}$ & $(0.001)$ \\
\hline Ninstitutions & 0.004 & $(0.003)$ & 0.001 & $(0.003)$ \\
\hline Big4 & $0.052^{* * * *}$ & $(0.007)$ & $0.024^{*}$ & $(0.008)$ \\
\hline Year effects & \multicolumn{2}{|l|}{ yes } & \multicolumn{2}{|c|}{ yes } \\
\hline Industry effects & \multicolumn{2}{|l|}{ no } & \multicolumn{2}{|c|}{ yes } \\
\hline Observations & \multicolumn{2}{|c|}{26,827} & \multicolumn{2}{|c|}{26,827} \\
\hline Adjusted $R^{2}$ & \multicolumn{2}{|c|}{$53.060 \%$} & \multicolumn{2}{|c|}{$54.490 \%$} \\
\hline Period & \multicolumn{2}{|c|}{$2009-2014$} & \multicolumn{2}{|c|}{ 2009-2014 } \\
\hline \multicolumn{5}{|l|}{ Wald $\chi^{2}$ Tests: } \\
\hline Redact + AlwaysGuider $\times$ Redact $\neq 0$ & \multicolumn{2}{|c|}{0.011 (n.s.) } & \multicolumn{2}{|c|}{0.006 (n.s.) } \\
\hline
\end{tabular}

This table provides results regarding our replication and extension of Table 3 in Heinle, Samuels and Taylor (2020). Panel A presents descriptive statistics grouped by always guider and non-always guider. Panel $\mathrm{B}$ presents results estimating the probability of a management earnings forecast conditional on having SEC confidential treatment orders in 10-K and 10-Q filings ("disclosure substitution"), and the differential relation for always-guiders. Always Guider is an indicator equal to one if the firm issued at least one management earnings forecast during each of the three prior fiscal years, and zero otherwise. IncentiveLab is an indicator equal to one if the firm is covered in ISS Incentive Lab (i.e., our "main sample"), and zero otherwise. The industry classification follows the 48 industry groups identified by Fama and French (1997). Standard errors are in parentheses

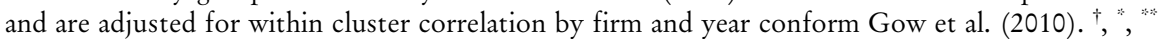
and ${ }^{* \%}$ indicate significance at two-tailed probability levels of $15 \%, 10 \%, 5 \%$, and $1 \%$, respectively. All variables are defined in the caption of Table 3.1 .

sample. (49 percent of the firms in ISS Incentive Lab are always-guiders.) If there indeed exist boundary conditions to the substitution effect conditional on firms' guidance history-because these firms have little room to provide incremental earnings guidance-then we should not empirically observe the substitution effect documented 
in Heinle et al. (2020) for firms with sticky earnings guidance-i.e., most firms in our sample.

Panel B in Table 3.A.II.A presents evidence consistent with the notion that there indeed exists a boundary condition to the substitution effect conditional on firms' guidance history. That is, we find that redacted mandatory disclosure is associated with greater voluntary earnings disclosure for the general population of firms. However, we also find that disclosure substitution between management earnings forecasts and SEC confidential treatment orders in 10-K and 10-Q filings is absent for firms consistently providing earnings guidance.

\section{A.II.B. Replication of Main Inferences}

In this section, we report our replicated findings of the main inferences in Heinle et al. (2020)-i.e., their Tables 2 and 3.

Table 3.A.II.B presents descriptive statistics. This table shows that the sample used in our analysis is similar to the sample used in Heinle et al. (2020)_our sample contains 26,827 observations for all firms with non-missing values for all required variables; their sample contains 27,401 observations. Furthermore, descriptive statistics appear similar across both samples.

Table 3.A.II.C presents results regarding our replication of Table 3 in Heinle et al. (2020). Panel A estimates this relation for the years 2009 through 2014 (i.e., their sample period). Panel B estimates this relation for the years 2006 through 2018 (i.e., our full sample period). Across all specifications, the coefficient on Redact is positive and statistically significant. In economic terms, the coefficients in Panel A are similar to the coefficients reported in Columns (1) through (3) in Table 3 in Heinle et al. (2020).

\section{A.II.C. Main Inferences for Subsamples}

In this section, we extend our replicated findings of the main inferences in Heinle et al. (2020) by estimating their equation for subsamples of firms based on S\&P indices

Table 3.A.II.D presents results regarding our replication of Table 3 in Heinle et al. (2020), whereby we estimate the equations for firms that are not part of any S\&P index. Consistent with Table 3.A.II.B, we find that, across all specifications, the coefficient on Redact is positive and statistically significant. In economic terms, the coefficients in Panel A are similar to the coefficients reported in Columns (1) through (3) in Table 3 in Heinle et al. (2020).

Tables 3.A.II.E through 3.A.II.H present results regarding our replication of Table 3 in Heinle et al. (2020), whereby we estimate the equations for firms that are part of the S\&P 500, S\&P 400, S\&P 600, and the ISS Incentive Lab universe, respectively. Across these specifications, we find that in only 1 out of 24 equations the coefficient on Redact is positive and statistically significant. In 22 out of 24 equations, we find that the coefficient on Redact is statistically insignificant.

Collectively, these findings imply that the disclosure substitution between management forecasts and SEC confidential treatment orders in 10-K and 10-Q filings reported in Heinle et al. (2020) is driven by firms that are not part of a S\&P index. For firms that are part of a S\&P index, we do not find this pattern. Hence, we conclude that the absence of this disclosure substitution in firms in the ISS Incentive Lab universe in 
Table 3.A.II.B. Definitions of variables and descriptive statistics

\begin{tabular}{lrrrrrr}
\hline & $(1)$ & $(2)$ & $(3)$ & $(4)$ & \multicolumn{1}{c}{$\begin{array}{c}(5) \\
\text { N }\end{array}$} & \multicolumn{1}{c}{$(6)$} \\
& N Obs & Mean & Std. Dev. & \multicolumn{1}{c}{ 25th } & \multicolumn{1}{c}{ 50th } & \multicolumn{1}{c}{75 th } \\
\hline Big4 & 26,827 & 0.710 & 0.454 & 0.000 & 1.000 & 1.000 \\
Leverage & 26,827 & 0.235 & 0.304 & 0.022 & 0.158 & 0.350 \\
Loss & 26,827 & 0.307 & 0.461 & 0.000 & 0.000 & 1.000 \\
MTB & 26,827 & 1.948 & 2.443 & 1.024 & 1.340 & 2.033 \\
NAnalysts & 26,827 & 7.846 & 5.485 & 0.000 & 12.000 & 12.000 \\
NInstitutions & 26,827 & 1.159 & 1.462 & 0.070 & 0.690 & 1.562 \\
NRedact & 26,827 & 0.176 & 0.550 & 0.000 & 0.000 & 0.000 \\
Redact & 26,827 & 0.120 & 0.325 & 0.000 & 0.000 & 0.000 \\
Returns & 26,827 & 1.209 & 0.580 & 0.890 & 1.122 & 1.388 \\
ROA & 26,827 & -0.018 & 0.237 & -0.016 & 0.022 & 0.067 \\
Size & 26,827 & 6.408 & 2.076 & 4.917 & 6.408 & 7.881 \\
Volatility & 26,827 & 0.124 & 0.085 & 0.068 & 0.101 & 0.152 \\
VolDisc Earn & 26,827 & 0.342 & 0.474 & 0.000 & 0.000 & 1.000 \\
VolDisc & 26,827 & 0.528 & 0.499 & 0.000 & 1.000 & 1.000 \\
\hline
\end{tabular}

This table presents descriptive statistics for our replication of Table 3 in Heinle, Samuels and Taylor (2020). The sample spans fiscal years 2009-2014 and contains 26,827 firm-years. Big4 is an indicator variable equal to one if the firm has a Big 4 auditor, and zero otherwise. Leverage is long term debt plus short term debt, scaled by total assets. Loss is an indicator variable equal to one if income before extraordinary items is negative, and zero otherwise. $M T B$ is market value of equity plus book value of liabilities divided by total assets. NAnalysts is the number of analysts that issue one-year ahead earnings forecasts during the fiscal year. NInstitutions is the number of institutional investors during the fiscal year, in hundreds. NRedact is the number of redacted disclosures the firms issued during the fiscal year. Redact is an indicator variable equal to one if the firm issued a redacted disclosure during the fiscal year, and zero otherwise. Returns is the buy and hold return over the fiscal year. $R O A$ is income before extraordinary items scaled by total assets. Size is the natural logarithm of market value of equity. Volatility is the standard deviation of monthly returns over the fiscal year. VolDisc Earn is an indicator variable equal to one if the firm issued a management earnings forecast during the fiscal year, and zero otherwise. VolDisc is an indicator variable equal to one if the firm issued a management forecast during the fiscal year, and zero otherwise.

our main analysis is likely not due to coding mistakes, but rather due to economic differences between these firms and firms that are not part of a S\&P index. 
Table 3.A.II.C. Disclosure substitution for full sample

Panel A. Full sample in 2009-2014

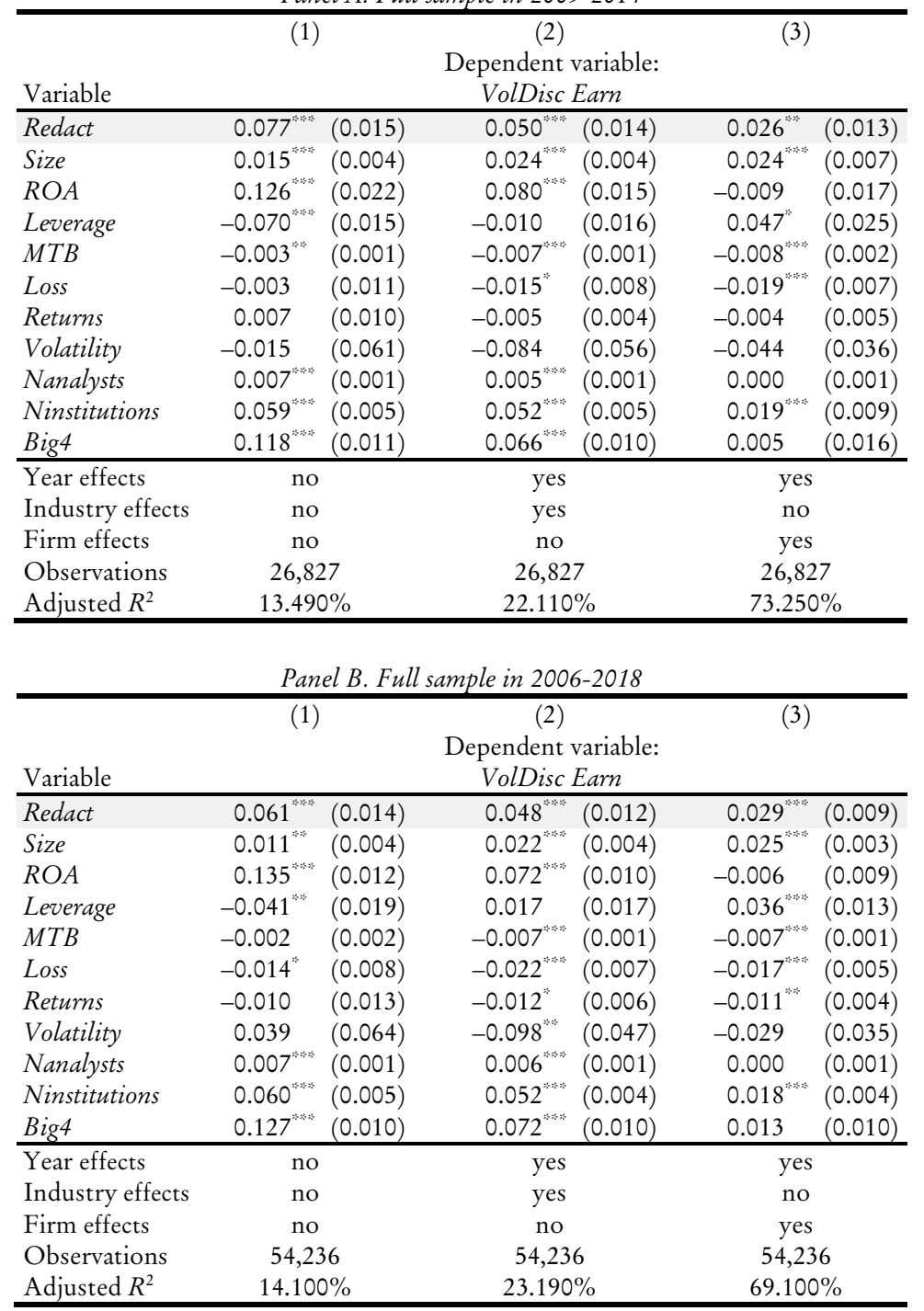

This table provides results regarding our replication of Table 3 in Heinle, Samuels and Taylor (2020), by estimating the probability of a management earnings forecast conditional on having SEC confidential treatment orders in $10-\mathrm{K}$ and $10-\mathrm{Q}$ filings ("disclosure substitution"). Panel A estimates this relation for the years 2009 through 2014 (i.e., the sample period in Heinle, Samuels and Taylor, 2020). Panel B estimates this relation for the years 2006 through 2018 (i.e., our full sample period). Standard errors are in parentheses and are adjusted for within cluster correlation by firm and time conform Gow et al. (2010). ", ${ }^{\prime \prime}$ and ${ }^{* * *}$ indicate significance at two-tailed probability levels of $10 \%, 5 \%$, and $1 \%$, respectively. All variables are defined in the caption of Table 3.A.II.B. 
Table 3.A.II.D. Disclosure substitution for no S\&P firms

Panel A. No SEP sample in 2009-2014

\begin{tabular}{|c|c|c|c|c|c|c|}
\hline \multirow{2}{*}{$\frac{\text { Variable }}{\text { Redact }}$} & \multicolumn{2}{|l|}{$(1)$} & \multicolumn{2}{|c|}{$\begin{array}{c}(2) \\
\text { Dependent variable: } \\
\text { VolDisc Earn }\end{array}$} & \multicolumn{2}{|l|}{ (3) } \\
\hline & $0.088^{3: 34}$ & $(0.017)$ & $0.073^{3: k n}$ & $(0.017)$ & $0.034^{3,35}$ & $(0.011)$ \\
\hline Size & 0.000 & $(0.004)$ & $0.010^{* *}$ & $(0.004)$ & $0.021^{* * *}$ & $(0.008)$ \\
\hline$R O A$ & $0.126^{* 3 *}$ & $(0.021)$ & $0.073^{* \ldots *}$ & $(0.014)$ & 0.002 & $(0.018)$ \\
\hline Leverage & $-0.065^{\ldots}$ & $(0.017)$ & -0.018 & $(0.018)$ & $0.045^{* *}$ & $(0.020)$ \\
\hline$M T B$ & $-0.004^{*}$ & $(0.001)$ & $-0.006^{* \ldots}$ & $(0.001)$ & $-0.007^{* *}$ & $(0.002)$ \\
\hline Loss & 0.013 & $(0.011)$ & -0.003 & $(0.008)$ & $-0.017^{*}$ & $(0.009)$ \\
\hline Returns & 0.003 & $(0.011)$ & -0.005 & $(0.005)$ & -0.005 & $(0.006)$ \\
\hline Volatility & 0.066 & $(0.072)$ & -0.014 & $(0.055)$ & -0.028 & $(0.039)$ \\
\hline Nanalysts & $0.007^{*}$ & $(0.001)$ & $0.006^{* \ldots}$ & $(0.001)$ & 0.000 & $(0.002)$ \\
\hline Ninstitutions & $0.083^{* * *}$ & $(0.009)$ & $0.078^{* * *}$ & $(0.009)$ & $0.031^{* * * ;}$ & $(0.011)$ \\
\hline Big4 & $0.113^{* * * 3}$ & $(0.011)$ & $0.066^{* * *}$ & $(0.011)$ & 0.003 & $(0.016)$ \\
\hline Year effects & \multicolumn{2}{|c|}{ 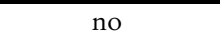 } & \multicolumn{2}{|l|}{ yes } & \multicolumn{2}{|l|}{ yes } \\
\hline Industry effects & \multicolumn{2}{|l|}{ no } & \multicolumn{2}{|l|}{ yes } & \multicolumn{2}{|l|}{ no } \\
\hline Firm effects & \multicolumn{2}{|c|}{ no } & \multicolumn{2}{|l|}{ no } & \multicolumn{2}{|l|}{ yes } \\
\hline Observations & \multicolumn{2}{|c|}{19,125} & \multicolumn{2}{|c|}{19,125} & \multicolumn{2}{|c|}{19,125} \\
\hline Adjusted $R^{2}$ & \multicolumn{2}{|c|}{$10.900 \%$} & \multicolumn{2}{|c|}{$18.690 \%$} & \multicolumn{2}{|c|}{$69.280 \%$} \\
\hline \multicolumn{7}{|c|}{ Panel B. No SEP sample in 2006-2018 } \\
\hline Variable & \multicolumn{2}{|c|}{$(1)$} & \multicolumn{2}{|c|}{$\begin{array}{l}\text { Dependent variable: } \\
\text { VolDisc Earn }\end{array}$} & (3) & \\
\hline Redact & $0.068^{* \% *}$ & $(0.016)$ & $0.069^{* \% 3}$ & $(0.013)$ & $0.032^{3 \%}$ & $(0.009)$ \\
\hline Size & -0.005 & $(0.004)$ & 0.007 & $(0.004)$ & $0.026^{* * *}$ & $(0.004)$ \\
\hline$R O A$ & $0.137^{* * * 2}$ & $(0.011)$ & $0.068^{* * * *}$ & $(0.009)$ & -0.002 & $(0.008)$ \\
\hline Leverage & $-0.042^{*}$ & $(0.017)$ & 0.001 & $(0.015)$ & $0.038^{* \ldots *}$ & $(0.011)$ \\
\hline$M T B$ & -0.002 & $(0.001)$ & $-0.004^{* * *}$ & $(0.001)$ & $-0.006^{* \ldots}$ & $(0.001)$ \\
\hline Loss & 0.006 & $(0.009)$ & -0.004 & $(0.008)$ & $-0.011^{* * *}$ & $(0.005)$ \\
\hline Returns & -0.006 & $(0.012)$ & -0.009 & $(0.005)$ & $-0.012^{* \ldots *}$ & $(0.004)$ \\
\hline Volatility & 0.072 & $(0.051)$ & -0.050 & $(0.039)$ & -0.021 & $(0.029)$ \\
\hline Nanalysts & $0.007^{* 0 \%}$ & $(0.001)$ & $0.006^{* \ldots}$ & $(0.001)$ & 0.000 & $(0.001)$ \\
\hline Ninstitutions & $0.083^{* \ldots}$ & $(0.009)$ & $0.077^{* * *}$ & $(0.008)$ & $0.029^{* * 3}$ & $(0.008)$ \\
\hline Big4 & $0.119^{* * 4}$ & $(0.010)$ & $0.073^{* * *}$ & $(0.010)$ & 0.011 & $(0.012)$ \\
\hline Year effects & \multicolumn{2}{|l|}{ no } & \multicolumn{2}{|l|}{ yes } & \multicolumn{2}{|c|}{ yes } \\
\hline Industry effects & \multicolumn{2}{|c|}{ no } & yes & & no & \\
\hline Firm effects & no & & no & & yes & \\
\hline Observations & 38,47 & & 38,47 & & 38,47 & \\
\hline Adjusted $R^{2}$ & 10.68 & $0 \%$ & 19.390 & & 64.430 & \\
\hline
\end{tabular}

This table provides results regarding our replication of Table 3 in Heinle, Samuels and Taylor (2020), by estimating the probability of a management earnings forecast conditional on having SEC confidential treatment orders in 10-K and 10-Q filings ("disclosure substitution") for firms that are not in a S\&P index. Panel A estimates this relation for the years 2009 through 2014 (i.e., the sample period in Heinle, Samuels and Taylor, 2020). Panel B estimates this relation for the years 2006 through 2018 (i.e., our full sample period). Standard errors are in parentheses and are adjusted for within cluster correlation by firm and time conform Gow et al. (2010). ", and indicate significance at two-tailed probability levels of $10 \%, 5 \%$, and $1 \%$, respectively. All variables are defined in the caption of Table 3.A.II.B. 
Table 3.A.II.E. Disclosure substitution for S\&P 500 firms

Panel A. SEP 500 sample in 2009-2014

\begin{tabular}{|c|c|c|c|c|c|c|}
\hline \multirow{2}{*}{$\frac{\text { Variable }}{\text { Redact }}$} & \multicolumn{2}{|l|}{ (1) } & \multicolumn{2}{|c|}{$\begin{array}{c}\text { (2) } \\
\text { Dependent variable: } \\
\text { VolDisc Earn }\end{array}$} & \multicolumn{2}{|l|}{ (3) } \\
\hline & 0.017 & $(0.050)$ & -0.016 & $(0.042)$ & $-0.071^{*}$ & $(0.029)$ \\
\hline Size & $-0.056^{* *}$ & $(0.026)$ & -0.013 & $(0.025)$ & 0.012 & $(0.034)$ \\
\hline$R O A$ & $-0.670^{* \ldots *}$ & $(0.223)$ & -0.456 & $(0.221)$ & $-0.411^{\text {w. }}$ & $(0.146)$ \\
\hline Leverage & -0.050 & $(0.034)$ & -0.014 & $(0.039)$ & $-0.108^{*}$ & $(0.062)$ \\
\hline$M T B^{\circ}$ & 0.006 & $(0.012)$ & $-0.027^{*}$ & $(0.012)$ & -0.016 & $(0.017)$ \\
\hline Loss & $-0.178^{* * *}$ & $(0.045)$ & $-0.110^{* *}$ & $(0.045)$ & -0.079 & $(0.041)$ \\
\hline Returns & 0.003 & $(0.058)$ & -0.007 & $(0.039)$ & 0.010 & $(0.023)$ \\
\hline Volatility & $-1.359^{* \ldots *}$ & $(0.521)$ & $-0.869^{*}$ & $(0.508)$ & -0.112 & (0.187) \\
\hline Nanalysts & $-0.023^{* * *}$ & $(0.007)$ & $-0.016^{* * *}$ & $(0.006)$ & -0.002 & $(0.004)$ \\
\hline Ninstitutions & $0.046^{* * *}$ & $(0.015)$ & $0.040^{* * *}$ & $(0.015)$ & 0.019 & $(0.019)$ \\
\hline Big4 & 0.181 & $(0.173)$ & -0.063 & $(0.168)$ & -0.390 & $(0.402)$ \\
\hline Year effects & \multicolumn{2}{|l|}{ no } & \multicolumn{2}{|l|}{ yes } & \multicolumn{2}{|c|}{ yes } \\
\hline Industry effects & \multicolumn{2}{|l|}{ no } & \multicolumn{2}{|l|}{ yes } & \multicolumn{2}{|l|}{ no } \\
\hline Firm effects & \multicolumn{2}{|l|}{ no } & \multicolumn{2}{|l|}{ no } & \multicolumn{2}{|c|}{ yes } \\
\hline Observations & \multicolumn{2}{|c|}{2,737} & \multicolumn{2}{|l|}{2,737} & \multicolumn{2}{|c|}{2,737} \\
\hline Adjusted $R^{2}$ & \multicolumn{2}{|c|}{$4.450 \%$} & \multicolumn{2}{|c|}{$26.630 \%$} & \multicolumn{2}{|c|}{$74.700 \%$} \\
\hline \multicolumn{7}{|c|}{ Panel B. SEP 500 sample in $2006-2018$} \\
\hline Variable & \multicolumn{2}{|c|}{$(1)$} & \multicolumn{2}{|c|}{$\begin{array}{l}\text { Dependent variable: } \\
\text { VolDisc Earn }\end{array}$} & (3) & \\
\hline Redact & -0.009 & $(0.045)$ & -0.035 & $(0.036)$ & -0.022 & $\overline{(0.023)}$ \\
\hline Size & -0.042 & $(0.025)$ & -0.003 & $(0.020)$ & 0.000 & $(0.019)$ \\
\hline$R O A$ & -0.270 & $(0.214)$ & -0.120 & $(0.192)$ & -0.039 & $(0.144)$ \\
\hline Leverage & -0.041 & $(0.039)$ & 0.009 & $(0.042)$ & -0.102 & $(0.078)$ \\
\hline$M T B$ & -0.003 & $(0.010)$ & $-0.038^{* n}$ & $(0.009)$ & -0.011 & $(0.007)$ \\
\hline Loss & -0.170 *** & $(0.039)$ & $-0.081^{* *}$ & $(0.032)$ & -0.036 & $(0.028)$ \\
\hline Returns & -0.032 & $(0.035)$ & -0.011 & $(0.018)$ & 0.001 & $(0.012)$ \\
\hline Volatility & $-1.262^{* \ldots *}$ & $(0.363)$ & $-0.748^{* *}$ & $(0.347)$ & -0.154 & $(0.132)$ \\
\hline Nanalysts & $-0.016^{* \ldots *}$ & $(0.006)$ & $-0.011^{* *}$ & $(0.005)$ & -0.001 & $(0.004)$ \\
\hline Ninstitutions & $0.026^{*}$ & $(0.014)$ & $0.023^{* * *}$ & $(0.011)$ & 0.009 & $(0.007)$ \\
\hline Big4 & 0.186 & $(0.176)$ & -0.035 & $(0.163)$ & -0.174 & $(0.213)$ \\
\hline Year effects & \multicolumn{2}{|c|}{ no } & \multicolumn{2}{|c|}{ yes } & \multicolumn{2}{|c|}{ yes } \\
\hline Industry effects & \multicolumn{2}{|c|}{ no } & yes & & no & \\
\hline Firm effects & no & & no & & yes & \\
\hline Observations & 5,51 & & 5,51 & & 5,51 & \\
\hline Adjusted $R^{2}$ & 3.253 & $3 \%$ & 26.18 & $0 \%$ & 71.460 & $0 \%$ \\
\hline
\end{tabular}

This table provides results regarding our replication of Table 3 in Heinle, Samuels and Taylor (2020), by estimating the probability of a management earnings forecast conditional on having SEC confidential treatment orders in 10-K and 10-Q filings ("disclosure substitution") for firms that are part of the S\&P 500 index. Panel A estimates this relation for the years 2009 through 2014 (i.e., the sample period in Heinle, Samuels and Taylor, 2020). Panel B estimates this relation for the years 2006 through 2018 (i.e., our full sample period). Standard errors are in parentheses and are adjusted for within cluster correlation by firm and time conform Gow et al. (2010). ", " and " indicate significance at two-tailed probability levels of $10 \%, 5 \%$, and $1 \%$, respectively. All variables are defined in the caption of Table 3.A.II.B. 
Table 3.A.II.F. Disclosure substitution for S\&P 400 firms

Panel A. SEP 400 sample in 2009-2014

(1) (2) (3)

Dependent variable:

\begin{tabular}{|c|c|c|c|c|c|c|}
\hline \multirow{2}{*}{$\frac{\text { Variable }}{\text { Redact }}$} & \multicolumn{6}{|c|}{ VolDisc Earn } \\
\hline & 0.073 & $(0.063)$ & -0.014 & $(0.053)$ & $0.080^{*}$ & $(0.045)$ \\
\hline Size & $-0.082^{* *}$ & $(0.033)$ & -0.047 & $(0.044)$ & 0.054 & $(0.033)$ \\
\hline$R O A$ & $0.584^{* \ldots}$ & $(0.204)$ & $0.379^{*}$ & $(0.178)$ & -0.223 & (0.188) \\
\hline Leverage & 0.141 & $(0.088)$ & 0.115 & $(0.086)$ & 0.193 & (0.131) \\
\hline$M T B$ & $0.022^{*}$ & $(0.013)$ & 0.002 & $(0.016)$ & 0.006 & $(0.017)$ \\
\hline Loss & -0.009 & $(0.044)$ & 0.023 & $(0.046)$ & -0.025 & $(0.032)$ \\
\hline Returns & $0.052^{* * *}$ & $(0.012)$ & $0.029^{*}$ & $(0.017)$ & -0.009 & $(0.021)$ \\
\hline Volatility & $-0.612^{\ldots \ldots *}$ & $(0.190)$ & $-0.536^{* * n}$ & $(0.235)$ & -0.233 & $(0.145)$ \\
\hline Nanalysts & -0.005 & $(0.006)$ & -0.003 & $(0.006)$ & 0.001 & $(0.003)$ \\
\hline Ninstitutions & $0.103^{* * * *}$ & $(0.028)$ & $0.103^{* * m}$ & $(0.027)$ & 0.011 & $(0.021)$ \\
\hline Big4 & 0.082 & $(0.098)$ & 0.006 & $(0.093)$ & -0.028 & $(0.263)$ \\
\hline Year effects & \multicolumn{2}{|l|}{ no } & \multicolumn{2}{|l|}{ yes } & \multicolumn{2}{|c|}{ yes } \\
\hline Industry effects & \multicolumn{2}{|c|}{ no } & \multicolumn{2}{|l|}{ yes } & \multicolumn{2}{|c|}{ no } \\
\hline Firm effects & \multicolumn{2}{|l|}{ no } & \multicolumn{2}{|l|}{ no } & \multicolumn{2}{|c|}{ yes } \\
\hline Observations & \multicolumn{2}{|c|}{2,052} & \multicolumn{2}{|c|}{2,052} & \multicolumn{2}{|c|}{2,052} \\
\hline Adjusted $R^{2}$ & \multicolumn{2}{|c|}{$4.962 \%$} & \multicolumn{2}{|c|}{$22.050 \%$} & \multicolumn{2}{|c|}{$77.340 \%$} \\
\hline
\end{tabular}

Panel B. SEP 400 sample in 2006-2018

(1) (2) (3)

Dependent variable:

\begin{tabular}{|c|c|c|c|c|c|c|}
\hline \multirow{2}{*}{$\frac{\text { Variable }}{\text { Redact }}$} & \multicolumn{6}{|c|}{ VolDisc Earn } \\
\hline & 0.055 & $(0.060)$ & -0.023 & $(0.052)$ & 0.057 & $(0.036)$ \\
\hline Size & -0.064 & $(0.027)$ & -0.030 & $(0.030)$ & 0.018 & $(0.020)$ \\
\hline$R O A$ & $0.677^{* * *}$ & $(0.178)$ & $0.415^{* *}$ & $(0.166)$ & 0.063 & $(0.121)$ \\
\hline Leverage & 0.177 & $(0.108)$ & 0.154 & $(0.099)$ & $0.177^{* \ldots *}$ & $(0.056)$ \\
\hline$M T B$ & 0.002 & $(0.015)$ & -0.018 & $(0.015)$ & -0.015 & $(0.007)$ \\
\hline Loss & 0.003 & $(0.040)$ & 0.009 & $(0.040)$ & -0.014 & $(0.026)$ \\
\hline Returns & $0.024^{*}$ & $(0.011)$ & $0.023^{*}$ & $(0.013)$ & -0.002 & $(0.015)$ \\
\hline Volatility & -0.244 & $(0.285)$ & -0.233 & $(0.228)$ & $-0.201^{* *}$ & $(0.096)$ \\
\hline Nanalysts & 0.003 & $(0.006)$ & 0.005 & $(0.006)$ & $0.007^{* 3}$ & $(0.003)$ \\
\hline Ninstitutions & $0.073^{* * * *}$ & $(0.021)$ & $0.070^{* * * *}$ & $(0.021)$ & $0.022^{*}$ & $(0.012)$ \\
\hline Big4 & 0.017 & $(0.090)$ & -0.038 & $(0.082)$ & -0.058 & $(0.074)$ \\
\hline Year effects & \multicolumn{2}{|l|}{ no } & \multicolumn{2}{|l|}{ yes } & \multicolumn{2}{|c|}{ yes } \\
\hline Industry effects & \multicolumn{2}{|c|}{ no } & \multicolumn{2}{|l|}{ yes } & \multicolumn{2}{|c|}{ no } \\
\hline Firm effects & \multicolumn{2}{|l|}{ no } & \multicolumn{2}{|l|}{ no } & \multicolumn{2}{|c|}{ yes } \\
\hline Observations & \multicolumn{2}{|c|}{4,212} & \multicolumn{2}{|c|}{4,212} & \multicolumn{2}{|c|}{4,212} \\
\hline Adjusted $R^{2}$ & \multicolumn{2}{|c|}{$4.547 \%$} & \multicolumn{2}{|c|}{$20.660 \%$} & \multicolumn{2}{|c|}{$72.840 \%$} \\
\hline
\end{tabular}

This table provides results regarding our replication of Table 3 in Heinle, Samuels and Taylor (2020), by estimating the probability of a management earnings forecast conditional on having SEC confidential treatment orders in 10-K and 10-Q filings ("disclosure substitution") for firms that are part of the S\&P 400 index. Panel A estimates this relation for the years 2009 through 2014 (i.e., the sample period in Heinle, Samuels and Taylor, 2020). Panel B estimates this relation for the years 2006 through 2018 (i.e., our full sample period). Standard errors are in parentheses and are adjusted for within cluster correlation by firm and time conform Gow et al. (2010). ", " and " indicate significance at two-tailed probability levels of $10 \%, 5 \%$, and $1 \%$, respectively. All variables are defined in the caption of Table 3.A.II.B. 
Table 3.A.II.G. Disclosure substitution for S\&P 600 firms

Panel A. SEP 600 sample in 2009-2014

(1) (2) (3)

Dependent variable: VolDisc Earn

\begin{tabular}{|c|c|c|c|c|c|c|}
\hline \multirow{2}{*}{$\frac{\text { Variable }}{\text { Redact }}$} & \multicolumn{6}{|c|}{ VolDisc Earn } \\
\hline & 0.037 & $(0.044)$ & -0.019 & $(0.042)$ & 0.018 & $(0.041)$ \\
\hline Size & 0.020 & $(0.023)$ & $0.044 \%$ & $(0.023)$ & 0.019 & $(0.029)$ \\
\hline$R O A$ & $0.397^{* a}$ & $(0.105)$ & $0.271^{* *}$ & $(0.114)$ & 0.002 & $(0.185)$ \\
\hline Leverage & -0.072 & $(0.084)$ & 0.127 & $(0.093)$ & 0.099 & (0.089) \\
\hline$M T B$ & 0.009 & $(0.013)$ & -0.008 & $(0.011)$ & -0.013 & $(0.022)$ \\
\hline Loss & 0.029 & $(0.040)$ & 0.011 & $(0.033)$ & -0.015 & $(0.041)$ \\
\hline Returns & 0.015 & $(0.026)$ & 0.002 & $(0.014)$ & 0.015 & $(0.013)$ \\
\hline Volatility & 0.342 & $(0.248)$ & 0.192 & $(0.128)$ & -0.078 & $(0.218)$ \\
\hline Nanalysts & -0.001 & $(0.004)$ & -0.001 & $(0.004)$ & -0.002 & $(0.002)$ \\
\hline Ninstitutions & $0.122^{* \ldots}$ & $(0.031)$ & $0.088^{* * * ;}$ & $(0.028)$ & 0.076 & $(0.026)$ \\
\hline Big4 & $0.084 *$ & $(0.042)$ & 0.018 & $(0.038)$ & 0.047 & $(0.034)$ \\
\hline Year effects & \multicolumn{2}{|c|}{ no } & \multicolumn{2}{|l|}{ yes } & \multicolumn{2}{|c|}{ yes } \\
\hline Industry effects & \multicolumn{2}{|c|}{ no } & \multicolumn{2}{|l|}{ yes } & \multicolumn{2}{|c|}{ no } \\
\hline Firm effects & \multicolumn{2}{|c|}{ no } & \multicolumn{2}{|l|}{ no } & \multicolumn{2}{|c|}{ yes } \\
\hline Observations & \multicolumn{2}{|c|}{2,913} & \multicolumn{2}{|c|}{2,913} & \multicolumn{2}{|c|}{2,913} \\
\hline Adjusted $R^{2}$ & \multicolumn{2}{|c|}{$5.338 \%$} & \multicolumn{2}{|c|}{$21.330 \%$} & \multicolumn{2}{|c|}{$72.540 \%$} \\
\hline
\end{tabular}

Panel B. SEP 600 sample in 2006-2018

(1) (2) (3)

Dependent variable:

\begin{tabular}{|c|c|c|c|c|c|c|}
\hline \multirow{2}{*}{$\frac{\text { Variable }}{\text { Redact }}$} & \multicolumn{6}{|c|}{ VolDisc Earn } \\
\hline & 0.040 & $(0.040)$ & -0.004 & $(0.038)$ & 0.032 & $(0.024)$ \\
\hline Size & 0.007 & $(0.021)$ & $0.042^{* * *}$ & $(0.019)$ & 0.000 & $(0.016)$ \\
\hline$R O A$ & $0.302^{* * *}$ & $(0.107)$ & 0.109 & $(0.105)$ & -0.007 & $(0.095)$ \\
\hline Leverage & -0.016 & $(0.071)$ & $0.147^{* *}$ & $(0.070)$ & $0.112^{* *}$ & $(0.057)$ \\
\hline$M T B$ & 0.006 & $(0.012)$ & -0.017 & $(0.011)$ & -0.003 & $(0.013)$ \\
\hline Loss & 0.023 & $(0.028)$ & -0.004 & $(0.024)$ & $-0.037^{*}$ & $(0.018)$ \\
\hline Returns & -0.022 & $(0.024)$ & -0.018 & $(0.016)$ & 0.001 & $(0.014)$ \\
\hline Volatility & $0.410^{*}$ & $(0.194)$ & 0.183 & $(0.177)$ & 0.007 & $(0.167)$ \\
\hline Nanalysts & 0.001 & $(0.004)$ & 0.000 & $(0.003)$ & -0.002 & $(0.002)$ \\
\hline Ninstitutions & $0.117^{* * *}$ & $(0.027)$ & $0.094^{* * * *}$ & $(0.022)$ & $0.093^{* * * 3}$ & $(0.024)$ \\
\hline Big4 & $0.097^{*}$ & $(0.039)$ & 0.024 & $(0.033)$ & 0.042 & $(0.030)$ \\
\hline Year effects & \multicolumn{2}{|l|}{ no } & \multicolumn{2}{|l|}{ yes } & \multicolumn{2}{|l|}{ yes } \\
\hline Industry effects & \multicolumn{2}{|c|}{ no } & \multicolumn{2}{|l|}{ yes } & \multicolumn{2}{|l|}{ no } \\
\hline Firm effects & \multicolumn{2}{|l|}{ no } & \multicolumn{2}{|l|}{ no } & \multicolumn{2}{|c|}{ yes } \\
\hline Observations & \multicolumn{2}{|c|}{6,043} & \multicolumn{2}{|c|}{6,043} & \multicolumn{2}{|c|}{6,043} \\
\hline Adjusted $R^{2}$ & \multicolumn{2}{|c|}{$4.734 \%$} & \multicolumn{2}{|c|}{$20.890 \%$} & \multicolumn{2}{|c|}{$65.530 \%$} \\
\hline
\end{tabular}

This table provides results regarding our replication of Table 3 in Heinle, Samuels and Taylor (2020), by estimating the probability of a management earnings forecast conditional on having SEC confidential treatment orders in 10-K and 10-Q filings ("disclosure substitution") for firms that are part of the S\&P 600 index. Panel A estimates this relation for the years 2009 through 2014 (i.e., the sample period in Heinle, Samuels and Taylor, 2020). Panel B estimates this relation for the years 2006 through 2018 (i.e., our full sample period). Standard errors are in parentheses and are adjusted for within cluster correlation by firm and time conform Gow et al. (2010). ", " and " indicate significance at two-tailed probability levels of $10 \%, 5 \%$, and $1 \%$, respectively. All variables are defined in the caption of Table 3.A.II.B. 
Table 3.A.II.H. Disclosure substitution for ISS Incentive Lab firms

Panel A. ISS Incentive Lab sample in 2009-2014

\begin{tabular}{|c|c|c|c|c|c|c|}
\hline \multirow{2}{*}{$\frac{\text { Variable }}{\text { Redact }}$} & \multicolumn{2}{|c|}{ (1) } & \multicolumn{2}{|c|}{$\begin{array}{c}(2) \\
\text { Dependent variable: } \\
\text { VolDisc Earn }\end{array}$} & \multicolumn{2}{|l|}{ (3) } \\
\hline & 0.004 & $(0.029)$ & -0.025 & $(0.026)$ & -0.014 & $(0.023)$ \\
\hline Size & -0.016 & $(0.013)$ & 0.021 & $(0.013)$ & $0.037^{* *}$ & $(0.018)$ \\
\hline$R O A$ & $0.173^{* *}$ & $(0.080)$ & 0.088 & $(0.080)$ & -0.070 & $(0.090)$ \\
\hline Leverage & -0.044 & $(0.028)$ & 0.012 & $(0.028)$ & 0.013 & $(0.047)$ \\
\hline$M T B$ & -0.001 & $(0.006)$ & $-0.023^{* \ldots *}$ & $(0.006)$ & $-0.016^{*}$ & $(0.007)$ \\
\hline Loss & $-0.067^{* * *}$ & $(0.025)$ & $-0.056^{* *}$ & $(0.024)$ & -0.026 & $(0.019)$ \\
\hline Returns & 0.012 & $(0.013)$ & $-0.020^{*}$ & $(0.010)$ & -0.002 & $(0.009)$ \\
\hline Volatility & $-0.661^{* \cdots *}$ & $(0.153)$ & $-0.455^{* * *}$ & $(0.166)$ & -0.150 & $(0.093)$ \\
\hline Nanalysts & -0.003 & $(0.003)$ & 0.000 & $(0.003)$ & 0.000 & $(0.003)$ \\
\hline Ninstitutions & $0.042^{* * *}$ & $(0.010)$ & $0.026^{* * *}$ & $(0.010)$ & 0.013 & $(0.013)$ \\
\hline Big4 & $0.132^{* * *}$ & $(0.066)$ & 0.073 & $(0.063)$ & -0.071 & $(0.122)$ \\
\hline Year effects & \multicolumn{2}{|l|}{ no } & \multicolumn{2}{|l|}{ yes } & \multicolumn{2}{|l|}{ yes } \\
\hline Industry effects & \multicolumn{2}{|c|}{ no } & \multicolumn{2}{|l|}{ yes } & \multicolumn{2}{|l|}{ no } \\
\hline Firm effects & \multicolumn{2}{|c|}{ no } & \multicolumn{2}{|l|}{ no } & \multicolumn{2}{|l|}{ yes } \\
\hline Observations & \multicolumn{2}{|c|}{7,226} & \multicolumn{2}{|c|}{7,226} & \multicolumn{2}{|c|}{7,226} \\
\hline Adjusted $R^{2}$ & \multicolumn{2}{|c|}{$4.768 \%$} & \multicolumn{2}{|c|}{$18.530 \%$} & \multicolumn{2}{|c|}{$74.940 \%$} \\
\hline \multicolumn{7}{|c|}{ Panel B. ISS Incentive Lab sample in 2006-2018 } \\
\hline Variable & \multicolumn{2}{|c|}{$(1)$} & \multicolumn{2}{|c|}{$\begin{array}{l}\text { Dependent variable: } \\
\text { VolDisc Earn }\end{array}$} & \multicolumn{2}{|l|}{ (3) } \\
\hline Redact & 0.009 & $(0.026)$ & -0.022 & $(0.024)$ & 0.018 & $(0.021)$ \\
\hline Size & -0.009 & $(0.012)$ & $0.019^{*}$ & $(0.010)$ & $0.017^{*}$ & $(0.009)$ \\
\hline$R O A$ & $0.185^{* * * 3}$ & $(0.059)$ & $0.101^{*}$ & $(0.057)$ & 0.003 & $(0.048)$ \\
\hline Leverage & -0.015 & $(0.033)$ & 0.050 & $(0.033)$ & -0.022 & $(0.041)$ \\
\hline$M T B$ & -0.002 & $(0.005)$ & $-0.027^{* * *}$ & $(0.006)$ & $-0.014^{* * \%}$ & $(0.004)$ \\
\hline Loss & $-0.079^{* * *}$ & $(0.020)$ & $-0.069^{* * *}$ & $(0.017)$ & $-0.026^{* *}$ & $(0.010)$ \\
\hline Returns & -0.011 & $(0.013)$ & -0.012 & $(0.010)$ & -0.003 & $(0.010)$ \\
\hline Volatility & $-0.421^{* \ldots}$ & $(0.162)$ & $-0.361^{* \ldots *}$ & $(0.123)$ & $-0.108^{* * *}$ & $(0.055)$ \\
\hline Nanalysts & 0.000 & $(0.003)$ & 0.002 & $(0.003)$ & 0.004 & $(0.002)$ \\
\hline Ninstitutions & $0.031^{* * *}$ & $(0.009)$ & $0.020^{* * *}$ & $(0.007)$ & 0.009 & $(0.006)$ \\
\hline Big4 & $0.136^{* *}$ & $(0.055)$ & $0.086^{*}$ & $(0.051)$ & -0.010 & $(0.055)$ \\
\hline Year effects & \multicolumn{2}{|l|}{ no } & \multicolumn{2}{|l|}{ yes } & \multicolumn{2}{|c|}{ yes } \\
\hline Industry effects & \multicolumn{2}{|l|}{ no } & \multicolumn{2}{|l|}{ yes } & no & \\
\hline Firm effects & no & & no & & yes & \\
\hline Observations & 15,35 & & 15,354 & & 15,35 & \\
\hline Adjusted $R^{2}$ & 3.969 & & $18.030^{\circ}$ & & 70.160 & $0 \%$ \\
\hline
\end{tabular}

This table provides results regarding our replication of Table 3 in Heinle, Samuels and Taylor (2020), by estimating the probability of a management earnings forecast conditional on having SEC confidential treatment orders in $10-\mathrm{K}$ and $10-\mathrm{Q}$ filings ("disclosure substitution") for firms in the ISS Incentive Lab universe. Panel A estimates this relation for the years 2009 through 2014 (i.e., the sample period in Heinle, Samuels and Taylor, 2020). Panel B estimates this relation for the years 2006 through 2018 (i.e., our full sample period). Standard errors are in parentheses and are adjusted for within cluster correlation by firm and time conform Gow et al. (2010). ", " and "* indicate significance at two-tailed probability levels of $10 \%, 5 \%$, and $1 \%$, respectively. All variables are defined in the caption of Table 3.A.II.B. 


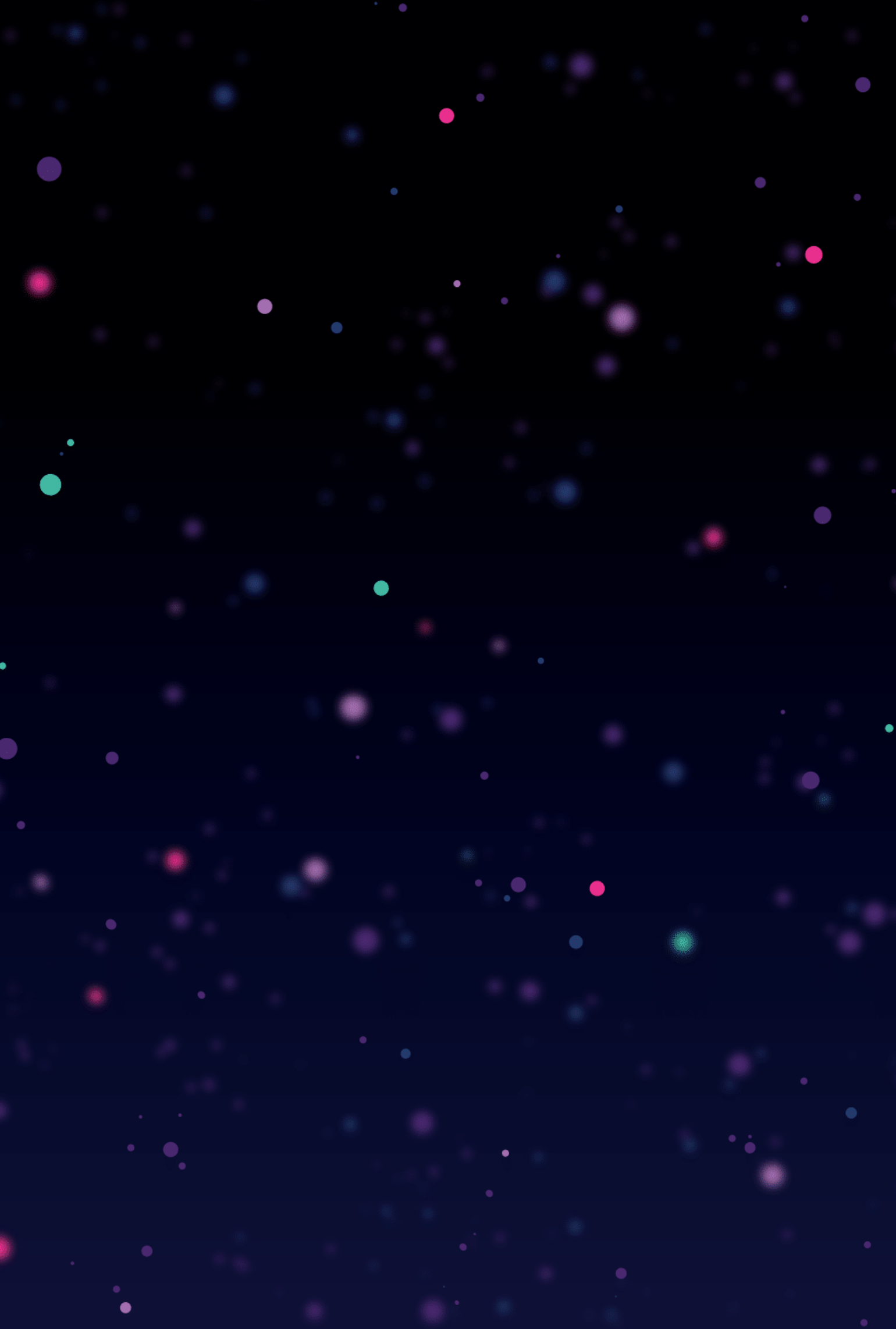




\section{5 \\ Discussion and Summary}

The use of incentive-compensation contracts based on relative performance has grown dramatically over the past 15 years. Nowadays two-thirds of S\&P 500 firms provide considerable and explicit incentives to managers to outperform peers, whereas only a quarter used such relative incentives in 2006. Given the ubiquity of relative performance plans, it is of great importance to investors, regulators, and practitioners to clearly understand how this incentive practice affects managerial decision-making. The goal is this dissertation is to fill this important void.

With regard to managerial decision-making, I consider three broad categories of decisions: (1) risk-taking; (2) competitive aggressiveness; and (3) information disclosure. I devote one study to each category of decisions, each of which attempts to examine some small piece of the overall relative performance evaluation and managerial decisionmaking puzzle. Below I present a synopsis of each study and its results in turn.

In the first study, I examine how relative performance evaluation relates to risktaking. Specifically, the goal of this study is to identify whether, how and why relative performance plans impact firm risk. To formalize the intuition for how and why relative performance plans give managers an incentive to pursue risk, I examine the incentive equilibrium in two stages in the standard backward fashion. In the first stage, I consider the best response of the manager to an-from his/her perspective-exogenous relative performance plan. In the second stage, I examine in more detail which firms wouldfrom the board's perspective-endogenously choose which weight on the characteristics within these relative performance plans, given managers' anticipated responses to thefrom the managers' perspective- exogenous incentive plan. Regarding the first stage, I predict that the incentive to take risk manifests synergistically through two characteristics of relative performance plans: (1) the convexity of the pay-performance relation; and (2) the difficulty of beating the peer group used as the benchmark for measuring relative firm performance. Intuitively, the incentive effects of these two characteristics interact: playing against superior peers for big prizes gives a greater incentive to take risks than does playing for smaller prizes. And so does playing for big prizes against superior peers compared to inferior peers. Regarding the second stage, I predict that firms that want to give their managers relatively strong relative performance incentives are those firms that have access to a sufficiently large array of investment projects. The intuition behind this prediction is that if the number of available projects 
is sufficiently large, then managers can actively shift the firm's strategy into the direction that yields the highest absolute returns (and, by definition, the highest relative return)consistent with shareholders' preferences. I present empirical evidence consistent with all these predictions. Moreover, I show that the risk-relation is stronger among: (1) managers evaluated on cash (vis-à-vis shares); (2) managers whose relative performance plan filters relatively more systematic risk; (3) managers with investment opportunities that have a relatively higher rate of return per unit of risk; (4) managers facing relatively fewer career concerns; and (5) managers whose stock options' payoffs have a relatively high sensitivity to return volatility.

In the second study, I examine how relative performance evaluation relates to competitive aggressiveness. Specifically, in this study I relate the existence of relative performance plans and, conditional on its existence, the extent to which firms select each other as peers to their competitive aggressiveness. When two firms select each other as peers, they are in direct competition with each other. Managers can respond to this competition in two ways: (1) sabotage; and (2) collusion. In terms of competitive aggressiveness, sabotage implies more competitive aggressiveness, whereas collusion implies less competitive aggressiveness. The intuition behind the sabotage prediction is that managers have an incentive to gain an advantage over competitors and improve the firm's relative position, which they can achieve by engaging in competitive actions. The intuition behind the collusion prediction is that managers have an incentive to commit to not being competitively aggressive, because being aggressive is costly-and potentially value-destroying. In essence, RPE gives managers incentives to engage in competitive actions, as long as these actions destroy peer value relatively more than own value. In this study, I present empirical evidence consistent with the sabotage hypothesis. That is, I find a positive association between the use of relative performance plans and competitive aggressiveness. Moreover, this finding is stronger among firms that are in direct competition with peer firms. My findings indicate that managers of such firms take more frequent as well as more complex competitive actions, relative to managers not evaluated on relative performance.

In the third study, I examine how relative performance evaluation relates to information disclosure. Specifically, the goal of this study is to examine how incentive plans based on relative performance are associated with: (1) the transparency of mandatory disclosure; (2) the provision of voluntary disclosure; and (3) the substitution between the two. Mandatory disclosures often require managers to disclose proprietary information that jeopardizes their firms' competitive position. One disclosure tactic to combat the proprietary costs of mandatory disclosure is to: (1) reduce their information content; and (2) increase voluntary disclosure of "less proprietary" information (e.g., summary performance expectations that reveal to investors the valuation implications of their proprietary information) to compensate for decreased disclosure of costlier proprietary information. I predict that relative performance plans play an important role in this disclosure tactic, because relative performance evaluation puts managers in direct competition with peers-which makes revealing information to peers is more costly than when evaluated based solely on individual performance. I present empirical evidence consistent with this prediction, but only for managers competing against peers on price. I find that managers competing on relative price redact more in their mandatory disclosures, but at the same time provide more voluntary earnings guidance. In contrast, 
I find that managers competing on relative accounting numbers redact more in their mandatory disclosures but substitute less voluntary earnings guidance. I further show that boards' choices for relative performance plan characteristics are consistent with proprietary cost considerations.

Collectively, my studies provide empirical evidence on the implications of incentive plans based on relative performance for numerous dimensions of managerial decisionmaking. My hope is that these insights spark much future work on incentivecompensation.

For example, one interesting avenue for future work relates to a general finding arising from all three studies in this dissertation, which is that much of the presented evidence is driven by strategic interactions between the focal firm and its peers (e.g., peer group difficulty and peer group overlap). These strategic interactions, however, are not directly observable from the focal firm's proxy statement - this requires one to examine a set of proxy statements of multiple firms. Thus, one key takeaway from this dissertation that opens many doors for future work is that individual proxy statements yield an incomplete picture of managers' "true" incentives. As such, there is much room to improve our understanding of managers' true incentives. Moreover, I see fruitful opportunities to further delve into the impact of strategic interactions, the dynamics of strategic interactions as well as interactions between different types of strategic interactions (e.g., implicit and explicit) on managerial decision-making.

Related to these strategic interactions, there is also room to further explore-and test-the tension between the sabotage and collusion hypotheses (discussed in more detail in the second study). For example, although I present empirical evidence consistent with the sabotage hypothesis, there exists evidence-both analytically and empiricallythat shows that relative performance evaluation incentivizes collusion in other settings (e.g., within-firms). In this regard, it would be interesting to better understand the forces that give rise to this differential "between-firms vis-à-vis within-firms" effect of relative performance evaluation. Moreover, within the sample of large U.S. firms studied in this dissertation, it would be interesting to see whether managers sabotage peer managers on other dimensions than those studied in the second study (e.g., on disclosure decisions, such as in the third study).

To conclude, another issue that deserves attention is our understanding of why firms use relative performance plans. Although we have seen a dramatic increase in the use of relative performance evaluation-from a quarter of S\&P 500 firms to two-third of S\&P 500 firms between 2006 and today-one might look at these figures and ask why onethird of firms choose not to use RPE in their managers' incentive-compensation plans, particularly in light of its strong theoretical support, and the fact that nearly all managers receive some form of performance stock award where vesting or the payout units is performance-based. 


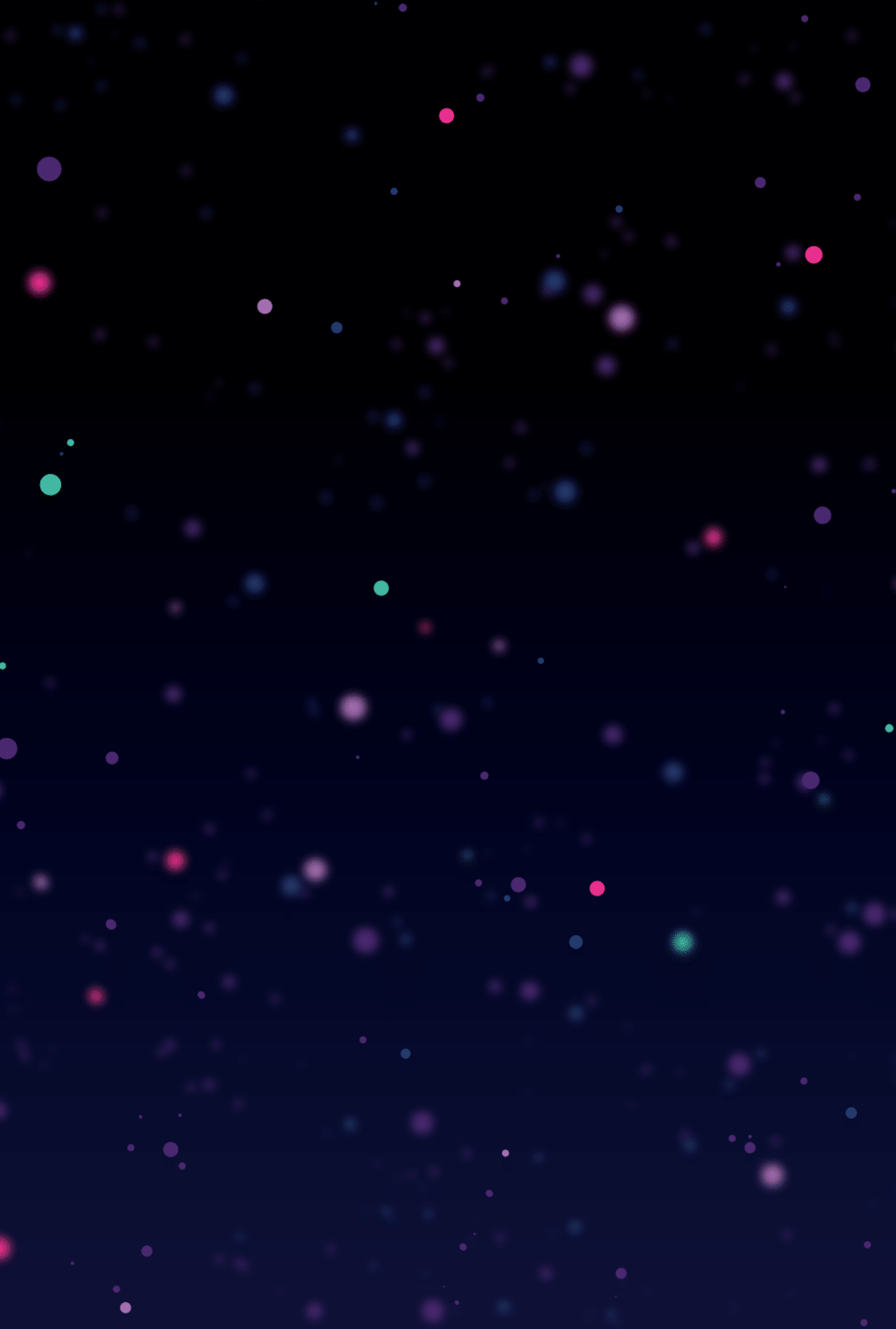




\section{6 \\ Discussie en Samenvatting (Discussion and Summary in Dutch)}

Het gebruik van prestatiebeloningen en bonusregelingen op basis van relatieve prestaties is enorm gegroeid in de afgelopen 15 jaar. Tegenwoordig geeft twee derde van de S\&P 500 bedrijven-de 500 grootste bedrijven op de Amerikaanse beursaanzienlijke en expliciete prestatiebeloningen aan hun managers om beter te presteren dan "peer" bedrijven, terwijl maar een kwart van de bedrijven zulke prestatiebeloningen gaf in 2006. Gezien deze toename in het gebruik van relatieve prestatiebeloningen is het van groot belang voor investeerders, toezichthouders, en de praktijk om duidelijk te begrijpen hoe deze bonusregelingen beslissingen van managers beïnvloeden. Het doel van dit proefschrift is om dit uit te pluizen.

In drie aparte studies kijk ik naar drie brede categorieën van beslissingen van managers, waaronder beslissingen die te maken hebben met: (1) het nemen van risico's; (2) de agressiviteit van het bedrijf; en (3) het openbaren van bedrijfsinformatie. Op deze manier probeert iedere studie een klein stukje van de relatie tussen relatieve prestatiebeloningen en beslissingen van managers helder te maken. Hieronder beschrijf ik kort de drie studies en resultaten.

In de eerste studie onderzoek ik hoe relatieve prestatiebeloningen gerelateerd zijn aan beslissingen die te maken hebben met het nemen van risico's. Het specifieke doel van deze studie is om te bepalen of, hoe, en waarom relatieve prestatiebeloningen een impact hebben op het risicoprofiel van het bedrijf. Ik bekijk dit in twee stappen. In de eerste stap bekijk ik hoe een manager zou reageren op het moment dat hij/zij werkt op basis van relatieve prestatiebeloningen, rekening houdend met het feit dat het contract van de manager wordt opgesteld door het bedrijf_-en niet door de manager zelf. In de tweede stap bekijk ik welk soort bedrijven-vanuit het bedrijf gezien-baat hebben bij het implementeren van relatieve prestatiebeloningen, gegeven de verwachte reactie van de manager die zal gaan werken onder dit contract. In de eerste stap verwacht ik dat het nemen van risico's gerelateerd is aan twee karakteristieken van relatieve prestatiebeloningen: (1) de sterkte van de beloningen; en (2) de moeilijkheidsgraad van het verslaan van de bedrijven waartegen de relatieve prestaties worden afgezet. Deze karakteristieken hebben een synergie: het spelen tegen moeilijke peer bedrijven voor grote beloningen geeft een grotere prikkel om risico te nemen dan het spelen tegen moeilijke peer bedrijven voor kleine beloningen. Ditzelfde geldt voor het spelen voor 
grote beloningen tegen moeilijke peer bedrijven versus makkelijke peer bedrijven. In de tweede stap verwacht ik dat vooral bedrijven die toegang hebben tot een groot scala aan investeringsmogelijkheden sterke relatieve prestatiebeloningen willen geven aan hun managers. Deze verwachting is gebaseerd op de gedachte dat als bedrijven veel investeringsmogelijkheden hebben, dan kunnen managers het bedrijf sturen in de richting die leidt tot de grootste absolute waarde van het bedrijf (en daarmee ook de grootste relatieve waarde van het bedrijf), in lijn met de verwachtingen van de aandeelhouders van het bedrijf. De resultaten van deze studie zijn in lijn met deze verwachtingen. Verder laat ik zien dat de prikkel voor nemen van risico's sterker is op het moment dat: (1) managers worden beloond in cash (versus aandelen van het bedrijf); (2) het relatieve contract effectiever is; (3) de investeringsmogelijkheden lucratiever zijn; (4) managers minder carrière-zorgen hebben; en (5) managers ook sterke aandelenopties binnen het bedrijf hebben.

In de tweede studie onderzoek ik hoe relatieve prestatiebeloningen gerelateerd zijn aan beslissingen die te maken hebben met de agressiviteit van het bedrijf. Hierbij focus ik op een specifiek karakteristiek van relatieve prestatiebeloningen: het feit dat peer bedrijven van het originele bedrijf ook eenzelfde relatieve prestatieregeling hebben én ook het originele bedrijf als hun peer kiezen, waardoor het originele bedrijf en zo'n peer in directe competitie met elkaar zijn. Een manager op twee manieren reageren op deze directe competitie: (1) agressief worden ten opzichte van de manager van het peer bedrijf (dus: meer agressiviteit); of (2) gaan samenwerken met de manager van het peer bedrijf (dus: minder agressiviteit). De eerste verwachting is gebaseerd op de gedachte dat een manager een prikkel heeft om het beter te doen dan zijn/haar peer; dit zou hij/zij kunnen doen door strategische beslissingen te nemen die nadelig zijn voor het peer bedrijf (e.g., een advertentiecampagne). De tweede verwachting is gebaseerd op de gedachte dat een manager in principe ook een prikkel heeft om niet té agressief te zijn, omdat dit waardevernietigend kan zijn: in de basis geven relatieve prestatiebeloningen managers een prikkel om meer waarde te vernietigen van het peer bedrijf dan van het eigen bedrijf. Dus, zelfs als het bedrijf "wint” (op een relatieve manier), kan dit nog steeds nadelig zijn voor de absolute waarde van het bedrijf. De resultaten van deze studie zijn in lijn met de eerste voorspelling: meer agressiviteit. De resultaten laten zien dat bedrijven met relatieve prestatiebeloningen die ook gekozen worden door peer bedrijven in hun relatieve prestatiebeloningen meer strategische beslissingen en ook meer complexe strategische beslissingen nemen om peer bedrijven te ondermijnen.

In de derde studie onderzoek ik hoe relatieve prestatiebeloningen gerelateerd zijn aan beslissingen die te maken hebben met het openbaren van bedrijfsinformatie. Het specifieke doel van deze studie is om te bepalen hoe relatieve prestatiebeloningen gerelateerd zijn aan: (1) de transparantie van informatie in verplichte bedrijfsrapporten; (2) het vrijwillig openbaren van bedrijfsinformatie; en (3) de substitutie tussen de twee. In verplichte bedrijfsrapporten moeten managers vaak gevoelige informatie openbaren die de competitieve positie van het bedrijf kan benadelen. Een tactiek die managers daarom vaak toepassen om dit te vermijden is: (1) gevoelige informatie achterhouden in deze verplichte bedrijfsrapporten; en (2) vrijwillig "minder gevoelige" informatie openbaren. Bijvoorbeeld, een bedrijf zal niet openbaren dat er een groot contract met een bepaalde klant aankomt, maar zal wel openbaren dat de prestaties van het bedrijf rooskleurig zullen zijn. Op deze manier krijgen investeerders toch informatie over het 
bedrijf, maar wordt gevoelige informatie (die beslissingen van peer bedrijven kan beïnvloeden op het moment dat details openbaar worden) achtergehouden van peer bedrijven. De verwachting in deze studie is dat managers die door hun relatieve prestatiebeloningen in directe competitie zijn met peer managers andere bedrijfsinformatie openbaren dan managers die geen relatieve prestatiebeloningen hebben. De resultaten van deze studie zijn in lijn met deze verwachting, maar alleen voor managers die met peer bedrijven concurreren op basis van de aandelenprijs van het bedrijf-en niet wanneer zij concurreren op maatstaven gebaseerd op de winst van het bedrijf. De resultaten laten zien dat managers die concurreren op basis van de aandelenprijs minder transparant zijn in verplichte bedrijfsrapporten, maar ook vrijwillig meer bedrijfsinformatie openbaar maken, terwijl managers die concurreren op basis van winstmaatstaven minder transparant zijn in verplichte bedrijfsrapporten én ook vrijwillig minder bedrijfsinformatie openbaar maken. Tot slot, de resultaten laten ook zien dat de keuze tussen concurrentie op basis van de aandelenprijs en maatstaven gebaseerd op de winst van het bedrijf in lijn is met overwegingen om managers prikkels te geven om informatie te achterhouden.

Al met al, de drie studies geven empirisch bewijs voor de gevolgen van relatieve prestatiebeloningen voor een breed scala aan beslissingen van managers. Mijn hoop is dat deze inzichten leiden tot toekomstige studies op het gebied van prestatiebeloningen en bonusregelingen.

Bijvoorbeeld, een interessante weg voor toekomstige studies is het voortborduren op een algemene bevinding in dit proefschrift: de bevinding dat een groot gedeelte van de resultaten gedreven wordt door directe en expliciete competitie tussen bedrijven (e.g., de moeilijkheidsgraad van het verslaan van de bedrijven waartegen de relatieve prestaties worden afgezet, en het feit dat peer bedrijven van het originele bedrijf ook eenzelfde relatieve prestatieregeling hebben én ook het originele bedrijf als hun peer kiezen). Echter, deze vorm van expliciete competitie is niet direct af te lezen uit bedrijfsrapporten-dit vereist bedrijfsrapporten van meerdere bedrijven. Dus, een belangrijke conclusie van dit proefschrift dat meerdere deuren voor toekomstige studies opent is de bevinding dat individuele bedrijfsrapporten mogelijk een incompleet beeld geven van de "echte" prikkels die managers hebben. Er zijn daarom onderzoeksmogelijkheden om de "echte" prikkels van managers beter te begrijpen. Daarnaast zijn er ook onderzoeksmogelijkheden om de impact van directe en expliciete competitie tussen bedrijven als ook de interactie tussen verschillende vormen van competitie beter te begrijpen.

Met betrekking tot deze expliciete interacties tussen bedrijven is er ook ruimte om de tensie tussen de agressiviteits- en samenwerkings-hypotheses verder uit te pluizen (zie ook studie 2 of Hoofdstuk 3 in dit proefschrift). Hoewel ik in dit proefschrift empirisch bewijs presenteer dat in lijn is met de agressiviteits-hypothese bestaat er ook empirisch bewijs dat in lijn is met de samenwerkings-hypothese (voornamelijk onderzoeken die binnen één bedrijf plaatsvinden). Het is interessant om de economische krachten die leiden tot deze verschillende effecten beter te begrijpen.

Tot slot, een laatste punt dat meer attentie nodig heeft is het beter begrijpen waarom bepaalde bedrijven relatieve prestatiebeloningen gebruiken en anderen niet. Hoewel er een sterke groei in het gebruik van dit mechanisme heeft plaatsgevonden-van een kwart van de S\&P 500 bedrijven naar twee derde van de S\&P 500 bedrijven tussen 2006 en nu- 
gebruikt nog steeds een derde van de bedrijven geen relatieve prestatiebeloningen. Dit is vooral verassend omdat er sterke theoretische argumenten zijn om dit mechanisme te gebruiken en bijna alle managers een vorm van prestatiebeloningen hebben. 



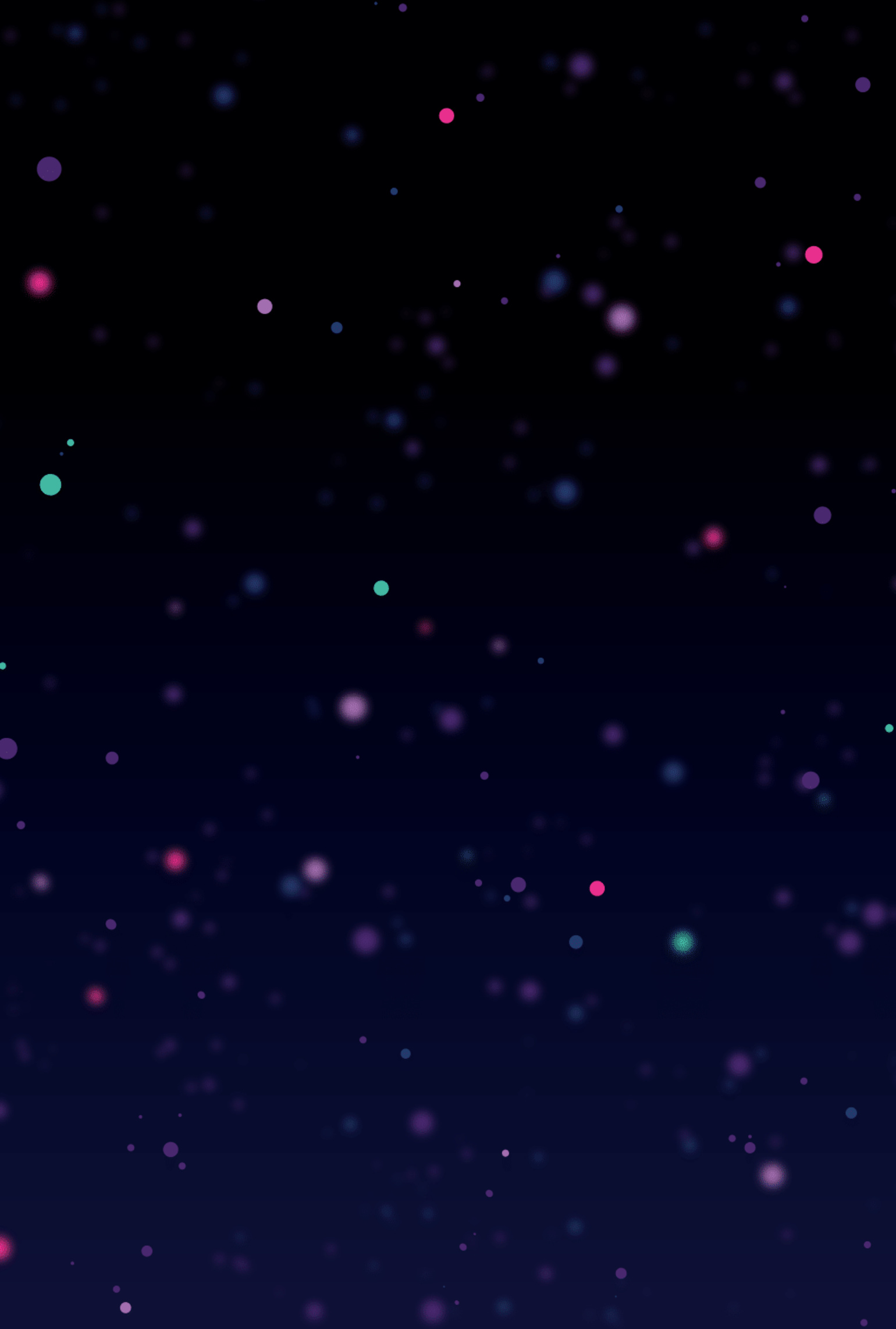




\section{0 \\ Impact}

The main objective of this dissertation is to provide insights into how-nowadays widely used-incentive-compensation contracts that base managers' pay on relative performance alter decisions of those managers. To paint a clear picture of the relation between relative performance evaluation and managerial decision-making, I examine in three distinct studies three broad categories of decisions that encompass a large range of managers' decisions: (1) risk-taking; (2) competitive aggressiveness; and (3) information disclosure.

The first study concludes that the incentive to take risk manifests synergistically through two characteristics of relative performance plans: (1) the convexity of the payperformance relation; and (2) the difficulty of beating the peer group used as the benchmark for measuring relative firm performance. It also concludes that this incentive is moderated by the pureness of the relative performance plan and contextual factors. The second study concludes that relative performance evaluation motivates managers to act aggressively toward peer firms, and that this incentive is driven by the extent to which peer firms also select the focal firm in their incentive plan. It also concludes that this incentive is moderated by the nature of this "tournament" between firms. The third study concludes that relative performance plans are associated with: (1) the transparency of mandatory disclosure; (2) the provision of voluntary disclosure; and (3) the substitution between the two. Specifically, it concludes that relative performance plans in which competition with peers is strong are negatively related with the transparency of mandatory disclosure and the provision of voluntary disclosure. It also concludes that the substitution between the two depends critically on whether managers compete with peers for market prices or accounting numbers. Collectively, my three studies conclude that relative performance evaluation has crucial implications for managerial decisions, but also conclude that there is no "one effect" on managerial decision-making. The dissertation therefore contributes to and has implications for policy, practice and research.

With regard to policy, the results of my dissertation have implications for setting incentive-compensation policies at firms. Such insights are important in light of arguments that misaligned incentive-compensation contracts induced managers to take inappropriate risks leading up to the 2008 financial crisis. For example, Chair of the U.S. Securities and Exchange Commission Chairman Mary L. Schapiro's (2010) noted in a speech to the National Association of Corporate Directors that: 
"[...] since misaligned or poorly-calibrated incentive compensation programs were widely believed to have promoted inappropriate risk-taking that contributed to the financial crisis, we added a requirement that companies assess whether their compensation programs expose them to material risks. [...] I think it is vital that boards understand how compensation practices affect risk-taking, and this new requirement brought that issue front and center for boards."

To this end, my dissertation provides insights-theoretically and empirically-into which characteristic of relative performance plans relate to a large range of managers' decisions. My dissertation therefore provides investors, regulators and practitioners with additional dimensions to consider in assessing whether and how incentive-compensation contracts expose firms to risks. In this regard, I show that the way in which a relative performance plan relates to managerial decisions depends on a multitude of plan characteristics, which not only individually but, more importantly, synergistically with other characteristics of the plan impact managers' decisions. These results highlight the notion that, in designing incentive-compensation contracts and understanding the expected relation with managerial decision-making, it is vital to carefully examine each plan's features-individually as well as synergistically with other features. The insights from this dissertation provide a basis for examining this.

With regard to practice, the results of my dissertation have implications beyond setting incentive-compensation policies at firms, and can be generalized to better understand firms' endeavors toward addressing pressing business questions and issues. One such issue relates to, for example, the need for sustainability; that is, issues relating to environmental, social and governance. A good example: continent-wide goals to cut $\mathrm{CO}_{2}$ emissions. For example, President Joseph Biden announced a new target for the United States of America to achieve a 50 percent reduction from 2005 levels in economywide net greenhouse gas pollution in 2030 (e.g., The White House, 2021). Similarly, the European Union has-as part of the European Union's 2030 climate and energy framework and current contribution to the Paris Agreement-put in place legislation to reduce emissions by at least 40 percent by 2030 (e.g., European Commission, 2021). These government movements-which may trigger legal pressure, stakeholder pressure and shareholder action (e.g., Climate Action 100+, 2021)-highlight the notion that sustainability will become-and, perhaps, has already become-equally important for the survival of a firm in the long term. ${ }^{89}$ From an incentive-compensation contracting perspective, the interesting question is how to motivate managers to shift their firms' focus toward sustainability. This is challenging, because investors, boards and managers might not be able to agree on a complete description of what the world looks like in a few decades as many components of "sustainability" may still be quite nebulous. As such, it might not be possible to design a "compete contract" that perfectly deals with all possible states of the world and specifies what the manager has to do in every possible state of the world. Instead, because of this uncertainty about the optimal road to sustainability, firms can only design complex and "incomplete contracts.” The desired

89. Climate Action $100+$ is an investor-led initiative to ensure the world's largest corporate greenhouse gas emitters take necessary action on climate change. 
contract would empower managers to work on ideas about how to run the firm more sustainably, pays managers hefty if they achieve this, but somehow also penalizes managers if they exploit this leeway for their own benefit (even though there is no clear definition of what to do and what not to do). The use of relative performance evaluation may fit in such a contract. ${ }^{90}$ This might be counterintuitive because relative performance plans generally discourage managers to pursue projects that are systematic in nature (under which $\mathrm{CO}_{2}$ emissions-and social activities in general-certainly fall) (also see study 1 or Chapter 2 in this dissertation). Instead, relative performance plans expose managers to the "idiosyncratic" (i.e., firm-specific) value of the firm and, thereby, motivate managers to pursue risks that are idiosyncratic in nature-e.g., projects that differ from peer firms' projects, so that the focal firm can outperform peer firms in a relative performance game. Although idiosyncratic risk typically refers to "upside risk," it certainly also refers to "downside risk." And it is precisely this idiosyncratic downside risk that may push managers to address sustainability issues. For example, if a concentrated group of institutional investors decides to coordinate an action toward a specific firm that does not sufficiently address sustainability issues, then that firm's stock price may crash (e.g., Ferrell, Liang, and Renneboog, 2016, Kim, Li, and Li, 2014). ${ }^{91}$ In a relative performance game, this idiosyncratic crash of an individual firm's stock price is detrimental to that firm's relative performance. Thus, the presence of large shareholders (who care about sustainability and allocate resources in a world where firms compete for such resources) coupled with significant exposure to the firm's idiosyncratic value may push managers to work themselves on sustainability - and not to "free-ride" on other firms' endeavors toward sustainability (e.g., Hart, 1983, Shleifer and Vishny, 1986). ${ }^{92,93}$ That is, to avoid coordinated actions and idiosyncratic crashes due to large shareholders, managers may lift their firms' sustainability performance in accordance with targets set by governments, shareholders, stakeholders, etc. All in all, this discussion brings in the perspective that the increasing use of relative performance evaluation could, in part, be driven by firms' endeavors toward addressing issues of sustainability. This perspective has implications for practice, because it highlights the role boards play in controlling/shifting managers' decisions and, thus, in tackling social problems. However,

90. In theory, firms could also design an incentive-compensation contract that directly compensates managers for systematic goals (e.g., $\mathrm{CO}_{2}$ emissions). However, this is costly to the manager, because his/her compensation would then be determined by factors outside his/her control. Moreover, such an incentivecompensation arrangement would give rise to the "free-rider problem," in which managers benefit from other firms' endeavors toward systematic goals (e.g., sustainability) without contributing themselves. These issues are eliminated when using relative performance evaluation (e.g., Holmström, 1982).

91. Good examples of these actions are the recent climate resolutions in the oil sector, some of which got clear majority votes by shareholders and the recent Dutch court ruling of Royal Dutch Shell plc. (e.g., De Rechtspraak, 2021).

92. Certainly, managers may also work on sustainability simply because investments in sustainability have significant idiosyncratic upside potential (e.g., Cao, Simin, and Zhao, 2008, Pástor and Veronesi, 2009). A good example is Tesla, Inc., which accelerated the world's transition to sustainable energy.

93. Theoretically, evaluating managers on relative performance may also motivate them to collude with peer managers. In the context of sustainability, this would, for example, imply that managers collectively decide not to work on sustainability. The evidence of study 2 (or Chapter 3 ) in this dissertation, however, suggests that this "collusion" hypothesis is not empirically descriptive in the setting of large U.S. firms. Nevertheless, it could be this behavior is prevalent in other settings. In that case, my study highlights the role that standardsetters and oversight bodies could play in tackling social problems. 
at current date, relatively little is known about this interplay between relative performance evaluation and corporate sustainability, which brings me to my final impact point: research.

With regard to research, the results of my dissertation provide fruitful opportunity for future research. For example, the above discussion highlights there is much work to be done to better understand boards' role-through setting incentive-compensation policies for and monitoring managers-in tackling social problems. In this regard, it would be interesting to see what, if any, the role of relative performance evaluation is in an optimal contract that motivates managers to work on sustainability, and whether boards' incentive-compensation choices are consistent with such optimal contracts. Beyond this extension, my dissertation suggests there is room to further understand managers' "true" incentives. In many of my studies, I conclude that individual proxy statements yield an incomplete picture of managers" "true" incentives, as many important and related forces are not directly observable from one firm's proxy statement. Finally, my dissertation creates new measurement techniques and brings measurement techniques from related literatures to the accounting literature. My hope is that these advancements inspire future work on incentive-compensation. 



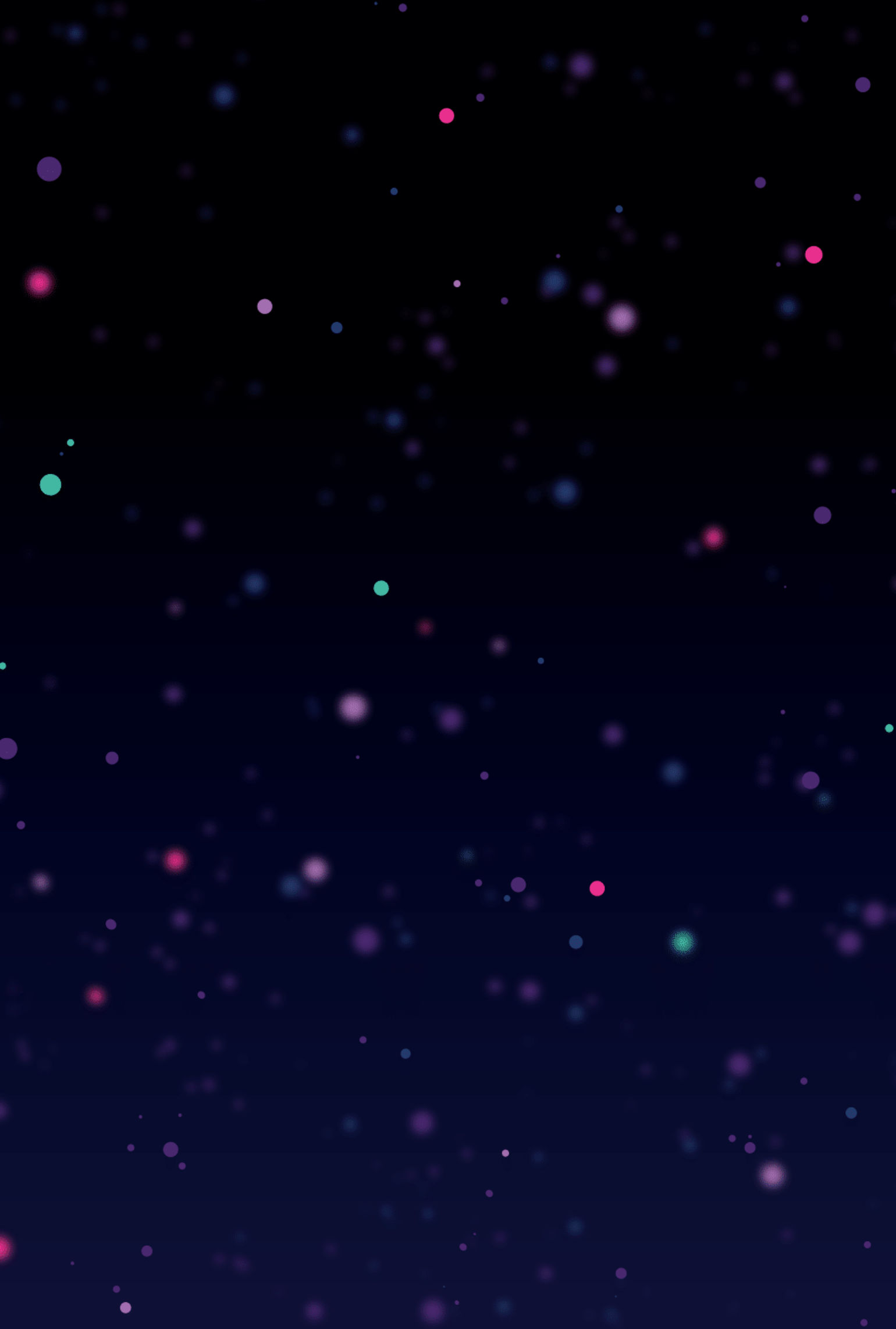




\section{8 \\ References}

1. Abdel-Khalik, A. R., and B. B. Ajinkya. 1982. Returns to informational advantages: The case of analysts' forecast revisions. The Accounting Review, 57(4), 661-680.

2. Aboody, D., and R. Kasznik. 2000. CEO stock option awards and the timing of corporate voluntary disclosures. Journal of Accounting and Economics, 29(1), 73100. doi: 10.1016/S0165-4101(00)00014-8

3. Acharya, V. V., and A. Bisin. 2009. Managerial hedging, equity ownership, and firm value. RAND Journal of Economics, 40 (1), 47-77. doi: 10.1111/j.17562171.2008.00055.x

4. Aggarwal, R. K., and A. A. Samwick. 1999. Executive compensation, strategic competition, and relative performance evaluation: Theory and evidence. Journal of Finance, 54(6), 1999-2043. doi: 10.1111/0022-1082.00180

5. Albuquerque, A., B. Chen, Q. Dong, and E. J. Riedl. 2019. Ex post settling up in cash compensation: New evidence. Contemporary Accounting Research, 36(4), 22832318. doi: 10.1111/1911-3846.12503

6. Albuquerque, A. M. 2009. Peer firms in relative performance evaluation. Journal of Accounting and Economics, 48(1), 69-89. doi: 10.1016/j.jacceco.2009.04.001

7. Albuquerque, A. M. 2014. Do growth-option firms use less relative performance evaluation? The Accounting Review, 89(1), 27-60. doi: 10.2308/accr-50574

8. Albuquerque, A. M., G. De Franco, and R. S. Verdi. 2013. Peer choice in CEO compensation. Journal of Financial Economics, 108(1), 160-181. doi: 10.1016/j.jfineco.2012.10.002

9. Altonji, J. G., T. E. Elder, and C. R. Taber. 2005. Selection on observed and unobserved variables: Assessing the effectiveness of catholic schools. Journal of Political Economy, 113(1), 151-184. doi: 10.1086/426036

10. Anatolyev, S. 2013. Instrumental variables estimation and inference in the presence of many exogenous regressors. The Econometrics Journal, 16(1), 27-72. doi: 10.1111/j.1368-423X.2012.00383.x

11. Andrews, I. 2018. Valid two-step identification-robust confidence sets for GMM. Review of Economics and Statistics, 100 (2), 337-348. doi: 10.1162/REST_a_00682

12. Andrews, I., J. H. Stock, and L. Sun. 2019. Weak instruments in instrumental variables regression: Theory and practice. Annual Review of Economics, 11(1), 727753. doi: 10.1146/annurev-economics-080218-025643 
13. Angrist, J. D. 2014. The perils of peer effects. Labour Economics, 30, 98-108. doi: 10.1016/j.labeco.2014.05.008

14. Angrist, J. D., and J. S. Pischke. (2009a). Mostly Harmless Econometrics: An Empiricist's Companion. Princeton and Oxford: Princeton University Press.

15. Angrist, J. D., and J. S. Pischke. 2009b. A note on bias in just identified IV with weak instruments. Working Paper.

16. Antle, R., and A. Smith. 1986. An empirical investigation of the relative performance evaluation of corporate executives. Journal of Accounting Research, 24(1), 1-39. doi: 10.2307/2490802

17. Armstrong, C. S. 2013. Discussion of "CEO compensation and corporate risktaking: Evidence from a natural experiment". Journal of Accounting and Economics, 56(2, Supplement 1), 102-111. doi: 10.1016/j.jacceco.2013.11.003

18. Armstrong, C. S., J. E. Core, and W. R. Guay. (2018). Why do CEOs hold equity? Working Paper.

19. Armstrong, C. S., S. Glaeser, S. Huang, and D. J. Taylor. 2019. The economics of managerial taxes and corporate risk-taking. The Accounting Review, 94(1), 1-24. doi: $10.2308 /$ accr-52193

20. Armstrong, C. S., and R. Vashishtha. 2012. Executive stock options, differential risk-taking incentives, and firm value. Journal of Financial Economics, 104(1), 7088. doi: 10.1016/j.jfineco.2011.11.005

21. AT\&T Inc. (2019). Proxy Statement 2018. Retrieved from https://www.sec.gov/Archives/edgar/data/0000732717/000119312519070797/d679 803ddef14a.htm

22. Atanasov, V., and B. Black. 2016. Shock-based causal inference in corporate finance and accounting research. Critical Finance Review, 5(2), 207-304. doi: 10.1561/104.00000036

23. Bakke, T. E., H. Mahmudi, and A. Newton. 2020. Performance peer groups in CEO compensation contracts. Financial Management, 49(4), 997-1027. doi: 10.1111/fima.12296

24. Balakrishnan, K., M. B. Billings, B. Kelly, and A. Ljungqvist. 2014. Shaping liquidity: On the causal effects of voluntary disclosure. Journal of Finance, 69(5), 2237-2278. doi: 10.1111/jofi.12180

25. Balakrishnan, K., J. L. Blouin, and W. R. Guay. 2018. Tax aggressiveness and corporate transparency. The Accounting Review, 94(1), 45-69. doi: 10.2308/accr52130

26. Bamber, L. S., J. John, and I. Y. Wang. 2010. What's my style? The influence of top managers on voluntary corporate financial disclosure. The Accounting Review, 85(4), 1131-1162. doi: 10.2308/accr.2010.85.4.1131

27. Barro, J. R., and R. J. Barro. 1990. Pay, performance, and turnover of bank CEOs. Journal of Labor Economics, 8(4), 448. doi: 10.1086/298230

28. Barth, M. E., W. R. Landsman, Y. S. Tian, and M. Yu. 2021. Does voluntary disclosure substitute for mandatory disclosure? Evidence from contract redactions. Working Paper.

29. Baum, C. F., M. E. Schaffer, and S. Stillman. 2007. Enhanced routines for instrumental variables/generalized method of moments estimation and testing. The Stata Journal, 7(4), 465-506. doi: 10.1177/1536867X0800700402 
30. Bens, D. A., P. G. Berger, and S. J. Monahan. 2011. Discretionary disclosure in financial reporting: An examination comparing internal firm data to externally reported segment data. The Accounting Review, 86(2), 417-449. doi: $10.2308 /$ accr. 00000019

31. Berger, P. G. 2011. Challenges and opportunities in disclosure research-A discussion of 'The financial reporting environment: Review of the recent literature'. Journal of Accounting and Economics, 51(1), 204-218. doi: 10.1016/j.jacceco.2011.01.001

32. Berger, P. G., and R. N. Hann. 2003. The impact of SFAS no. 131 on information and monitoring. Journal of Accounting Research, 41(2), 163-223. doi: 10.1111/1475679X.00100

33. Berger, P. G., and R. N. Hann. 2007. Segment profitability and the proprietary and agency costs of disclosure. The Accounting Review, 82(4), 869-906. doi: 10.2308/accr.2007.82.4.869

34. Bertomeu, J., J. H. Evans, M. Feng, and A. Tseng. 2020. Tacit collusion and voluntary disclosure: Theory and evidence from the U.S. Automotive industry. Management Science, 67(3), 1851-1875. doi: 10.1287/mnsc.2019.3531

35. Bertomeu, J., and P. J. Liang. 2015. Disclosure policy and industry fluctuations. Management Science, 61(6), 1292-1305. doi: 10.1287/mnsc.2014.2003

36. Beyer, A., D. A. Cohen, T. Z. Lys, and B. R. Walther. 2010. The financial reporting environment: Review of the recent literature. Journal of Accounting and Economics, 50(2), 296-343. doi: 10.1016/j.jacceco.2010.10.003

37. Bizjak, J., S. Kalpathy, Z. F. Li, and B. Young. 2021. The role of peer firm selection in explicit relative performance awards. Working Paper, 1-57.

38. Black, D. E., S. S. Dikolli, and C. Hofmann. 2015. Peer group composition, peer performance aggregation, and detecting relative performance evaluation. Working Paper.

39. Black, F., and M. Scholes. 1973. The pricing of options and corporate liabilities. Journal of Political Economy, 81(3), 637. doi: 10.1086/260062

40. Bloomfield, M. J. 2021. Compensation disclosures and strategic commitment: Evidence from revenue-based pay. Journal of Financial Economics. doi: 10.1016/j.jfineco.2021.04.006

41. Bloomfield, M. J., W. R. Guay, and O. Timmermans. 2021. Relative performance evaluation and the peer group opportunity set. Working Paper.

42. Bloomfield, M. J., C. M. P. Marvão, and G. Spagnolo. 2020. Relative performance evaluation, sabotage and collusion. Working Paper.

43. Boone, A. L., I. V. Floros, and S. A. Johnson. 2016. Redacting proprietary information at the initial public offering. Journal of Financial Economics, 120(1), 102-123. doi: 10.1016/j.jfineco.2015.06.016

44. Bourveau, T., G. She, and A. Žaldokas. 2020. Corporate disclosure as a tacit coordination mechanism: Evidence from cartel enforcement regulations. Journal of Accounting Research, 58(2), 295-332. doi: 10.1111/1475-679X.12301

45. Boyd, J. H., and G. De Nicoló. 2005. The theory of bank risk taking and competition revisited. Journal of Finance, 60(3), 1329-1343. doi: 10.1111/j.15406261.2005.00763.x 
46. Brochet, F., L. Faurel, and S. McVay. 2011. Manager-specific effects on earnings guidance: An analysis of top executive turnovers. Journal of Accounting Research, 49(5), 1123-1162. doi: 10.1111/j.1475-679X.2011.00420.x

47. Brown, K. C., W. V. Harlow, and L. T. Starks. 1996. Of tournaments and temptations: An analysis of managerial incentives in the mutual fund industry. Journal of Finance, 51(1), 85-110. doi: 10.1111/j.1540-6261.1996.tb05203.x

48. Bryan, S., L. Hwang, and S. Lilien. 2000. CEO stock - based compensation: An empirical analysis of incentive - intensity, relative mix, and economic determinants. Journal of Business, 73(4), 661-693. doi: 10.1086/209658

49. Campbell, J. Y., M. Lettau, B. G. Malkiel, and Y. Xu. 2001. Have individual stocks become more volatile? An empirical exploration of idiosyncratic risk. Journal of Finance, 56(1), 1-43. doi: 10.1111/0022-1082.00318

50. Cao, C., T. Simin, and J. Zhao. 2008. Can growth options explain the trend in idiosyncratic risk? Review of Financial Studies, 21(6), 2599-2633. doi: $10.1093 / \mathrm{rfs} / \mathrm{hhl} 039$

51. Carpenter, J. N. 2000. Does option compensation increase managerial risk appetite? Journal of Finance, 55(5), 2311-2331. doi: 10.1111/0022-1082.00288

52. Carter, M. E., C. D. Ittner, and S. L. C. Zechman. 2009. Explicit relative performance evaluation in performance-vested equity grants. Review of Accounting Studies, 14(2), 269-306. doi: 10.1007/s11142-009-9085-8

53. Chen, E. L., R. Katila, R. McDonald, and K. M. Eisenhardt. 2010. Life in the fast lane: Origins of competitive interaction in new vs. established markets. Strategic Management Journal, 31(13), 1527-1547. doi: 10.1002/smj.894

54. Cheng, Q., and K. Lo. 2006. Insider trading and voluntary disclosures. Journal of Accounting Research, 44(5), 815-848. doi: 10.1111/j.1475-679X.2006.00222.x

55. Chevalier, J., and G. Ellison. 1997. Risk taking by mutual funds as a response to incentives. Journal of Political Economy, 105(6), 1167-1200. doi: 10.1086/516389

56. Chevron Corporation. (2019). Proxy Statement 2018. Retrieved from https://www.sec.gov/Archives/edgar/data/93410/000119312519106207/d581752d def14a.htm

57. Climate Action 100+. (2021). Global investors driving business transition. Retrieved from https://www.climateaction100.org/

58. Coles, J. L., N. D. Daniel, and L. Naveen. 2006. Managerial incentives and risktaking. Journal of Financial Economics, 79(2), 431-468. doi: 10.1016/j.jfineco.2004.09.004

59. Coles, J. L., Z. F. Li, and A. Y. Wang. 2018. Industry tournament incentives. Review of Financial Studies, 31(4), 1418-1459. doi: 10.1093/rfs/hhx064

60. Connelly, B. L., K. B. Lee, L. Tihanyi, S. T. Certo, and J. L. Johnson. 2019.

Something in common: Competitive dissimilarity and performance of rivals with common shareholders. Academy of Management Journal, 62 (1), 1-21. doi: 10.5465/amj.2017.0515

61. Connelly, B. L., L. Tihanyi, D. J. Ketchen, Jr., C. M. Carnes, and W. J. Ferrier. 2017. Competitive repertoire complexity: Governance antecedents and performance outcomes. Strategic Management Journal, 38(5), 1151-1173. doi: $10.1002 / \mathrm{smj} .2541$ 
62. Conyon, M. J., J. E. Core, and W. R. Guay. 2011. Are U.S. CEOs paid more than U.K. CEOs? Inferences from risk-adjusted pay. Review of Financial Studies, 24(2), 402-438. doi: 10.1093/rfs/hhq112

63. Core, J. E. 2001. A review of the empirical disclosure literature: discussion. Journal of Accounting and Economics, 31(1), 441-456. doi: 10.1016/S0165-4101(01)00036-2

64. Core, J. E., and W. R. Guay. 1999. The use of equity grants to manage optimal equity incentive levels. Journal of Accounting and Economics, 28(2), 151-184. doi: 10.1016/S0165-4101(99)00019-1

65. Core, J. E., and W. R. Guay. 2002. Estimating the value of employee stock option portfolios and their sensitivities to price and volatility. Journal of Accounting Research, 40(3), 613-630. doi: 10.1111/1475-679X.00064

66. Core, J. E., W. R. Guay, and D. F. Larcker. 2003. Executive equity compensation and incentives: A survey. Economic Policy Review, 9(1), 27.

67. Covin, J. G., and T. J. Covin. 1990. Competitive aggressiveness, environmental context, and small firm performance. Entrepreneurship: Theory E Practice, 14(4), 35-50. doi: 10.1177/104225879001400406

68. Cragg, J. G., and S. G. Donald. 1993. Testing identifiability and specification in instrumental variable models. Econometric Theory, 9(2), 222-240. doi: 10.1017/S0266466600007519

69. De Angelis, D., and Y. Grinstein. 2019. Relative performance evaluation in CEO compensation: A talent-retention explanation. Journal of Financial and Quantitative Analysis, 1-47. doi: 10.1017/S0022109019000504

70. De Rechtspraak. (2021). Royal Dutch Shell must reduce CO2 emissions. Retrieved from https://www.rechtspraak.nl/Organisatie-encontact/Organisatie/Rechtbanken/Rechtbank-Den-Haag/Nieuws/Paginas/RoyalDutch-Shell-must-reduce-CO2-emissions.aspx

71. Dechow, P. M., A. P. Hutton, and R. G. Sloan. 1996. Economic consequences of accounting for stock-based compensation. Journal of Accounting Research, 34, 1-20. doi: $10.2307 / 2491422$

72. Dechow, P. M., and R. G. Sloan. 1991. Executive incentives and the horizon problem: An empirical investigation. Journal of Accounting and Economics, 14(1), 51-89. doi: 10.1016/0167-7187(91)90058-S

73. Dedman, E., and C. Lennox. 2009. Perceived competition, profitability and the withholding of information about sales and the cost of sales. Journal of Accounting and Economics, 48(2/3), 210-230. doi: 10.1016/j.jacceco.2009.07.003

74. Demerjian, P. R., B. Lev, and S. E. McVay. 2012. Quantifying managerial ability: A new measure and validity tests. Management Science, 58(7), 1229-1248. doi: 10.1287/mnsc. 1110.1487

75. Diamond, D. W., and R. E. Verrecchia. 1982. Optimal managerial contracts and equilibrium security prices. Journal of Finance, 37(2), 275-287. doi: 10.1111/j.15406261.1982.tb03550.x

76. Dikolli, S. S., V. Diser, C. Hofmann, and T. Pfeiffer. 2018. CEO power and relative performance evaluation. Contemporary Accounting Research, 35(3), 1279-1296. doi: 10.1111/1911-3846.12316 
77. Dikolli, S. S., C. Hofmann, and T. Pfeiffer. 2013. Relative performance evaluation and peer-performance summarization errors. Review of Accounting Studies, 18(1), 34-65. doi: 10.1007/s11142-012-9212-9

78. Drake, K. D., and M. Martin. 2020. Implementing relative performance evaluation: The role of life cycle peers. Journal of Management Accounting Research, 32(2), 107135. doi: $10.2308 /$ jmar-52580

79. Drake, M. S., N. M. Guest, and B. J. Twedt. 2014. The media and mispricing: The role of the business press in the pricing of accounting information. The Accounting Review, 89(5), 1673-1701. doi: 10.2308/accr-50757

80. Dye, R. A. 1984. The trouble with tournaments. Economic Inquiry, 22(1), 147-149. doi: 10.1111/j.1465-7295.1984.tb00675.x

81. Dye, R. A. 1992. Relative performance evaluation and project selection. Journal of Accounting Research, 30(1), 27-52. doi: 10.2307/2491090

82. Dyreng, S. D., M. Hanlon, and E. L. Maydew. 2008. Long - run corporate tax avoidance. The Accounting Review, 83(1), 61-82. doi: 10.2308/accr.2008.83.1.61

83. Edmans, A., X. Gabaix, and A. Landier. 2008. A multiplicative model of optimal CEO incentives in market equilibrium. Review of Financial Studies, 22(12), 48814917. doi: $10.1093 / \mathrm{rfs} / \mathrm{hhn} 117$

84. Edmans, A., L. Goncalves-Pinto, M. Groen-Xu, and Y. Wang. 2018. Strategic news releases in equity vesting months. The Review of Financial Studies, 31(11), 40994141. doi: $10.1093 / \mathrm{rfs} / \mathrm{hhy} 070$

85. Eisenhardt, K. M., and J. A. Martin. 2000. Dynamic capabilities: What are they? Strategic Management Journal, 21(10/11), 1105.

86. Equilar. (2020). Executive long-term incentive plans 2020. Retrieved from https://info.equilar.com/2435-2020-ltip

87. European Commission. (2021). Progress made in cutting emissions. Retrieved from https://ec.europa.eu/clima/policies/strategies/progress_en

88. Fama, E. F., and K. R. French. 1993. Common risk factors in the returns on stock and bonds. Journal of Financial Economics, 33(1), 3-56. doi: 10.1016/0304405X(93)90023-5

89. Fama, E. F., and K. R. French. 1997. Industry costs of equity. Journal of Financial Economics, 43(2), 153-193. doi: 10.1016/S0304-405X(96)00896-3

90. Fama, E. F., and J. D. MacBeth. 1973. Risk, return, and equilibrium: Empirical tests. Journal of Political Economy, 81(3), 607-636. doi: 10.1086/260061

91. Feichter, C., F. Moers, and O. Timmermans. 2021. Relative performance evaluation and competitive aggressiveness. Working Paper.

92. Ferrell, A., H. Liang, and L. Renneboog. 2016. Socially responsible firms. Journal of Financial Economics, 122(3), 585-606. doi: 10.1016/j.jfineco.2015.12.003

93. Ferrier, W. J. 2001. Navigating the competitive landscape: The drivers and consequences of competitive aggressiveness. Academy of Management Journal, 44(4), 858-877. doi: 10.2307/3069419

94. Ferrier, W. J., and D. W. Lyon. 2004. Competitive repertoire simplicity and firm performance: The moderating role of top management team heterogeneity. Managerial and Decision Economics, 25(6/7), 317-327. doi: 10.1002/mde.1193

95. Ferrier, W. J., K. G. Smith, and C. M. Grimm. 1999. The role of competitive action in market share erosion and industry dethronement: A study of industry leaders 
and challengers. Academy of Management Journal, 42(4), 372-388. doi: $10.2307 / 257009$

96. Fershtman, C., and K. L. Judd. 1987. Equilibrium incentives in oligopoly. American Economic Review, 77(5), 927-940.

97. Fombrun, C. J., and A. Ginsberg. 1990. Shifting gears: Enabling change in corporate aggressiveness. Strategic Management Journal, 11(4), 297-308. doi: 10.1002/smj.4250110405

98. Francis, B., I. Hasan, S. Mani, and P. Ye. 2016. Relative peer quality and firm performance. Journal of Financial Economics, 122(1), 196-219. doi: 10.1016/j.jfineco.2016.06.002

99. French, K. R., G. W. Schwert, and R. F. Stambaugh. 1987. Expected stock returns and volatility. Journal of Financial Economics, 19(1), 3-29. doi: 10.1016/0304405X (87) 90026-2

100. Fu, F. 2009. Idiosyncratic risk and the cross-section of expected stock returns. Journal of Financial Economics, 91(1), 24-37. doi: 10.1016/j.jfineco.2008.02.003

101. Garvey, G. T. 1997. Marketable incentive contracts and capital structure relevance. Journal of Finance, 52(1), 353-378. doi: 10.1111/j.1540-6261.1997.tb03820.x

102. Garvey, G. T., and T. T. Milbourn. 2003. Incentive compensation when executives can hedge the market: Evidence of relative performance evaluation in the cross section. Journal of Finance, 58(4), 1557-1581. doi: 10.1111/1540-6261.00577

103. Gibbons, R. (1992). Game Theory for Applied Economists: Princeton University Press.

104. Gibbons, R., and K. J. Murphy. 1990. Relative performance evaluation for chief executive officers. Industrial and Labor Relations Review, 43(3), 30-51. doi: $10.2307 / 2523570$

105. Gibbons, R., and K. J. Murphy. 1992. Optimal incentive contracts in the presence of career concerns: Theory and evidence. Journal of Political Economy, 100 (3), 468. doi: $10.1086 / 261826$

106. Givoly, D., and J. Lakonishok. 1979. The information content of financial analysts' forecasts of earnings: Some evidence on semi-strong inefficiency. Journal of Accounting and Economics, 1(3), 165-185. doi: 10.1016/0165-4101(79)90006-5

107. Glaeser, S. 2018. The effects of proprietary information on corporate disclosure and transparency: Evidence from trade secrets. Journal of Accounting and Economics, 66(1), 163-193. doi: 10.1016/j.jacceco.2018.04.002

108. Glaeser, S., and W. R. landsman. 2019. Deterrent Disclosure. Working Paper.

109. Goetzmann, W. N., and A. Kumar. 2005. Why do individual investors hold underdiversified portfolios? Working Paper.

110. Gong, G., L. Y. Li, and J. Y. Shin. 2011. Relative performance evaluation and related peer groups in executive compensation contracts. The Accounting Review, 86(3), 1007-1043. doi: 10.2308/accr.00000042

111. Gong, G., L. Y. Li, and H. Yin. 2019. Relative performance evaluation and the timing of earnings release. Journal of Accounting and Economics, 67(2-3), 358-386. doi: $10.1016 /$ j.jacceco.2019.03.002

112. Gormley, T. A., D. A. Matsa, and T. T. Milbourn. 2013. CEO compensation and corporate risk: Evidence from a natural experiment. Journal of Accounting and Economics, 56(2), 79-101. doi: 10.1016/j.jacceco.2013.08.001 
113. Gow, I. D., G. Ormazabal, and D. J. Taylor. 2010. Correcting for cross-sectional and time-series dependence in accounting research. The Accounting Review, 85(2), 483-512. doi: 10.2308/accr.2010.85.2.483

114. Goyal, A., and P. Santa-Clara. 2003. Idiosyncratic risk matters! Journal of Finance, 58(3), 975-1007. doi: 10.1111/1540-6261.00555

115. Graham, J. R., C. R. Harvey, and S. Rajgopal. 2005. The economic implications of corporate financial reporting. Journal of Accounting and Economics, 40 (1), 3-73. doi: $10.1016 /$ j.jacceco.2005.01.002

116. Guay, W. R. 1999. The sensitivity of CEO wealth to equity risk: an analysis of the magnitude and determinants. Journal of Financial Economics, 53(1), 43-71. doi: 10.1016/S0304-405X(99)00016-1

117. Ha, S., F. Ma, and A. Žaldokas. 2020. Motivating collusion. Working Paper.

118. Hainmueller, J. 2017. Entropy balancing for causal effects: A multivariate reweighting method to produce balanced samples in observational studies. Political Analysis, 20(1), 25-46. doi: 10.1093/pan/mpr025

119. Hall, B. J., and K. J. Murphy. 2000. Optimal exercise prices for executive stock options. American Economic Review, 90(2), 209-214. doi: 10.1257/aer.90.2.209

120. Hall, B. J., and K. J. Murphy. 2002. Stock options for undiversified executives. Journal of Accounting and Economics, 33(1), 3-42. doi: 10.1016/S01654101(01)00050-7

121. Hansen, L. P. 1982. Large sample properties of generalized method of moments estimators. Econometrica, 50(4), 1029-1054. doi: 10.2307/1912775

122. Harris, M. S. 1998. The association between competition and managers' business segment reporting decisions. Journal of Accounting Research, 36(1), 111-128. doi: $10.2307 / 2491323$

123. Hart, O. 1983. The market mechanism as an incentive scheme. Bell Journal of Economics, 14(2), 366-382. doi: 10.2307/3003639

124. Hayes, R. M., and R. Lundholm. 1996. Segment reporting to the capital market in the presence of a competitor. Journal of Accounting Research, 34(2), 261-279. doi: $10.2307 / 2491502$

125. Healy, P. M., and K. G. Palepu. 2001. Information asymmetry, corporate disclosure, and the capital markets: A review of the empirical disclosure literature. Journal of Accounting and Economics, 31(1), 405-440. doi: 10.1016/S01654101(01)00018-0

126. Heinle, M. S., D. Samuels, and D. J. Taylor. 2020. Proprietary costs and disclosure substitution: Theory and empirical evidence. Working Paper.

127. Hoberg, G., and G. Phillips. 2010. Product market synergies and competition in mergers and acquisitions: A text-based analysis. Review of Financial Studies, 23(10), 3773-3811. doi: 10.1093/rfs/hhq053

128. Hoberg, G., and G. Phillips. 2016. Text-based network industries and endogenous product differentiation. Journal of Political Economy, 124(5), 1423-1465. doi: 10.1086/688176

129. Holmström, B. 1982. Moral hazard in teams. Bell Journal of Economics, 13(2), 324340. doi: $10.2307 / 3003457$

130. Holmström, B. 1999. Managerial incentive problems: A dynamic perspective. Review of Economic Studies, 66(1), 169-182. doi: 10.1111/1467-937X.00083 
131. Horowitz, J. L., and C. F. Manski. 1995. Identification and robustness with contaminated and corrupted data. Econometrica, 63(2), 281-302. doi: $10.2307 / 2951627$

132. Horowitz, J. L., and C. F. Manski. 1998. Censoring of outcomes and regressors due to survey nonresponse: Identification and estimation using weights and imputations. Journal of Econometrics, 84(1), 37-58. doi: 10.1016/S03044076(97)00077-8

133. Horowitz, J. L., and C. F. Manski. 2000. Nonparametric analysis of randomized experiments with missing covariate and outcome data. Journal of the American Statistical Association, 95(449), 77-84. doi: 10.2307/2669526

134. Huddart, S. 1994. Employee stock options. Journal of Accounting and Economics, 18(2), 207-231. doi: 10.1016/0165-4101(94)00363-7

135. Hvide, H. K. 2002. Tournament rewards and risk taking. Journal of Labor Economics, 20(4), 877-898. doi: 10.1086/342041

136. Imhoff, E. A., and G. J. Lobo. 1984. Information content of analysts' composite forecast revisions. Journal of Accounting Research, 22(2), 541-554. doi: $10.2307 / 2490663$

137. Janakiraman, S. N., R. A. Lambert, and D. F. Larcker. 1992. An empirical investigation of the relative performance evaluation hypothesis. Journal of Accounting Research, 30(1), 53-69. doi: 10.2307/2491091

138. Jayaraman, S., T. T. Milbourn, F. S. Peters, and H. Seo. 2020. Product market peers and relative performance evaluation. The Accounting Review. doi: 10.2308/TAR2018-0284

139. Jensen, M. C. 1986. Agency costs of free cash flow, corporate finance, and takeovers. American Economic Review, 76(2), 323-329.

140. Jensen, M. C., and W. H. Meckling. 1976. Theory of the firm: Managerial behavior, agency costs and ownership structure. Journal of Financial Economics, 3(4), 305-360. doi: 10.1016/0304-405X(76)90026-X

141. Jin, L. 2002. CEO compensation, diversification, and incentives. Journal of Financial Economics, 66(1), 29-63. doi: 10.1016/S0304-405X(02)00150-2

142. Joh, S. W. 1999. Strategic managerial incentive compensation in Japan: Relative performance evaluation and product market collusion. Review of Economics and Statistics, 81(2), 303-313. doi: 10.1162/003465399558094

143. Johnson \& Johnson. (2020). Proxy Statement 2019. Retrieved from https://www.sec.gov/Archives/edgar/data/200406/000020040620000018/jnjproxy2 020.htm

144. Kahl, M., J. Liu, and F. A. Longstaff. 2003. Paper millionaires: how valuable is stock to a stockholder who is restricted from selling it? Journal of Financial Economics, 67(3), 385-410. doi: 10.1016/S0304-405X(02)00258-1

145. Katz, M. L. 1991. Game-playing agents: Unobservable contracts as precommitments. RAND Journal of Economics, 22(3), 307-328. doi: $10.2307 / 2601049$

146. Kim, S., and J. Y. Shin. 2017. Executive bonus target ratcheting: Evidence from the new executive compensation disclosure rules. Contemporary Accounting Research, 34(4), 1843-1879. doi: 10.1111/1911-3846.12350 
147. Kim, Y., H. Li, and S. Li. 2014. Corporate social responsibility and stock price crash risk. Journal of Banking and Finance, 43, 1-13. doi: 10.1016/j.jbankfin.2014.02.013

148. Kini, O., and R. Williams. 2012. Tournament incentives, firm risk, and corporate policies. Journal of Financial Economics, 103(2), 350-376. doi:

10.1016/j.jfineco.2011.09.005

149. Kleibergen, F., and R. Paap. 2006. Generalized reduced rank tests using the singular value decomposition. Journal of Econometrics, 133(1), 97-126. doi: 10.1016/j.jeconom.2005.02.011

150. Knoeber, C. R., and W. N. Thurman. 1994. Testing the theory of tournaments: An empirical analysis of broiler production. Journal of Labor Economics, 12(2), 155179. doi: $10.1086 / 298354$

151. Kolesár, M., R. Chetty, J. Friedman, E. Glaeser, and G. W. Imbens. 2015. Identification and inference with many invalid instruments. Journal of Business and Economic Statistics, 33(4), 474-484. doi: 10.1080/07350015.2014.978175

152. Kothari, S. P. (2020). Key Economic Buzzwords with Chairman Jay Clayton and DERA Director S.P. Kothari. Retrieved from https://www.youtube.com/watch?v=1w7bzKJjGYs

153. Kräkel, M., and D. Sliwka. 2004. Risk taking in asymmetric tournaments. German Economic Review, 5(1), 103-116. doi: 10.1111/j.1465-6485.2004.00096.x

154. Kumar, A. 2009. Who gambles in the stock market? Journal of Finance, 64(4), 1889-1933. doi: 10.1111/j.1540-6261.2009.01483.x

155. Lambert, R. A. 2001. Contracting theory and accounting. Journal of Accounting and Economics, 32(1-3), 3-87. doi: 10.1016/S0165-4101(01)00037-4

156. Lambert, R. A., D. F. Larcker, and R. E. Verrecchia. 1991. Portfolio considerations in valuing executive compensation. Journal of Accounting Research, 29(1), 129-149. doi: $10.2307 / 2491032$

157. Lambert, R. A., D. F. Larcker, and K. Weigelt. 1993. The structure of organizational incentives. Administrative Science Quarterly, 38(3), 438-461. doi: $10.2307 / 2393375$

158. Lambert, R. A., C. Leuz, and R. E. Verrecchia. 2011. Information asymmetry, information precision, and the cost of capital. Review of Finance, 16(1), 1-29. doi: $10.1093 / \mathrm{rof} / \mathrm{rfr} 014$

159. Larcker, D. F., and T. O. Rusticus. 2010. On the use of instrumental variables in accounting research. Journal of Accounting and Economics, 49(3), 186-205. doi: 10.1016/j.jacceco.2009.11.004

160. Lazear, E. P., and S. Rosen. 1981. Rank-order tournaments as optimum labor contracts. Journal of Political Economy, 89(5), 841-864. doi: 10.1086/261010

161. Leary, M. T., and M. R. Roberts. 2014. Do peer firms affect corporate financial policy? Journal of Finance, 69(1), 139-178. doi: 10.1111/jofi.12094

162. Leland, H. E. 1998. Agency costs, risk management, and capital structure. Journal of Finance, 53(4), 1213-1243. doi: 10.1111/0022-1082.00051

163. Lennox, C. S., and C. W. Park. 2006. The informativeness of earnings and management's issuance of earnings forecasts. Journal of Accounting and Economics, 42(3), 439-458. doi: 10.1016/j.jacceco.2006.05.001 
164. Lewellen, K. 2006. Financing decisions when managers are risk averse. Journal of Financial Economics, 82(3), 551-589. doi: 10.1016/j.jfineco.2005.06.009

165. Li, F., R. Lundholm, and M. Minnis. 2013. A measure of competition based on 10$\mathrm{k}$ filings. Journal of Accounting Research, 51(2), 399-436. doi: 10.1111/j.1475679X.2012.00472.x

166. Ljungqvist, A., L. Zhang, and L. Zuo. 2017. Sharing risk with the government: How taxes affect corporate risk taking. Journal of Accounting Research, 55(3), 669707. doi: 10.1111/1475-679X.12157

167. Low, A. 2009. Managerial risk-taking behavior and equity-based compensation. Journal of Financial Economics, 92(3), 470-490. doi: 10.1016/j.jfineco.2008.05.004

168. Lundblad, C. 2007. The risk return tradeoff in the long run: 1836-2003. Journal of Financial Economics, 85(1), 123-150. doi: 10.1016/j.jfineco.2006.06.003

169. Lys, T. Z., and S. Sohn. 1990. The association between revisions of financial analysts' earnings forecasts and security-price changes. Journal of Accounting and Economics, 13(4), 341-363. doi: 10.1016/0165-4101(90)90009-S

170. Ma, P., J. Y. Shin, and C. C. Y. Wang. 2019. rTSR: When do relative performance metrics capture relative performance? Working Paper, 1-58.

171. Ma, P., J. Y. Shin, and C. C. Y. Wang. 2021. rTSR: Properties, determinants, and consequences of benchmark choice. Working Paper, 1-47.

172. Manski, C. F. 1989. Anatomy of the selection problem. Journal of Human Resources, 24(3), 343-360. doi: 10.2307/145818

173. Manski, C. F. 1990. Nonparametric bounds on treatment effects. American Economic Review: Papers and Proceedings, 80(2), 319-323.

174. Manski, C. F. 1993. Identification of endogenous social effects: The reflection problem. Review of Economic Studies, 60(3), 531-542. doi: 10.2307/2298123

175. Manski, C. F. (2003). Partial Identification of Probability Distributions (1st ed.). New York, NY: Springer-Verlag.

176. Markowitz, H. 1952. Portfolio selection. Journal of Finance, 7(1), 77-91. doi: 10.1111/j.1540-6261.1952.tb01525.x

177. Meridian Compensation Partners LLC. (2019). 2019 Corporate Governance $\mathcal{E}$ Incentive Design Survey. Retrieved from https://www.meridiancp.com/wpcontent/uploads/Meridian-2019-Governance-and-Design-Survey.pdf

178. Merton, R. C. 1973a. An intertemporal capital asset pricing model. Econometrica, 41(5), 867-887. doi: 10.2307/1913811

179. Merton, R. C. $1973 \mathrm{~b}$. Theory of rational option pricing. Bell Journal of Economics and Management Science, 4(1), 141. doi: 10.2307/3003143

180. Merton, R. C. 1987. A simple model of capital market equilibrium with incomplete information. Journal of Finance, 42(3), 483-510. doi: 10.1111/j.15406261.1987.tb04565.x

181. Meulbroek, L. K. 2001. The efficiency of equity-linked compensation: Understanding the full cost of awarding executive stock options. Financial Management, 30(2), 5-44. doi: 10.2307/3666404

182. Mitton, T., and K. Vorkink. 2007. Equilibrium underdiversification and the preference for skewness. Review of Financial Studies, 20(4), 1255-1288. doi: 10.1093/revfin/hhm011 
183. Montiel Olea, J. L., and C. Pflueger. 2013. A robust test for weak instruments. Journal of Business and Economic Statistics, 31(3), 358-369. doi: 10.1080/00401706.2013.806694

184. Mookherjee, D. 1984. Optimal incentive schemes with many agents. Review of Economic Studies, 51(3), 433-446. doi: 10.2307/2297432

185. Morck, R., B. Yeung, and W. Yu. 2000. The information content of stock markets: why do emerging markets have synchronous stock price movement? Journal of Financial Economics, 58(1/2), 215-260. doi: 10.1016/S0304-405X(00)00071-4

186. Murphy, K. J. 2000. Performance standards in incentive contracts. Journal of Accounting and Economics, 30(3), 245-278. doi: 10.1016/S0165-4101(01)00013-1

187. Nadkarni, S., T. Chen, and J. Chen. 2016. The clock is ticking! Executive temporal depth, industry velocity, and competitive aggressiveness. Strategic Management Journal, 37(6), 1132-1153. doi: 10.1002/smj.2376

188. Nalebuff, B. J., and J. E. Stiglitz. 1983. Prizes and incentives: Towards a general theory of compensation and competition. Bell Journal of Economics, 14(1), 21-43. doi: $10.2307 / 3003535$

189. Ndofor, H. A., D. G. Sirmon, and X. He. 2011. Firm resources, competitive actions and performance: Investigating a mediated model with evidence from the in-vitro diagnostics industry. Strategic Management Journal, 32(6), 640-657. doi: 10.1002/smj. 901

190. Noe, C. F. 1999. Voluntary disclosures and insider transactions. Journal of Accounting and Economics, 27(3), 305-326. doi: 10.1016/S0165-4101(99)00014-2

191. Noh, S., E. C. So, and J. P. Weber. 2019. Voluntary and mandatory disclosures: Do managers view them as substitutes? Journal of Accounting and Economics, 68(1), 101243. doi: 10.1016/j.jacceco.2019.101243

192. Obama, B. (2009). Remarks of President Barack Obama 21st Century Financial Regulatory Reform. Retrieved from https://www.npr.org/templates/story/story.php? storyId=105523464

193. Oster, E. 2019. Unobservable selection and coefficient stability: Theory and evidence. Journal of Business and Economic Statistics, 37(2), 187-204. doi: 10.1080/07350015.2016.1227711

194. Palazzo, B. 2012. Cash holdings, risk, and expected returns. Journal of Financial Economics, 104(1), 162-185. doi: 10.1016/j.jfineco.2011.12.009

195. Panousi, V., and D. Papanikolaou. 2012. Investment, idiosyncratic risk, and ownership. Journal of Finance, 67(3), 1113-1148. doi: 10.1111/j.15406261.2012.01743.x

196. Park, H., and D. Vrettos. 2015. The moderating effect of relative performance evaluation on the risk incentive properties of executives' equity portfolios. Journal of Accounting Research, 53(5), 1055-1108. doi: 10.1111/1475-679X.12092

197. Park, J., J. Sani, N. Shroff, and H. White. 2019. Disclosure incentives when competing firms have common ownership. Journal of Accounting and Economics. doi: 10.1016/j.jacceco.2019.02.001

198. Pástor, L'., and P. Veronesi. 2009. Technological revolutions and stock prices. American Economic Review, 99(4), 1451-1483. doi: 10.1257/aer.99.4.1451

199. Porter, M. E. (1998). Competitive Advantage. New York, NY: Free Press. 
200. Rajgopal, S., and T. Shevlin. 2002. Empirical evidence on the relation between stock option compensation and risk taking. Journal of Accounting and Economics, 33(2), 145-171. doi: 10.1016/S0165-4101(02)00042-3

201. Rego, S. O., and R. Wilson. 2012. Equity risk incentives and corporate tax aggressiveness. Journal of Accounting Research, 50(3), 775-809. doi: 10.1111/j.1475679X.2012.00438.x

202. Rindova, V., W. J. Ferrier, and R. Wiltbank. 2010. Value from gestalt: How sequences of competitive actions create advantage for firms in nascent markets. Strategic Management Journal, 31(13), 1474-1497. doi: 10.1002/smj.892

203. Robinson, J. 1934. What is perfect competition? Quarterly Journal of Economics, 49(1), 104-120. doi: 10.2307/1883878

204. Rosen, S. 1986. Prizes and incentives in elimination tournaments. American Economic Review, 76(4), 701-715.

205. Ross, S. A. 2004. Compensation, incentives, and the duality of risk aversion and riskiness. Journal of Finance, 59(1), 207-225. doi: 10.1111/j.15406261.2004.00631.x

206. Sargan, J. D. 1958. The estimation of economic relationships using instrumental variables. Econometrica, 26(3), 393-415. doi: 10.2307/1907619

207. Schapiro, M. L. (2010). Remarks at the NACD Annual Corporate Governance Conference [https://www.sec.gov/news/speech/2010/spch101910mls.htm].

208. Scharfstein, D. S., and J. C. Stein. 1990. Herd behavior and investment. American Economic Review, 80(3), 465-479.

209. Seo, H. 2021. Peer effects in corporate disclosure decisions. Journal of Accounting and Economics, 71(1), 101364. doi: 10.1016/j.jacceco.2020.101364

210. Sharpe, W. F. 1964. Capital asset prices: A theory of market equilibrium under conditions of risk. Journal of Finance, 19(3), 425-442. doi: 10.1111/j.15406261.1964.tb02865.x

211. Shleifer, A., and R. W. Vishny. 1986. Large shareholders and corporate control. Journal of Political Economy, 94(3), 461-488. doi: 10.1086/261385

212. Shleifer, A., and R. W. Vishny. 1997. A survey of corporate governance. Journal of Finance, 52(2), 737-783. doi: 10.1111/j.1540-6261.1997.tb04820.x

213. Sklivas, S. D. 1987. The strategic choice of managerial incentives. RAND Journal of Economics, 18(3), 452-458. doi: 10.2307/2555609

214. Staiger, D., and J. H. Stock. 1997. Instrumental variables regression with weak instruments. Econometrica, 65(3), 557-586. doi: 10.2307/2171753

215. Stickel, S. E. 1991. Common stock returns surrounding earnings forecast revisions: More puzzling evidence. The Accounting Review, 66(2), 402-416.

216. Stock, J. H., J. H. Wright, and M. Yogo. 2002. A survey of weak instruments and weak identification in generalized method of moments. Journal of Business and Economic Statistics, 20(4), 518-529. doi: 10.1198/073500102288618658

217. Stock, J. H., and M. Yogo. (2005). Testing for weak instruments in linear IV regression. In D. W. K. Andrews \& J. H. Stock (Eds.), Identification and inference for econometric models: Essays in honor of Thomas Rothenberg (pp. 80-108). Cambridge: Cambridge University Press.

218. Stulz, R. M. 1990. Managerial discretion and optimal financing policies. Journal of Financial Economics, 26(1), 3-27. doi: 10.1016/0304-405X(90)90011-N 
219. Sun, L. 2018. Implementing valid two-step identification-robust confidence sets for linear instrumental-variables models. The Stata Journal, 18(4), 803-825. doi: 10.1177/1536867X1801800404

220. The Coca-Cola Company. (2019). Proxy Statement 2018. Retrieved from https://www.sec.gov/Archives/edgar/data/21344/000120677419000735/ko3422831 -def14a.htm

221. The White House. (2021). FACT SHEET: President Biden Sets 2030 Greenhouse Gas Pollution Reduction Target Aimed at Creating Good-Paying Union Jobs and Securing U.S. Leadership on Clean Energy Technologies. Retrieved from https://www.whitehouse.gov/briefing-room/statements-releases/2021/04/22/factsheet-president-biden-sets-2030-greenhouse-gas-pollution-reduction-target-aimedat-creating-good-paying-union-jobs-and-securing-u-s-leadership-on-clean-energytechnologies/

222. Tian, Y. S. 2004. Too much of a good incentive? The case of executive stock options. Journal of Banking and Finance, 28(6), 1225-1245. doi: 10.1016/S03784266(03)00122-5

223. Tice, F. M. 2020. Explicit relative performance evaluation and managerial decisionmaking: Evidence from firm performance and risk-taking behavior. Working Paper, 1-64. doi: $10.2139 /$ ssrn. 2645956

224. Timmermans, O. 2021. What are the risk-taking properties of long-term incentive plans based on relative performance? Working Paper.

225. Tsui, D. 2018. Value-risk tradeoffs and managerial incentives. Working Paper.

226. U.S. Securities and Exchange Commission. (2000). Selective disclosure and insider trading [SEC release no. 33-7881]. Retrieved from https://www.sec.gov/rules/final/33-7881.htm

227. U.S. Securities and Exchange Commission. (2003). Management's report on internal control over financial reporting and certification of disclosure in exchange act periodic reports [SEC release no. 33-8238]. Retrieved from https://www.sec.gov/rules/final/33-8238.htm

228. U.S. Securities and Exchange Commission. (2006). Executive compensation and related person disclosure [SEC Release No. 33-8732A]. Retrieved from https://www.sec.gov/rules/final/2006/33-8732a.pdf

229. U.S. Securities and Exchange Commission. (2010a). Assessment of Corporation Finance's Confidential Treatment Processes and Procedures. Retrieved from https://www.sec.gov/files/479.pdf

230. U.S. Securities and Exchange Commission. (2010b). Proxy disclosure enhancements [SEC Release No. 33-9089]. Retrieved from https://www.sec.gov/rules/final/2009/33-9089.pdf

231. U.S. Securities and Exchange Commission. (2018). SEC adopts final rules for disclosure of hedging policies. Retrieved from https://www.sec.gov/news/pressrelease/2018-291

232. U.S. Securities and Exchange Commission. (2021). What We Do. Retrieved from https://www.sec.gov/Article/whatwedo.html

233. United Parcel Service Inc. (2019). Proxy Statement 2018. Retrieved from https://www.sec.gov/Archives/edgar/data/1090727/000120677419000877/ups3448 911-def14a.htm 
234. Verrecchia, R. E. 2001. Essays on disclosure. Journal of Accounting and Economics, 32(1), 97-180. doi: 10.1016/S0165-4101(01)00025-8

235. Verrecchia, R. E., and J. Weber. 2006. Redacted Disclosure. Journal of Accounting Research, 44(4), 791-814. doi: 10.1111/j.1475-679X.2006.00216.x

236. Vickers, J. 1985. Delegation and the theory of the firm. The Economic Journal, 95, 138-147. doi: $10.2307 / 2232877$

237. Vilcassim, N. J., V. Kadiyali, and P. K. Chintagunta. 1999. Investigating dynamic multifirm market interactions in price and advertising. Management Science, 45(4), 499-518. doi: 10.1287/mnsc.45.4.499

238. Vrettos, D. 2013. Are relative performance measures in CEO incentive contracts used for risk reduction and/or for strategic interaction? The Accounting Review, 88(6), 2179-2212. doi: 10.2308/accr-50548

239. Wagenhofer, A. 1990. Voluntary disclosure with a strategic opponent. Journal of Accounting and Economics, 12(4), 341-363. doi: 10.1016/0165-4101(90)90020-5

240. Weitzman, M. L. 1980. The "ratchet principle" and performance incentives. Bell Journal of Economics, 11(1), 302. doi: 10.2307/3003414

241. Wooldridge, J. M. (2010). Econometric analysis of cross section and panel data. Cambridge, MA: The MIT Press.

242. Wruck, K. H., and Y. Wu. 2021. Do CEOs make their own luck? Relative versus absolute performance evaluation and firm risk. Journal of Financial and Quantitative Analysis (forthcoming), 1-82. doi: 10.2139/ssrn.3048401

243. Yermack, D. 1995. Do corporations award CEO stock options effectively? Journal of Financial Economics, 39(2), 237-269. doi: 10.1016/0304-405X(95)00829-4

244. Zingales, L. (1998). Corporate governance. In P. Newman (Ed.), The New Palgrave Dictionary of Economics and the Law. New York: Stockton Press.

245. Zwiebel, J. 1995. Corporate conservatism and relative compensation. Journal of Political Economy, 103(1), 1-25. doi: 10.1086/261973 


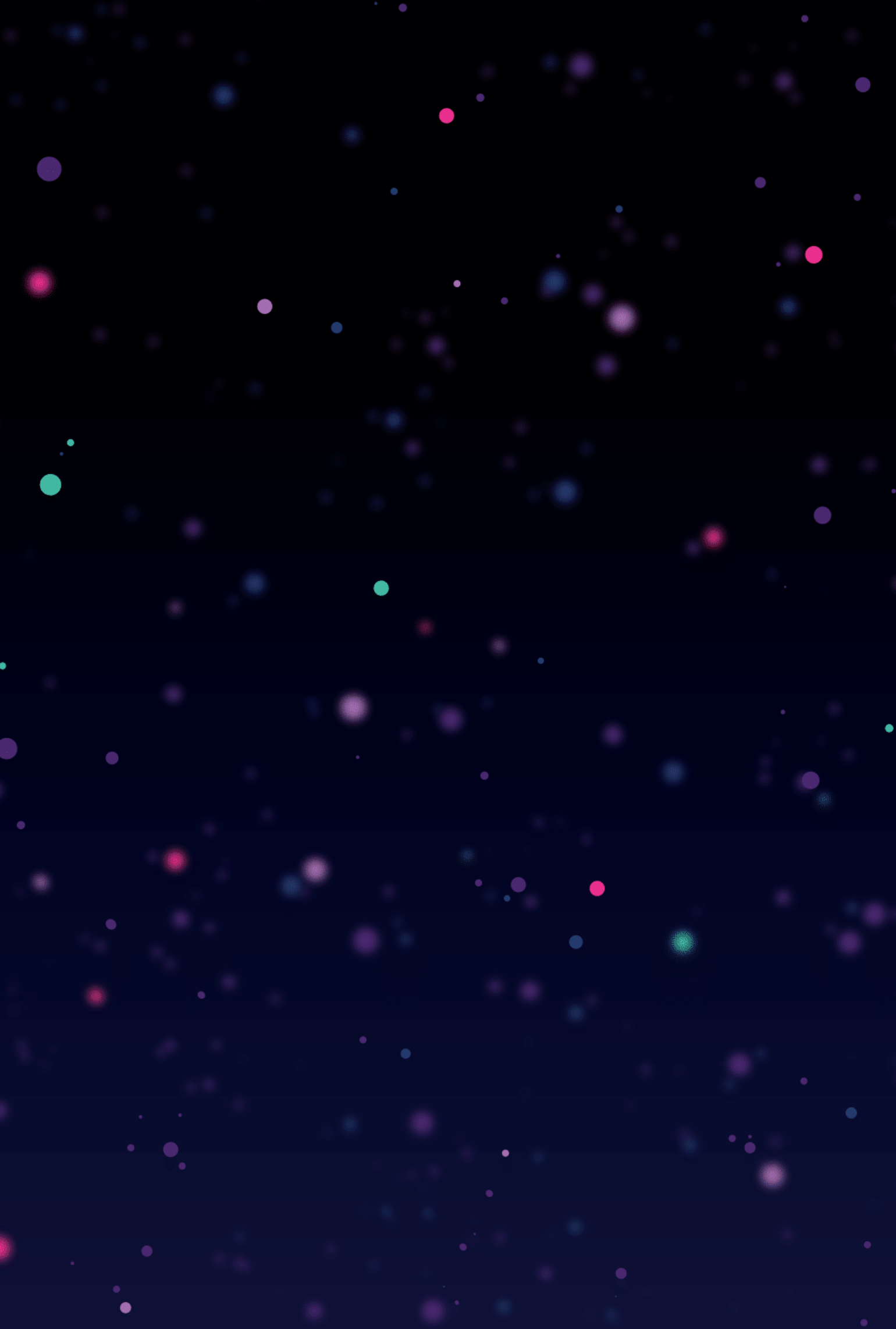




\section{9}

\section{Vitae}

Oscar Timmermans was born on May 10, 1993, in Sittard, the Netherlands. He received his Bachelor of Applied Science (B.ASc.) in Business Economics in 2014 after graduating from Zuyd Hogeschool in Sittard, the Netherlands, and his Master of Science (M.Sc.) in Business Research (specialization in Accounting) in 2017 after graduating cum laude from Maastricht University in Maastricht, the Netherlands.

In September 2017, Oscar joined the Ph.D. program in Accounting at the Department of Accounting and Information Management at Maastricht University. During his Ph.D., he was a visiting Ph.D. Student at The Wharton School of the University of Pennsylvania in Philadelphia, United States of America. Oscar presented his research at various international conferences and workshops, including the 11th Conference on New Directions in Management Accounting (2018, Belgium), 16th Annual Conference for Management Accounting Research (2019, Germany), 42nd Annual Congress of the European Accounting Association (2019, Cyprus), Management Accounting Section Midyear Meeting (2020, Houston; 2021, online), Amsterdam Business School, Bocconi University, Copenhagen Business School, Frankfurt School of Finance \& Management, KU Leuven, London School of Economics and Political Science, Maastricht University, The Wharton School and University of Rochester.

As of September 2021, Oscar will continue his academic career as an Assistant Professor in the Department of Accounting at the London School of Economics and Political Science. 